Identificação e tratamento dos problemas de desempenho de redes de sensores expostas por arquiteturas orientadas a serviço

Thiago Caproni Tavares 



\title{
Identificação e tratamento dos problemas de desempenho de redes de sensores expostas por arquiteturas orientadas a serviço
}

\author{
Thiago Caproni Tavares
}

Orientadora: Profa. Dra. Regina Helena Carlucci Santana

Tese apresentada ao Instituto de Ciências Matemáticas e de Computação - ICMC-USP, como parte dos requisitos para obtenção do título de Doutor em Ciências - Ciências de Computação e Matemática Computacional. VERSÃO REVISADA 
Ficha catalográfica elaborada pela Biblioteca Prof. Achille Bassi e Seção Técnica de Informática, ICMC/USP, com os dados fornecidos pelo(a) autor(a)

Caproni Tavares, Thiago

C231i Identificação e tratamento dos problemas de desempenho de redes de sensores expostas por arquiteturas orientadas a serviço / Thiago Caproni Tavares; orientador Regina Helena Carlucci Santana. - São Carlos, 2014. $143 \mathrm{p}$.

Tese (Doutorado - Programa de Pós-Graduação em Ciências de Computação e Matemática Computacional) - Instituto de Ciências Matemáticas e de Computação, Universidade de São Paulo, 2014.

1. Avaliação de Desempenho. 2. Qualidade de Serviço. 3. Web Services. I. Helena Carlucci Santana, Regina, orient. II. Título. 
E ainda que tivesse o dom de profecia, e conhecesse todos os mistérios e toda a ciência, e ainda que tivesse toda a fé, de maneira tal que transportasse os montes, e não tivesse amor, nada seria. 

Aos meus pais, Aluísio e Ida, para vocês todo meu amor e gratidão. 



\section{Agradecimentos}

À Deus, em primeiro lugar, por me conceder paciência, saúde, e coragem para transpor as dificuldades encontradas pelo caminho.

Aos meus pais, Aluísio e Ida e ao meu irmão Kairon, por todo o incentivo e amor a mim dedicados durante toda a minha vida. Obrigado pelo amor incondicional.

À Profa. Regina, a quem serei eternamente grato, pelo suporte, orientação e paciência ao longo de todos esses anos de trabalho. Ao Prof. Marcos pelas lições e ensinamentos. Obrigado por todas as oportunidades a mim conferidas.

À minha namorada Keninha, por ser minha companheira durante todos esses anos. Você que suportou com firmeza todos os momentos dificeis, e não me deixou desistir quando tudo parecia perdido. Todo meu amor e gratidão a você.

À família "buscapé", pelo carinho e amor demonstrados no decorrer dos últimos anos. Lembremse sempre do amor e admiração que tenho por todos vocês.

Ao Prof. Júlio Cézar, pelo suporte no processo de submissão dos trabalhos originados da tese.

Aos Swerts, os quais considero parte da minha família. A eles, que sempre estiveram presentes nos bons e maus momentos da vida. Em especial, agradeço meu amigo Felipe pelos conselhos e amizade.

Aos meus amigos machadenses em especial Renato (Tucho), Ney, Thiago e Márcio, pela presença constante em minha vida.

Aos meus amigos do IFSULDEMINAS, em especial Luiz Flávio, Claudino e Neidinha, Branquinho, Rafael, Fábio, Julierme e João Olímpio.

Ao Vinícius Souza que contribuiu nas correções do trabalho. Muito obrigado meu amigo.

Aos amigos do LaSDPC pelo convívio alegre e saudável.

Aos professores do LaSDPC, que contribuíram com sugestões e discussões sobre o trabalho.

Aos demais funcionários do ICMC, pessoal da secretaria da Pós-Graduação, pessoal da cantina, vigilantes, faxineiras e todos aqueles que de alguma forma contribuíram para o sucesso deste trabalho.

Ao IFSULDEMINAS, campus Inconfidentes, que me concedeu afastamento das atividades docentes para a finalização deste trabalho.

À CAPES, CNPq e FAPESP pelo suporte financeiro. 

ste trabalho de doutorado tem como objetivo principal mostrar que a abstração de redes de sensores, por meio de arquiteturas orientadas a serviço, pode impor alguma degradação do desempenho, mas não inviabiliza a maioria das aplicações. A metodologia utilizada na condução deste trabalho consta de experimentos que realizam avaliações de desempenho que analisam o comportamento de diferentes mecanismos de exposição de redes de sensores, bem como avalia três dos principais serviços do modelo de interfaces do Sensor Web Enablement (SWE). Os resultados obtidos mostram diferenças de desempenho significativas entre os métodos de acesso considerados. Esses resultados ainda mostram que a sobrecarga gerada não é significativa se comparada com a frequência de obtenção de observações da maioria das redes de sensores. Visando minimizar os problemas de desempenho impostos pelo framework SWE é proposta e implementada uma arquitetura de provisão de qualidade de serviço (QoS), denominada Sensor Web Architecture (SWARCH). Um estudo de caso da SWARCH demonstra que é possível reduzir os tempos de resposta no acesso aos serviços do SWE por meio de um Broker que monitora constantemente diferentes provedores de serviços. 

his $\mathrm{PhD}$ work aims to show that the abstraction of sensor networks, by means of service-oriented architectures, may impose some performance degradation, but it does not invalidate most applications. The methodology used to conduct this research consists of experiments that realize performance evaluations that analyze the behavior of different mechanisms of exposure of sensor networks, and evaluates the three major services of the Sensor Web Enablement (SWE) model interfaces. The results show significant differences in performance between the methods of considered access. The results also show that the generated overhead is not significant when compared with the frequency of obtaining observations of most wireless sensor networks. Aiming to minimize the performance issues imposed by the SWE framework, an architecture providing quality of service (QoS) called Sensor Web Architecture (SWARCH) is proposed and implemented. A case study of SWARCH demonstrates that it is possible to reduce response times when accessing the SWE services through a Broker that constantly monitors various service providers. 

Resumo

$\begin{array}{lll}\text { Abstract } & \text { iii }\end{array}$

$\begin{array}{lll}\text { Lista de Siglas } & \text { Xv }\end{array}$

1 Introdução $\quad 1$

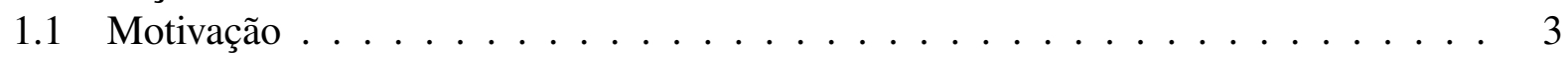

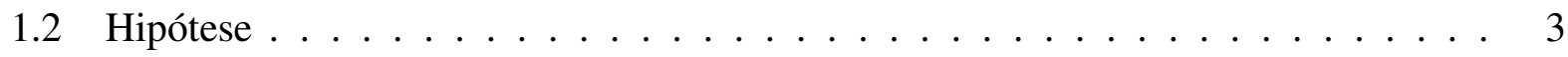

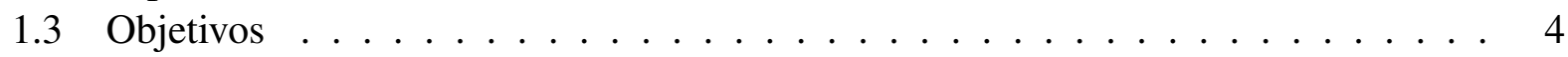

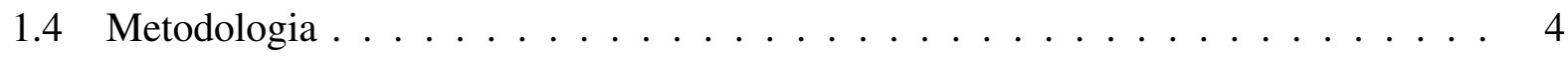

1.5 Estrutura do documento . . . . . . . . . . . . . . . . . 5

2 Redes de Sensores e Seus Mecanismos de Abstração $\quad 7$

2.1 Arquitetura das Redes de Sensores . . . . . . . . . . . . . . . . . . . . . . 8

2.1.1 Taxonomia de Aplicações em Redes de Sensores . . . . . . . . . . . . . . . . 13

2.1.2 Aplicações em Redes de Sensores . . . . . . . . . . . . . . . . . . 15

2.1.3 Características de Redes de Sensores Reais . . . . . . . . . . . . . . . . 18

2.2 Mecanismos de Abstrações em Redes de sensores . . . . . . . . . . . . . . . . . . 20

2.2.1 Abstração de Nó . . . . . . . . . . . . . . . . . . . . . . . 21

2.2 .2 Abstração de Rede . . . . . . . . . . . . . . . . . . . . . . . . . . . . . . . . . 22

2.3 Abstração de Infraestrutura . . . . . . . . . . . . . . . . . . . . . . . . . . . . . . . . . 22

2.3.1 Orientação a Serviço . . . . . . . . . . . . . . . . . . 23

2.3.2 Requisitos de Abstrações de Infraestrutura . . . . . . . . . . . . . . . . 26

2.3.3 Propostas de Abstração de Infraestrutura . . . . . . . . . . . . . . . . . . 29

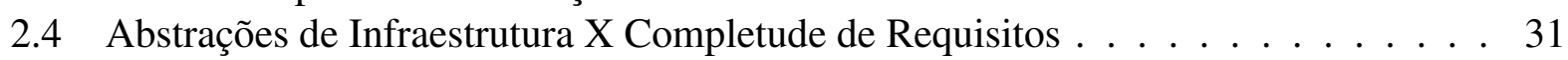

2.5 Considerações Finais . . . . . . . . . . . . . . . . . 33

3 Sensor Web Enablement $\quad 35$

3.1 Conceitos Iniciais . . . . . . . . . . . . . . . . . . . . . . . . . . . . . . . . . . . . . . . . . .

3.2 Modelo de Informação . . . . . . . . . . . . . . . . . . . . 36

3.2 .1 SWE Common . . . . . . . . . . . . . . . . . 37

3.2 .2 Sensor Model Language . . . . . . . . . . . . . . . . . . . . . . 40

3.2 .3 Observation \& Measurement . . . . . . . . . . . . . . . 43

3.3 Modelo de Interfaces . . . . . . . . . . . . . . . . . . . 45 
3.3.1 Sensor Observation Service . . . . . . . . . . . . . . . . . 46

3.3.2 Sensor Event Service . . . . . . . . . . . . . . . . . . . 50

3.3.3 Sensor Planing Service . . . . . . . . . . . . . . . . . . . . . . . . . . . . . 53

3.3 .4 Serviços de Descoberta . . . . . . . . . . . . . . . . . . . 54

3.4 Considerações Finais . . . . . . . . . . . . . . . . . . . 55

4 Avaliações de Desempenho $\quad 57$

4.1 Metodologia de Avaliação de Desempenho . . . . . . . . . . . . . . . . . . 58

4.2 Avaliação de Diferentes Métodos de acesso . . . . . . . . . . . . . . . . . . . 59

4.2.1 Planejamento de Experimentos . . . . . . . . . . . . . . . . 61

4.2 .2 Ambiente de Testes . . . . . . . . . . . . . . . . . 62

4.2 .3 Execução dos Experimentos . . . . . . . . . . . . . . . . . . . . . . 64

4.2 .4 Análise dos Resultados . . . . . . . . . . . . . . . . . . . . 65

4.2.5 Análise da viabilidade de Utilização de SOA para Acesso a Redes de Sensores ............................ 73

4.3 Avaliação dos Serviços SWE . . . . . . . . . . . . . . . . . 75

4.3.1 Planejamento de Experimentos . . . . . . . . . . . . . . . 76

4.3.2 Ambiente de Testes . . . . . . . . . . . . . . . . . . 78

4.3.3 Execução dos Experimentos . . . . . . . . . . . . . . . . 78

4.3.4 Análise dos Resultados para o serviço SOS . . . . . . . . . . . . . . . . . 79

4.3.5 Análise dos Resultados para o serviço SES . . . . . . . . . . . . . . . . . . 80

4.3.6 Análise dos Resultados para o serviço SIR . . . . . . . . . . . . . . . . 84

4.3.7 Análise Geral dos Serviços SWE . . . . . . . . . . . . . . . . . . 86

4.4 Considerações Finais . . . . . . . . . . . . . . . . . . . . . . 87

5 Sensor Web Architecture $\quad 89$

5.1 Qualidade de Serviço em Redes de Sensores . . . . . . . . . . . . . . . . . . . 90

5.2 Qualidade de Serviço nos Padrões SWE . . . . . . . . . . . . . . . . . . . 92

5.3 Descrição da Arquitetura . . . . . . . . . . . . . . . . . . . . . . . . 94

5.3.1 Mensagens na Arquitetura . . . . . . . . . . . . . . 96

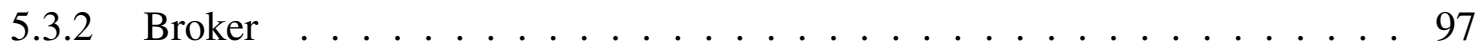

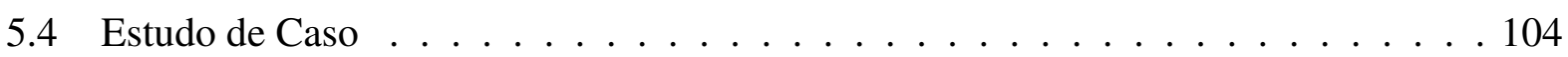

5.4.1 Planejamento de Experimentos . . . . . . . . . . . . . . . . 105

5.4 .2 Ambiente de Testes . . . . . . . . . . . . . . . . . . . . . . . . . . . . . . . . . . . . . . .

5.4 .3 Execução dos Experimentos . . . . . . . . . . . . . . . . . . . . . . . . . . . . . . . . . . . .

5.4.4 Análise dos Resultados . . . . . . . . . . . . . . . . . . . 106

5.5 Considerações Finais . . . . . . . . . . . . . . . . . . . 111

6 Conclusão $\quad 113$

6.1 Dificuldades Encontradas . . . . . . . . . . . . . . . . . . 115

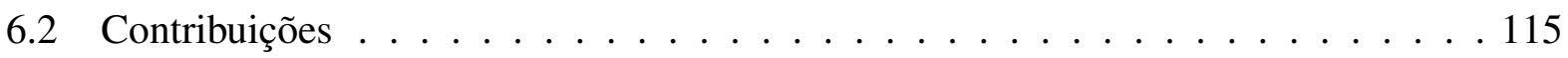

6.3 Produção Científica . . . . . . . . . . . . . . . . . . 116

6.3.1 Artigos Diretamente Relacionados à Tese . . . . . . . . . . . . . . . . 116

6.3.2 Artigos Publicados em Coautoria . . . . . . . . . . . . . . . . . . . . . . . . . . . . . . . . . .

6.4 Trabalhos Futuros . . . . . . . . . . . . . . . . . 117

$\begin{array}{ll}\text { A Exemplo de um documento SensorML } & 119\end{array}$ 
B Códigos Complementares $\quad 125$

B.1 Métodos de Acesso . . . . . . . . . . . . . . . . . . . . . . 125

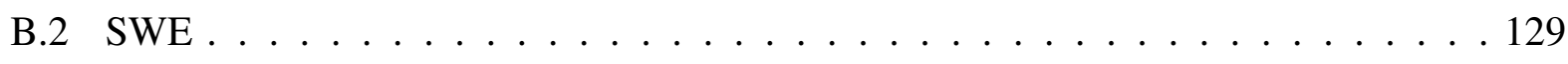





\section{Lista de Figuras}

2.1 Modelo conceitual de uma Rede de Sensores - Adaptado de (Akyildiz e Vuran, 2010) . . . . . . . . . . . . . . . . . . . . 9

2.2 Arquitetura de Redes de Sensores - Adaptado de (Yick et al., 2008; Akyildiz e Vuran, 2010). . . . . . . . . . . . . . . . . . . . . . . . 10

2.3 Taxonomia de Aplicações em Redes de Sensores - Adaptado de (Mottola e Picco, 2011) . . . . . . . . . . . . . . . . . . . . . 14

2.4 Gráfico de frequência acumulada da quantidade dispositivos de sensoriamento em implementações de redes de sensores-Adaptado de (Strazdins et al., 2013). . . . . 19

2.5 Gráfico de tipos de sensores - Adaptado de (Strazdins et al., 2013). . . . . . . . . . 20

2.6 Gráfico de taxa de amostragem em redes de sensores - Adaptado de (Strazdins et

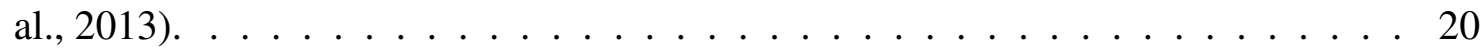

2.7 Níveis de abstrações de Aplicações em Redes de Sensores - Adaptado de (Laukkarinen et al., 2012). . . . . . . . . . . . . . . . . . . . . 21

2.8 Linha do tempo no desenvolvimento de plataformas de Sensores (Akyildiz e Vu-

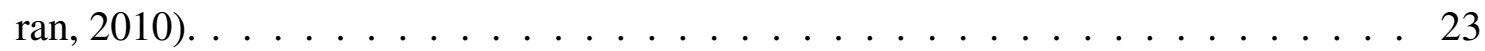

2.9 Interações entre componentes dos serviços Web - Adaptado de (Duggan, 2012). . . 24

3.1 Nova geração do modelo de informação do SWE - Adaptado de (Bröring et al., 2011) . . . . . . . . . . . . . . . . . . 37

3.2 Elementos de um documento O\&M - (OGC, 2014a). . . . . . . . . . . . . . 44

3.3 Nova geração do modelo de interfaces do SWE - Adaptado de (Bröring et al., 2011). 46

3.4 Diagrama de Sequência do Serviço SOS (Consumidor) - Adaptado de (GEONOVUM, 2013). . . . . . . . . . . . . . . . . . . . . . 49

3.5 Diagrama de Sequência do Serviço SOS (Produtor) - Adaptado de (OGC, 2013c). . 50

3.6 Diagrama de Sequência do Serviço SES . . . . . . . . . . . . . . . . . . 51

4.1 Métodos de acesso: Arquitetura do Ambiente de Testes . . . . . . . . . . . . . . 63

4.2 Diagrama de Sequência do script de avaliação . . . . . . . . . . . . . . . . . 66

4.3 Métodos de acesso: Gráfico de Intervalos de Confiança $(\mathrm{F} 1)$. . . . . . . . . . . . 67

4.4 Métodos de acesso: Gráficos de Tamanhos de Mensagens e Tempos de Resposta

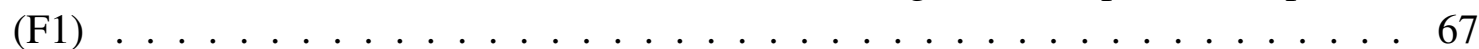

4.5 Métodos de acesso: Gráfico de Intervalos de Confiança (F2) . . . . . . . . . . . . 69

4.6 Métodos de acesso: Gráficos de Tamanhos de Mensagens e Tempos de Resposta

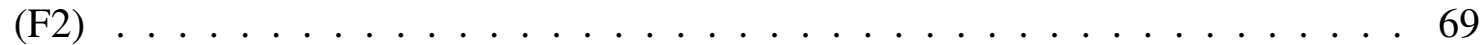

4.7 Métodos de acesso: Gráficos de Análise de Desempenho RMI x SOS . . . . . . . . 71 
4.8 Métodos de acesso: Gráficos de Análise de Desempenho REST x SOS . . . . . . . 72

4.9 Métodos de acesso: Gráficos de Análise de Desempenho SOAP x SOS . . . . . . . 73

4.10 SWE: Arquitetura do Ambiente de Testes . . . . . . . . . . . . . . 78

4.11 Métodos de acesso: Gráfico de Intervalos de Confiança (SOS) . . . . . . . . . . 80

4.12 SWE: Gráficos de Tamanhos de Mensagens e Tempos de Resposta (SOS) . . . . . 81

4.13 SWE: Gráficos de Análise de Desempenho (SOS) . . . . . . . . . . . . . . . . 81

4.14 Métodos de acesso: Gráfico de Intervalos de Confiança (SES) . . . . . . . . . . . . 82

4.15 SWE: Gráficos de Tamanhos de Mensagens e Tempos de Resposta (SES) . . . . . 82

4.16 SWE: Gráficos de Análise de Desempenho (SES) . . . . . . . . . . . . . . . . 83

4.17 Métodos de acesso: Gráfico de Intervalos de Confiança (SIR) . . . . . . . . . . . . 84

4.18 SWE: Gráficos de Tamanhos de Mensagens e Tempos de Resposta (SIR) . . . . . . 84

4.19 SWE: Gráficos de Análise de Desempenho (SIR) . . . . . . . . . . . . . . . . 85

5.1 Arquitetura Tradicional SWE X SWARCH . . . . . . . . . . . . . . . 95

5.2 Elementos da SWARCH . . . . . . . . . . . . . . . . . . . 97

5.3 Diagrama de Classes do Broker . . . . . . . . . . . . . . . . . . . . . . 98

5.4 Diagrama de Sequência da SWARCH . . . . . . . . . . . . . . . . 101

5.5 Diagrama de Sequência da SESSubmodule . . . . . . . . . . . . . . . . 103

5.6 SWARCH: Gráfico de Intervalos de Confiança (SES) . . . . . . . . . . . . . . 107

5.7 SWARCH: Gráficos de Análise de Desempenho (SES) . . . . . . . . . . . . . . 107

5.8 SWARCH: Gráfico de Intervalos de Confiança (SOS) . . . . . . . . . . . . . . 108

5.9 SWARCH: Gráficos de Análise de Desempenho (SOS) . . . . . . . . . . . . . . . . . . . . . . . . . . . . .

5.10 SWARCH: Gráfico de Intervalos de Confiança (SIR) . . . . . . . . . . . . . . 110

5.11 SWARCH: Gráficos de Análise de Desempenho (SIR) . . . . . . . . . . . . . . 110 


\section{Lista de Tabelas}

2.1 Características de abstrações de infraestrutura - Adaptado de (Laukkarinen et al.,

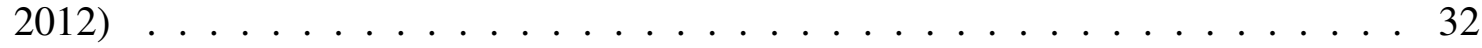

3.1 Propostas para implementação de um serviço de descoberta (Bröring et al., 2011) 54

4.1 Fatores da Avaliação de Desempenho dos Métodos de acesso . . . . . . . . . . . . 62

4.2 Métodos de acesso: Configurações de Hardware . . . . . . . . . . . . . . . . . . . 63

4.3 Médias dos Tempos de Resposta para o filtro F1 . . . . . . . . . . . . . . . . 66

4.4 Desvios Padrão dos Tempos de Resposta para o filtro F1 . . . . . . . . . . . . . 67

4.5 Médias dos Tempos de Resposta para o filtro F2 . . . . . . . . . . . . . . . . . . 69

4.6 Desvios Padrão dos Tempos de Resposta para o filtro F2 . . . . . . . . . . . . . 69

4.7 Fatores da Avaliação de Desempenho dos Serviços SWE . . . . . . . . . . . . . 77

5.1 Requisitos de QoS para os Serviços SWE . . . . . . . . . . . . . . . . . . . . 94

5.2 Fatores para a Validação da SWARCH . . . . . . . . . . . . . . . . . . . . . . . . . . . . . . . . . . . .

5.3 SWARCH: Configurações de Hardware . . . . . . . . . . . . . . . . . . 106 



\section{Lista de Códigos}

3.1 Exemplos de Documentos O\&M . . . . . . . . . . . . . . . . 45

3.2 SOS - Exemplo de uma Mensagem GetObservation . . . . . . . . . . . . . . . . . . 47

3.3 SOS - Exemplo de uma Mensagem InsertObservation . . . . . . . . . . . . . . . 48

3.4 SES - Exemplo de um Filtro Nível $1 \ldots \ldots$. . . . . . . . . . . . . 51

3.5 SES - Exemplo de um Filtro Nível $2 \ldots \ldots \ldots$

5.1 Mensagem de Busca na SWARCH . . . . . . . . . . . . . . . . . 97

A.1 Elementos keywords e identification . . . . . . . . . . . . . . . . . 120

A.2 Elementos classification e validTime . . . . . . . . . . . . . . 120

A.3 Elemento capabilities . . . . . . . . . . . . . . . . . . . 121

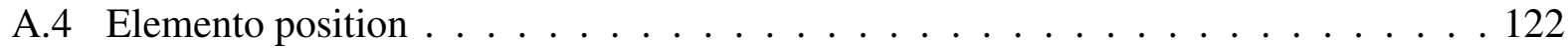

A.5 Elemento inputs . . . . . . . . . . . . . . . . . . . 122

A.6 Elemento component . . . . . . . . . . . . . . . . . . . . . 123

B.1 Métodos de Acesso: Requisição RMI . . . . . . . . . . . . . . . . . . . 125

B.2 Métodos de Acesso: Resposta RMI . . . . . . . . . . . . . . . . . . . 125

B.3 Métodos de Acesso: Requisição REST . . . . . . . . . . . . . . . . . . . . 126

B.4 Métodos de Acesso: Resposta REST . . . . . . . . . . . . . . . . . . . . 126

B.5 Métodos de Acesso: Requisição SOAP . . . . . . . . . . . . . . . . . . . . . 126

B.6 Métodos de Acesso: Resposta SOAP . . . . . . . . . . . . . . . . . . . . . 126

B.7 Métodos de Acesso: Requisição SOS . . . . . . . . . . . . . . . . . . . . . 127

B.8 Métodos de Acesso: Resposta SOS . . . . . . . . . . . . . . . . . . . . . 127

B.9 SWE: Level1 Subscription . . . . . . . . . . . . . . . . . . . . . . . . . . . . 129

B.10 SWE: Level2 Subscription . . . . . . . . . . . . . . . . . . . . . . 129

B.11 SWE: SES Notification . . . . . . . . . . . . . . . . . . 131 



\section{Lista de Siglas}

APIs: Application Programming Interface

B2B: Business to Business

BPEL: Business Process Execution Language

C4ISR: Comand, Control, Communications, Computers, Intelligence, Surveillance and Reconnaissance

CEP: Complex Event Precessing

CIPs: Critical Infraestructure Protection

CORBA: Commom Object Request Broker Architecture

DTD: Document Type Definition

EML: Event Pattern Markup Language

ESP: Event Strean Processing

FES: Filter Encoding Specification

GSN: Global Sensor Network

JAXB: Java Arquitecture for XML Binding

JSON: Java Object Notation

KP: Knowledge Processor

MAC: Media Acess Control

NAWMS: Autonomous Water Monitoring System

O\&M: Observation and Measurement

OGC: OpenGis Consortium

OWS: Web Ontology Language

QoS: Quality of Service

REST: Representational State Transfer

RMI: Remote Method Invocation

SAS: Sensor Alert Service

SDI: Spatial Data Infrastructure

SensorML: Sensor Model Language

SES: Sensor Event Service

SIB: Semantic Information Broker

SIR: Sensor Instance Registry

SOA: Service Oriented Architecture

SOAP: Simple Object Acess Protocol

SOR: Sensor Observable Registry

SOS: Sensor Observation Service

SPS: Sensor Planing Service 
SWARCH: Sensor Web Architecture

SWE: Sensor Web Enablement

SWIOT: Sensor Web for IoT

TI: Tecnologia da Informação

TML: Transducer Marckup Language

UDDI: Universal Description, Discovery and Integration

uom: unity of measurement

URL: Universal Resourse Locator

W3C: World Wide Web Consortium

WNS: Web Notification Service

WSDL: Web Service Description Language

WSS : Web Service Security

XML: eXtensible Markup Language

XSD: XML-Schema Definition 


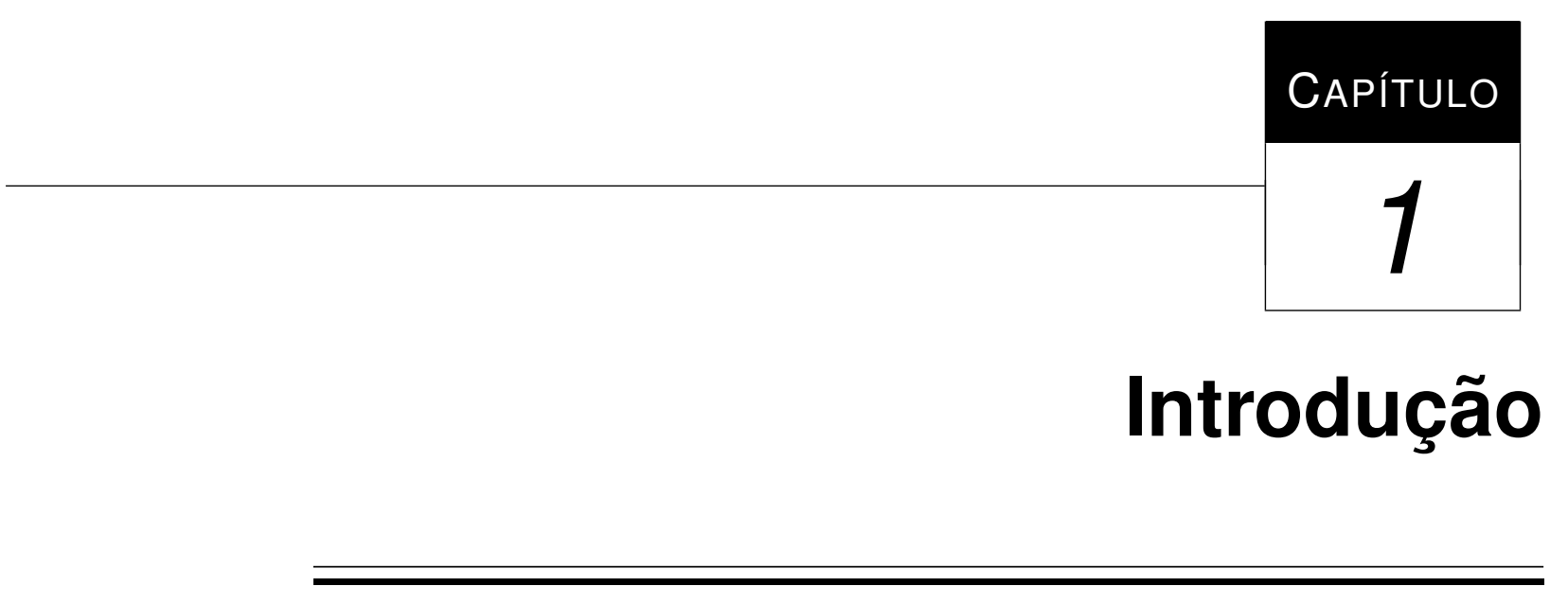

$\mathrm{U}$

ma rede de sensores é composta por sensores que monitoram um ou um conjunto de fenômenos, e cujos resultados obtidos são enviados para uma aplicação ou usuário final. As redes de sensores são utilizadas em diversos tipos de aplicações de monitoramento e rastreamento. O grande avanço das aplicações das redes de sensores tem sido possível devido ao aprimoramento e redução de custos das plataformas de sensoriamento (Yick et al., 2008; Akyildiz e Vuran, 2010). Um grande desafio na utilização de redes de sensores está na viabilidade de gerenciálas e na disponibilização das observações para utilização em diferentes aplicações. Por um lado, tem-se a infraestrutura composta pelos sensores e pelas estratégias de utilização desses dispositivos e das informações obtidas por eles. Por outro lado, têm-se aplicações ou observadores que devem receber e processar as informações segundo suas regras de negócio. As redes de sensores devem possuir ainda uma infraestrutura para comunicação, tanto entre os sensores, quanto entre a rede e os observadores.

Pesquisas em redes de sensores vêm sendo conduzidas em diversos contextos. Desenvolvimento de plataformas de hardware (Tavli et al., 2012), sistemas operacionais (Farooq e Kunz, 2011), protocolos de comunicação (Huang et al., 2013), sincronização de tempo (Lasassmeh e Conrad, 2010), segurança (Ameen et al., 2012), localização (Cucuringu et al., 2012) e middlewares (Laukkarinen et al., 2012) são exemplo de temas tratados na literatura especializada. Em (Oppermann et al., 2014) é apresentado um estudo investigativo que analisa mais de sessenta redes de sensores implantadas nos últimos dez anos. O estudo mostra que esse tipo de rede pode ser aplicado em diversos domínios tais como monitoramento de ambientes, monitoramento de incêndios florestais, agricultura de precisão, plantas industriais, aplicações militares e saúde. As aplicações de redes de sensores podem ser compostas por centenas ou até milhares de nós. Em 
geral, os dispositivos de sensoriamento, protocolos de comunicação e componentes de software são heterogêneos em termos de capacidade computacional, modelos de programação e ferramentas de desenvolvimento. Ou seja, a natureza heterogênea das redes de sensores faz com que seja necessário lidar com diferentes plataformas, assim como utilizar modelos e linguagens de programação distintos. Esse tipo de problema pode ser minimizado através da inserção de uma camada de abstração que fornece mecanismos comuns para programar, acessar e extrair dados de uma rede de sensores (Delicato et al., 2014a).

Abordagens para a redução de problemas de interoperabilidade entre sistemas heterogêneos em redes de sensores vêm sendo propostas por meio da padronização do acesso às informações por meio de arquiteturas orientadas a serviço (SOA, Service-Oriented Architecture). Tais tipos de abordagens podem ser observadas em (Priyantha et al., 2008; Neto e Ribeiro, 2010; Mohamed e Al-Jaroodi, 2011; Delicato et al., 2014a). Uma analogia interessante para o entendimento de como a utilização de SOA auxilia no desenvolvimento de sistemas interoperáveis é apresentada em (Colan, 2004). No ano de 221 a.C. o imperador Qin Shi Huang Di unificou vários estados em conflito dentro de um novo país, chamado atualmente de China. Isso se deu através da introdução de padrões que consolidaram a cultura e facilitaram as atividades de comércio. Um padrão interessante relaciona-se às dimensões que as carroças deveriam possuir para permitir que todas pudessem trafegar, de maneira eficiente, nas estradas que também tiveram suas dimensões padronizadas. A unificação da escrita é outro exemplo de padronização utilizado para permitir a troca de mensagens pela população. Não obstante, o imperador ainda iniciou a construção da muralha da China. De modo semelhante aos sistemas de informação, o imperador Qin desenvolveu modelos padronizados de transporte, troca de mensagens e segurança (como um firewall). Analogamente, a integração de sistemas em tempos modernos tem se beneficiado de padrões onde aplicações disponíveis sobre uma variedade de ambientes heterogêneos se comuniquem. A criação de aplicações de redes de sensores sobre o arcabouço das tecnologias tradicionalmente utilizadas por arquiteturas orientadas a serviço tem o intuito de minimizar os problemas decorrentes do caráter heterogêneo das plataformas de sensoriamento (Colan, 2004).

As arquiteturas orientadas a serviço foram propostas como ponto comum entre negócios e TI (Tecnologia da Informação). Essa abordagem tem sido utilizada por grandes corporações como ferramenta para facilitar o desenvolvimento e adaptação de sistemas corporativos de maneira a atender o dinamismo do mercado. A decomposição dos sistemas em serviços bem definidos que se comunicam utilizando um conjunto de padrões caracteriza o principal apelo desse modelo arquitetural. Essa decomposição permite que vários serviços sejam recombinados em novos processos, aumentando a capacidade de uma empresa na adaptação a novos contextos de mercado. Os conceitos de SOA podem ser aplicados para a construção de serviços publicados na Web: os chamados serviços Web (do termo em inglês, Web services). De uma maneira simplificada, os serviços Web podem ser definidos como uma forma de expor um serviço através da Web. Ou seja, eles são instanciações de uma arquitetura orientada a serviço para exposição de serviços na Web. A popularidade dos serviços Web, como uma alternativa para a construção de aplicações "business to 
business"(B2B), fez com que as definições sobre a arquitetura e seus tipos de instanciações se sobrepusessem. Embora os serviços Web tenham sido definidos inicialmente para a resolução de problemas de TI dentro do contexto de processos de negócios, eles também podem ser aplicados para a exposição de redes de sensores (Chu e Buyya, 2007).

Propostas de adoção de SOA no âmbito das redes de sensores também são referenciadas como mecanismos de abstração de infraestruturas. Esses mecanismos oferecem as ferramentas necessárias para gerenciá-las. A literatura apresenta diversas implementações desses mecanismos de abstração. Um estudo investigativo que analisa diversos tipos de implementações de mecanismos de abstração é apresentado em (Laukkarinen et al., 2012). Geralmente, as abstrações são utilizadas para facilitar o acesso às informações oferecidas pelas redes de sensores em relação à instalação, manutenção e execução de aplicações. Nesses casos, a literatura ainda considera as redes de sensores como serviços Web, também denominados sensores Web. Ou seja, utilizam-se especificações e linguagens para realizar uma abstração das complexidades dos sistemas de sensoriamento. Nesse tipo de abordagem, interfaces padronizadas são providas auxiliando o acesso às observações das redes. O OpenGIS Consortium (OGC), consórcio constituído por mais 400 empresas e instituições acadêmicas, está trabalhando na definição de um framework composto por diversos tipos de padrões e especificações com o intuito de utilizá-los no desenvolvimento de redes de sensores disponibilizadas como serviços (OGC, 2013b). Esse framework é chamado de Sensor Web Enablement (SWE).

\subsection{Motivação}

A aplicação de abordagens como o SWE traz consigo todas as vantagens em relação à interoperabilidade e flexibilidade provida pela orientação a serviço. Porém, todas as desvantagens com relação a desempenho também são herdadas em consequência da utilização de protocolos textuais (text-based) comumente aplicados nesse paradigma.

Arquiteturas orientadas a serviços podem ser consideradas como uma área emergente no contexto das redes de sensores. Questões relativas a desempenho ainda são pouco exploradas nesse domínio. Dessa forma, a análise dos problemas de desempenho das arquiteturas orientadas a serviço no contexto das redes de sensores é o objeto de investigação desta tese de doutorado.

\subsection{Hipótese}

Conforme apresentado na motivação deste trabalho, as questões básicas que são tratadas nesta tese relacionam-se com o desempenho associado a obtenção de informações de uma rede de sensores. Desse modo, as seguintes questões guiam o trabalho desenvolvido. A degradação de desempenho imposta pela utilização de SOA como forma de expor infraestruturas de redes de sensores pode inviabilizar a utilização das informações obtidas em algum tipo de aplicação? Seria possível 
minimizar essa degradação? Seria possível prover qualidade de serviço com a utilização de SOA para acesso a uma rede de sensores?

A tese defendida neste trabalho considera a utilização de uma arquitetura orientada a serviço como forma de abstrair infraestruturas de redes de sensores sem degradar o desempenho no acesso às observações geradas por elas a ponto de inviabilizar o seu uso. A adoção desse modelo arquitetural não compromete os requisitos de qualidade definidos pelos consumidores finais, mesmo que esse tipo de arquitetura adicione uma sobrecarga no desempenho das aplicações construídas sobre esse paradigma.

\subsection{Objetivos}

Para comprovar a tese proposta, deve-se inicialmente responder às seguintes questões no que concerne a utilização de SOA para abstração das complexidades das redes de sensores:

1. Existem grandes variações de desempenho na utilização de SOA em relação a outros métodos de acesso, como por exemplo, mecanismos binários?

2. Existem diferenças significativas em relação ao desempenho quando se utilizam diferentes formas de implementação de arquiteturas orientadas a serviço que abstraem redes de sensores?

3. Aplicações de redes de sensores toleram possíveis problemas de desempenho das arquiteturas orientadas a serviço?

4. Há uma forma de redução dos possíveis problemas de desempenho no contexto de redes de sensores abstraídas por SOA?

Assim, o objetivo principal desta tese de doutorado é quantificar a sobrecarga imposta pela utilização de SOA como forma de abstrair infraestruturas de redes de sensores e demonstrar a viabilidade de sua utilização, tanto em termos de desempenho quanto em termos de prover qualidade de serviço.

\subsection{Metodologia}

Para atingir o objetivo definido na Seção 1.3 e para comprovar a tese proposta neste trabalho, devem-se analisar os resultados obtidos em experimentos que utilizem diferentes formas de abstrair infraestruturas de redes de sensores através de SOA e compará-los com resultados onde orientação a serviço não é aplicada. Deve-se ainda demonstrar a possibilidade de considerar atributos de qualidade de serviço nesse tipo de arquitetura. 
Desse modo, a metodologia utilizada para o desenvolvimento desta tese possui como base a investigação da literatura e a utilização de ferramentas e APIs (Application Programming Interface) destinadas a construção de protótipos de software necessários a condução deste estudo. Assim, a metodologia proposta pode ser divida em cinco etapas principais:

1. Estudar as propostas das arquiteturas orientadas a serviços utilizadas para abstrair infraestruturas de redes de sensores;

2. Selecionar a proposta mais apropriada, considerando:

- Aderência da industria e instituições acadêmicas;

- Conformidade com os requisitos exigidos para as implementações de abstrações de infraestruturas, segundo critérios estabelecidos em (Laukkarinen et al., 2012);

- Maturidade de APIs e ferramentas de desenvolvimento;

- Extensão da atividade de pesquisa na área;

3. Comparar o desempenho da abordagem selecionada com outros mecanismos de abstração;

4. Avaliar o desempenho da proposta selecionada em relação as suas próprias características;

5. Propor e implementar uma arquitetura que provê qualidade de serviço, considerando parâmetros de desempenho, no contexto da proposta selecionada.

\subsection{Estrutura do documento}

Esta tese está organizada da seguinte forma. O Capítulo 2 apresenta uma análise de literatura sobre a utilização de SOA no contexto das redes de sensores, além de introduzir os conceitos básicos desse tipo de rede. O Capítulo 3 discorre sobre os padrões do SWE, destacando seus modelos de informação e interfaces. O SWE é composto por um extenso conjunto de padrões e linguagens. Contudo, o OGC ainda não disponibilizou uma ferramenta, como o W3Schools fornecido pelo World Wide Web Consortium (W3C), que facilite o entendimento dos padrões SWE. Assim, o Capítulo 3 contribui no sentido de prover um material que auxilie a compreensão do framework SWE, incluindo exemplos e detalhamento de códigos. O Capítulo 4 discute duas avaliações que tem o intuito de investigar questões de desempenho na exposição de redes de sensores através de arquiteturas orientadas a serviço. A primeira avaliação investiga o desempenho de diferentes mecanismos na abstração de redes de sensores. Por sua vez, a segunda avaliação tem o objetivo de analisar o comportamento dos três dos principais serviços SWE frente a variação de diferentes tipos de filtros utilizados na solicitação de informações desses serviços. O Capítulo 5 apresenta uma arquitetura para a provisão de qualidade de serviço, no contexto dos padrões do SWE, chamada de SWARCH. Essa arquitetura adiciona um elemento chamado Broker que monitora constantemente os serviços 
SWE. O Capítulo 5 ainda discute uma avaliação que valida a utilização dessa arquitetura. Por fim, o Capítulo 6 apresenta as conclusões e os trabalhos futuros que poderão ser desenvolvidos a partir do trabalho discutido nesta tese. 


\section{Redes de Sensores e Seus Mecanismos de Abstração}

A $\mathrm{s}$ redes de sensores são infraestruturas que englobam elementos de sensoriamento e monitoração, computação e comunicação. Esse tipo de rede provê a possibilidade de instrumentar, observar e reagir a eventos e fenômenos em diversos tipos de ambientes (Sohraby et al., 2007). As redes de sensores são compostas basicamente por três partes: sistema de nós, rede e ambiente físico. Nesse modelo, o sistema de nós pode ser decomposto em hardware e software. A plataforma de hardware é definida por uma unidade de processamento, um transceptor de radiofrequência, sensores e bateria. O modelo de software inclui sistemas operacionais, middlewares, pilha de protocolos e software da aplicação. Por sua vez, os nós são conectados uns aos outros pela rede que define a topologia e a transferência de pacotes. O modelo do ambiente é caracterizado pelos parâmetros físicos que variam temporal e espacialmente (Du et al., 2010).

Redes de sensores têm sido utilizadas em uma gama de aplicações e em diversos tipos de domínios (Wang et al., 2008). A literatura destaca uma série de aplicações em: monitoração (militares, médicas e ambientais), previsão de desastres naturais (enchentes e terremotos), exploração de ambientes hostis (monitoração de vulcões) e prédios inteligentes (Burrell et al., 2004; Shnayder et al., 2005; Werner-Allen et al., 2006; Ramamurthy et al., 2007; Komninos, 2010; Mikhaylov et al., 2012; Iyengar e Brooks, 2012; Liu et al., 2013). Em aplicações de monitoramento e rastreamento de alvos militares, as redes de sensores podem ajudar na detecção e identificação de invasores e na coordenação de movimentação de tropas e tanques de guerra (Yick et al., 2008).

Diferentemente das redes tradicionais, as redes de sensores possuem restrições no que diz respeito a projeto e recursos. Em geral, os nós que compõem a rede apresentam restrições de recursos 
que incluem limitações sobre a quantidade de energia, baixa faixa de comunicação, processamento e armazenamento de dados. O ambiente onde a rede está instalada define algumas características tais como tamanho, esquema de posicionamentos dos nós e a topologia da rede. O tamanho da rede varia de acordo com o ambiente que está sendo monitorado. Poucos nós são necessários para ambientes fechados enquanto que para ambientes abertos ocorre um crescimento da quantidade de nós para aumentar a abrangência do monitoramento. O esquema de disposição ad hoc (sem um planejamento definido) dos nós é preferido ao posicionamento estruturado quando se encontra um ambiente inacessível aos seres humanos ou quando a rede é composta por muitos nós (Yick et al., 2008).

Pesquisas em redes de sensores visam suprir essas limitações através da introdução de novos conceitos de projeto, desenvolvimento e aperfeiçoamento de protocolos, construção de novas aplicações e desenvolvimento de algoritmos (Yick et al., 2008). Uma parte dessa diversidade de pesquisas trata o desenvolvimento de mecanismos de abstração dos elementos da rede que proveem suporte no desenvolvimento, manutenção, publicação e execução de aplicações. Essa linha de pesquisa representa uma tarefa desafiadora e não trivial que visa principalmente preencher uma lacuna que há entre os requisitos de alto nível das aplicações e as complexidades dos elementos que compõem as redes de sensores sem fio (Philipp et al., 2011; Mottola e Picco, 2012; Laukkarinen et al., 2012).

\subsection{Arquitetura das Redes de Sensores}

A arquitetura das redes de sensores, apresentada conceitualmente na Figura 2.1, é composta por diversos elementos tais como o campo de sensoriamento, nós sensores, sink nodes, gerenciadores de dados e consumidores. Os nós sensores geralmente estão dispostos em um campo de sensoriamento seguindo algum tipo de topologia (ad hoc ou infraestruturada). Cada um dos nós possui a capacidade de coletar e rotear dados para um nó sorvedouro ou sink node. Geralmente, os sink nodes são dispositivos que possuem maior poder computacional quando comparados com os sensores que compõem a rede. Eles também executam a função de encaminhar os dados coletados pelos sensores para uma interface que os gerencia, permitindo acesso aos consumidores finais. Esse encaminhamento pode ser feito através da internet, satélites ou qualquer tipo de rede sem fio (WiFi, redes mesh, redes de telefonia, WiMax e etc.). Além disso, também é possível que o sink node esteja diretamente conectado com os consumidores finais. Os nós sensores exercem duas funções principais:

1. Fonte de dados: nós fontes que executam uma comunicação de dados para informar uma medição;

2. Roteador: nós sensores que participam no encaminhamento de pacotes recebidos de outros nós para o próximo destino em um caminho chamado de multi-hop até o sink node. 


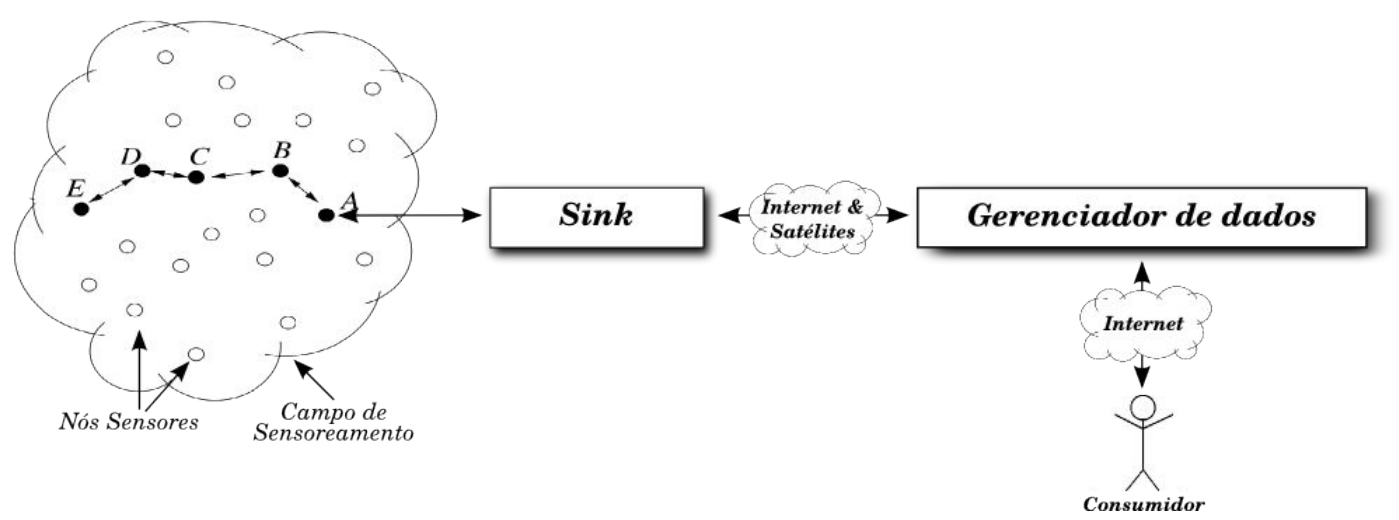

Figura 2.1: Modelo conceitual de uma Rede de Sensores - Adaptado de (Akyildiz e Vuran, 2010).

As plataformas de sensoriamento podem ser definidas como sistemas embarcados individuais responsáveis por interagir com o ambiente através de vários tipos de sensores. Esses sensores podem fazer medições como temperatura, umidade relativa do ar, luminosidade e velocidade do vento. Outras tarefas como processamento local e comunicação com nós vizinhos compõem o conjunto de atividades realizadas por uma plataforma de sensoriamento. Um sensor típico é composto por três componentes que podem estar organizados em placas individuais ou embarcados em um único sistema. Esses componentes são definidos da seguinte forma (Akyildiz e Vuran, 2010):

- Módulos sem fio (mote): são os componentes chave das redes de sensores uma vez que eles possuem a capacidade de comunicação e a memória programável onde residem os códigos das aplicações. O módulo sem fio é constituído por um microcontrolador, um transceptor, fonte de energia, unidade de memória, um ou vários sensores. Uma grande variedade de plataformas de sensoriamento foi desenvolvida nos últimos anos;

- Placas de sensoriamento (sensor boards): são montadas sobre os motes e embarca vários tipos de sensores. Essas placas possuem uma área de prototipagem onde é possível conectar sensores customizados. Placas de sensores podem ser encontradas separadamente como o caso dos modelos MTS300/400 que são utilizados pela família Mica. Alternativamente, os sensores podem estar integrados com os módulos sem fio, como são os casos das plataformas Telos e OracleSPOT;

- Placas de programação (programming board): são também conhecidas como placas gateway que fornecem múltiplas interfaces incluindo portas Ethernet, WiFi, USB e Serial. Essas portas são utilizadas para conectar diferentes tipos de motes às redes tradicionais ou localmente a um computador. As plataformas de sensoriamento devem estar conectadas a uma placa de programação para o carregamento de aplicações na memória dos motes.

As aplicações que são carregadas nas plataformas de sensoriamento devem ser amparadas por um conjunto de elementos que tornam possíveis a sua utilização. A Figura 2.2 apresenta esses elementos. De modo geral, esses elementos podem ser classificados em três grupos: 


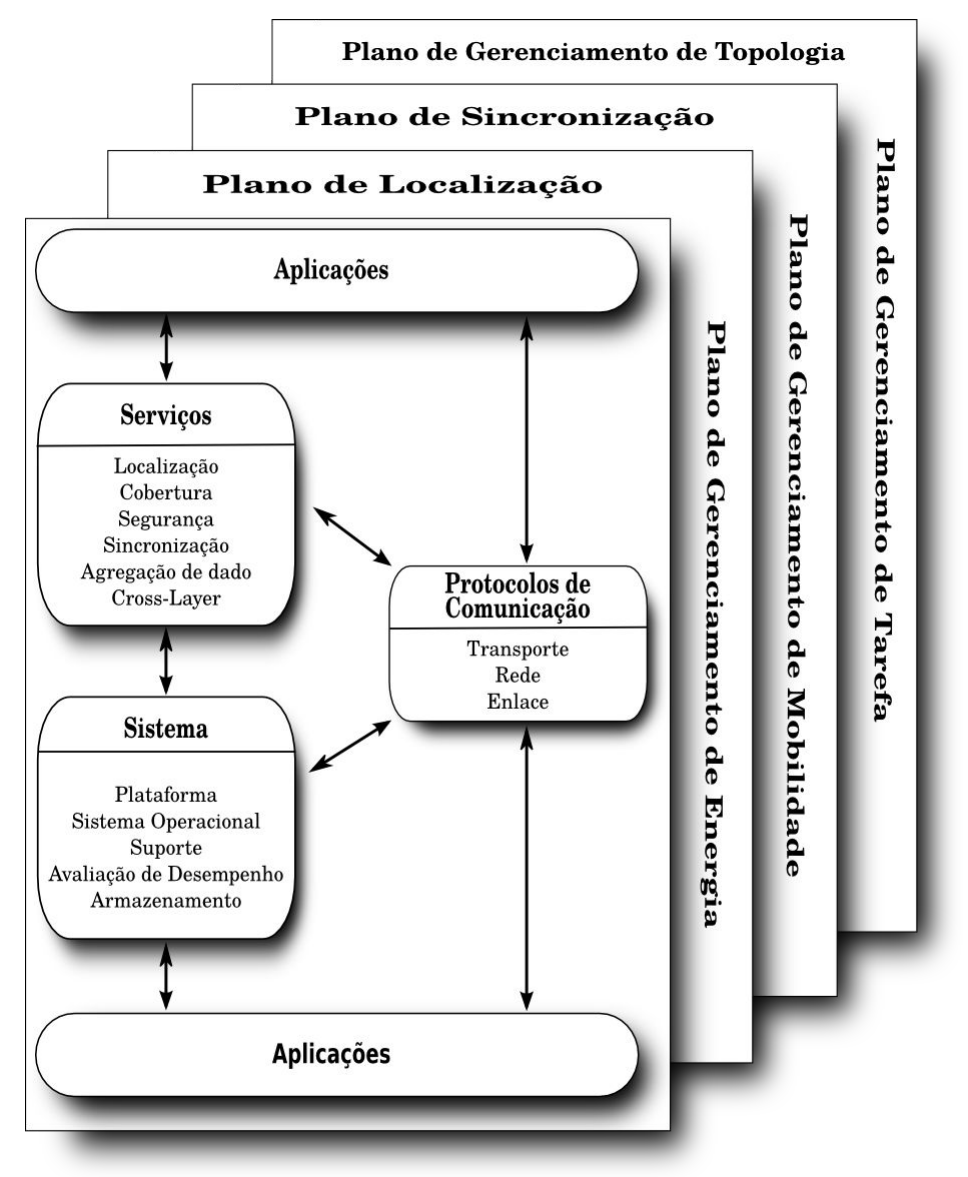

Figura 2.2: Arquitetura de Redes de Sensores - Adaptado de (Yick et al., 2008; Akyildiz e Vuran, 2010).

1. Sistema: cada nó sensor representa um sistema individual. Para suportar diferentes tipos de aplicações sobre o sistema de sensores é necessário o desenvolvimento de novas plataformas, sistemas operacionais e esquemas de armazenamento de dados;

2. Protocolos de comunicação: permitem a comunicação entre aplicações e sensores, além de permitir a comunicação entre diversos sensores;

3. Serviços: desenvolvidos para aumentar e melhorar o desempenho e a eficiência da rede.

Sob a perspectiva dos requisitos da aplicação e do gerenciamento da rede, os nós sensores devem ser capazes de se auto-organizarem. Os nós devem se organizar dentro da rede para que eles estejam aptos a se gerenciar eficientemente. A criação de novos protocolos de comunicação para um gerenciamento eficaz dos nós visa suprir as deficiências no que concerne às limitações de energia, processamento e armazenamento. Por sua vez, os protocolos de comunicação são compostos por cinco camadas que, em conjunto, executam a troca de pacotes de dados. Assim como no modelo TCP/IP, os protocolos de comunicação em redes de sensores também são divididos nas camadas de aplicação, transporte, rede, enlace e física. Adicionalmente, as redes de sensores possuem um conjunto de planos de gerenciamento que pode ser tratado por diversas camadas da pilha de protocolos. 
O gerenciamento de energia define a utilização da fonte energética dos sensores. Por exemplo, o sensor pode desligar o receptor de dados quando uma mensagem é recebida de um de seus vizinhos. Isso evita o recebimento de mensagens duplicadas. Outra técnica de economia de energia pode ser feita através de solicitações aos nós vizinhos para o não envio de mensagens de roteamento, reservando o restante do poder energético para as tarefas de sensoriamento. Por sua vez, o gerenciamento de mobilidade detecta e registra os movimentos dos nós sensores de maneira a manter a rota dos dados até o consumidor. O conhecimento do posicionamento de cada sensor é importante para que seja possível executar técnicas de balanceamento no consumo de energia e processamento de tarefas. O plano de gerenciamento de tarefas é responsável por balancear e escalonar as tarefas de sensoriamento entre os nós que compõem a rede. É importante ressaltar que, em determinados cenários, tanto as tarefas de sensoriamento quanto de roteamento não envolvem simultaneamente todos os sensores da rede. Assim, é possível que determinados sensores executem apenas tarefas de sensoriamento, enquanto outros podem executar tanto tarefas de sensoriamento quanto roteamento. Em geral, a definição das tarefas executadas pelos sensores é balizada no nível de energia de cada nó. Esse tipo de plano de gerenciamento é necessário para que os sensores trabalhem conjuntamente através de um mecanismo que visa a eficiência no consumo de energia.

A camada física trata mecanismos de modulação, seleção e geração de frequência e detecção de sinal dos dados. A camada de enlace é responsável pela multiplexação de fluxos de dados, detecção de frames e pelos mecanismos de controle de erros e de gerenciamento da utilização do canal. Nesse último, são utilizadas técnicas MAC (da sigla em inglês, Media Access Control) para minimizar colisões das transmissões entre nós vizinhos. Por sua vez, a camada de rede é responsável por encontrar caminhos entre os nós de sensoriamento e, também, entre sensores e o sink node. Isso deve ser feito através de técnicas de roteamento que utilizem os nós como intermediários nessa comunicação. Geralmente, técnicas existentes no contexto do roteamento em redes ad hoc não satisfazem os requisitos das redes de sensores que devem prover eficiência no consumo de energia e agregação de dados de múltiplos nós vizinhos através de processamento local. Além disso, os nós podem não conter mecanismos de identificação única, devido ao fato da rede ser composta por um grande número de nós que podem ser endereçados pelos seus dados ou informações de localização. Outra importante função da camada de rede é permitir a comunicação externa entre a rede de sensores com outras redes de sensores e com a Internet.

A camada de transporte é especialmente necessária para permitir o acesso às redes de sensores por meio da Internet e outras redes externas. O TCP, com seus mecanismos de janelas de transmissão, não fornece os requisitos necessários para satisfazer as exigências impostas pelo ambiente das redes de sensores. Nas redes de sensores é necessário considerar endereçamentos baseados em dados ou localização para indicar os destinos dos pacotes de dados. Fatores como consumo de energia, escalabilidade e roteamento centralizado nos dados exigem uma manipulação diferente dos dados pela camada de transporte. Dessa forma, a camada de transporte possui duas funcionalidades principais: confiabilidade e controle de congestionamento. Recursos limitados e custos altos no consumo de energia prejudicam as técnicas de confiabilidade. De forma contrária, as re- 
des de sensores podem utilizar algoritmos que tratam a confiabilidade através do reconhecimento da localização dos sensores. O controle de congestionamento deve ser implementado para mitigar os efeitos nocivos do alto tráfego de dados durante a ocorrência de um evento detectado por vários sensores. A falta de um controle de congestionamento pode ser prejudicial ao consumo de energia uma vez que o processamento dos pacotes tem alto custo computacional, tendo em vista processamento, armazenamento e transmissão.

Por último, a camada de aplicação inclui tanto a aplicação quanto funcionalidades de gerenciamento. Além do código da aplicação, filas de processamento de tarefas que são executadas nos nós também se encontram na camada de aplicação. A arquitetura em camadas das redes de sensores foi inicialmente adotada devido ao seu sucesso com a Internet. No entanto, implementações de aplicações de redes de sensores revelam que o canal sem fio tem impacto significante nas camadas mais altas da pilha de protocolos. Adicionalmente, restrições de recursos e as especificidades de cada aplicação conduzem as pesquisas para soluções cross-layer que aplicam alguns tipos de funcionalidades a mais de uma camada. Além das funcionalidades das camadas de protocolos, as redes de sensores definem várias funcionalidades que auxiliam sua operação. Por exemplo, cada sensor da rede é equipado com seu próprio relógio (clock) interno utilizado nas operações de aferição e, também, por protocolos de sincronização. Cada evento é relacionado a informações temporais que são controladas pelos relógios internos dos sensores. Na maioria das vezes, os consumidores precisam de informações obtidas colaborativamente entre vários sensores e, portanto, informações de tempo devem ser consistentes. Para realizar essa consistência de tempo é necessário o desenvolvimento de protocolos de sincronização que são mantidos por um gerenciador específico para essa tarefa. Outro fator importante é a localização da informação dos fenômenos observados pela rede que podem ser associados ao tempo em que eles foram obtidos. Algumas redes de sensores como aquelas que executam aplicações de rastreamento de objetos utilizam informações de localização na implementação de seus algoritmos. Finalmente, soluções de gerenciamento de topologia são aplicadas para manter a conectividade e cobertura das redes de sensores. Esse tipo de gerenciamento ajuda a determinação de níveis da potência do sinal na transmissão de dados, diminuindo o consumo de energia enquanto mantém a conectividade entre os nós.

Localização é um conceito importante para as redes sensores, como pôde ser observado na discussão das camadas da pilha de protocolos. Os sensores de uma rede podem ser classificados quanto a sua localização em: sensores in-situ ou remotos. Sensores que estão em contato direto com o fenômeno observado por eles são definidos como dispositivos in-situ. Um termômetro pode ser considerado in-situ uma vez que ele pode medir a temperatura do motor de um carro, a temperatura ambiente de uma casa ou temperatura corporal de uma pessoa. Em todos esses casos, é necessário que o dispositivo de sensoriamento esteja em contato direto com o objeto observado. Em geral, sensores que determinam condições meteorológicas são ditos in-situ pela necessidade de estarem no local onde as medições são realizadas. Outro exemplo de sensores in-situ pode ser dado por dispositivos que medem o nível de água em rios ou oceanos. Geralmente, esse tipo de 
sensor é utilizado para o monitoramento de enchentes e devem estar posicionados no local onde ocorrem as observações.

Diferentemente dos sensores in-situ, sensores remotos não estão em contato direto com o fenômeno observado. Ou seja, a medição é realizada indiretamente de maneira ativa ou passiva. Sensores remotos ativos emitem ondas eletromagnéticas que viajam até o objeto e retornam o resultado da observação. Exemplos desse tipo de sensor podem ser dados por um radar que afere a velocidade de um veículo, um Raio-X que utiliza ondas eletromagnéticas para produzir imagens do corpo humano ou ainda um sonar que utiliza ondas sonoras refletidas. Por outro lado, sensores remotos passivos tem a função de observar ondas eletromagnéticas emitidas por objetos. Uma câmera é um exemplo de sensor remoto passivo, pois ela capta a luz e a transforma em uma imagem. Como comentado no início deste capítulo, as redes de sensores podem ser utilizadas em diversos tipos de aplicações. Contudo, é necessário entender as características e perfis dessas aplicações. A Seção 2.1.1 discute uma taxonomia que classifica os tipos de aplicações existentes nas redes de sensores.

\subsubsection{Taxonomia de Aplicações em Redes de Sensores}

A literatura apresenta um conjunto de soluções para projetar e desenvolver diversas aplicações que utilizam redes de sensores, como pode ser observado no trabalho apresentado por Mottola e Picco (2011). Sensores disponíveis no mercado oferecem nós genéricos (propósito geral) e nós de ligação (gateway). Os nós de propósito geral possuem a tarefa de obter informações de ambientes monitorados. Eles podem ser equipados por uma variedade de dispositivos que medem atributos físicos como luz, temperatura, umidade, pressão atmosférica, velocidade, aceleração, acústica, campo magnético, entre outros. Nós de ligação são responsáveis por obter informações de sensores genéricos e transmiti-las para uma estação base ( $\operatorname{sink}$ ). Esses nós têm maior capacidade de processamento, autonomia de energia e poder de transmissão de dados. A combinação desses dois tipos de sensores é posicionada em determinado tipo de ambiente para formar o que pode ser chamado de redes de sensores (Yick et al., 2008).

A extensa atividade de pesquisa tem alavancado o paradigma de redes de sensores. Como comentado anteriormente, diversos temas de pesquisa são discutidos na literatura especializada como consumo de energia, middlewares de gerenciamento, sistemas operacionais, protocolos de comunicação e algoritmos de roteamento. Outro tema bastante discutido é com relação à aplicabilidade das redes de sensores no mundo e as potenciais vantagens de se utilizar tal paradigma (Yick et al., 2008; Akyildiz e Vuran, 2010; Mottola e Picco, 2011). Mottola e Picco (2011) apresentam um trabalho onde é realizado um estudo sobre o estado da arte na programação de aplicações de redes de sensores. A Figura 2.3 apresenta uma taxonomia desenvolvida pelos autores que classificam os tipos de aplicações encontradas no contexto desse tipo de rede. A taxonomia sugerida define cinco dimensões que consideram características como o objetivo da aplicação, padrões de interação, mobilidade, espaço e tempo. 


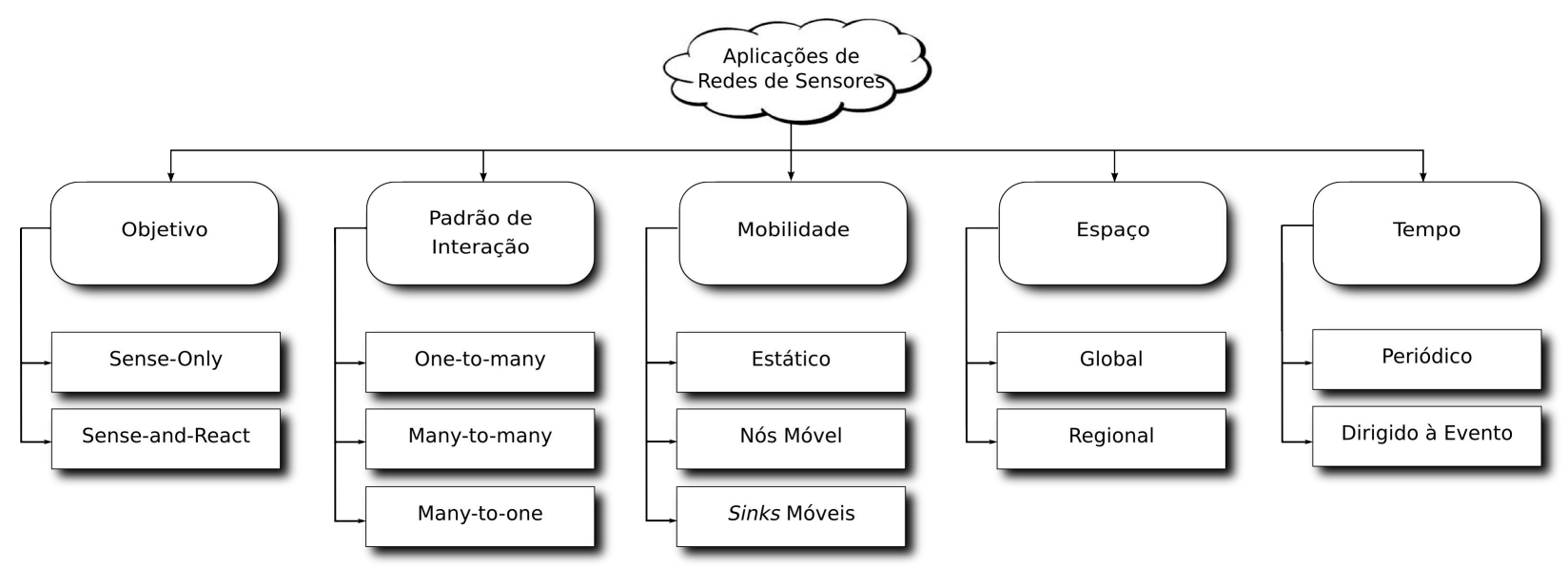

Figura 2.3: Taxonomia de Aplicações em Redes de Sensores - Adaptado de (Mottola e Picco, 2011).

O objetivo da aplicação define o comportamento dos dispositivos de sensoriamento. Nesse caso, os sensores podem apenas realizar medições (Sense-Only), ou então, reagir aos dados mensurados. No caso de aplicações (Sense-Only), os dados obtidos pelos sensores são enviados a um sink node que processa e armazena os dados que passam, posteriormente, por uma análise. Por outro lado, alguns tipos de aplicações utilizam um comportamento onde os sensores reagem a algum evento mensurado (Sense-and-React). O padrão Sense-and-React modifica o objetivo da aplicação. Em princípio, os dados sensoriados continuam sendo reportados a um sink node que também gerencia a lógica dos comandos de controle enviados aos atuadores. Entretanto, é aconselhável mover as aplicações e a lógica de controle para os nós dentro da rede de maneira a reduzir a latência e o consumo de energia, além de aumentar a confiabilidade ao remover um ponto de falha único. Isso modifica a arquitetura da rede de forma significativa. Exemplos de aplicações Sense-and-React podem ser dados por sistemas que fazem controle de ventilação, luminosidade ou, até mesmo, aparelhos de ar-condicionado em prédios inteligentes.

O padrão de interação define como os nós da rede interagem entre si. A definição do padrão de interação é afetada pelo objetivo da rede. As redes Sense-Only utilizam, na maioria dos casos, uma interação de muitos para um (many-to-one) onde ocorre a concentração dos dados para um ponto centralizado. Em contrapartida, a interação um para muitos (one-to-many) pode ser utilizada para o envio de comandos de configuração para as plataformas de sensoriamento e modificação, por exemplo, da frequência na atividade de medição. Já a interação de muitos para muitos (manyto-many) é utilizada em cenários onde há a presença de vários sink nodes, como o caso das redes Sense-and-React.

Redes de sensores são caracterizadas pela dinamicidade em suas topologias induzindo flutuações na conectividade dos nós. Algumas aplicações introduzem esse dinamismo devido ao suporte oferecido por elas aos dispositivos móveis. Por exemplo, algumas aplicações podem embutir nós de sensoriamento a entidades móveis como robôs ou animais. Outros tipos de aplicações podem 
utilizar ainda sink nodes móveis que se movem oportunisticamente para próximo dos dispositivos de sensoriamento e realizam a coleta dos dados.

O processamento distribuído de algumas aplicações pode alcançar diferentes porções do espaço físico compreendido por uma rede, assim como ser desencadeado em diferentes instantes de tempo. Esses aspectos são tipicamente determinados pelos fenômenos que estão sendo monitorados. A extensão do processamento distribuído no espaço pode ocorrer de maneira global onde toda rede é envolvida. O processamento global ocorre em aplicações onde os fenômenos de interesse se encontram espalhados pela área geográfica onde a rede está instalada. Diferentemente do processamento global, o processamento regional ocorre em apenas uma área específica. No que diz respeito ao tempo, dois tipos de processamentos são possíveis: periódico e dirigido a evento. Aplicações que são projetadas para processar continuamente observações de sensores são ditas periódicas. Por outro lado, aplicações dirigidas a eventos são caracterizadas por duas fases: (1) durante a detecção de um evento, o sistema se mantém praticamente em repouso, com pouca ou nenhuma atividade de comunicação; (2) quando uma condição de um evento é alcançada (por exemplo, um sensor mede um valor acima de um determinado limite), a rede inicia um processamento distribuído.

Atualmente existem vários tipos de redes de sensores tais como: redes de sensores terrestres, subterrâneas, subaquáticas, multimídia e móveis (Yick et al., 2008). Essas redes podem ser aplicadas em diferentes contextos tais como: militares, ambientais, saúde, domésticas, industriais e comerciais. A Seção 2.1.2 discute esses contextos onde as tecnologias em redes de sensores têm sido aplicadas.

\subsubsection{Aplicações em Redes de Sensores}

Redes de sensores são compostas por diferentes tipos de sensores. Dentre eles, destacam-se os sensores sísmicos, térmicos, visuais, infravermelho, acústicos e radares. Todos esses tipos de sensores podem ser aplicados para monitorar uma grande variedade de condições ambientais tais como temperatura, umidade, pressão, velocidade, direção, movimento, luminosidade, níveis de ruído, presença ou ausência de objetos. Todos esses tipos de monitoramentos podem ser aplicados na construção de diversos tipos de aplicações. Em (Akyildiz e Vuran, 2010) são apresentadas cinco categorias de aplicações em redes de sensores.

\section{Aplicações Militares}

Redes de sensores podem ser utilizadas em sistemas militares de comando, controle, comunicação, computação, inteligência, vigilância, reconhecimento de território e definição de alvos. As redes de sensores são sistemas de sensoriamento que trazem grandes benefícios para aplicações militares devido a características como rápida instalação, auto-organização e tolerância a falhas. Tais características são importantes para a construção de sistemas C4ISR (Command, Control, Communications, Computers, Intelligence, Surveillance and Reconnaissance). As redes de sensores 
podem ser dispostas através da instalação de uma grande quantidade (alta densidade) de dispositivos de baixo custo onde a destruição de alguns nós por ações hostis não afetam uma operação militar. Outros tipos de aplicações militares dizem respeito ao monitoramento de forças amigas, de equipamentos e munições, de deslocamento de tropas, de reconhecimento de terrenos e tropas inimigas, de detecção de ataques químicos, biológicos e nucleares.

O Smart Dust é considerado um dos primeiros projetos que utilizam uma rede de sensores para fins militares. O objetivo desse projeto é fornecer tecnologias para redes de sensores que são utilizadas para operações militares em ambientes hostis (Kahn et al., 1999). Na área militar, a utilização da rede de sensores consiste na sua instalação em locais onde a operação da mesma oferece risco aos seres humanos. Nesse caso, as aplicações militares incluem a coleta de informações sobre a movimentação de inimigos e armas químicas. O principal objetivo do Smart Dust é o desenvolvimento de plataformas de sensores com baixas dimensões. O sensor resultante desse projeto é um protótipo com sensores de, aproximadamente, cem milímetros cúbicos.

\section{Aplicações Ambientais}

A capacidade de coordenação autônoma das redes de sensores podem ser utilizadas para implementar uma série de aplicações de monitoramento de ambientes. Algumas dessas aplicações incluem rastreamento da movimentação de pássaros, pequenos animais e insetos, monitoramento de condições ambientais que afetam colheitas, monitoramento de irrigações, detecção química e biológica, agricultura de precisão, pesquisa meteorológica e geofísica, detecção de enchentes, estudos de poluição atmosférica e rios.

Uma aplicação interessante com a utilização de redes de sensores é o monitoramento de ambientes onde o acesso humano é difícil ou até mesmo impossível. Um exemplo desse tipo de aplicação diz respeito ao monitoramento de vulcões. Nesse caso, uma rede de sensores pode ser instalada próxima a vulcões ativos e obter informações que não eram possíveis anteriormente com a utilização de outras tecnologias. Werner-Allen et al. (2006) apresentam uma prova de conceitos sobre a aplicação de uma rede de sensores no monitoramento de vulcões. Em 2004, uma pequena rede de sensores com três nós equipados com microfones foram utilizados para monitorar as atividades de um vulcão em erupção (Vulcão Tangurahua - Equador). No ano seguinte, nós TMote Sky equipados com sensores sísmicos e acústicos foram utilizados durante 19 dias para monitorar o vulcão Reventador (Equador). Os nós sensores foram equipados com antenas externas que aumentavam a faixa de comunicação. Tais sensores fornecem informações a um laptop (função sink node) equipado com uma antena bidirecional que realizava a coleta dos dados e o gerenciamento da rede remotamente.

\section{Aplicações de Saúde}

A combinação de sensores com dispositivos médicos torna possível a utilização de uma rede de sensores na área da saúde. Por exemplo, essa combinação permite o desenvolvimento de aplicações 
que forneçam diagnóstico de doenças, administração de medicamentos, monitoramento de movimento de insetos ou pequenos animais, telemonitoramento de dados fisiológicos e rastreamento de médicos e pacientes no ambiente hospitalar.

O projeto CodeBlue da universidade Harvard é um exemplo de aplicação de redes de sensores na área da saúde. Nesse caso, os sensores são utilizados para monitorar sinais vitais de pacientes em hospitais. Esses sinais são monitorados com sensores contendo oxímetros (instrumento para medir quantidade de oxigênio nas hemoglobinas), eletrocardiógrafo (aparelho que efetua o eletrocardiograma) e eletromiógrafo (aparelho para monitorar a atividade elétrica do coração). Com esses sensores é possível monitorar batimento cardíaco, níveis de saturação de oxigênio no sangue, atividades elétricas do coração, movimentos e atividades musculares dos pacientes (Pantelopoulos e Bourbakis, 2010).

\section{Aplicações Domésticas}

Os avanços tecnológicos em sensores trazem a possibilidade de integrar dispositivos domésticos com dispositivos de sensoriamento. Por exemplo, pode-se construir uma rede de sensores com fornos de micro-ondas, refrigeradores e DVD players, bem como realizar o monitoramento do consumo de água. Todas essas aplicações oferecem facilidade aos usuários em realizar o controle dos dispositivos domésticos ou a interação entre eles localmente, ou até mesmo através da Internet ou satélites. Assim, as redes de sensores permitem a interconexão de vários dispositivos domésticos em uma residência e o controle dos mesmos de uma maneira conveniente e simples.

Um exemplo interessante de aplicação doméstica é o projeto NAWMS (Autonomous Water Monitoring System). O objetivo do NAWMS é localizar a perda na utilização de água e informar o morador sobre o seu uso mais eficiente. Uma vez que as empresas que realizam a distribuição apenas informam o total de água utilizada em uma residência, torna-se difícil o monitoramento de consumo em diferentes fontes com relação a esse total. O processo de monitoramento de água através de uma rede de sensores nesse projeto é a instalação de um sensor em cada um dos canos do sistema de encanamento, a um custo reduzido. Esse sistema melhora a eficiência no consumo de água em residências, podendo ser bastante utilizado no futuro devido a possíveis problemas de racionamento de água.

\section{Aplicações Industriais}

Redes de sensores cabeadas têm sido utilizadas na indústria nos campos de sensoriamento industrial e aplicações de controle tais como controle de acesso e automação de prédios. Contudo, o custo associado a instalação de sensores cabeados limitam a aplicabilidade desses sistemas. Adicionalmente, mesmo que um sistema de sensoriamento seja instalado na planta industrial, a atualização desse sistema terá um custo tão elevado quanto a instalação de um novo sistema. Além de sistemas de sensoriamento cabeado, existe ainda o monitoramento manual que é usado em aplicações industriais para realizar manutenção preventiva. Nessa situação, uma pessoa especializada 
auxiliada por um dispositivo computacional, como um Handheld, é necessária para a realização do monitoramento. Assim, a pessoa responsável pelo processo de monitoramento obtém os dados de uma central para a análise. Enquanto sistemas de sensoriamento cabeados incorrem em alto custo, sistemas manuais possuem precisão limitada e requerem pessoal especializado. Ao contrário, as redes de sensores sem fio podem trazer uma solução alternativa interessante a esses tipos de sistemas devido a sua fácil instalação, alta granularidade e alta precisão. Todas essas características são providas por meio de unidades de energia por baterias e comunicação sem fio.

Algumas das principais aplicações das redes de sensores no contexto industrial são: o monitoramento da fadiga de materiais, os escritórios inteligentes, gerenciamento de estoque, monitoramento de qualidade de produto, controle e orientação de robôs em ambientes de fabricação automática, controle ambiental de escritórios, brinquedos e museus interativos, controle e automação de processos industriais, detecção e monitoramento de roubo de carros, dentre outras. A manutenção preventiva é uma aplicação muito utilizada em plantas industriais para monitorar equipamentos de alto custo. Contudo, os sistemas existentes não têm obtido boa aceitação, pois a manutenção dos mesmos costuma ultrapassar os ganhos com o monitoramento. A utilização desse tipo de aplicação através de uma rede de sensor tem se mostrado uma boa alternativa em dois estudos de caso: em uma fábrica de semicondutores e em um petroleiro. Diversos outros exemplos de aplicações de redes de sensores em ambientes reais podem ser encontrados em (Werner-Allen et al., 2006; Yick et al., 2008).

\subsubsection{Características de Redes de Sensores Reais}

Um trabalho que propõe regras para o projeto de sistemas operacionais para plataforma de sensores pode ser encontrado em (Strazdins et al., 2013). Essas regras foram definidas a partir da análise de redes de sensores instaladas em ambientes reais. O trabalho apresentado pelos autores definiu aspectos importantes em quarenta projetos reais de redes de sensores encontrados na literatura. As redes analisadas datam entre os anos de 2002 e 2011 e compreendem todos os tipos de aplicações que foram discutidas na Seção 2.1.2.

\section{Estado das implementações}

O estado das implementações das redes de sensores discutidas em (Strazdins et al., 2013) apresenta a maturidade das aplicações. Essa análise caracterizou o estado das implementações em três categorias: protótipo, piloto e estável. A maioria das implementações analisadas foram categorizadas como protótipos ou pilotos. Apenas duas implementações foram consideradas estáveis, como são os casos das redes apresentadas em (Ceriotti et al., 2009; Dyo et al., 2010). Sobre a quantidade de nós, representada por um gráfico de frequência na Figura 2.4, verificou-se que $80 \%$ das implementações de redes de sensores contêm quantidades inferiores a 50 dispositivos de sensoriamento, $50 \%$ apresentam até 20 nós e $34 \%$ utilizam quantidades inferiores a 10 dispositivos. 


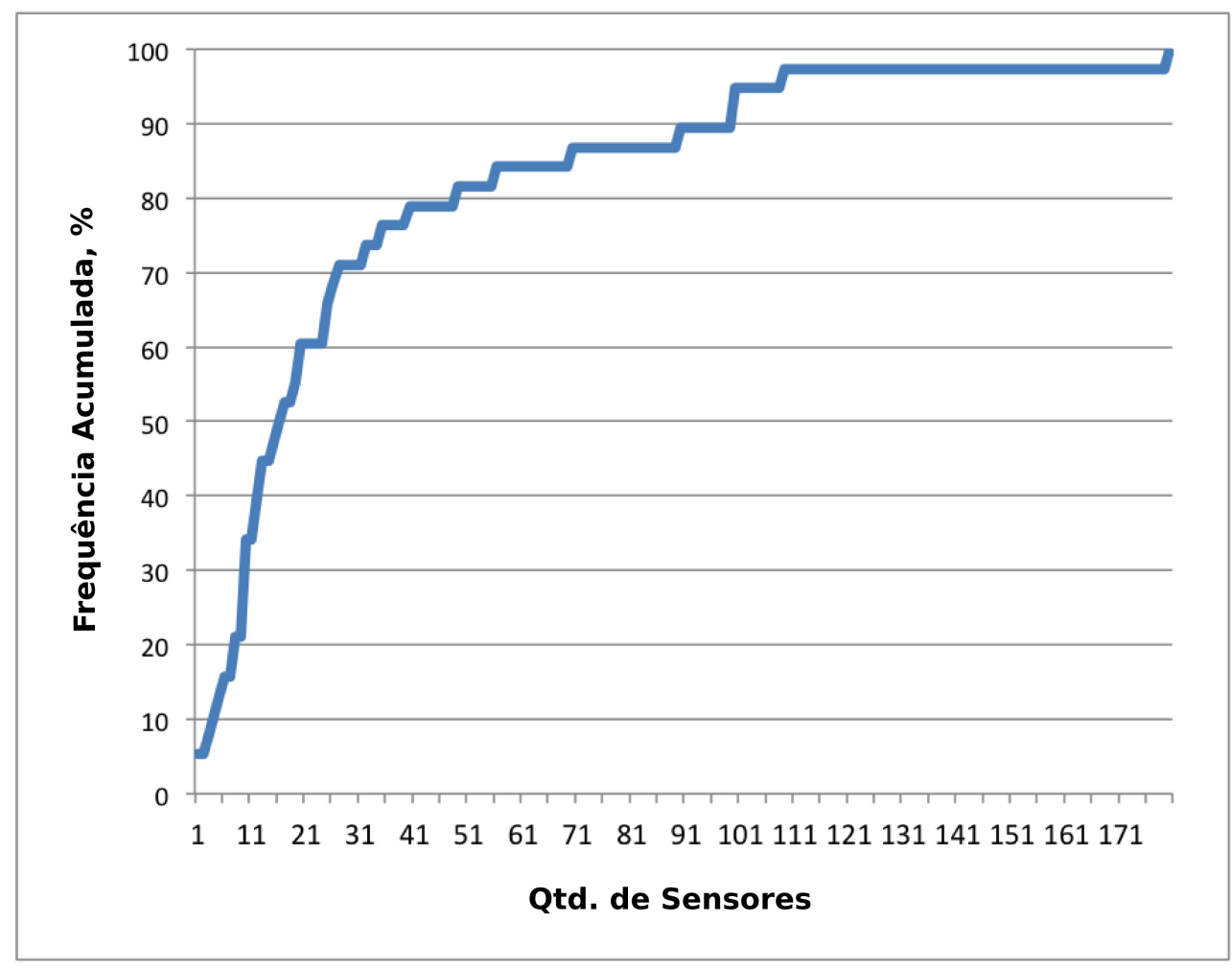

Figura 2.4: Gráfico de frequência acumulada da quantidade dispositivos de sensoriamento em implementações de redes de sensores- Adaptado de (Strazdins et al., 2013).

\section{Tipos de Sensores}

Outra análise apresentada no estudo realizado em (Strazdins et al., 2013), é sobre os tipos de sensores utilizados nas implementações. Como pode ser observado na Figura 2.5, sensores de temperatura, luminosidade e aceleração são os mais populares nas redes de sensores estudadas. Em geral, $43 \%$ das redes de sensores, utilizam sensores de temperatura.

\section{Taxas de Amostragens}

Outro aspecto importante, com relação aos tipos de dispositivos de sensoriamento, diz respeito a sua taxa de amostragem (sampling rate). A maioria das implementações possui baixas taxas de amostragem, onde os nós definem um baixo ciclo de trabalho com amostragens menores que $1 \mathrm{~Hz}$. Em outras palavras, a maioria das redes de sensores analisadas não efetua mais de uma ação de sensoriamento por segundo. A Figura 2.6 mostra um gráfico que categoriza as faixas de taxas de amostragem mais comumente utilizadas em redes de sensores. Segundo (Strazdins et al., 2013), algumas aplicações reportam dados apenas uma vez ao dia, enquanto que outras utilizam uma transmissão de dados em tempo real a $100 \mathrm{~Hz}$.

Esta seção apresentou os elementos básicos que compõem uma arquitetura de redes de sensores assim como suas principais áreas de aplicação. Ademais, características de aplicações reais documentadas na literatura também foram discutidas. Vale ressaltar ainda a importância do entendimento do funcionamento e das particularidades da arquitetura das redes de sensores e de suas 


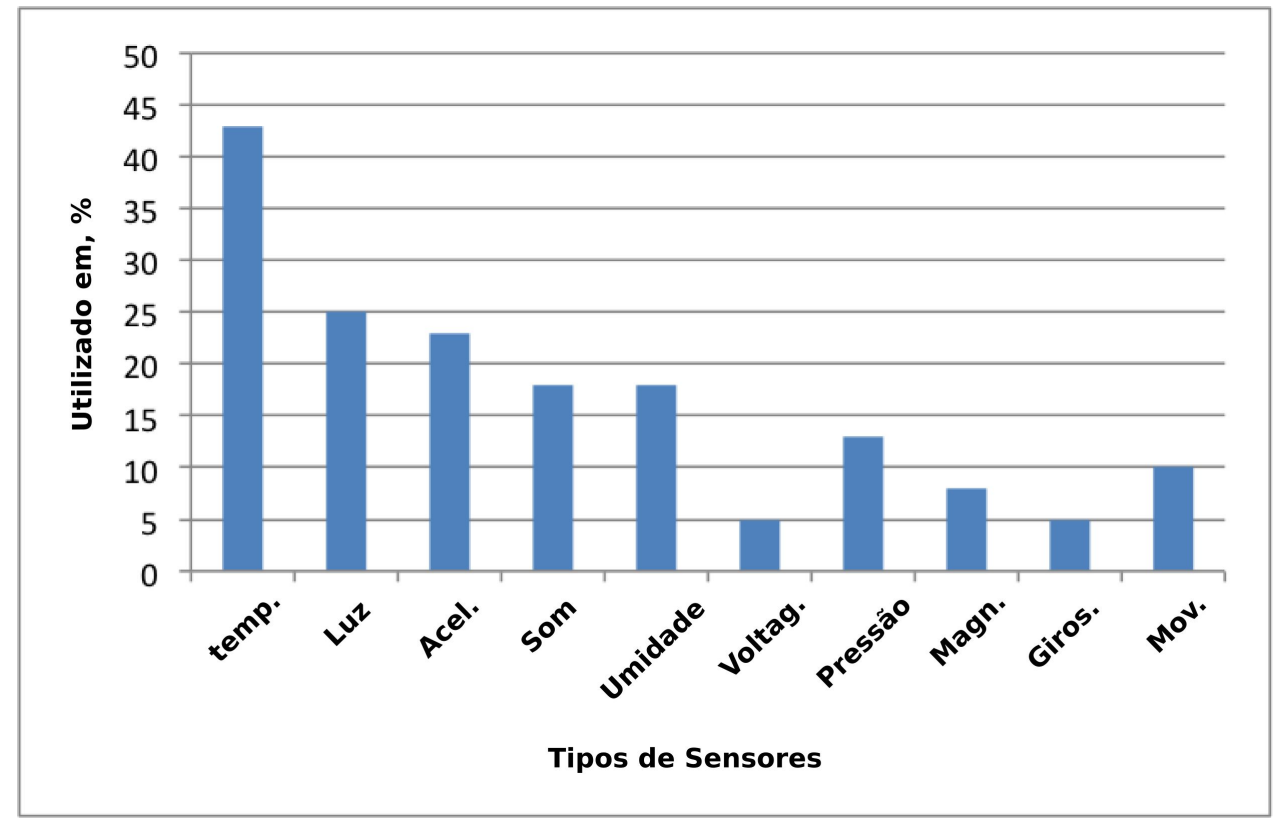

Figura 2.5: Gráfico de tipos de sensores - Adaptado de (Strazdins et al., 2013).

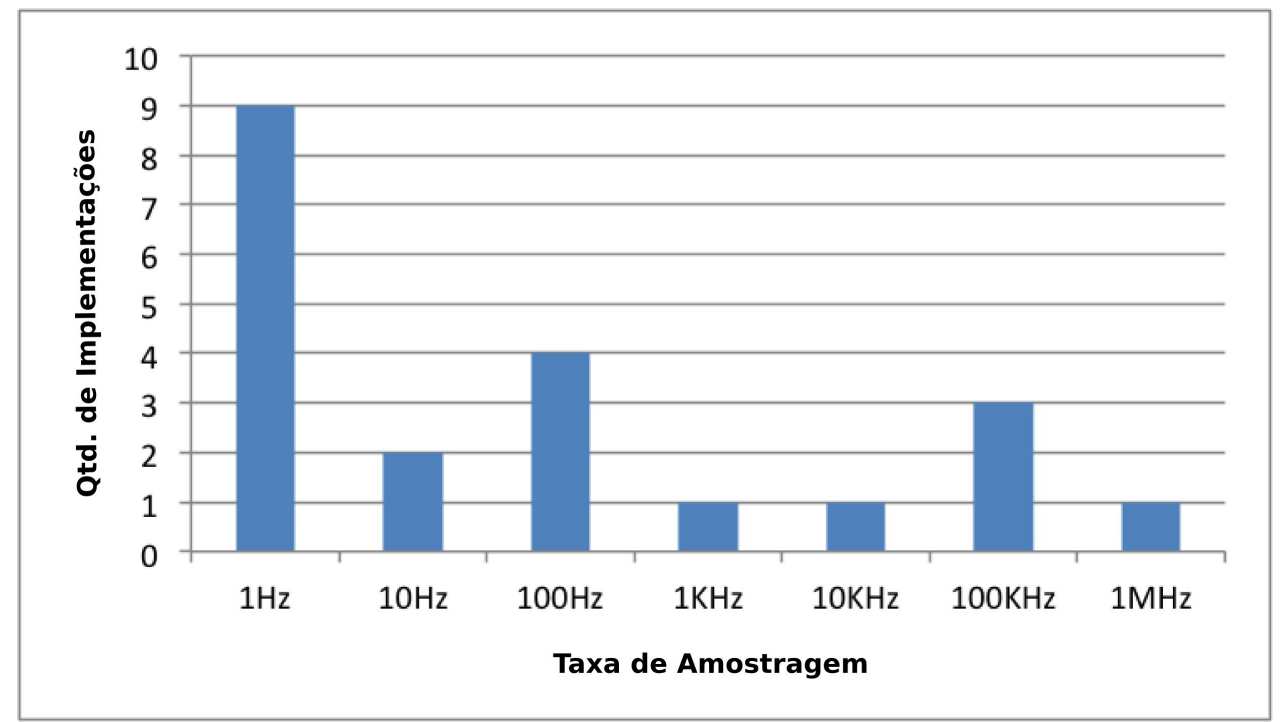

Figura 2.6: Gráfico de taxa de amostragem em redes de sensores - Adaptado de (Strazdins et al., 2013).

aplicações para a compreensão de seus mecanismos de abstração. As Seções 2.2 e 2.3 discorrem e diferenciam os tipos de abstrações existentes, contextualizando os mecanismos de orientação a serviço utilizados no cenário de redes de sensores.

\subsection{Mecanismos de Abstrações em Redes de sensores}

Como observado na Seção 2.1, a obtenção de dados em redes de sensores não é uma tarefa trivial. Isso se deve à complexidade no desenvolvimento de aplicações que, em geral, tratam questões como restrições de recursos, complexidade de protocolos de comunicação e a heterogeneidade das 
tecnologias envolvidas nas plataformas de sensoriamento. No entanto, diferentes níveis de abstração desses problemas podem tornar mais simples o desenvolvimento de aplicações em redes de sensores. Segundo (Laukkarinen et al., 2012), existem três níveis de abstrações em aplicações de redes de sensores: abstrações de nó, rede e infraestrutura. A Figura 2.7 posiciona cada uma dessas abstrações dentro do contexto da arquitetura de redes de sensores.

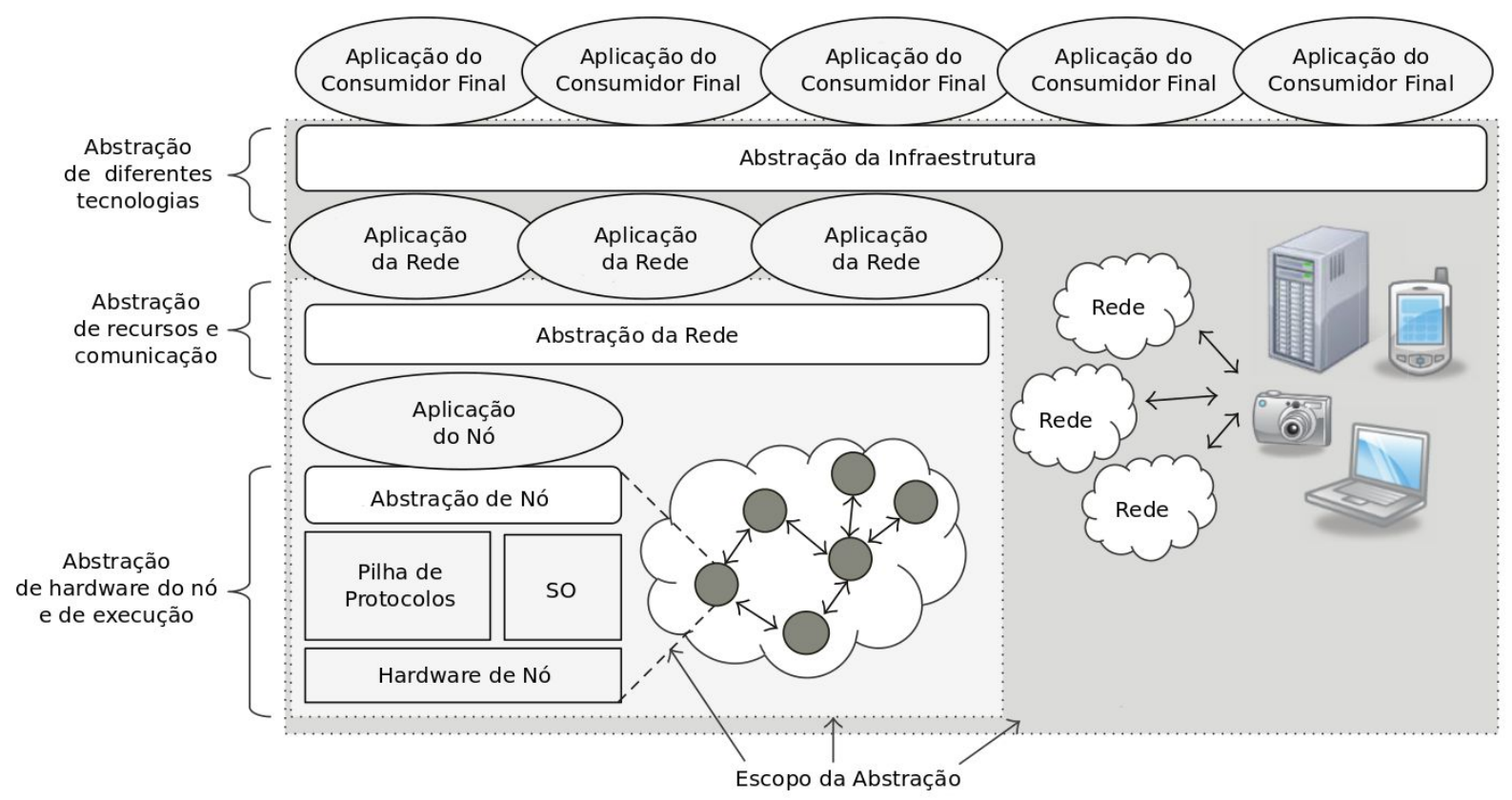

Figura 2.7: Níveis de abstrações de Aplicações em Redes de Sensores - Adaptado de (Laukkarinen et al., 2012).

\subsubsection{Abstração de Nó}

A abstração de nós fornece mecanismos para esconder complexidades de hardware dos nós e dos protocolos de comunicação utilizados por eles. Nesse caso, os desenvolvedores da aplicação, executada em cada nó individual da rede, utilizam a abstração do nó para facilitar o seu desenvolvimento. Sistemas operacionais embarcados ou máquinas virtuais são propostas utilizadas frequentemente para a abstração de nós. Essas abstrações podem ser exemplificadas por propostas tais como a TinyOS (Levis et al., 2004; TinyOS, 2014), Contiki (Contiki, 2014), Maté (Levis e Culler, 2002) e Squawk (Simon e Cifuentes, 2005; SPOT, 2014). As aplicações podem executar ações como leitura de sensores, processamento de observações e comunicação dos dados utilizando um conjunto de interfaces e serviços oferecidos pelas propostas de abstração de nós. O desenvolvimento das aplicações nos nós pode ser feito através da utilização de linguagens de programação como C, NesC (Gay et al., 2003) ou Java. 


\subsubsection{Abstração de Rede}

A abstração de rede fornece serviços como acesso a dados por meio de mecanismos de consultas (queries), e também, processamento desses dados através de técnicas de agregação e fusão. Além disso, serviços de distribuição para as aplicações dos nós como compartilhamento de observações através de abstrações de memória distribuída também são fornecidos. TinyDB (Madden et al., 2005), COUGAR (Yao e Gehrke, 2002), Agilla (Fok et al., 2009) e TinyLine (Curino et al., 2005) são exemplos de abstrações de rede. A abstração de rede provê acesso aos dados observados pela rede, mas esses dados raramente são suficientes para as aplicações dos consumidores finais. Em geral, esses dados são combinados com informações de metadados (localização física, unidades de medida e descrição). Os dados são processados e combinados com outras tecnologias ou arquivados para uma análise posterior. Uma vez que a abstração de rede não consegue fornecer todos os dados exigidos pelos consumidores finais, é necessário um nível superior de abstração chamado abstração de infraestrutura.

\subsection{Abstração de Infraestrutura}

As primeiras seções deste capítulo trataram os conceitos básicos utilizados no domínio das redes de sensores. Por sua vez, esta seção atende a primeira etapa da metodologia proposta na Seção 1.4, associando as propostas de orientação a serviço às redes de sensores.

Abstração de infraestrutura tipicamente descreve os mesmos requisitos cobertos pela abstração de rede. Essa metodologia de abstração também é referenciada como um middleware de redes de sensores. Entretanto, as unidades funcionais dos mecanismos que representam esse tipo de abstração são diferentes. Em abstração de rede, nós heterogêneos são abstraídos atrás de uma ou mais interfaces. Já na abstração de infraestrutura, uma ou mais interfaces abstraem múltiplas redes de sensores heterogêneas. O propósito geral é separar aplicações ou consumidores finais das complexidades na interação com redes de sensores heterogêneas. Abstração de infraestrutura é uma área de pesquisa relativamente nova em redes de sensores e vem recebendo atenção das comunidades científicas e da indústria (Laukkarinen et al., 2012). Isso se deve a uma diversidade de perfis de aplicações disponíveis. Várias aplicações de redes de sensores estão sendo desenvolvidas por meio da aplicação de diferentes tecnologias. A diversidade de tecnologias começa já no desenvolvimento das plataformas de sensoriamento. A Figura 2.8 apresenta uma linha do tempo, entre os anos de 1998 e 2009, no desenvolvimento dessas plataformas. Em geral, cada uma dessas plataformas possui seu próprio modelo de programação, sistemas operacionais e protocolos de comunicação. A abstração de infraestrutura facilita o desenvolvimento das aplicações dos consumidores finais, tornando as redes de sensores independentes de tecnologias. Em geral, as propostas de abstração de infraestrutura utilizam uma arquitetura orientada a serviço para fornecer interoperabilidade entre as redes de sensores (Mohamed e Al-Jaroodi, 2011; Jung et al., 2012; Kyusakov et 


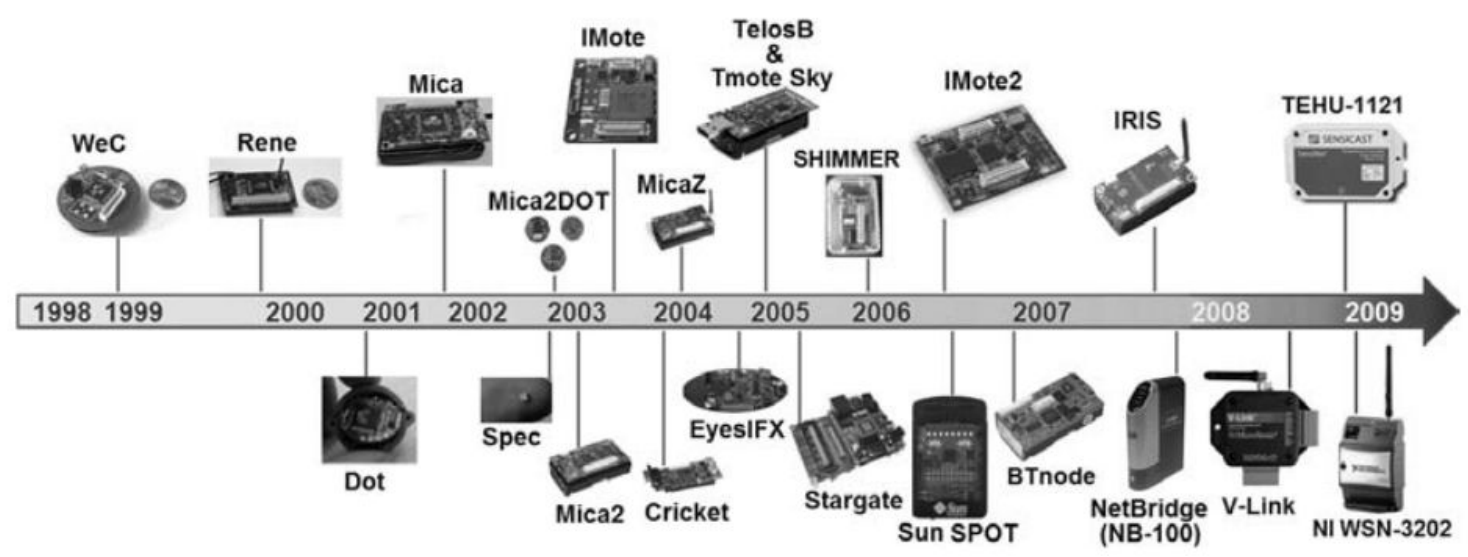

Figura 2.8: Linha do tempo no desenvolvimento de plataformas de Sensores (Akyildiz e Vuran, 2010).

al., 2013). A Seção 2.3.1 discute os conceitos fundamentais das arquiteturas orientadas a serviço, assim como sua utilização no contexto das redes de sensores.

\subsubsection{Orientação a Serviço}

SOA deve ser vista e entendida como um modelo arquitetural independente de qualquer plataforma tecnológica. Ela dá suporte à integração de negócios através de serviços e assegura que os sistemas computacionais possam se adaptar a novas regras de negócio (Papazoglou, 2003; Delen e Demirkan, 2013). Segundo (Gartner, 2013), SOA pode ser definida como um tipo arquitetural que promove agilidade organizacional e redução de custos no processo de implementação de aplicações comerciais. Arquiteturas orientadas a serviço têm sido instanciadas em ambientes corporativos através serviços Web que possuem um conjunto de interações e componentes apresentados na Figura 2.9. Os principais elementos de uma arquitetura orientada a serviço instanciada como serviço Web são o consumidor, o registro e o provedor do serviço. O provedor é responsável por fornecer a descrição do serviço no registro que, segundo os padrões dos serviços Web, é implementado pelo Universal Description, Discovery and Integration (UDDI). Essa descrição é feita por meio da Web Service Description Language (WSDL). A publicação das descrições dos serviços em documentos WSDL ficam disponíveis aos consumidores que podem acessá-las através de uma busca no registro. O documento WSDL define, dentre outras características, a localização e as operações disponibilizadas pelo serviço. Com essas informações, o consumidor é capaz de acessar o serviço. A Figura 2.9 também pode ser associada as Figuras 2.1 e 2.7. O provedor de serviços da Figura 2.9 é aplicado no âmbito do Gerenciador de Dados da Figura 2.1 e na Abstração de Infraestrutura da Figura 2.7.

Adicionalmente, os protocolos e mecanismos de descrição e descoberta de serviços utilizados para instanciar uma arquitetura orientada a serviço através de serviços Web utilizam as seguintes linguagens básicas: 


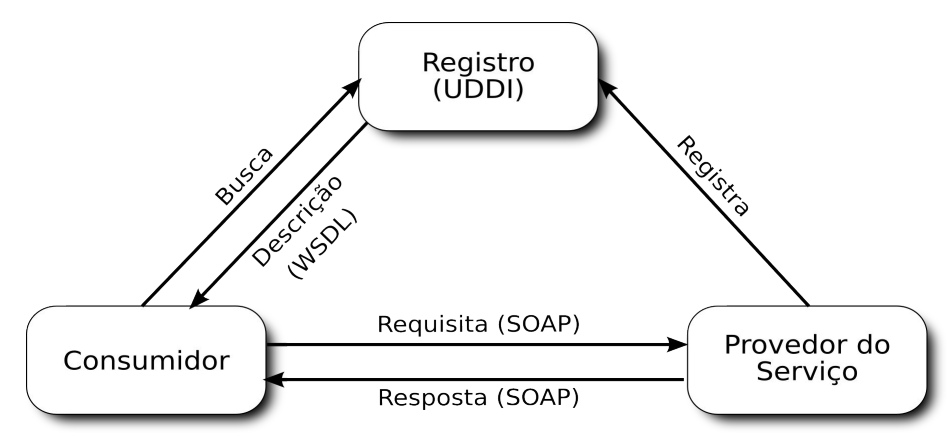

Figura 2.9: Interações entre componentes dos serviços Web - Adaptado de (Duggan, 2012).

- eXtensible Markup Language: desenvolvida pelo XML Working Group (originalmente conhecido como SGML Editorial Review Board) e formada sob a supervisão do W3C em 1996. O XML é uma tecnologia chave utilizada em muitos contextos. Ela oferece um formato de dados estruturado, extensível, flexível e padronizado. O XML é utilizado como linguagem base no núcleo das tecnologias utilizadas na pilha da arquitetura dos serviços Web;

- Document Type Definition: define a construção legal dos blocos de um documento XML. Define quais elementos e atributos um documento XML deve possuir e como eles estarão dispostos no documento;

- XML Schema: baseada em XML, é comumente referenciado como XML Schema Definition (XSD). Na prática, o XSD possui a mesma função que o DTD. No entanto, o XSD é mais poderoso que o DTD devido ao suporte a tipos de dados, a utilização da sintaxe da linguagem XML e ao fato de ser extensível.

Os serviços Web podem ser vistos como componentes de software onde os detalhes da implementação são escondidos por uma interface. Ferramentas como java2WSDL e Apache Axis fornecem formas de se obter essas interfaces a partir de sistemas orientados a objetos já existentes (Yu et al., 2007). A interface de um serviço Web possui um conjunto de operações que pode ser utilizado por consumidores na Web. Os serviços Web são compostos por um conjunto de camadas que tratam de aspectos como segurança, confiabilidade, controle transacional e protocolos de transporte. Dentre essas camadas, destacam-se:

- Camada de Descrição: contém a semântica formal para representar as mensagens que os serviços Web podem entender, descrevendo as restrições de dados dentro das mensagens. Além disso, essa camada tem como responsabilidade definir a maneira como os serviços Web são acessados. O WSDL é a linguagem padrão utilizada para descrever serviços Web;

- Camada de Descoberta: oferece processos e mecanismos pelos quais os serviços Web podem ser encontrados. O UDDI é o padrão associado com essa camada; 
- Camada de Mensagem: responsável por oferecer mecanismos de transmissão de dados pela rede. O principal protocolo utilizado, dentro do mundo dos serviços Web, é o Simple Object Access Protocol (SOAP) (W3C, 2007);

- Camada de Confiabilidade: responsável por garantir que um processo de negócio seja completamente executado pelos seus participantes. Para cumprir essa tarefa é necessário um mecanismo que possibilite uma entrega confiável das mensagens trocadas entre clientes e provedores de serviço. A principal tecnologia envolvida nessa camada é o WSReliableMessaging;

- Camada de Transações: transações são um conceito fundamental na construção de aplicações distribuídas confiáveis. Os serviços Web requerem um comportamento coordenado fornecido através de um mecanismo tradicional no controle das operações, e consequentemente, da aplicação. O WS-Coordination em conjunto com suas extensões compõem a principal tecnologia dessa camada;

- Camada de Segurança: define as especificações necessárias para oferecer mecanismos de comunicação confiáveis. Tais especificações são apresentadas dentro dos padrões do Web Service Security (WSS) (OASIS, 2004);

- Camada de Processo de Negócio: especifica uma ordem de execução de um conjunto de serviços Web. Os serviços Web podem ser ordenados de diferentes formas para cumprir diferentes regras de negócio. Adicionalmente, essa camada é responsável por definir os dados compartilhados entre os serviços, os parceiros que estão envolvidos no processo e as relações existentes entre eles. Uma linguagem chamada de Business Process Execution Language (BPEL) é utilizada na especificação desses processos de negócio e as suas relações com os serviços Web;

- Camada de Gerenciamento: responsável por gerenciar os recursos e as configurações dos serviços Web. Ela gerencia o desempenho, a taxa de utilização, a disponibilidade e as configurações dos serviços dentro da arquitetura dos serviços Web. O WS-Management é responsável por oferecer os mecanismos de gerenciamento especificados nessa camada;

- Camada de transporte: especifica os protocolos de comunicação utilizados na troca de mensagens entre clientes e provedores de serviço. Dentre os principais protocolos destacamse o HTTP, SMTP e FTP.

As arquiteturas orientadas a serviço foram propostas inicialmente para atender demandas impostas pelo mundo corporativo (Erl, 2005; Duggan, 2012). No entanto, em (Kyusakov et al., 2013; Delicato et al., 2014b) são apresentadas propostas de aplicação das linguagens e protocolos básicos de serviços Web para a exposição dos dados gerados por redes de sensores. Segundo os dois 
trabalhos, aplicar orientação a serviço no contexto das redes de sensores tem o objetivo de preencher uma lacuna existente entre infraestruturas de tecnologia da informação e redes de sensores. Os autores ainda afirmam que é crescente o interesse do mundo corporativo em aplicações de monitoramento, controle e rastreamento que utilizam redes de sensores. Basicamente, as soluções apresentadas descrevem a rede de sensores através de documentos WSDL. A exposição dos dados observados por uma rede de sensores é realizada através de serviços Web que utilizam mensagens SOAP como base na atividade de comunicação. De maneira contrária, muitas abordagens que utilizam a orientação a serviço para abstrair as complexidades das redes de sensores não utilizam os padrões tradicionais dos serviços Web. Em geral, a maioria dessas abordagens propõe novos mecanismos de descrição, de descoberta e de acesso as redes de sensores utilizando como base a linguagem XML. Esses novos mecanismos se diferenciam de linguagens como o WSDL e ferramentas de registro como o UDDI, mas mantêm o conceito da orientação a serviço. Diversas dessas abordagens são discutidas na Seção 2.3.3. Contudo, uma descrição dos requisitos necessários nas implementações de abstrações de infraestruturas é apresentada na Seção 2.3.2.

\subsubsection{Requisitos de Abstrações de Infraestrutura}

O paradigma básico das abstrações de infraestrutura é separar as complexidades das tecnologias de sensoriamento das aplicações desenvolvidas pelos consumidores finais. Essas tecnologias podem ser modificadas sem a necessidade de submeter alterações às aplicações dos consumidores finais. No entanto, a provisão desse tipo de abstração deve ser implementada seguindo um conjunto de requisitos que são necessários para atender às necessidades das aplicações e que são discutidos a seguir (Laukkarinen et al., 2012).

\section{Interoperabilidade de Tecnologias}

Tecnologias de redes de sensores distintas devem ser homogeneizadas para as aplicações dos consumidores finais. Esse é um dos principais desafios de uma implementação de abstração de infraestrutura. Interoperabilidade de tecnologia é composta por três requisitos: acesso uniforme aos dados, ontologia e homogeneização de características tecnológicas. O acesso uniforme aos dados exige métodos de acesso aos dados das tecnologias abstraídas. Diversos modelos de entrega de dados de redes de sensores são apresentados em (Chen e Varshney, 2004). Segundo os autores, as redes de sensores oferecem três tipos de modelos de entrega de dados: dirigido a consulta, dirigido a eventos e contínuo. Da mesma forma, em (Laukkarinen et al., 2012) é definido que o acesso aos dados nas implementações de abstrações de infraestrutura também ocorrem através desses modelos de entrega. No modelo dirigido a consulta, as requisições das aplicações devem definir uma janela de tempo na qual se tem interesse em receber observações. Por sua vez, o modelo dirigido a evento, também conhecido com publish/subscribe, define condições de disparo de notificações ou alertas. Ou seja, o consumidor ou aplicação final assina o serviço de alerta e 
recebe notificações quando elas estiverem disponíveis. E por último, o modelo contínuo transmite dados de observação a aplicação final continuamente.

A homogeneização do formato dos dados é obtida através de ontologias. A principal tarefa de uma ontologia é remover a heterogeneidade da definição de dados entre diferentes tecnologias. Uma ontologia descreve formatos, unidades e faixa de valores possíveis para um determinado tipo de dado. Isso simplifica o desenvolvimento de aplicações. Uma determinada aplicação pode exigir que os valores de observações de temperatura estejam sempre no mesmo formato e na mesma unidade como, por exemplo, graus Celsius. Caso contrário, aplicações que utilizam diferentes fontes de dados, sem o emprego de ontologias, devem processar e formatar separadamente os dados de cada uma das tecnologias. Utilizando uma ontologia comum, as aplicações finais tornamse tecnologicamente independentes.

Redes de sensores possuem uma série de características que podem ser homogeneizadas. A lista dessas características pode até se tornar exaustiva, e em alguns casos, transparência é uma necessidade. Configurações, conceito de tempo e mecanismos de entrega de dados para as tecnologias abstraídas são características tipicamente necessárias ao processo de homogeneização dos mecanismos de abstração de infraestrutura. Redes de sensores são limitadas em relação a poder computacional e raramente oferecem relógios clocks em tempo real, sendo os pacotes de dados limitados em tamanho e incapazes de fornecer, com precisão, o horário em que uma determinada observação foi efetuada. No entanto, homogeneização do formato de tempo também pode ser cumprida através da definição de uma ontologia. Em muitos casos, as redes de sensores não funcionam apenas como provedores, mas também como consumidores de dados. Nesses casos, devem-se fornecer métodos de entrega de dados às tecnologias que estão sendo abstraídas pelas abstrações de infraestrutura. Por exemplo, uma rede de sensores entrega dados de medições que podem ser utilizados para controlar atuadores como condicionadores de ar.

\section{Descoberta de serviços}

Os serviços oferecidos por uma rede de sensores não estão continuamente acessíveis. Isso ocorre devido a problemas de comunicação, falhas de hardware ou falta de energia. Por exemplo, interfaces de descoberta são disponíveis no conjunto de serviços do SWE que permitem os consumidores realizarem buscas por meio da definição de critérios tais como nome dos fenômenos observados, tipos de sensores e serviços e intervalos de tempo de aferição. Os mecanismos de abstração de infraestrutura devem considerar três questões principais nos serviços de descoberta. Primeiro, as redes devem oferecer seus próprios métodos de descoberta que devem ser homogeneizados para facilitar o desenvolvimento das aplicações finais. Segundo, a descoberta do serviço deve ser suficientemente genérica de forma a possibilitar a expansão do serviço para aquelas tecnologias que não seguem os paradigmas das redes de sensores ou que são completamente diferentes dos serviços de sensoriamento tradicionais (Laukkarinen et al., 2012). O terceiro ponto diz respeito a escalabilidade e transparência. A maioria das aplicações não está interessada nos sensores 
propriamente ditos, mas nas medições executadas por eles. Entretanto, a precisão das aferições realizadas pelos sensores pode ser importante. Além disso, não é raro que algumas aplicações possam necessitar de informações sobre o nome do fabricante do sensor. Dessa forma, é importante que os serviços de descoberta forneçam informações em vários níveis de detalhamento e transparência para atender esse tipo de demanda.

\section{Metadados}

Os dados de observações obtidos pelas redes de sensores não são suficientes para as aplicações finais. A maioria das aplicações necessita de vários tipos de metadados tais como descrição de localização, tipo de hardware, precisão das medições e propósito das medições. A descrição da localização pode ser utilizada, por exemplo, para determinar a posição de um paciente monitorado por sensores em um hospital. A quantidade de metadados a ser disponibilizada aos consumidores finais deve ser a mais completa possível. Mecanismos de abstração de infraestrutura devem suportar, no mínimo, os metadados tipicamente fornecidos pelas tecnologias que estão abstraindo. As abstrações de infraestrutura devem permitir a adição do mesmo tipo de metadado para diferentes tipos de tecnologias, caso haja uma heterogeneidade de metadados entre eles. Por exemplo, abstrações de infraestrutura devem exigir das tecnologias abstraídas adaptadores que completam o conjunto de metadados exigidos para as observações. Adicionalmente, metadados também podem ser fornecidos por serviços específicos. Um repositório de mapas pode, por exemplo, ser provido pelas abstrações de sensores.

\section{Processamento}

Um dos principais serviços de processamento oferecidos por uma abstração de infraestrutura é a agregação de dados. Agregação de dados é um paradigma utilizado em redes de sensores que permite a combinação de dados oriundos de várias fontes ou rotas. Esse tipo de processamento visa eliminar redundância nos dados, minimizar o número de transmissões e economizar energia (Krishnamachari et al., 2002). Em geral, mecanismos de agregação seguem algoritmos definidos pelos administradores da rede. Por exemplo, um determinado mecanismo de agregação pode definir que dados de temperatura obtidos por diferentes fontes de sensoriamento devem ser sumarizados ou agregados através de uma média aritmética simples, ou ainda, por uma equação mais complexa. Métodos de definição de serviços de processamento, onde podem ser descritos algoritmos de agregação e fusão de dados, fornecem aos menos dois benefícios as abstrações de infraestruturas:

1. Dados agregados podem ser reutilizados entre diferentes aplicações finais. Essa agregação permite promover uma redução na quantidade de dados requisitados à rede, além de reduzir o tráfego. Adicionalmente, é possível simplificar o desenvolvimento das aplicações quando estas necessitam de serviços de agregação; 
2. A abstração de infraestrutura possui mais recursos computacionais que as redes de sensores. Dessa forma, é possível executar agregações de dados mais complexas em processamento no nível da infraestrutura. As abstrações de infraestrutura podem fornecer serviços mais adequados aos consumidores finais. Por exemplo, processamentos no nível de infraestrutura podem detectar informações importantes nos dados observados e criar eventos ou novas medições que podem ser enviados aos consumidores finais.

As abstrações de infraestrutura devem permitir a criação de novos serviços de processamento. Adicionalmente, tais serviços devem oferecer interfaces para a descrição ou criação de novas tarefas de processamento.

\subsubsection{Propostas de Abstração de Infraestrutura}

Algumas propostas de abstração de infraestrutura podem ser encontradas na literatura, como a Global Sensor Network (GSN) (Aberer et al., 2007). A GSN é uma abordagem para abstrair redes de sensores através da definição de sensores virtuais pelos quais se oferece uma estrutura homogeneizada. A linguagem XML é utilizada para definir um sensor virtual. Cada um dos sensores virtuais possui uma ou múltiplas entradas que podem ser diferentes tipos de sensores reais ou sensores virtuais. Uma linguagem do tipo SQL é utilizada para receber e processar dados obtidos através dos sensores virtuais. Além disso, a GSN ainda fornece um conjunto de metadados que podem ser utilizados para a descoberta e identificação dos sensores.

Os conjuntos de ferramentas chamados de SenseWeb e SensorMap também são propostas de abstrações de infraestrutura que utilizam serviços Web (Grosky et al., 2007). O SensorWeb é utilizado para manipular sensores, sejam eles cabeados, sem fio ou móveis por meio de uma API. Um componente coordenador é responsável por encaminhar requisições de dados de aplicações, homogeneizar os formatos de dados, armazenar observações e fornecer um serviço de descoberta de recursos. Sensores são conectados através de gateways adaptados que uniformizam o acesso. Um gateway, denominado DataHub, é fornecido como referência para aqueles que não desejam implementá-lo. Um proxy móvel é utilizado para conectar sensores móveis ao SenseWeb e entregar observações de acordo com a localização dos mesmos quando disponíveis. Transformadores de dados são utilizados para processar dados. O componente coordenador executa uma indexação desses transformadores de maneira a fornecer um serviço de descoberta aos usuários do serviço. Por sua vez, o SensorMap é definido como uma aplicação que está disposta no topo do SenseWeb. Ele fornece um conjunto de ferramentas que é empregado para apresentar os sensores registrados no SenseWeb sobre um mapa. SenseWeb e o SensorMap juntos fornecem uma maneira completa de agregação de dados que podem ser publicados na Web.

Outra proposta de abstração de infraestrutura pode ser encontrada em (Jeong et al., 2010). O trabalho mostra um middleware, denominado Lamses, para redes de sensores através de uma arquitetura que concentra a criação de aplicações cientes de contexto (context-aware) através dos 
dados observados pela rede. O middleware é composto por um motor de processamento de contexto, um gerenciador de metainformações, um gerenciador de redes de sensores e um controlador e gerenciador de consultas. O motor ciente de contexto processa os dados e eventos mensurados criando eventos cientes de contexto. Os dados são manipulados e armazenados como pacotes XML. Posteriormente, esses pacotes podem ser acessados por aplicações através de consultas.

Por sua vez, o SeNsIM propõe uma arquitetura e um modelo de dados que permite uma interoperabilidade entre diferentes tecnologias de sensoriamento (Casola et al., 2009). O objetivo dessa proposta é adaptar tecnologias existentes através de interfaces que oferecem serviços de exposição dos dados de redes de sensores. O SeNsIM possui dois componentes principais chamados de wrappers e mediator. Os wrappers conectam-se a um mediador que utiliza uma interface de consulta XML para expor dados aos consumidores finais. Ou seja, os dados obtidos pela rede são unificados através de um formato XML.

Por fim, o Smart-M3 também pode ser considerado como uma plataforma de interoperabilidade para redes de sensores (Korzun et al., 2011). Ele permite que dispositivos de sensoriamento sejam compartilhados através de informações semânticas através de uma API de ontologia. Nessa abordagem, cada dispositivo possui um Knowledge Processor (KP) que pode armazenar e receber informações de um componente chamado de Semantic Information Broker (SIB). Por exemplo, um telefone celular pode ser utilizado para controlar sensores, atuadores e aparelhos domésticos através do Smart-M3. KPs podem se comunicar através de um SIB inserindo, consultando ou publicando dados em sua base de armazenamento. O Smart-M3 é considerado mais um protocolo de comunicação que uma infraestrutura de abstração. No entanto, ele exige que se defina uma ontologia comum para o armazenamento da informação que pode se diferenciar dependendo do tipo da aplicação. Ou seja, aplicações domésticas podem ter uma ontologia diferente de uma aplicação comercial. O Smart-M3 é a única proposta, comparada com as discutidas anteriormente, que interage diretamente com os dispositivos de sensoriamento. Nessa abordagem não há a necessidade de uma aplicação consumidora final. Os dispositivos de sensoriamento podem, por exemplo, controlar a condição da qualidade do ar em um determinado ambiente através das definições ontológicas determinadas a ele.

Um dos mais completos mecanismos de abstração de infraestrutura é apresentado pelo OGC em (OGC, 2014c). O OGC vem desenvolvendo e propondo um conjunto de especificações e interfaces, baseados em XML, para a abstração de redes de sensores. Essas especificações e interfaces compõem um framework, denominado SWE, que fornece um mecanismo completo para acesso, gerenciamento e controle de redes de sensores. O SWE possui três especificações principais, denominadas SWE Common, Sensor Model Language (SensorML) e Observation and Measurement (O\&M) que são utilizadas para homogenização de tipos de dados, descrição de sensores e descrição de observações, respectivamente. Além disso, quatro interfaces de acesso aos dados das redes abstraídas pelo framework são fornecidas: Sensor Observation Service (SOS), Sensor Event Service (SES), Sensor Planing Service (SPS), e Sensor Instance Registry (SIR). Todas essas especificações e interfaces são discutidas detalhadamente no Capítulo 3. 


\subsection{Abstrações de Infraestrutura X Completude de Re- quisitos}

O principal objetivo deste trabalho é estudar a influência da utilização de uma arquitetura orientada a serviço no contexto das redes de sensores, considerando a hipótese de que a utilização desse modelo arquitetural não inviabiliza o acesso às redes de sensores. Diferentes opções de arquiteturas orientadas a serviço podem ser utilizadas para abstrair infraestruturas de redes de sensores vem sendo apresentadas na literatura como pôde ser observado na Seção 2.3.3. A Tabela 2.1 sumariza algumas dessas opções de acordo com os requisitos que devem ser implementados por elas para atender as demandas dos consumidores finais. Todas as abordagens discutidas apresentam deficiências no atendimento de algum ou alguns dos requisitos expostos na Seção 2.3.2, exceto o framework SWE.

A GSN embora seja considerada uma solução completa, possui uma lacuna na definição de ontologias. Nesse caso, o formato de dados é descrito como parte de um sensor virtual. Essa solução pode ser versátil, porém, os consumidores finais ou até outros sensores virtuais devem entender todas as possibilidades de estruturas na formatação dos dados. A implementação de aplicações pode se tornar confusa e mais complexa caso essas estruturas não sejam fornecidas de uma maneira formal. Por exemplo, um sensor pode utilizar um valor inteiro (integer) na aferição de uma temperatura enquanto outro pode definir a mesma medição como um tipo real (float). Além disso, a GSN não apresenta uma indicação de como os sensores virtuais utilizam os serviços de processamento. Por sua vez, o SenseWeb e SensorMap não podem ser definidos como uma solução genérica para a abstração de infraestruturas. As duas soluções apenas coletam os dados de sensores publicados em uma interface Web, não possibilitando o controle de redes que utilizam atuadores. Outro ponto negativo é com relação à falta de definição de ontologias formais para uniformização dos dados.

A solução provida pelo Lamses suporta apenas o processamento ciente de contexto. Ela possui um gerenciador de consultas que pode entregar dados ou controlar comandos para um sensor abstraído, mas esse processo não está bem definido. Os metadados, por sua vez, descrevem apenas um conjunto limitado de atributos dos dispositivos de sensoriamento, focando principalmente em descrições de hardware e identificadores do dispositivo. Tais informações não suprem completamente as necessidades das aplicações que utilizam dados de redes de sensores. Já o SeNsIM não fornece metadados ou suporte ao processamento, embora apresente um mecanismo de uniformização de dados através de XML. Em relação ao Smart-M3, pode-se destacar a falta de suporte a definição de metadados e processamento, além de não especificar uma ontologia própria para a descrição dos formatos de dados. 


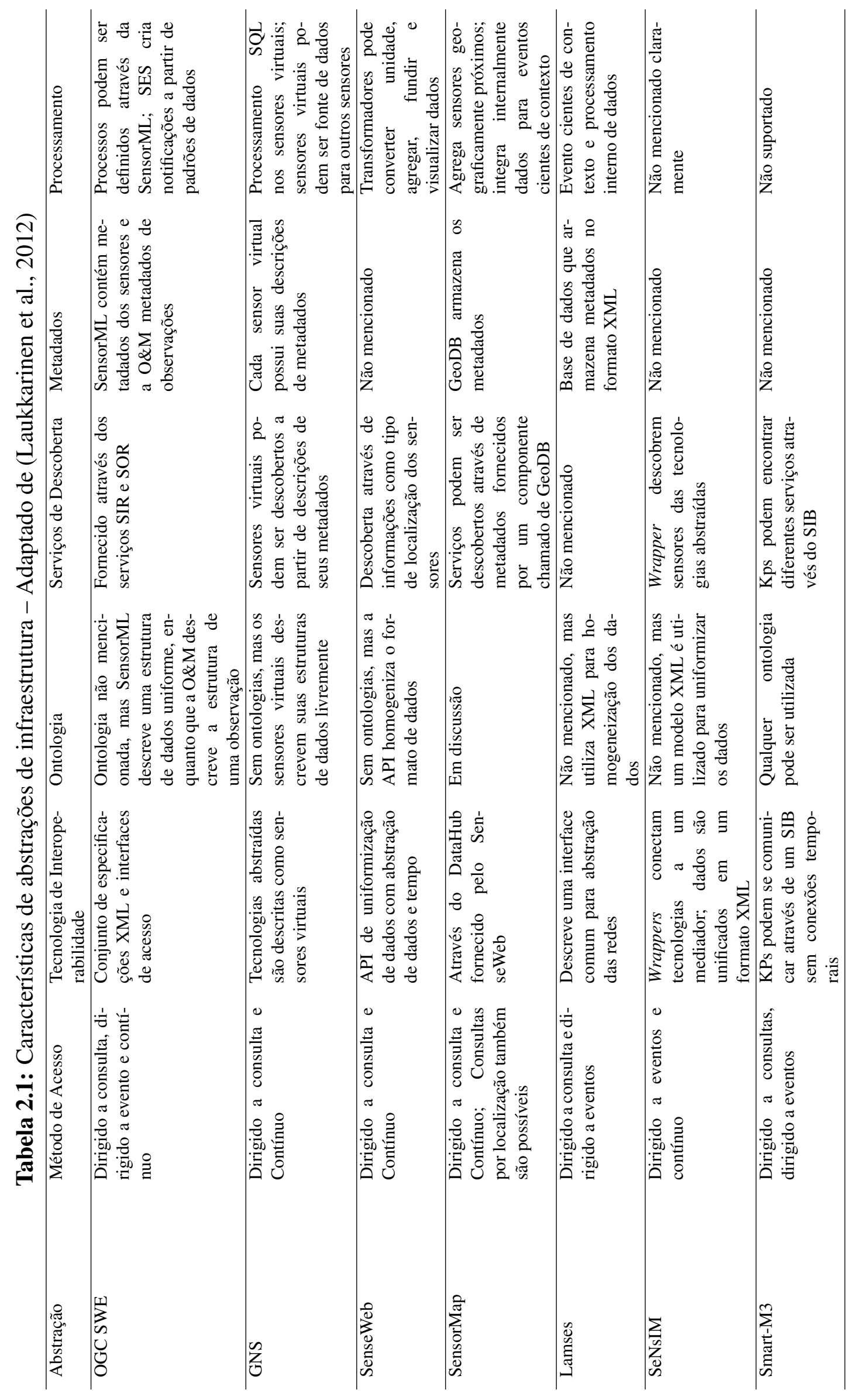


Diferentemente das outras abordagens discutidas nesta seção, os padrões e a especificação do SWE cumprem completamente os requisitos definidos para as implementações de abstração de infraestrutura. A utilização desse framework no desenvolvimento desta tese é justificada, uma vez que ele cumpre com os critérios destacados no passo 2 da metodologia proposta na Seção 1.4. Ou seja, o SWE cumpre com os critérios que podem ser estabelecidos da seguinte forma:

- Conformidade com os requisitos exigidos nas implementações de abstrações de infraestruturas, destacados na Tabela 2.1;

- Adesão de 473 empresas e instituições acadêmicas de diversas partes do mundo, inclusive do Brasil (representado pela Fundação CpqD) (OGC, 2014b);

- Oferecimento de ferramentas e APIs por empresas como a $52^{\circ}$ North, que proveem suporte ao desenvolvimento e manutenção de sistemas de abstração de infraestrutura, seguindo o modelo SWE (52North, 2014a);

- Extensa e atual atividade de pesquisa na definição e utilização dos padrões SWE (Jiang et al., 2013; Schade et al., 2013; Görgü et al., 2013; Hu et al., 2014; Giménez et al., 2014; Culibrk et al., 2014).

\subsection{Considerações Finais}

Arquiteturas orientadas a serviço utilizadas para abstrair as complexidades inerentes as redes de sensores podem ser consideradas, como discutido nesta seção, uma realidade. Dentre as propostas discutidas, o framework SWE se apresentou como o mecanismo de abstração mais adequado para a condução do estudo da viabilidade de se utilizar SOA no contexto das redes de sensores. Embora os mecanismos de abstração de infraestrutura baseados em orientação a serviço venham sendo utilizados, questões de desempenho podem dificultar a empregabilidade desse tipo arquitetural dependendo dos perfis das aplicações. Tipos de sensores, taxas de amostragem e tamanho de pacotes de dados são aspectos que influenciam o delineamento de aplicações reais em redes de sensores, como pôde ser verificado na Seção 2.1.3. Assim, o Capítulo 3 visa apresentar, em detalhes, as especificações e padrões do framework SWE. O delineamento do framework SWE é determinante para a compreensão das avaliações de desempenho e de uma arquitetura de provisão de qualidade de serviço mostradas nos Capítulos 4 e 5, respectivamente. 



\section{Sensor Web Enablement}

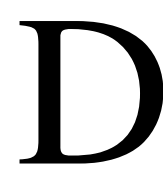

esde 2003, um grupo de trabalho da OGC tem discutido um conjunto de padrões que formam o SWE. Como já comentado no Capítulo 2, os padrões definidos pelo SWE representam uma proposta de abstração de infraestrutura onde as complexidades dos protocolos de comunicação, da arquitetura de hardware e das linguagens de programação utilizadas nas plataformas de sensoriamento são escondidas através de interfaces comuns. A transparência ou abstração oferecida por esses padrões facilitam o desenvolvimento de aplicações, permitindo ao desenvolvedor concentrar-se especificamente na lógica da sua aplicação e não nos detalhes dos protocolos de comunicação e modelos de programação. Este capítulo tem o objetivo de apresentar os conceitos e padrões fundamentais do SWE, uma vez que o entendimento dos demais capítulos desta tese dependem das informações aqui discutidas.

\subsection{Conceitos Iniciais}

O trabalho realizado em (Bröring et al., 2011) apresenta um estudo sobre o framework de especificações do SWE. Esse trabalho discute os recentes desenvolvimentos e aponta as principais mudanças dos padrões definidos no SWE 1.0 para o que os autores chamam de SWE 2.0. Adicionalmente, são apresentados novos conceitos e boas práticas que ainda não se tornaram padrões dentro do framework, mas que têm sido discutidos no âmbito dos grupos de trabalho responsáveis pela definição dos padrões. Dentro do contexto do framework SWE 1.0, aprovado entre os anos de 2006 e 2007, foram definidas as seguintes funcionalidades:

- Descrição dos dados dos sensores para facilitar o processamento pelas aplicações; 
- Descrição de metadados dos sensores que incluem definição de suas propriedades e características. Além disso, foram definidos metadados que descrevem características de qualidade das medições como, por exemplo, a precisão das medições coletadas;

- Definição de interfaces que permitem o acesso às observações e metadados de sensores. Tais interfaces utilizam os padrões que uniformizam os formatos de dados, além de oferecer serviços de localização de observações através de mecanismos de consultas;

- Modificação (tasking) das propriedades dos sensores. Por exemplo, alteração do zoom de uma câmera de sensoriamento.

A nova geração do framework SWE adiciona outras funcionalidades, no entanto, algumas delas ainda não foram aprovadas como padrões. Dentre elas, destacam-se os avanços na funcionalidade de alerta da primeira geração, chamado mecanismos de eventos (eventing) e a definição de serviços de descoberta de sensores. As funcionalidades descritas nas especificações das duas gerações do SWE são dividas em dois subgrupos informais, o modelo de informação (information model) que inclui os modelos de dados e codificações e o modelo de interface (interface model) que compreende as diferentes especificações de interfaces de serviços Web. Os modelos de interfaces foram inicialmente chamados de modelos de serviço para evitar confusões de nomenclaturas com o padrão SWE Service Model (Bröring et al., 2011). OSWE Service Model é um padrão que define pacotes de tipos de dados para uso comum entre os serviços do SWE (OGC, 2006).

\subsection{Modelo de Informação}

O modelo de informação, apresentado na Figura 3.1, compreende um conjunto de padrões que define modelos de dados para a codificação das observações dos sensores, assim como para seus metadados. Com esse intuito, a primeira geração do SWE continha três especificações: Observation \& Measurements (O\&M), Sensor Model Language (SensorML) e o Transducer Marckup Language (TML). Em contrapartida, a nova geração do SWE define novas versões para as especificações O\&M e SensorML. Além disso, o modelo de informação ainda fornece uma especificação chamada de SWE Common. Essa especificação é utilizada para definir um modelo de dados de baixo nível para troca de dados relacionados a sensores. A SWE Common, estava inicialmente inserida na especificação do SensorML 1.0. No entanto, ela foi retirada e disponibilizada de forma isolada e nomeada como SWE Common 2.0. Essa mudança foi requerida devido à necessidade de outras especificações utilizarem a SWE Common para a definição de seus tipos de dados.

Por sua vez, o padrão TML, que pode ser definido como um protocolo das camadas de aplicação e apresentação para a troca de dados arquivados ou de tempo real, utilizado por qualquer tipo de sistema de nós, foi retirado do conjunto de especificações do SWE. A TML tem o objetivo de manipular qualquer sistema de sensores que o suporte, sem que um usuário desse sistema tenha algum conhecimento prévio sobre sua utilização. A TML suporta a codificação de dados de 


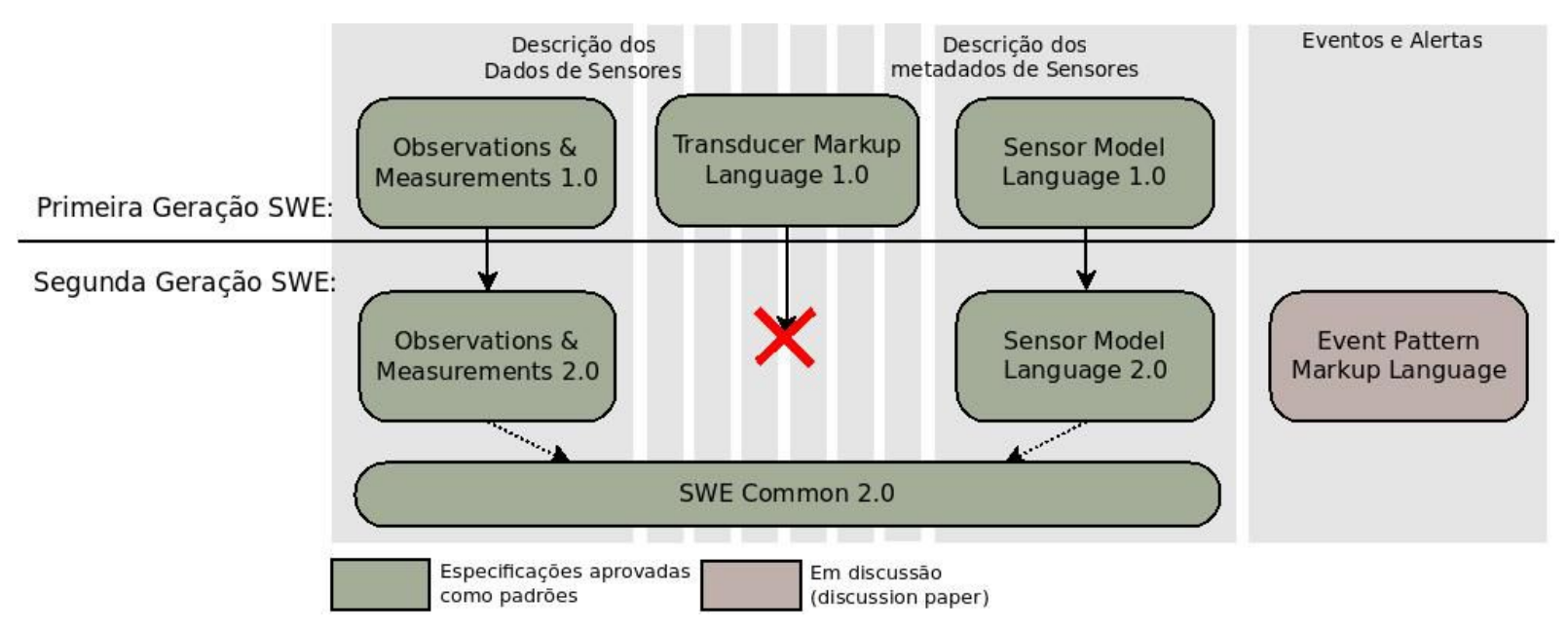

Figura 3.1: Nova geração do modelo de informação do SWE - Adaptado de (Bröring et al., 2011).

sensores assim como seus metadados, mas com um enfoque no fluxo de dados. O OGC entendeu que essa linguagem tem sido raramente utilizada na prática e removeu-a do conjunto de especificações na nova geração dos padrões SWE. Contudo, outras especificações foram criadas como a Event Pattern Markup Language (EML) que é utilizada para definir padrões de eventos como regras de processamento para a Complex Event Processing (CEP) e para a Event Stream Processing (ESP). Essas novas técnicas podem ser implementadas dentro de serviços do Sensor Alert Service ou do Sensor Event Service. Nas próximas seções são detalhadas as especificações do modelo de informação do SWE.

\subsubsection{SWE Common}

Atualmente, o SWE Common encontra-se na versão 2.0, podendo ser definido como um modelo de baixo nível para acesso e troca de dados de sensores abstraídos pelo framework SWE. Esse modelo permite que aplicações e/ou servidores estruturem, codifiquem e transmitam um conjunto de dados de sensores em uma maneira alto descritiva e habilitada semanticamente. Ou seja, o modelo de dados da SWE Common é utilizado para definir a representação, a natureza, a estrutura e a codificação dos dados relacionados a sensores. Assim, aplicações podem compreender semanticamente o valor dos dados bem como a forma em que esses dados foram codificados (OGC, 2008b). O modelo de dados da SWE Common foi proposto tanto para descrever dados estáticos (armazenados) quanto dados gerados dinamicamente (on the fly). Esse modelo de dados pode definir várias categorias de observações de sensores desde um simples valor de temperatura, até imagens obtidas por satélites a fluxos de vídeos em tempo real.

A linguagem SWE Common é uma implementação em XML desse modelo de dados e é utilizada por vários outros padrões do framework SWE tais como a SensorML e o serviço Sensor Observation Service (SOS). Esses dados não são, necessariamente, informações oriundas de observações, mas podem ser também dados auxiliares, como informações sobre o status de um de- 
terminado sensor. Um conjunto de dados (dataset) é composto por componentes que são valores necessários para o entendimento e interpretação dos mesmos por máquinas ou seres humanos. Assim, o SWE Common Data Model fornece várias informações que são necessárias para alcançar esse objetivo. Diversas características dos dados são tratadas pela SWE Common: representação, natureza e semântica, qualidade, estrutura e padrão de codificação.

\section{Representação de dados}

A representação de dados define como os valores são representados e armazenados digitalmente. Cada componente (ou campo) carrega um valor que representa o estado de uma propriedade. Essa representação varia dependendo da natureza do método utilizado para capturar e/ou utilizar um determinado tipo de dado. Por exemplo, a temperatura de um fluido pode ser representada como um número decimal, expressado em graus Celsius $\left(25,4^{\circ} \mathrm{C}\right)$ ou categoricamente como uma lista de possíveis valores (congelado, frio, normal, quente e muito quente). Os principais tipos de representações utilizados são: booleano, categórico, contínuo, numérico, discreto e Textual.

\section{Natureza dos dados}

A natureza dos dados pode ser definida como uma informação necessária para entender o que o valor de uma propriedade representa. Ela é conectada a uma semântica fornecida por fontes externas tais como dicionários, taxonomias ou ontologias. A natureza dos dados é independente do tipo de representação utilizada e não inclui informações sobre como os dados são medidos ou adquiridos. Dentro de natureza de dados, pode-se determinar as seguintes características:

- Informações legíveis para humanos: a descrição do componente de dados, que está presente em todos os tipos de dados definidos na SWE Common, pode conter qualquer tamanho de texto para este fim. O rótulo do componente é utilizado para definir pequenas informações que podem ser lidas por seres humanos (short name). Isso é útil para que os consumidores de dados identifiquem rapidamente a propriedade representada;

- Semântica robusta: cada tipo de dado na SWE Common permite uma associação com uma informação semântica externa que pode ser codificada em várias linguagens, como por exemplo a Web Ontology Language (OWL). A SWE Common pode ser utilizada em combinação com qualquer tecnologia de Web semântica. Assim, é possível conectar a descrição de um conjunto de dados do SWE a uma taxonomia fornecida em um registro externo.

\section{Qualidade do Dado}

Informações de qualidade podem ser essenciais para o consumidor dos dados. Desse modo, o SWE Common Data Model fornece uma forma simples e flexível para associar informações qualitativas com cada componente de um conjunto de dados, tais como: 
- Informação de qualidade simples: uma informação de qualidade simples pode ser associada com qualquer componente de dado escalar, na forma de um intervalo ou outro valor escalar. A qualidade da informação definida nesse caso aplica um valor de qualidade ao dado medido e pode ser representada por um valor numérico, categórico, textual ou por uma faixa de valores. Por exemplo, a qualidade de uma medida pode ser definida como "alta precisão" ou "baixa precisão". Essas informações podem alertar o consumidor das observações de possíveis imprecisões nos dados obtidos pelos sensores. A informação de qualidade pode ser estática, por exemplo, sobre todo um conjunto de dados ou dinâmica para cada observação mensurada;

- Valores NIL (null): o conceito de um valor NIL é utilizado para indicar que o valor atual da propriedade não pode ser aferido em um determinado fluxo de dado, e que nesse caso, um código especial deve ser utilizado. A razão pela qual o valor não é incluído é essencial para uma boa interpretação do problema que ocasionou a não leitura dos dados pelos sensores. Nesse caso, um valor NIL é determinado por um mapeamento entre códigos e suas definições das razões pelas quais os problemas ocorreram. Por exemplo, um sensor de temperatura deve definir um código para expressar que uma determinada temperatura não pode ser medida porque está abaixo ou acima da sua capacidade de leitura. Nesse caso, um código deve ser expressado para determinar incapacidade de leitura para valores de temperatura abaixo e outro código para valores acima da capacidade do sensor.

\section{Estrutura de Dados}

A estrutura de dados define como pedaços individuais de dados são agrupados, ordenados, repetidos e intercalados para formar um fluxo de dados completo. Os modelos da SWE Common são baseados em estruturas comumente utilizadas em ciência da computação e formalizada na especificação ISO 11404 (ISO, 2007). Tipos de dados agregados são definidos da seguinte forma:

- Record: composto por uma lista de campos, sendo que cada um deles possui uma chave que o identifica. Além disso, é possível associar ao tipo Record um tipo de dado específico que pode ser uma estrutura escalar ou agregada;

- Array: composto por vários elementos do mesmo tipo, usualmente indexado por um inteiro. O tipo de dados de cada elemento pode ser qualquer estrutura de dados;

- Choice: composto por uma lista de alternativas, sendo que cada item dessa lista é determinado por um rótulo (tag).

\section{Codificação de Dados}

O conceito chave do modelo de dados da SWE Common é a habilidade de separar seus próprios valores de dados de suas descrições da estrutura de dados, de sua semântica e de sua representação. 
Isso permite que metadados sejam utilizados de forma robusta para a definição do conteúdo e significado dos conjuntos de dados enquanto mantém sua capacidade de representar os valores de dados através de uma maneira eficiente. Métodos de codificação de dados definem como os dados são encapsulados em blocos que podem ser transferidos ou armazenados através de vários protocolos e formatos. Diferentes métodos permitem a codificação de dados através de XML, texto (CSV) ou binário. Tais dados podem ainda ser comprimidos e criptografados de uma maneira independente. Isso permite que qualquer método de codificação seja selecionado e utilizado, baseando-se em determinados requisitos, tais como desempenho, ferramentas de reuso e alinhamento com padrões já existentes.

\subsubsection{Sensor Model Language}

Redes de sensores são difíceis de serem descobertas e acessadas. Os dados gerados por elas são, na maioria das vezes, processados apenas dentro de sistemas específicos. Embora, seja possível alcançar certos níveis de interoperabilidade em determinados sistema de redes de sensores, o custo de desenvolvimento, extensão e manutenção desses sistemas são elevados. Isso se deve a falta de padrões que facilitem a construção desses sistemas e permitam que diferentes plataformas possam ser integradas sem que sejam demandados esforços demasiados. Nesse contexto, a Sensor Model Language fornece uma linguagem comum para descrição virtual de qualquer sistema de sensores, assim como a determinação de algoritmos que realizam pós-processamentos sobre os dados observados nesses sistemas (OGC, 2007b).

Como discutido anteriormente na Seção 2.1.2, as redes de sensores têm sido utilizadas em vários tipos de aplicações. Sensores são dispositivos que realizam medições de quantidades físicas. As medições de um sensor podem ser modeladas como um processo pelo qual um fenômeno é observado em algum momento no tempo. A SensorML provê um framework comum para descrição de qualquer processo ou cadeia de processo (process chain). O objetivo da SensorML é definir processos e componentes de processamento associados com as medições e transformações posteriormente realizadas sobre essas observações. Os valores dessas medições são dependentes de características específicas dos sensores como, por exemplo, o tipo de sensor utilizado nas aferições. Ou seja, os valores dependem das metodologias de detecção utilizadas pelas plataformas de sensoriamento (OGC, 2007b). A SensorML tem funções que podem ser destacadas da seguinte forma:

- Descrição de sensores e sistema de sensores;

- Fornecimento de informações para a descoberta de observações;

- Suporte ao processamento e análises das observações;

- Fornecimento de descrições sobre o processo pelo qual os dados foram obtidos; 
- Arquivamento das propriedades fundamentais dos sistemas de sensores.

Por sua vez, a definição de como é realizado o processamento dos dados aferidos pelas redes de sensores é uma tarefa importante dentro das propostas de abstração de infraestrutura. Através da SensorML, é possível o cumprimento desse requisito. O elemento principal da SensorML é determinado por um tipo de dado chamado AbstractedProcess. Todos os outros tipos de dados são derivados desse tipo de dado. Os tipos de processos derivados podem ser divididos em dois grupos: processos físicos (por exemplo, dispositivos de sensoriamento) e processos não físicos (por exemplo, etapas de processamento que devem ser executadas sobre os dados mensurados). $\mathrm{O}$ AbstractedProcess contém propriedades que são relevantes para todos os outros tipos de processos derivados. Essas propriedades podem ser definidas como: nome, descrição, valores de entrada e saída, parâmetros e metadados. No caso dos dispositivos de sensoriamento físicos, as entradas são os fenômenos observados. Contudo, em processos não físicos, entradas podem ser qualquer tipo de valor obtido através dos fenômenos observados ou um resultado de um outro processo não físico. Por outro lado, dados de saída são criados por qualquer um dos tipos de processos (valores observados ou resultados de um cálculo).

Em resumo, na SensorML, um sensor é definido como um processo capaz de observar um fenômeno e retornar um valor calculado dessa observação. Ou seja, é possível que o sistema de sensores realize algum cálculo sobre os dados observados antes de disponibilizá-los nas interfaces de acesso (pós-processamento). A SensorML permite uma descrição detalhada de um processo que inclui, principalmente, uma lista de entradas, saídas, parâmetros e métodos de processo. Adicionalmente, metadados de processo podem incluir sua identificação e classificação tanto quanto características como disponibilidade e descrição espacial (OGC, 2007b). Os metadados para um processo podem ser subdivididos em 5 subgrupos:

1. Informações gerais: identificadores de processos e uma lista de classificadores que facilitam a descoberta dos sensores (tipo de sensor e tipo de aplicação);

2. Restrições (constraints): informações sobre segurança e restrições legais. Nesse caso, podem ainda ser fornecidas informações sobre o período de tempo pelo qual a descrição do processo é valida;

3. Propriedades (properties): características ou capacidades de um determinado sensor que auxilia em sua descoberta. As propriedades incluem, por exemplo, propriedades como frequência e precisão das medições, além de características como dimensões dos sensores;

4. Referências (references): informações que permitem determinar como documentos adicionais sobre processos podem ser encontrados, bem como o contato dos responsáveis pelos dados (por exemplo, e-mail do administrador do sistema);

5. História (history): lista de eventos que descreve a história do sensor. Nessa lista, são encontradas informações como atividades de manutenção, mudanças de parâmetros e etc. 


\section{Tipos de Processos na SensorML}

Como comentado, a SensorML permite a descrição de dois tipos de processos que são denominados processos físicos e não físicos. A diferença básica entre eles é determinada pela relevância de se conhecer sua localização. O processo é dito não físico quando sua localização não é importante e físico quando esse tipo de informação é exigido (OGC, 2007b).

Processos não físicos podem ser compreendidos como operações matemáticas. O elemento básico de um processo não físico é chamado de ProcessModel. Esse elemento contém uma propriedade chamada de method. Essa propriedade descreve a operação matemática executada pelo processo. Processos mais complexos podem ser descritos através de um tipo chamado de ProcessChain. Esse tipo de dado permite a combinação de vários elementos ProcessModel. Os vários elementos ProcessModel são encapsulados em uma lista que compõe o ProcessChain. Nesse tipo de dado complexo, são descritos os vínculos entre as entradas e saídas dos elementos ProcessModel.

Por outro lado, os processos físicos são definidos no tempo e no espaço. Esse processo expressa um relacionamento temporal e espacial. Os processos físicos devem ser utilizados quando há a necessidade de se vincular a localização do processo com o tempo em que os dados foram obtidos através desse processo. O tipo de um processo físico é chamado de Component. Essa é a menor unidade de um processo físico. Ou seja, um elemento Component não pode ser subdividido. Processos físicos mais complexos podem ser descritos utilizando o tipo System que pode agregar tanto os componentes individuais quanto outros sistemas. Uma estação meteorológica pode ser utilizada pra exemplificar a definição de um processo físico. Nesse caso, vários componentes podem ser definidos tais como termômetros, pluviômetros e anemômetros. A definição de processos provida pela SensorML, é importante devido ao fato de que ela permite a descrição de algoritmos que são utilizados para agregação e sumarização de dados. Isso permite que aplicações ou consumidores finais saibam exatamente a forma como os dados obtidos por eles foram gerados. Um exemplo comentado de um documento SensorML pode ser encontrado no Apêndice A.

A linguagem SensorML vinha sendo discutida em (OGC, 2013d). No entanto, o OGC deu fim ao processo de discussão, através de uma publicação que confirma a definição da versão 2.0 da SensorML (OGC, 2013a). Resumidamente, pode-se dizer que a versão 1.0 foca principalmente nas seguintes funcionalidades (Bröring et al., 2011):

- Suporte a descoberta de sensores através de um mecanismo de codificação de metadados;

- Provisão de informações que podem ser utilizadas para entendimento e análise dos dados produzidos pelo sensor, por exemplo, parâmetros de calibração dos sensores;

- Suporte à descrição das fases do pós-processamento executados sobre os dados do sensor de maneira a permitir uma análise da forma como esses dados foram criados. 
A versão 2.0 da SensorML define algumas modificações em relação à versão 1.0. A principal modificação é a separação da SWE Common em padrões distintos. Atualmente, a SWE Common, anteriormente fornecida com a versão 1.0 da SensorML, é provida em um padrão exclusivo. Em relação às novas funcionalidades providas pela SensorML 2.0, pode-se destacar as seguintes adições (OGC, 2013a):

- Suporte à extensão de propriedades através de XML Schemas externos;

- Melhor suporte à definição de posicionamento e estados dinâmicos. Por exemplo, localização, orientação, velocidade e aceleração;

- Melhor suporte à herança que permite descrições mais compactas de dispositivos e processos;

- Acesso direto à valores em tempo real e fluxo de dados.

A Seção 3.2.3, discute a especificação Observation and Measurements (O\&M) que é utilizada para padronizar a representação e trocas de resultados de observações.

\subsubsection{Observation \& Measurement}

O padrão O\&M tem a função de modelar conceitualmente as relações entre diferentes aspectos do processo de captura dos dados. Ou seja, a especificação O\&M oferece uma forma de descrever a ação de observar e trocar informações de observações obtidas durante o processo de aquisição de dados de mensuração por redes de sensores. Uma observação pode ser definida como um evento que ocorre em um certo ponto do tempo quando é gerado um valor através da observação de um determinado fenômeno. Além do tempo e o valor da observação, o padrão O\&M ainda é capaz de descrever outras propriedades tais como o processo utilizado para gerar o valor da observação assim como sua localização e precisão. O padrão O\&M considera o valor de uma observação como uma aproximação de um atributo encontrado na característica que se tem interesse em observar. Adicionalmente, metadados são incluídos nas observações de maneira a permitir a análise e interpretação dos dados que foram observados (OGC, 2011a).

O conjunto de esquemas (documentos XML Schema) definidos na especificação O\&M não apenas permite a definição das observações, como também oferece mecanismos para a descrição dos fenômenos que são observados. Dessa forma, pode-se criar dicionários que podem ser utilizados para definir os fenômenos. Esses dicionários podem ser utilizados em diversos domínios de aplicação. Nesse contexto, um dicionário é definido como uma base que permite um entendimento geral dos dados obtidos pelos sensores. O modelo básico para a descrição de observações tem como base as propriedades, destacadas na Figura 3.2. Essas propriedades podem ser definidas da seguinte forma: 
- featureOfInterest: característica específica ao domínio da aplicação que diz respeito a uma representação do objetivo da observação. Representa o objeto do mundo real sobre o qual a observação é feita;

- ObservedProperty: descreve o fenômeno pelo qual o resultado da observação fornece uma estimativa do seu valor. Essa propriedade deve ser associada com o tipo de objeto definido pela propriedade featureOfInterest;

- Procedure: descreve o processo utilizado para gerar o resultado da observação;

- result: contém o valor da observação (Procedure). Em geral, esse valor é gerado por um sensor, mas um observador humano ou até mesmo um modelo de simulação pode ser utilizado para produzi-lo;

- samplingTime: descreve o tempo em que os dados das observações foram coletados para um determinado featureOfInterest;

- ResultTime: apresenta o tempo quando o processo (procedure) associado com a observação foi aplicado. O resultTime pode ser omitido, caso seja idêntico ao samplingTime;

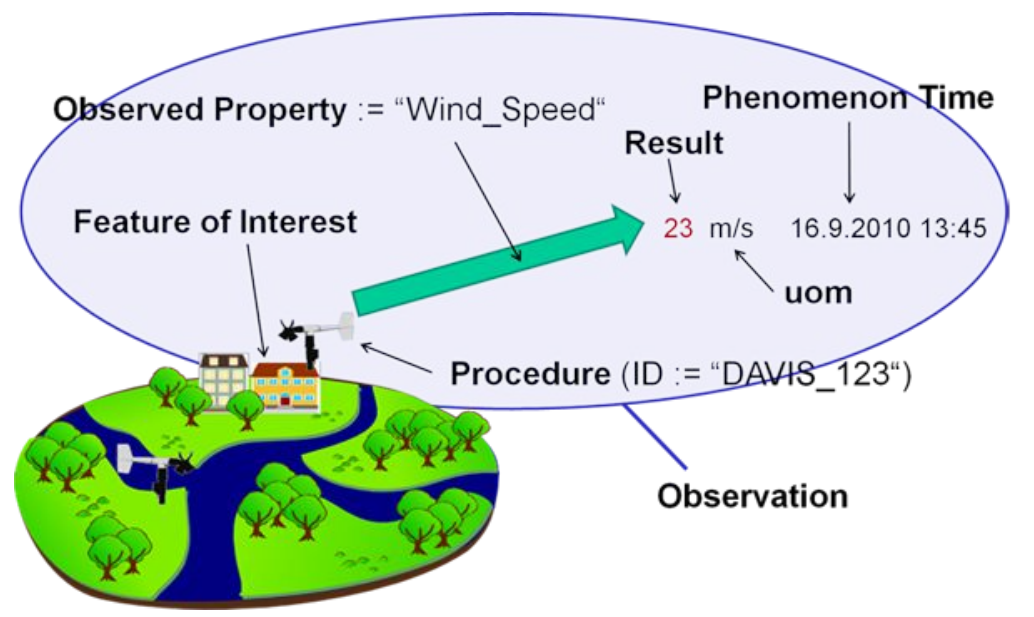

Figura 3.2: Elementos de um documento O\&M - (OGC, 2014a).

Os tipos de dados (resultados de observações) definidos através do modelo de observação são diversos. As observações podem ser especializadas de maneira a restringir o tipo de dado dos resultados obtidos nas observações. Os exemplos de documentos O\&M apresentados no Código 3.1, demonstram uma medição representada em valor numérico (porcentagem da umidade relativa do ar - linha 2) e uma categoria que define a condição do tempo (claro, nublado, chuvoso - linha 15). Um detalhe interessante do elemento result no documento O\&M é em relação ao atributo uom (unity of measurement - linha 12). Nesse elemento é possível determinar, para valores numéricos, a unidade utilizada para representar esses valores. Essa propriedade evita que ocorram confusões em relação à unidades de medidas que podem variar, por exemplo, de um país para o outro como, 
Código 3.1: Exemplos de Documentos O\&M

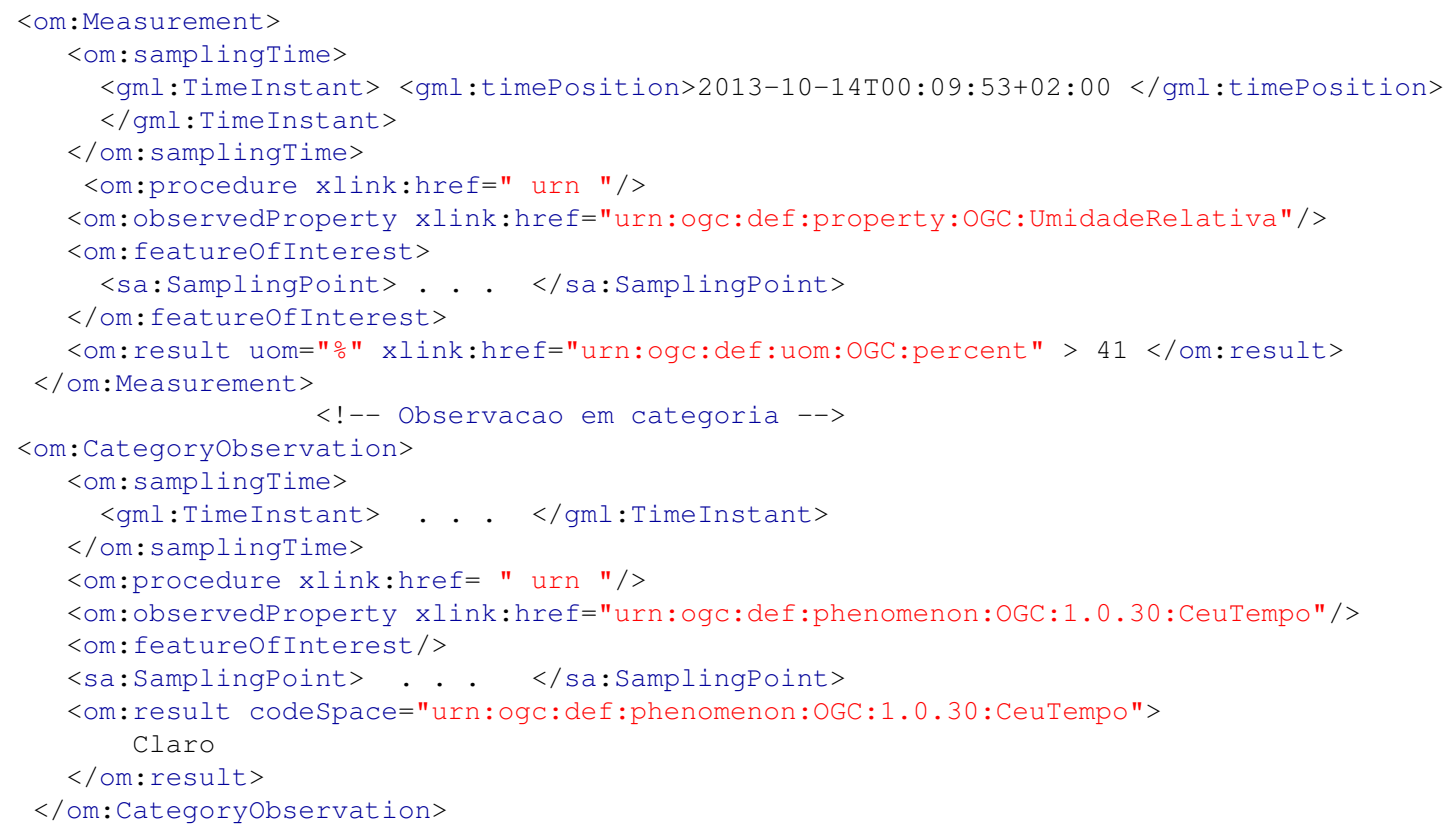

por exemplo, milhas e quilômetros. Além disso, o padrão O\&M ainda permite a utilização de estruturas de dados mais complexas tais como vetores (arrays). Nesse caso, é possível retornar informações de múltiplas observações em um único documento O\&M (OGC, 2011a).

\subsection{Modelo de Interfaces}

O modelo de interfaces do SWE compreende um conjunto de padrões que determina diferentes interfaces de acesso para rede de sensores por meio de serviços Web. A primeira geração do SWE, o chamado SWE 1.0, determinava quatro tipos de interfaces de serviços. O Sensor Observation Service (SOS) é um serviço, dirigido a consulta, que provê uma interface de acesso aos resultados de observações e metadados de sensores. O Sensor Alert Service (SAS) é um serviço, dirigido a eventos, que fornece uma interface onde se pode registrar e receber alertas das redes sensores quando essas redes identificarem que um determinado dado observado cumpre com os critérios estabelecidos pelo assinante do serviço. Por outro lado, o Sensor Planning Service (SPS) oferece uma interface que permite modificações de parâmetros dos sensores como, por exemplo, da frequência das medições. Por fim, o SWE estabeleceu o Web Notification Service que não está ligado diretamente a sensores, mas que oferece um mecanismo para se enviar notificações assíncronas (Bröring et al., 2011). É comum que o serviço SAS utilize os serviços do WSN para implementar o serviço de alerta.

A nova geração do SWE, como pode ser observado na Figura 3.3, é composta por versões mais recentes dos serviços SOS e SPS (versão 2.0) e uma modificação do serviço de alerta SAS para uma versão mais completa, denominada Sensor Event Service (SES). Essa modificação retirou 
a necessidade de utilização de outro serviço, no caso o serviço WNS, para a construção de um sistema de alerta. Além disso, foram incluídos serviços de descoberta que permitem o cadastro de sensores em uma base de armazenamento. Isso faz com que os sensores possam ser descobertos através de uma interface comum. Os serviços de descoberta criados, dentro do conjunto de padrões do SWE, são chamados de: Sensor Observable Registry (SOR) e Sensor Instance Registry (SIR). As Seções 3.3.1, 3.3.2, 3.3.3 e 3.3.4 apresentam, em maiores detalhes, os serviços SOS, SES, SPS e os serviços de descoberta, respectivamente.

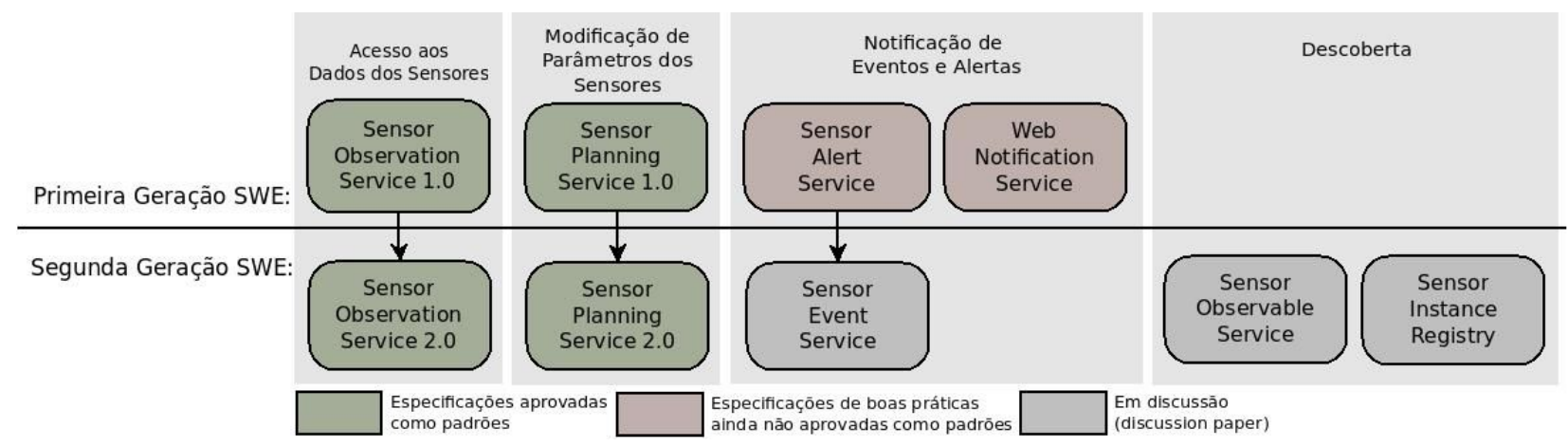

Figura 3.3: Nova geração do modelo de interfaces do SWE - Adaptado de (Bröring et al., 2011).

\subsubsection{Sensor Observation Service}

O objetivo principal do serviço SOS é fornecer um padrão de acesso às observações geradas por qualquer tipo de redes de sensores. O SOS utiliza o padrão O\&M para encapsular as observações, enquanto que a SensorML é utilizada para descrever os metadados dessas redes. Além disso, o SOS tem como função a organização e o armazenamento de sistemas de sensores através de métodos de inserção e remoção de documentos SensorML. O núcleo do serviço SOS define três operações principais (OGC, 2013c):

- GetCapabilities: provê acesso aos metadados e informações detalhadas sobre as operações disponibilizadas pelo servidor SOS;

- DescribeSensor: permite a consulta de metadados sobre os sensores disponibilizados pelo servidor SOS;

- GetObservation: fornece acesso às observações através de vários tipos de filtros tais como espacial, temporal e temático (seleção por determinados tipos de sensores). O Código 3.2 apresenta um exemplo de uma mensagem GetObservation onde está definido, na linha 8, um filtro espacial. Nesse filtro são descritas as coordenadas que definem a localização dos sensores seguindo um padrão chamado de EPSG 4326.

O serviço SOS define alguns documentos que são extensões do núcleo principal. Esses documentos são definidos da seguinte forma (OGC, 2013c): 
Código 3.2: SOS - Exemplo de uma Mensagem GetObservation

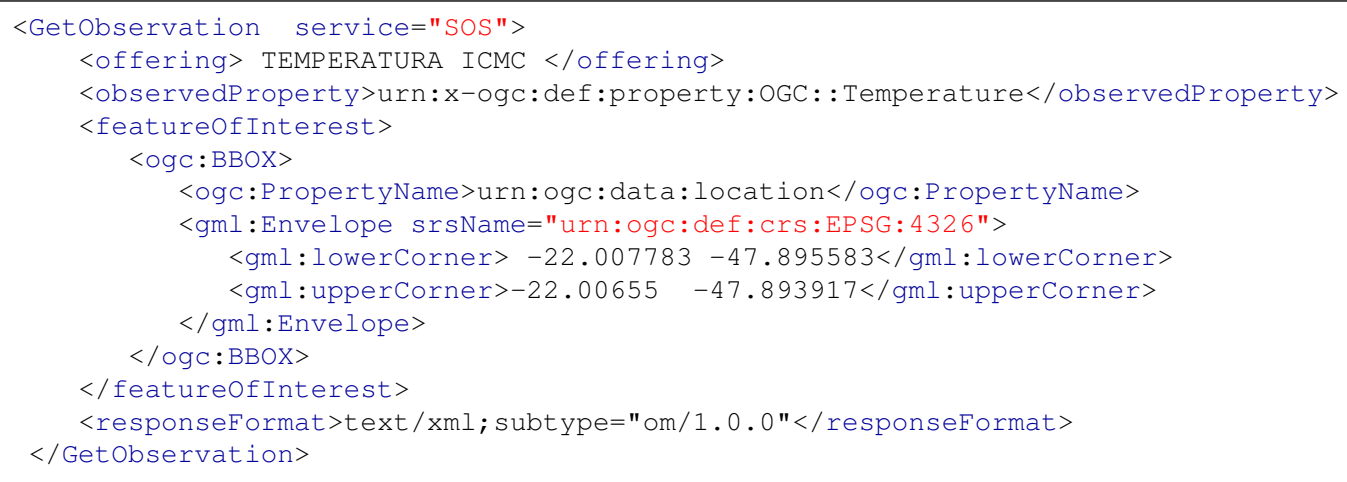

- GetObservationByID: permite o acesso às observações de um serviço SOS através de um identificador que especifica uma determinada observação;

- GetFeatureOfInterest: permite o acesso direto às observações das features of interest que estão disponibilizadas pelo Serviço SOS;

- GetFeatureOfInterestTime: provê informações sobre o período de tempo das observações disponíveis para um determinado FeatureOfInterest.

O serviço SOS ainda oferece um conjunto de mensagens que são utilizadas para gerenciar os metadados armazenados em sua base de dados. As seguintes mensagens são especificadas no padrão para tal finalidade:

- InsertSensor: permite o registro de novos sensores;

- DeleteSensor: permite a remoção de sensores bem como suas observações;

- InsertObservation: permite a inserção de observações no serviço SOS. O Código 3.3 apresenta um exemplo de mensagem para a inserção de uma observação sobre a umidade relativa do ar de um sensor localizado no telhado do prédio de pesquisa do ICMC.

Por último, seguem quatro tipos de mensagens utilizadas para manipulação dos resultados de observações:

- InsertResultTemplate: permite a inserção de um modelo (template) que descreve a estrutura dos valores que são codificados nas requisições InsertResult e GetResult;

- InsertResult: permite a inserção de resultados de observações em um servidor SOS. Para realizar a inserção de um resultado é necessário, a priori, inserir um template de metadados de observação. Esse tipo de mensagem é necessária para submeter valores brutos seguindo a estrutura e codificação definida na requisição InsertResultTemplate; 
Código 3.3: SOS - Exemplo de uma Mensagem InsertObservation

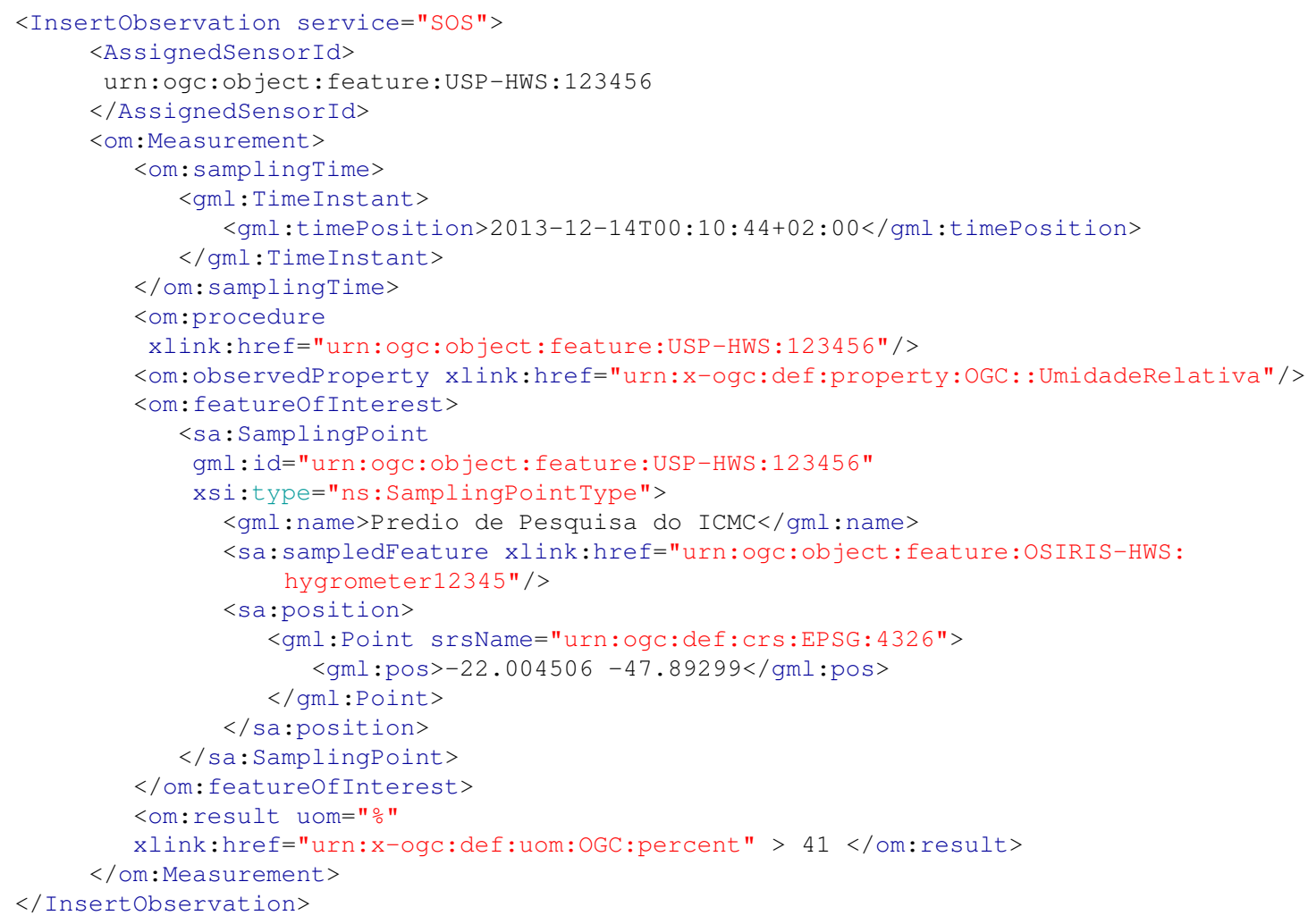

- GetResultTemplate: provê acesso ao template contendo a estrutura dos resultados que são retornados através da invocação da operação GetResult;

- GetResult: provê acesso às observações sem a codificação de metadados e informações sobre a estrutura dos resultados.

Em geral, o consumidor SOS tem interesse em receber observações de uma ou mais instâncias desse tipo de serviço. Assim, duas abordagens são utilizadas no acesso ao serviço:

- Visão centralizada no Sensor: o consumidor já possui informações sobre a existência de determinados sensores e está interessado nas observações fornecidas por eles;

- Visão centralizada na observação: o consumidor está interessado em observações de áreas geográficas específicas e determinados fenômenos, mas ainda não tem informações sobre os sensores que fornecem essas informações.

Em ambos os casos, o mecanismo utilizado pelo consumidor para receber as observações está demonstrado no diagrama de sequência da Figura 3.4. O primeiro passo para acessar um serviço SOS é realizar uma busca no catálogo onde estão armazenados os sensores abstraídos pelo serviço. Por sua vez, o catálogo retorna um ou mais URLs de instâncias de serviços SOS que atendem os critérios de busca definidos pelo consumidor. Assim, o consumidor descobre as operações que podem ser realizadas no serviço através de uma mensagem GetCapabilities. A instância SOS retorna 


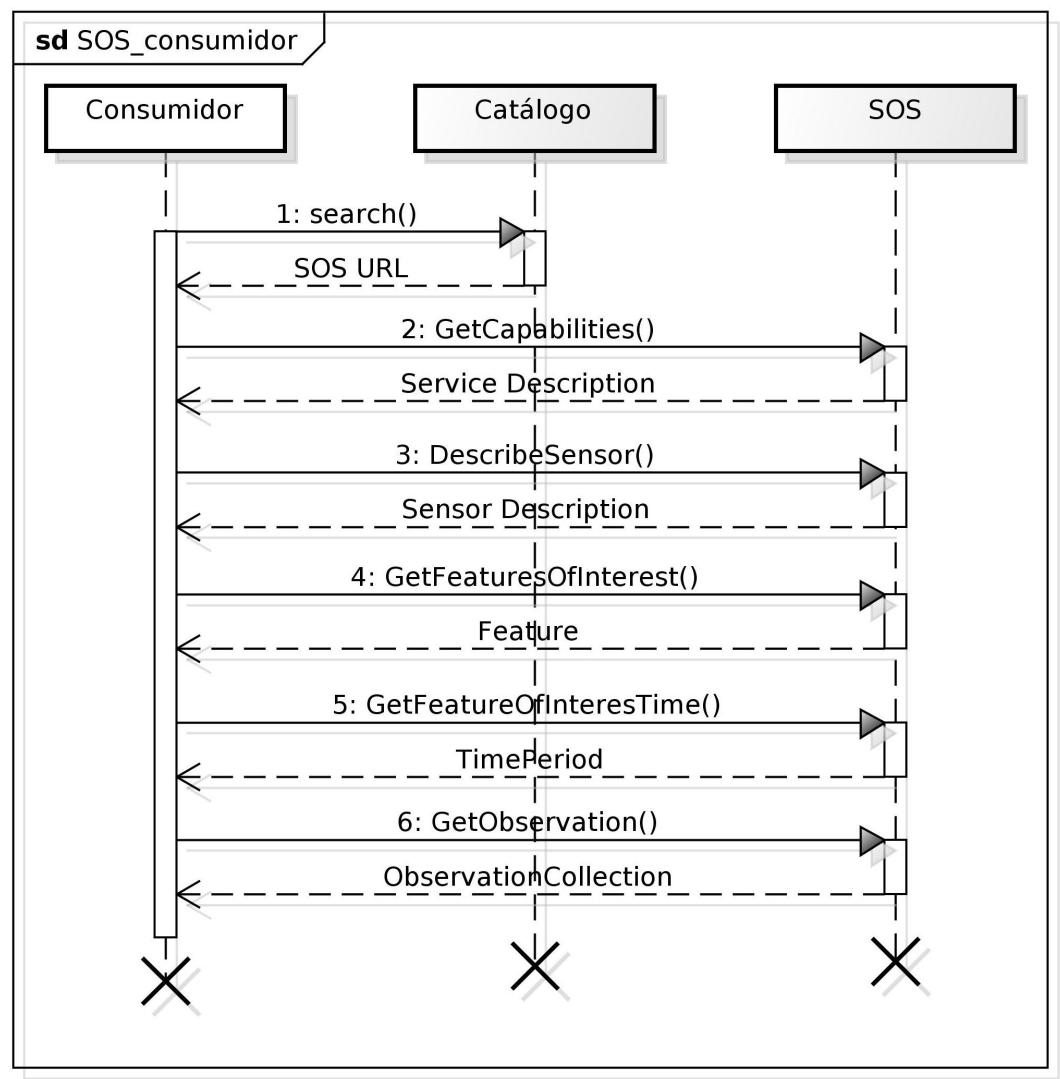

Figura 3.4: Diagrama de Sequência do Serviço SOS (Consumidor) - Adaptado de (GEONOVUM, 2013).

a descrição das operações suportadas por ela, permitindo que o consumidor acesse a descrição do sensor por meio de uma mensagem GetDescription. A resposta a essa mensagem retorna um documento SensorML que é utilizado para as demais operações tais como GetFeatureOfInterest, GetFeatureOfInterestTime e GetObservation (OGC, 2013c).

O serviço SOS fornece ainda uma interface para os produtores de dados que, em geral, são softwares das plataformas de sensoriamento responsáveis por concentrar as observações realizadas pelas redes de sensores. Esses produtores possuem capacidade de processamento suficiente para gerar documentos XML que podem ser submetidos ao serviço SOS. Ou seja, o operador da rede de sensores estabelece um link entre o produtor de dados e a instância SOS. A Figura 3.5 mostra um diagrama de sequência demonstrando a interação entre o produtor e o serviço SOS. A primeira interação do produtor de dados com o serviço SOS realiza o registro do sensor. A resposta do serviço para essa interação é um identificador do sensor registrado que pode ser utilizado em outras operações tais como atualizações na descrição e no status do sensor. Uma vez realizado o registro, o produtor de dados está habilitado a inserir observações na base de dados do serviço SOS. O SOS retorna, também, um identificador para cada observação submetida a ele (OGC, 2013c).

A interação entre consumidor, produtor e provedor SOS, como observado nas Figuras 3.4 e 3.5, possui operações síncronas e são utilizados para a construção de aplicações que necessitam de informações providas por operações no modelo requisição/resposta (dirigido a consulta). No 


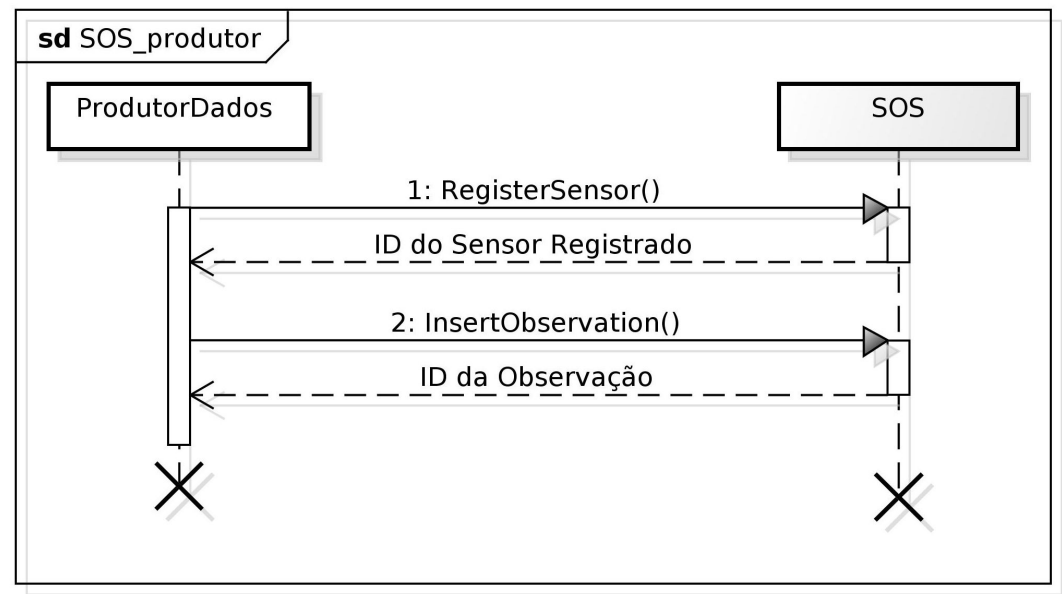

Figura 3.5: Diagrama de Sequência do Serviço SOS (Produtor) - Adaptado de (OGC, 2013c).

entanto, o SWE fornece um serviço assíncrono que permite a construção de aplicações orientadas a eventos. A Seção 3.3.2 apresenta o serviço assíncrono do SWE que é denominado como SES.

\subsubsection{Sensor Event Service}

O serviço SES pode ser definido como um aprimoramento do serviço SAS, definido no SWE 1.0. Ele é conhecido como um serviço publish/subscribe (dirigido a eventos), que é caracterizado por um serviço assíncrono e, dessa forma, exige uma assinatura por parte do seu consumidor. Alguns métodos opcionais podem ainda adicionar dinamicamente novos sensores, permitindo a emissão de novas notificações. O SES ainda não pode ser considerado como um padrão do SWE, pois ainda há uma discussão sobre sua especificação como apresentado no documento disponibilizado em (OGC, 2008a). Não houve atualizações no documento de discussão até a finalização desta tese de doutorado. A Figura 3.6 demonstra o fluxo principal de mensagens utilizado em uma interação padrão entre os elementos que compõem o serviço. Em primeiro lugar, é necessário que o produtor de dados realize um registro no serviço. A partir desse momento, consumidores do serviço podem assinar o serviço e receber notificações.

As notificações recebidas pelo serviço SES (enviadas pelo produtor de dados) são classificadas em diversos tópicos (OGC, 2008a). Esses tópicos definem as notificações como informações de gerenciamento, expiração e de observações. O administrador do sistema, por exemplo, pode estar interessado em receber notificações que informem parâmetros de gerenciamento. Essas mensagens são compostas, principalmente, por três elementos: SensorID, SensorStatus (Registered, Unregistered, Paused, Resumed) e description (human readable). Já as notificações de expiração determinam o tempo pelo qual as informações de registro deixam de ser válidas. Assim como as notificações de gerenciamento, as notificações de expiração também são compostas por três elementos: SensorID, ServerTime (horário de geração da notificação no serviço) e ExpirationTime (ponto no tempo em que o registro expira). Os dois tipos de notificações são importantes para o gerenciamento e conhecimento sobre o funcionamento dos sensores. No entanto, as notificações 


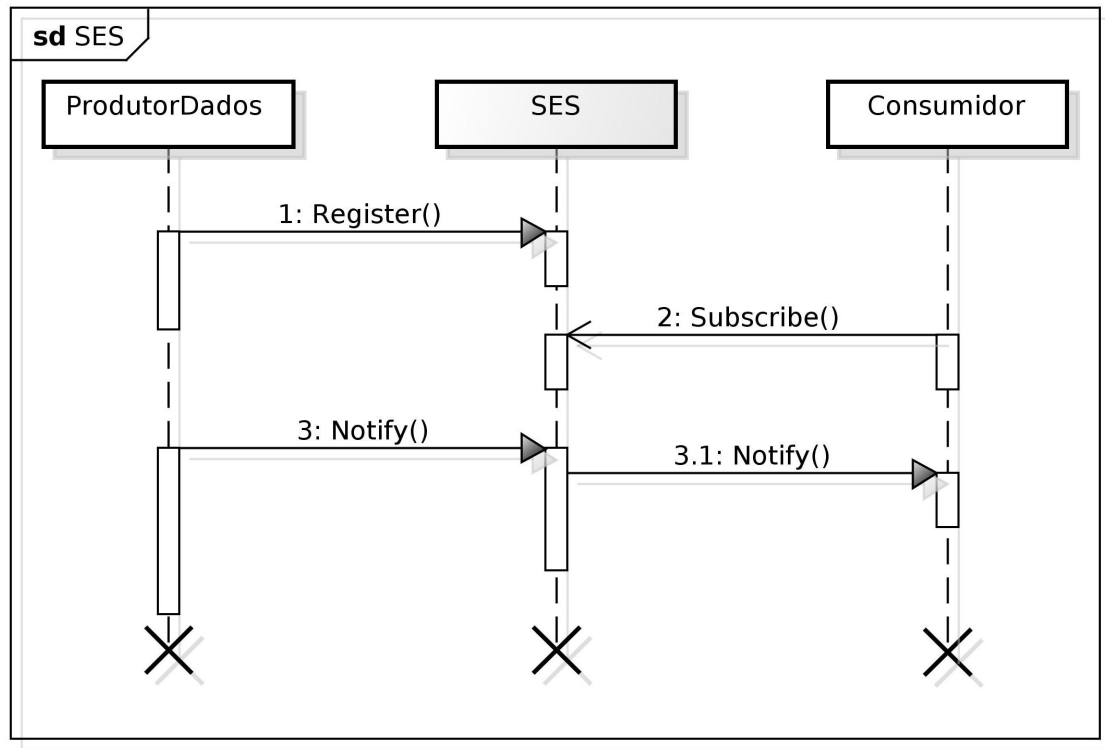

Figura 3.6: Diagrama de Sequência do Serviço SES.

Código 3.4: SES - Exemplo de um Filtro Nível 1

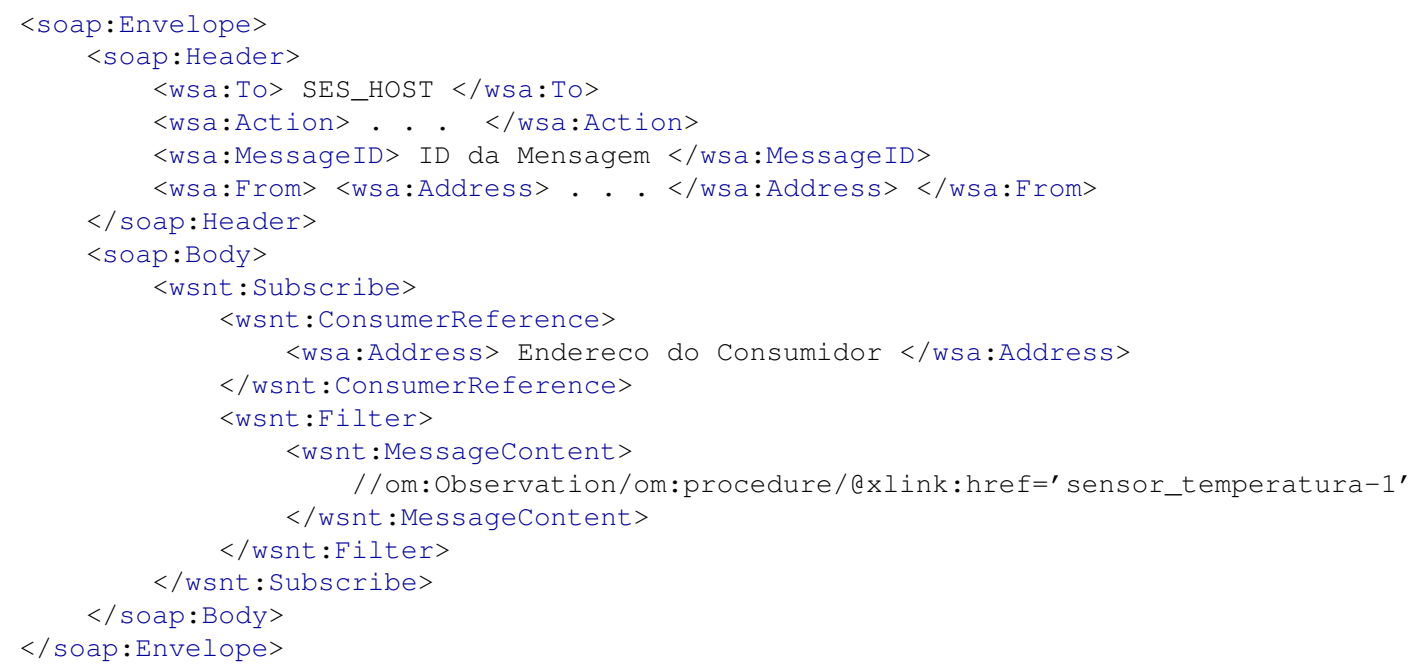

de observações podem ser descritas como a principal função do serviço SES. Através delas, os consumidores do serviço podem receber informações de eventos ocorridos nos objetos do mundo real que são observados pelos sensores. Nesse caso, consumidores podem determinar filtros que especificam os critérios que devem ser utilizados para o disparo de notificações.

O serviço SES oferece três níveis (levels) de filtros. O nível 1 especifica um filtro através de uma expressão XPath. XPath é uma linguagem utilizada para endereçar partes de um documento XML utilizando uma sintaxe non-XML que facilita sua utilização dentro de URIs e de valores de atributos XML (W3C, 1999). Nesse nível de filtro, que está exemplificado no Código 3.4, o serviço SES realiza uma checagem das mensagens enviadas pelos produtores de dados comparando as expressões cadastradas na base de dados do serviço. Quando o serviço encontra uma correspondência da mensagem recebida do produtor de dados com a expressão XPath cadastrada na base 
Código 3.5: SES - Exemplo de um Filtro Nível 2

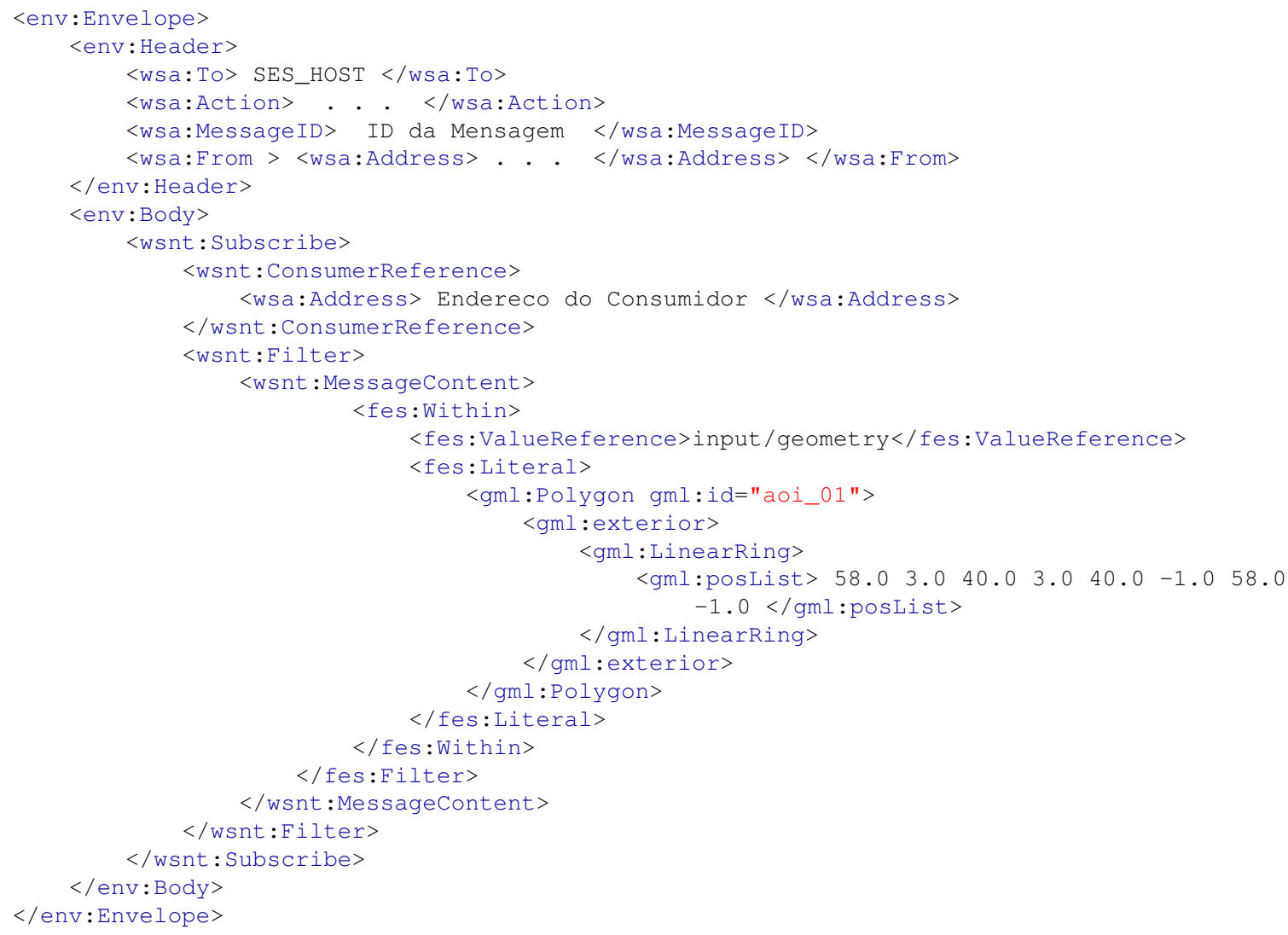

de dados do serviço (definida na linha 15 do documento demonstrado no Código 3.4) ocorre um encaminhamento dessa notificação para o URI definido no elemento wsa:Address (linha 11).

Por sua vez, o nível 2 do SES permite a definição de filtros espaciais, temporais e de comparação. Um exemplo de registro de filtro nível 2 é apresentado no Código 3.5. Nesse caso, é apresentado um filtro espacial. Ou seja, o serviço SES emitirá uma notificação aos consumidores registrados, caso a mensagem recebida do produtor de dados tenha origem em um sensor dentro da posição espacial definida na linha 21. O nível 2 permite também que o consumidor defina um filtro de comparação. Os filtros de comparação permitem o cadastro de comparações que determinam gatilhos de eventos. Por exemplo, a definição de gatilhos que emitam notificações de temperatura quando um determinado sensor aferir um valor superior a $100^{\circ} \mathrm{C}$. O cadastro de filtros é realizado por meio da especificação Filter Encoding Specification (FES) (OGC, 2010a).

Por último, a definição do nível 3 permite a combinação de vários eventos em contraste a definição de eventos simples do nível 2. No nível 3 consideram-se os eventos ocorridos durante uma determinada janela de tempo. Por exemplo, diferentes tipos de fluxos de eventos podem ser definidos, tais como:

- Contagem de eventos ocorridos dentro uma determinada janela de tempo; 
- Cálculo da média de valores de fenômenos observados em um determinado período de tempo, e dessa forma, permitir que notificações sejam disparadas apenas quando um certo limite for alcançado;

- Contagem de novos eventos com uma determinada propriedade que exceda um limite dentro de uma janela de tempo;

- Cálculo da média de uma certa propriedade presente nos últimos 5 eventos do sensor XYZ que exceda um determinado valor.

Além disso, outros tipos de mensagens como Unsubscribe (utilizada para cancelar a assinatura do serviço), Pause (utilizada para pausar uma assinatura) e Resume (utilizada para reativar um assinatura pausada) podem ser submetidas ao serviço SES. O serviço SES está entre as principais interfaces de acesso do framework SWE. Um outro importante serviço, denominado SPS, é utilizado para acessar e alterar parâmetros de configuração de sensores. A Seção 3.3.3 descreve as funcionalidades do serviço SPS.

\subsubsection{Sensor Planing Service}

Alguns sensores ou plataformas de sensores suportam uma configuração dinâmica em tempo de execução. Por exemplo, modificar a configuração da frequência com que os dados são mensurados. Esse tipo de operação é chamada de tasking e é disponibilizada pelo serviço SPS. O SPS é um serviço Web que permite a modificação de tarefas (tasking) dos sensores. Essa interface agrega operações que cobrem um processo completo de controle e planejamento das tarefas realizadas pelos elementos de sensoriamento. O serviço SPS fornece um conjunto de mensagens que acessam funções tais como (OGC, 2011b):

- GetFeasibility: obtém os tipos de tarefas que são gerenciáveis no sensor;

- Submit: submete e modifica configurações/status de tarefas;

- GetStatus: obtém o status de uma tarefa;

- DescribeTasking: permite que consumidores tenham informações suficientes para formular suas próprias requisições através de uma sintaxe que define as tarefas que podem ser requisitadas.

A versão 2.0 do serviço insere o SWE Common para a descrição de tarefas e seus parâmetros além de incluir novas operações como o Reserve que tem funcionamento semelhante ao Submit com a diferença que a tarefa somente é enviada após uma mensagem de confirmação (Confirm). 


\subsubsection{Serviços de Descoberta}

O framework SWE suporta uma integração flexível de todas as fontes de dados de sensores para a construção de aplicações de sensoriamento. Entretanto, a disponibilidade e interoperabilidade dessas fontes de dados devem ser complementadas por mecanismos de descoberta que permitem ao usuário encontrar os dados que atendam suas necessidades. Em (OGC, 2007a) é apresentada uma especificação onde é definido um catálogo para descoberta em sistemas denominados Spatial Data Infrastructure (SDI). Os SDIs podem ser definidos como infraestruturas de dados que implementam um framework de dados geográficos, metadados, usuários e ferramentas que são interativamente conectadas de forma a possibilitar o uso de dados espaciais em uma maneira eficiente e interoperável (GSDI, 2012). Contudo, devido às especificidades das redes de sensores, essa proposta de catálogo não pode ser aplicada diretamente ao contexto dos sensores Web (Wachowicz, 2010; Bröring et al., 2011).

Diferentes modelos de metadados podem ser utilizados em serviços de registro: SensorML dentro do SWE e o ebRIM utilizado por catálogos (OASIS, 2001). A estrutura dinâmica das redes de sensores faz com que as soluções de busca através de catálogos OGC não sejam suficientes para cumprir as exigências desse tipo de serviço. Isso faz com que essa questão seja tratada como um desafio a ser transposto pela comunidade da Sensor Web Enablement. Outras questões importantes no contexto da descoberta de sensores diz respeito a coleta automática de metadados e o tratamento de problemas semânticos tais como a descrição dos fenômenos que são observados pelos sensores. A Tabela 3.1 descreve quatro propostas de soluções de serviços de descoberta que podem, futuramente, tornar-se um padrão no framework SWE.

Tabela 3.1: Propostas para implementação de um serviço de descoberta (Bröring et al., 2011)

\begin{tabular}{l|l}
\hline \multicolumn{1}{c|}{ Especificação } & \multicolumn{1}{c}{ Descrição } \\
\hline $\begin{array}{l}\text { SensorML Profile } \\
\text { for Discovery }\end{array}$ & $\begin{array}{l}\text { Documentos SensorML asseguram a presença de um conjunto mínimo } \\
\text { de metadados que são necessários para a descoberta de sensores. }\end{array}$ \\
\hline $\begin{array}{l}\text { SensorML- } \\
\text { ebRIM Mapping }\end{array}$ & $\begin{array}{l}\text { Mapeamento de elementos SensorML dentro de um catálogo de infor- } \\
\text { mação ebRIM de maneira a permitir o gerenciamento de metadados } \\
\text { pelos catálogos OGC. }\end{array}$ \\
\hline SIR & $\begin{array}{l}\text { Serviço Web para gerenciamento de metadados; isso inclui a coleção de } \\
\text { metadados, gerenciamento de informações de status e funcionalidades } \\
\text { para submissão de informações para os catálogos OGC. }\end{array}$ \\
\hline SOR & $\begin{array}{l}\text { Serviço Web para acesso às definições de fenômenos e exploração dos } \\
\text { relacionamentos semânticos entre diferentes fenômenos. }\end{array}$ \\
\hline
\end{tabular}

Os esforços do SWE para a criação de mecanismos de descoberta compreendem tanto o modelo de informação quanto o modelo de interfaces. A linguagem SensorML do modelo de informação fornece os metadados necessários para o mapeamento de informações de sensores que podem ser cadastrados em abordagens como ebRIM. Por conseguinte, dois tipos de serviços Web são discutidos: SIR e SOR. O SIR tem sido discutido como uma interface que possui funcionalidades 
de coleta, gerenciamento e transformação de metadados, assim como o SOR que também inclui um gerenciamento semântico dos fenômenos observados por sensores (OGC, 2010c,b). É importante destacar que tanto o serviço SIR quanto SOR ainda são definidos como discussion papers pelo OGC e, portanto, ainda não são considerados padrões do framework.

A interface SIR é utilizada nesta tese como o serviço de registro de sensores que compõe uma arquitetura de provisão de qualidade de serviço apresentada no Capítulo 5. Essa interface fornece funcionalidades para coletar, gerenciar, transformar e transferir metadados de sensores (OGC, 2010b). Esse serviço tem o objetivo de preencher as lacunas existentes entre a linguagem SensorML e sistemas SDIs. Para alcançar esses objetivos, algumas funcionalidades são disponibilizadas:

- Coleta de metadados de sensores (coleta automática e inserção manual de documentos SensorML);

- Funcionalidade de descoberta de sensores através dos metadados fornecidos pelos elementos que compõem um documento SensorML;

- Gerenciamento de informações de status dos sensores cadastrados na sua base de dados (por exemplo, encontrar todos os sensores com nível de bateria crítico);

- Transformação de metadados de sensores baseados em documentos SensorML para modelos de informação baseados em catálogos OGC.

\subsection{Considerações Finais}

Este capítulo discutiu o framework SWE em detalhes de maneira a fundamentar o entendimento dos padrões e linguagens utilizadas por essa abordagem no processo de abstração de infraestruturas de redes de sensores. Como pôde ser observado, há um extensivo e complexo conjunto de padrões compondo o SWE. O estudo do framework permitiu o desenvolvimento de avaliações de desempenho que são apresentadas no Capítulo 4 e, também, o projeto e desenvolvimento de uma arquitetura de provisão de qualidade de serviço, discutida no Capítulo 5. As avaliações apresentadas no Capítulo 4 visam analisar o impacto de desempenho na utilização dos padrões SWE, dada as complexidades aqui discutidas. 



\section{Avaliações de Desempenho}

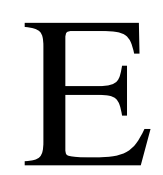

ste capítulo tem como objetivo apresentar os resultados de dois experimentos desenvolvidos durante este trabalho de doutorado que possibilitam quantificar as diferenças no desempenho quando formas distintas de obtenção de dados de redes de sensores foram consideradas.

Inicialmente é apresentado um experimento que considera quatro tipos de mecanismos de acesso que provêem diferentes formas de obtenção de dados de redes de sensores. Os resultados desse experimento permitem quantificar a variação de desempenho na utilização de diferentes implementações de SOA em relação, por exemplo, a métodos binários. A análise desses mecanismos de acesso a redes de sensores responde à primeira questão definida nos objetivos desta tese (Seção 1.3). Esse mesmo experimento oferece ainda uma comparação entre formas distintas de implementação de arquiteturas orientadas a serviço que abstraem redes de sensores, o que possibilita responder a segunda questão dos objetivos. Baseando-se nos resultados obtidos e em diversos trabalhos disponíveis na literatura, pode-se analisar a viabilidade de se utilizar SOA para abstrair as complexidades das redes de sensores. Essa análise, apresentada na Seção 4.2.5, responde a terceira questão dos objetivos deste trabalho. Contudo, todo o conjunto de experimentos e a análise dos dados obtidos na avaliação dos diversos mecanismos de acesso estão apresentados na Seção 4.2.

Finalmente, o segundo experimento apresentado neste capítulo (Seção 4.3), considera apenas os serviços SWE onde diferentes tipos de filtros podem modificar o desempenho de acesso a redes de sensores. Nessa avaliação são tomados três serviços que compõem o modelo de interfaces do SWE: SOS, SES e SIR. Os resultados obtidos com esse experimento oferecem as informações necessárias para a definição de formas de redução dos possíveis problemas de desempenho no contexto de redes de sensores abstraídas por SOA, que são apresentadas no Capítulo 5. 
A Seção 4.1 descreve a metodologia utilizada para o desenvolvimento de experimentos nesta tese.

\subsection{Metodologia de Avaliação de Desempenho}

A metodologia utilizada para a realização das avaliações de desempenho discutidas neste capítulo seguiu um conjunto de etapas que pode ser descrito da seguinte forma:

1. Planejamento de experimentos;

2. Criação de um ambiente de testes;

3. Execução dos testes e coleta de dados;

4. Análise dos resultados.

O planejamento de experimentos define uma etapa fundamental para a avaliação de desempenho. Nessa etapa são caracterizados os fatores ou características que devem ser consideradas visando avaliar quais influenciam o desempenho do sistema computacional em questão. Cada um desses fatores possui níveis que são os possíveis valores assumidos por eles. A utilização de uma metodologia adequada permite avaliar a influência de cada fator e ainda a interação entre os fatores. Durante o planejamento dos experimentos é necessário ainda determinar a quantidade de dados coletados e a quantidade de replicações. A definição da quantidade de replicações é necessária para a validação estatística dos experimentos. Ademais, o planejamento de experimentos deve ser projetado para maximizar a quantidade de dados coletados em um número mínimo de testes. Existem diversas formas de se realizar esse planejamento, tais como (Jain, 1991):

- Planejamento simples: nesse planejamento deve-se iniciar uma configuração inicial, fixar cada um dos fatores, variando os demais. Nesse caso, é possível verificar qual fator influencia o desempenho. O planejamento simples tem a vantagem de ser facilmente implementado, mas não permite analisar a relação entre fatores além de ser estatisticamente ineficiente.

- Fatorial completo: nesse planejamento são utilizadas todas as combinações considerando todos os fatores e todos os níveis. Com esse tipo de planejamento é possível avaliar todos os fatores e determinar o efeito de cada um deles nos experimentos e a interação entre eles. A principal desvantagem de um planejamento de experimentos na forma fatorial completo é a quantidade de experimentações que devem ser realizadas.

- Fatorial parcial: consiste na definição de apenas uma fração dos experimentos definidos no planejamento fatorial completo. Nesse caso, realiza-se apenas uma parte dos experimentos. 
É importante destacar que as avaliações de desempenho apresentadas neste capítulo fazem uso do planejamento fatorial completo. Além disso, definiu-se em 30 o número de replicações executadas para cada tipo de experimento. Esse valor permite uma boa precisão estatística. A definição e criação do ambiente de testes também faz parte do processo de avaliação de desempenho. A descrição desse ambiente visa explicitar os elementos de hardware e software utilizados e a forma como eles foram configurados durante o processo da avaliação. Por sua vez, cada avaliação de desempenho também discute as ferramentas utilizadas para a execução dos testes e a coleta de dados. Por último, a análise dos resultados apresenta as análises estatísticas obtidas como resultado das avaliações através de um conjunto de gráficos. Diversos tipos de gráficos são utilizados na discussão da análise dos resultados. Dentre eles, destacam-se:

- Gráficos de intervalos de confiança: nesses gráficos são mostradas as variações dos tempos de respostas médios tendo em consideração a variação nos níveis de fatores. Os intervalos de confiança calculados utilizam um alpha de 0,05 (95\% de confiabilidade);

- Gráficos de Pareto: nesses gráficos são ilustradas as influências de cada um dos fatores nos testes. Os gráficos de Pareto utilizam uma linha vertical que indica o ponto onde os fatores começam a ter influência nos experimentos. Dessa forma, fatores que se encontram acima dessa linha têm influência nos tempos de resposta;

- Gráficos de efeitos principais: permitem analisar quais dos fatores possuem diferenças mais acentuadas na execução dos testes;

- Gráficos de interação entre os fatores: permitem analisar a interação entre os fatores a medida que seus níveis variam.

\subsection{Avaliação de Diferentes Métodos de acesso}

Como discutido na Seção 2.2, a orientação a serviço é utilizada no acesso a redes de sensores. Contudo, os serviços Web, representantes mais comuns em instanciações de arquiteturas orientadas a serviço, podem apresentar problemas de desempenho. Variações de desempenho podem ser encontradas na comparação das ferramentas e tecnologias tradicionalmente utilizadas para o desenvolvimento de serviços Web com abordagens de objetos distribuídos binários, tais como o CORBA (Common Object Request Broker Architecture) ou RMI (Remote Method Invocation). Avaliações de desempenho comparando serviços Web com objetos distribuídos podem ser encontradas em diversos trabalhos, como por exemplo, em (Elfwing et al., 2002; Juric et al., 2004).

Entretanto, pesquisas que comparam o desempenho desses mecanismos de acesso no contexto das redes de sensores não foram encontradas. A avaliação realizada tem o objetivo de analisar o desempenho do acesso a uma rede de sensores através de diferentes implementações de serviços Web tais como o Representational State Transfer (REST), SOAP e SOS e de uma abordagem de objetos distribuídos binários (RMI). 
Embora o serviço SOS também utilize o protocolo SOAP na troca de mensagens entre clientes e serviços, ele ainda inclui uma sobrecarga no encapsulamento de metadados das observações que são definidos pelo padrão O\&M. Em outras palavras, um documento O\&M é anexado ao corpo da mensagem SOAP. Já os testes definidos nesta avaliação denominados SOAP e REST não utilizam nenhuma abstração adicional na definição dos metadados e dados das observações, além da utilização da linguagem XML para descrever tais dados. O mecanismo binário RMI é utilizado para servir como referência de desempenho para as abordagens textuais (XML).

A escolha dos métodos em questão foi motivada pela popularidade desses mecanismos. Ou seja, existe um conjunto de ferramentas e APIs que suportam a implementação desses métodos que provêem suporte ao desenvolvimento de aplicações distribuídas. Cogitou-se, por exemplo, utilizar métodos que utilizam apenas a programação de sockets como abordagem de método binário. Contudo, considerou-se que a programação pura de sockets não é trivial e pouco utilizada. Por exemplo, o RMI abstrai todas as complexidades de serialização de dados e tratamento de exceções e erros, facilitando o processo de programação.

A avaliação exposta nesta seção é complementar ao trabalho apresentado em (Rouached et al., 2012). Nesse trabalho, os autores definem uma avaliação comparando a busca de documentos O\&M através de SOAP e dois tipos de implementação de REST. Por sua vez, a avaliação apresentada nesta seção diversifica os tipos de métodos de acesso através da inclusão de um método binário, além de considerar outros fatores que influenciam o desempenho da aquisição das observações dos sensores. Além disso, a implementação do método REST, utilizada na avaliação de diferentes métodos de acesso, não considera o encapsulamento das observações em documentos O\&M, mas apenas em XML. Exceto para o serviço SOS que está detalhado na Seção 3.3.1, uma breve descrição dos demais métodos de acesso utilizados nesta avaliação de desempenho pode ser definida da seguinte forma:

- RMI: mecanismo que permite ao programador criar uma aplicação distribuída baseada na tecnologia Java, onde os métodos de objetos remotos podem ser requisitados por diferentes máquinas virtuais Java, possivelmente em diferentes locais. Aplicações que utilizam RMI compreendem dois programas distintos: um servidor e um cliente. Um servidor cria alguns objetos remotos tornando-os acessíveis por meio de um registro de objetos chamado de RMIRegistry. Após esse registro, clientes podem requisitar métodos desses objetos. Um programa cliente típico pode obter diversas referências remotas a um ou mais objetos em um servidor. Um objeto remoto RMI implementado para a avaliação de desempenho apresentada nesta seção provê acesso aos dados. Todo esse processo de requisição dos dados é feito com o intermédio de um stub (gerado por uma ferramenta chama rmic - rmi compiler) que deixa transparente para o programador toda a complexidade do estabelecimento da conexão, requisição e recebimento dos dados;

- REST: mecanismo que possui um estilo arquitetural onde os elementos que o compõem visam utilizar os princípios fundamentais de projeto da Web promovendo alta escalabilidade, 
desempenho e abstração de recursos de sistemas baseados nesse tipo de abordagem. REST não é considerado um padrão e sim um conjunto de restrições (ou regras) que devem ser seguidas para a construção de sistemas nele baseados. Um sistema REST deve seguir o paradigma cliente/servidor, não armazenar estado (stateless) e possuir uma interface comum. Um serviço REST deve ser fornecido como um recurso que pode ser endereçado na Web e acessado através dos recursos providos pelo protocolo HTTP. Ou seja, Um recurso pode ser endereçado através de um URL e acessado por meio de métodos tais como GET e POST do protocolo HTTP. REST não é estritamente relacionado ao protocolo HTTP, mas é tradicionalmente associado a ele. Outro conceito importante diz respeito às representações que são utilizadas para transferir documentos XML ou JSON (Java Object Notation) para representar objetos de dados e seus atributos. Ou seja, dados representados em XML ou JSON são trocados durante interações entre clientes e servidores (Upadhyaya et al., 2011);

- SOAP: como comentado na Seção 2.3.1, o protocolo SOAP é tradicionalmente utilizado na construção de serviços Web. Embora o protocolo seja independente de protocolos da camada de aplicação, ele também é quase sempre associado ao protocolo HTTP (como ocorre no REST). Dessa forma, o protocolo SOAP é definido como um protocolo da camada de mensagens dos serviços Web, onde suas mensagens são utilizadas para a invocação desses serviços e recepção de dados retornados por eles.

A escolha dos métodos de acesso descritos considerou a popularidade e provisão de ferramentas que facilitam o desenvolvimento dos métodos. REST e SOAP são amplamente utilizados no cenário corporativo e acadêmico, como pode ser observado em (McWilliam et al., 2013). Por sua vez, o RMI é uma API importante para o desenvolvimento de aplicações de distribuídas e que pertence ao kit de desenvolvimento da linguagem Java.

\subsubsection{Planejamento de Experimentos}

O planejamento de experimentos estabelecido para a avaliação de desempenho dos mecanismos de acesso considera os fatores determinados na Tabela 4.1. O fator tipo de acesso é composto por quatro níveis variando as formas de acesso definidas para esta avaliação. Dois níveis de filtros são considerados no fator tipos de filtro. $\mathrm{O}$ filtro denominado $\mathrm{F} 1$ considera requisições ao serviço que solicitam apenas uma observação, enquanto que o F2 considera requisições que retornam 288 observações. Esse valor de 288 observações considera a solicitação de observações durante um período de um dia com uma rede de sensores realizando uma observação a cada 5 minutos. Já o fator quantidade de threads considera 10 variações de carga. A variação na quantidade de threads simula o comportamento de vários clientes acessando simultaneamente os serviços. A variação no número de threads é uma técnica comum em ferramentas de avaliação de desempenho como o 
Jmeter $^{1}$ e httperf ${ }^{2}$. Por fim, o tempo de resposta define a métrica (ou variável de resposta) utilizada na condução dos experimentos.

Tabela 4.1: Fatores da Avaliação de Desempenho dos Métodos de acesso

\begin{tabular}{c|c}
\hline Fatores & Níveis \\
\hline Tipos de acesso & RMI, REST, SOAP e SOS \\
\hline Tipos de filtro & F1 (1 Observação), F2 (288 Observações) \\
\hline Qtd. de threads & $20,40,60,80,100,120,140,160,180,200$ \\
\hline \multicolumn{2}{c}{ Métrica de Avaliação } \\
\hline & Tempo de Resposta \\
\hline
\end{tabular}

A Seção 4.2.2 detalha o ambiente de testes considerando os elementos de hardware e software utilizados para realização dos experimentos.

\subsubsection{Ambiente de Testes}

A importância do projeto da infraestrutura de hardware utilizado em uma avaliação de desempenho de sistemas computacionais reside no fato da capacidade dos recursos providos por eles poderem influenciar a execução das experimentações. Os elementos de hardware utilizados na execução dos testes estão definidos na Tabela 4.2. A Figura 4.1 mostra a definição da arquitetura do ambiente de testes. A arquitetura utilizada na definição dos experimentos baseou-se no trabalho apresentado em (Wang et al., 2009) onde é proposto o acesso a dispositivos de sensoriamento através de um serviço Web. Entretanto, o ambiente de testes criado na avaliação de desempenho apresentada nesta seção possui algumas diferenças em comparação à arquitetura definida em (Wang et al., 2009). A arquitetura proposta tem os métodos de acesso, no lado do servidor, como um concentrador das informações da rede de sensores e um cliente que acessa os dados providos por esses métodos. Diferentemente, a arquitetura proposta em (Wang et al., 2009) possui um serviço Web como um gateway que permite o acesso a um determinado nó dentro da rede. Isto é, o ambiente de testes discutido em (Wang et al., 2009) não considera o armazenamento de informações em um banco de dados gerenciado pelo serviço Web, executando o acesso diretamente nos sensores.

\footnotetext{
${ }^{1}$ https://jmeter.apache.org/usermanual/test_plan.html

${ }^{2}$ http://www.hpl.hp.com/research/linux/httperf/
} 


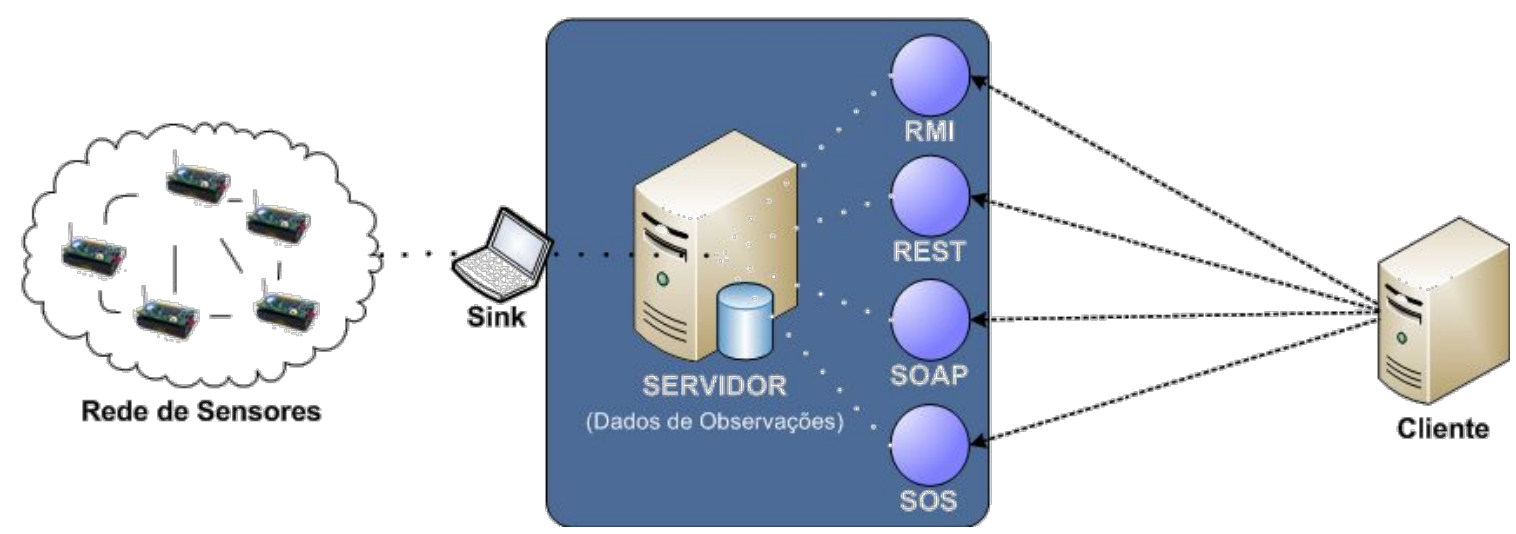

Figura 4.1: Métodos de acesso: Arquitetura do Ambiente de Testes

Tabela 4.2: Métodos de acesso: Configurações de Hardware

\begin{tabular}{c|l|l}
\hline \multicolumn{3}{c}{ Configuração dos Nós Físicos } \\
\hline \multicolumn{3}{c}{$\begin{array}{c}\text { Intel(R) Core(TM)2 Quad CPU Q9400 of 2.66GHz; } \\
\text { Memória: 8 GB RAM DDR 3. }\end{array}$} \\
\hline Componente & \multicolumn{3}{c}{ Configuração } & \multicolumn{1}{c}{ Máquinas Virtuais } \\
\hline Servidor & $\begin{array}{l}\text { Processadores: 2; } \\
\text { Memória 2GB; Disco: }\end{array}$ & $\begin{array}{l}\text { Responsável por executar as aplicações servidoras } \\
\text { dos métodos de acesso (RMI, REST, SOAP e SOS) }\end{array}$ \\
\hline Cliente & $\begin{array}{l}\text { Processadores: } 2 ; \\
\text { Memória 2GB; Disco: }\end{array}$ & $\begin{array}{l}\text { Responsável por executar as aplicações clientes } \\
\text { que acessam os métodos de acesso. Um script es- } \\
\text { crito em Perl foi utilizado para automatizar as exe- } \\
\text { cuções dessas aplicações. }\end{array}$ \\
\hline
\end{tabular}

As implementações dos métodos de acesso, utilizados para a provisão dos dados observados pela rede de sensores, foram desenvolvidas na linguagem de programação Java. Além disso, servidores de aplicação como o Apache Tomcat (na versão 7.0.39) (Apache, 2014b) e o Apache Axis (na versão 3.05) (Apache, 2014a) foram utilizados para a execução dos métodos de acesso tais como REST, SOAP e SOS. O método de acesso via RMI utilizou uma API incorporada ao kit de desenvolvimento da linguagem Java (SDK). A implementação das aplicações servidora e consumidora do método de acesso REST foi desenvolvida por meio de uma API chamada de Java Architecture for XML Binding (JAXB). Essa API permite que desenvolvedores criem classes Java que podem ser expostas através de documentos XML através de anotações. Anotações também são utilizadas para a criação de métodos que podem ser expostos como serviços. Tais serviços são requisitados para retornarem, no caso dos testes apresentados nesta seção, documentos XML que encapsulam observações dos sensores. Por sua vez, as aplicações para o teste do protocolo SOAP foram implementadas utilizando uma API chamada de Apache Axiom. A Axiom é fornecida em conjunto com o servidor de aplicação Axis onde ela é utilizada para o processamento de mensagens SOAP. Já a implementação dos testes sobre o serviço SOS foi realizada através da utilização de ferramentas fornecidas pela $52^{\circ}$ North (52North, 2014a). A implementação da aplicação consumi- 
dora para acessar o serviço SOS, foi desenvolvida através de uma API chamada de OX-Framework que fornece funções básicas para acessar os serviços do modelo de interfaces do SWE (52North, 2014b).

Outro ponto importante na arquitetura proposta para essa avaliação de desempenho diz respeito à base de dados que armazena os dados das observações providas pelos métodos de acesso. A base de dados foi criada simulando uma rede de sensores enviando uma medição de temperatura a cada 5 minutos durante o período de um mês, totalizando 8640 observações inseridas no banco de da-

dos. É importante destacar ainda a utilização do modelo de banco de dados relacional do serviço SOS, uma vez que ele possui todas as tabelas necessárias para o armazenamento dos metadados e observações utilizadas nas experimentações. Todos os mecanismos de acesso utilizaram a mesma base de dados para recuperar as informações solicitadas pelas aplicações consumidoras desenvolvidas para a avaliação de desempenho em questão. Isso foi feito para manter uma uniformidade no acesso à base de dados entre todos os métodos de acesso. Contudo, a forma de encapsulamento dessas informações por cada um desses mecanismos difere segundo as especificidades de cada um dos mecanismos de acesso.

\subsubsection{Execução dos Experimentos}

A execução dos testes seguiu um modelo fatorial completo onde todas as combinações dos níveis dos fatores foram considerados. Foram executados um total de 80 experimentos $\left(4_{\text {acesso }} *\right.$ $2_{\text {filtro }} * 10_{\text {threads }}$ ). Além disso, cada um dos 80 testes foram replicados 30 vezes de forma alcançar uma validade estatística. Os testes realizados contaram com o auxílio de um script escrito em Perl que automatizou o processo de avaliação. Esse script possui os seguintes parâmetros de entrada:

\section{- Parâmetros de controle dos experimentos:}

- Aplicação: determina qual aplicação cliente (RMI, REST, SOAP ou SOS) deverá ser executa para a realização dos experimentos.

- Número de threads: define a quantidade de threads executadas nos experimentos. Nesse caso cada thread simula um cliente.

- Média Exponencial: define a média da função exponencial utilizada para a geração das requisições por cada uma das threads. No caso dos experimentos apresentados nesta seção, utilizou-se uma função exponencial de média 120. Ou seja, as requisições enviadas pela threads segue uma taxa de 120 requisições por minuto seguindo um função de distribuição exponencial.

- Número de Requisições: determina a quantidade de requisições que serão enviadas por cada thread em um teste. Definiu-se em 10 o número de requisições enviadas por cada uma das threads. Associando o número de requisições com a média exponencial, pode-se dizer que cada uma das threads envia 10 requisições aos serviços seguindo uma função exponencial de média 120. 
- Replicações: ajusta a quantidade de replicações dos testes para a obtenção de uma validade estatística. É importante ressaltar que todos os experimentos dos métodos de acesso utilizaram 30 replicações.

- Endereço do Serviço: define o endereço (URL) onde estão localizados os servidores dos métodos de acesso.

- Caminho do Arquivo de Resultados: define o local no sistema de arquivos onde serão armazenado os resultados dos testes.

\section{- Parâmetros de definição de consulta aos sensores:}

- Nome do Sensor: define o nome do sensor pelo qual deseja-se receber observações.

- Tempo Inicial: indica o início do período pelo qual se deseja obter observações. O tempo inicial de ambos os filtros (F1 e F2) utilizados nos testes foi definido como 2013-02-13T00:00:00Z

- Tempo Final: determina o tempo final para o retorno das observações. Continuando o exemplo do item anterior definiu-se em 2013-02-13T00:05:00Z o valor final para as observações do filtro F1 e 2013-02-13T23:59:59Z para o filtro F2. Ou seja, o filtro F1 é definido com o horário que vai de 2013-02-13T00:00:00Z a 2013-02-13T00:05:00Z. Essa definição de horário retorna apenas uma observação. Por outro lado, o filtro F2 é definido por um período entre 2013-02-13T00:00:00Z e 2013-02-13T23:59:59Z, retornando 288 observações.

Um exemplo do funcionamento do script criado para a avaliação dos métodos de acesso é apresentado na Figura 4.2. O script apresentado nesta seção tem o mesmo funcionamento para cada um dos métodos avaliados. Primeiramente, ele instancia os clientes específicos de cada método. Esses clientes são implementados basicamente em duas classes: TestsThreads e Requestor. A classe TestsThreads é responsável por instanciar todos os parâmetros discutidos como número de thre$a d s$, média exponencial e etc. Além disso, essa classe controla e gerencia um conjunto de threads que são instâncias da classe Requestor. Dessa forma, cada objeto da classe Requestor submete 10 requisições às aplicações servidoras (MethodServer) de cada um dos métodos considerados utilizando uma função exponencial com média de 120 requisições por minuto.

Os experimentos dos métodos de acesso foram executados através do script discutido nesta seção. Então, os dados foram coletados, tabulados e analisados. Esse processo possibilitou que a fase de análise de resultados fosse cumprida e apresentada na Seção 4.2.4.

\subsubsection{Análise dos Resultados}

Esta seção tem por objetivo expor uma análise dos resultados obtidos durante a execução dos experimentos para avaliação de desempenho dos diferentes métodos para acesso aos dados de 


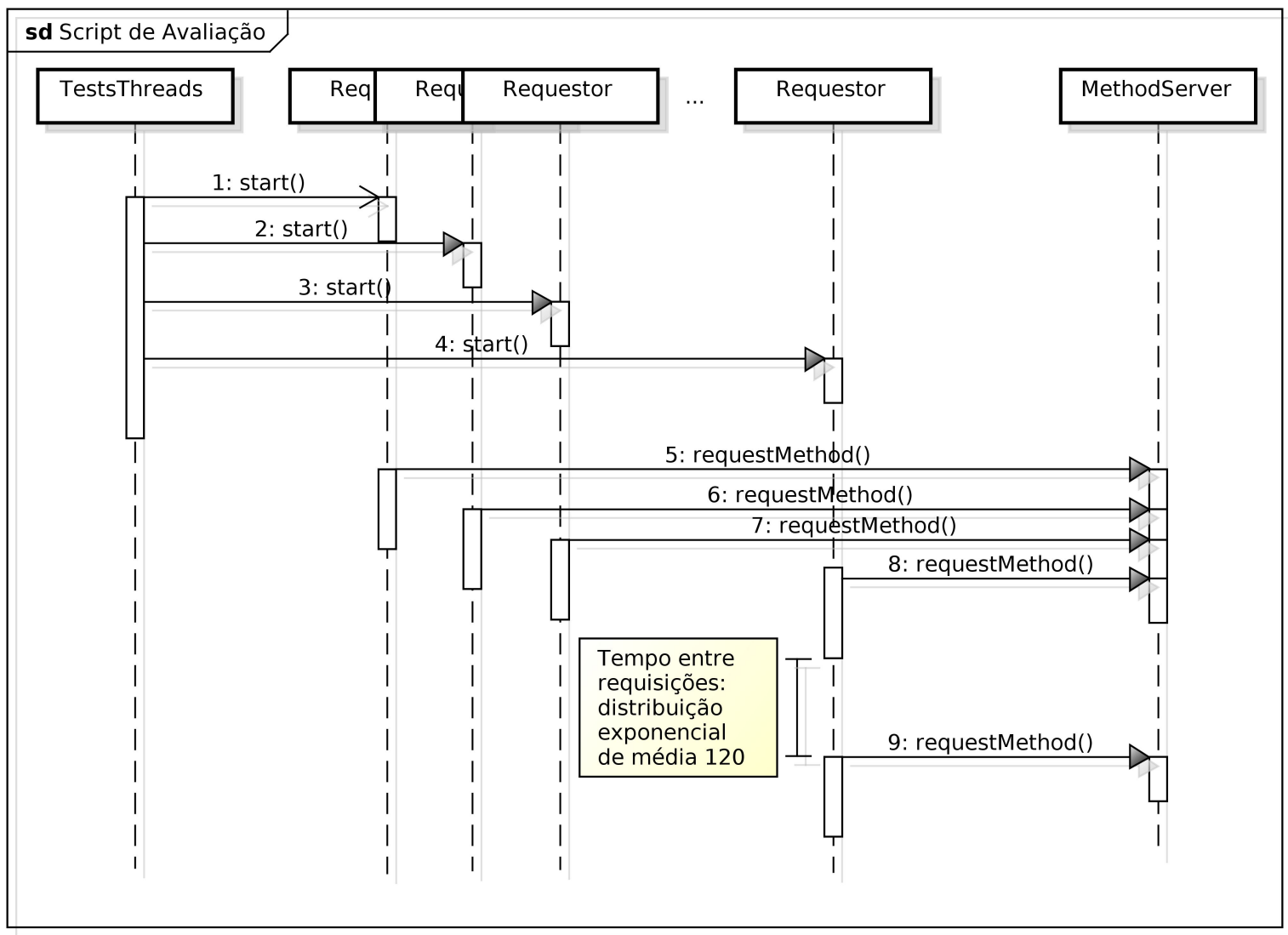

Figura 4.2: Diagrama de Sequência do script de avaliação

uma rede de sensores. Os gráficos das Figuras 4.3 e 4.5 apresentam as médias e os intervalos de confiança para os experimentos que avaliam o filtro que retorna apenas uma observação e o filtro que retorna 288 observações, respectivamente. Os gráficos mostram, além das médias, os intervalos de confiança das variações da quantidade de threads para cada um dos métodos de acesso considerados. Vale relembrar que os intervalos de confiança foram calculados com um $\alpha=0,05$ (95\% de confiabilidade).

Tabela 4.3: Médias dos Tempos de Resposta para o filtro F1

\begin{tabular}{c|c|c|c|c|c|c|c|c|c|c}
\hline & $\mathbf{2 0}$ & $\mathbf{4 0}$ & $\mathbf{6 0}$ & $\mathbf{8 0}$ & $\mathbf{1 0 0}$ & $\mathbf{1 2 0}$ & $\mathbf{1 4 0}$ & $\mathbf{1 6 0}$ & $\mathbf{1 8 0}$ & $\mathbf{2 0 0}$ \\
\hline RMI & 2,30 & 1,82 & 1,56 & 1,51 & 1,48 & 1,48 & 1,46 & 1,64 & 1,45 & 1,45 \\
\hline REST & 2,85 & 1,99 & 1,76 & 1,70 & 1,63 & 1,63 & 1,67 & 1,65 & 1,64 & 1,62 \\
\hline SOAP & 7,01 & 6,44 & 6,61 & 5,70 & 5,47 & 5,74 & 6,37 & 5,50 & 5,57 & 5,53 \\
\hline SOS & 17,43 & 15,56 & 16,24 & 14,71 & 15,99 & 17,12 & 17,91 & 20,13 & 24,33 & 25,23 \\
\hline
\end{tabular}

O gráfico da Figura 4.3 mostra que os métodos de acesso através de RMI e REST apresentam tempos de resposta semelhantes. Por outro lado, acessos via SOAP apresentam valores 3,5 vezes mais altos que os acessos realizados através de RMI ou REST. Já o acesso através do serviço SOS possui tempos de resposta até 4,5 vezes maiores em comparação ao acesso via SOAP. Esses resultados podem ser melhor observados através dos valores apresentados na Tabela 4.3 que apresenta 


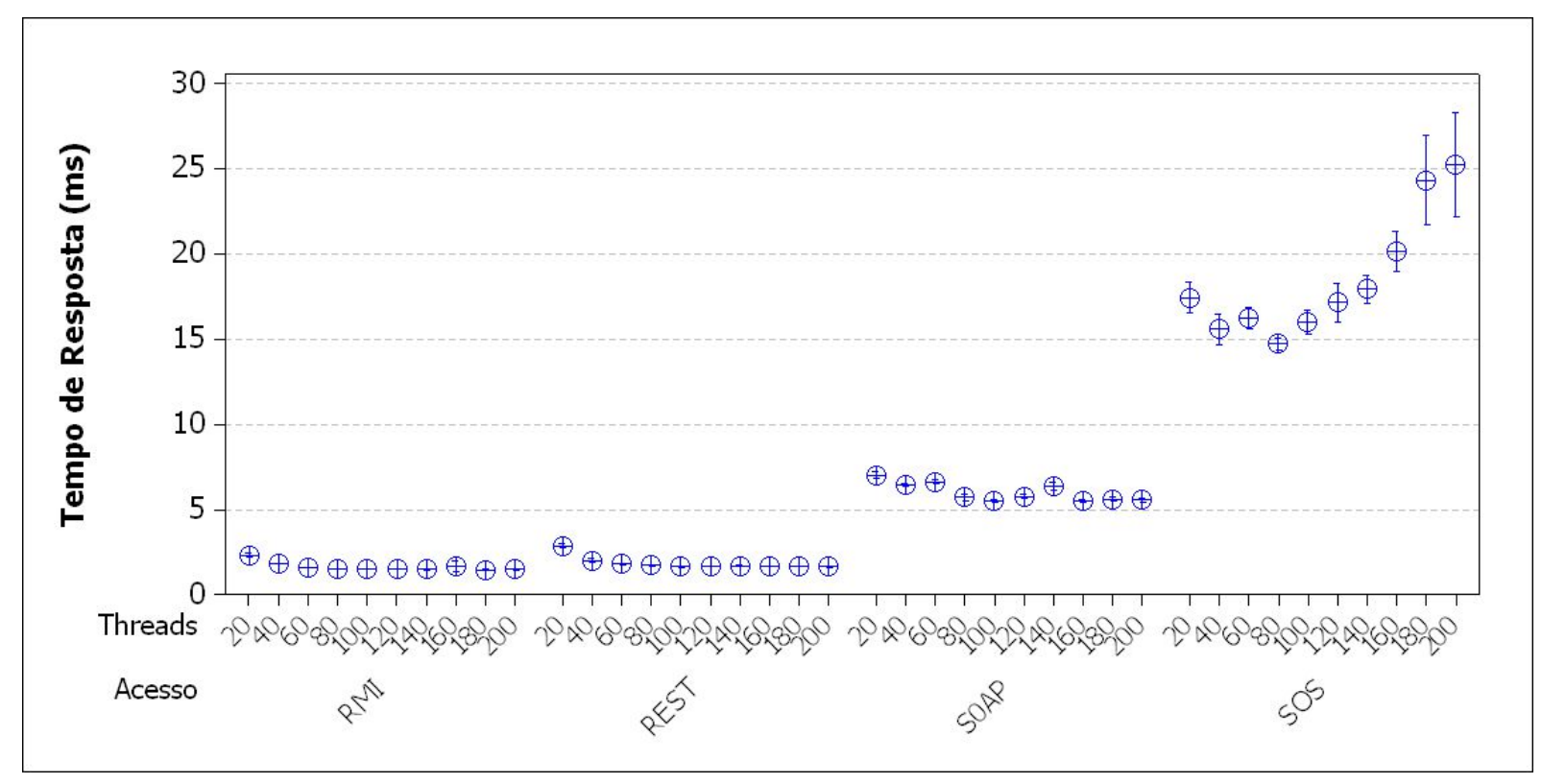

Figura 4.3: Métodos de acesso: Gráfico de Intervalos de Confiança (F1)

Tabela 4.4: Desvios Padrão dos Tempos de Resposta para o filtro F1

\begin{tabular}{c|c|c|c|c|c|c|c|c|c|c}
\hline & $\mathbf{2 0}$ & $\mathbf{4 0}$ & $\mathbf{6 0}$ & $\mathbf{8 0}$ & $\mathbf{1 0 0}$ & $\mathbf{1 2 0}$ & $\mathbf{1 4 0}$ & $\mathbf{1 6 0}$ & $\mathbf{1 8 0}$ & $\mathbf{2 0 0}$ \\
\hline RMI & 0,32 & 0,03 & 0,03 & 0,03 & 0,04 & 0,05 & 0,04 & 0,87 & 0,04 & 0,04 \\
\hline REST & 0,30 & 0,31 & 0,14 & 0,11 & 0,08 & 0,05 & 0,09 & 0,08 & 0,07 & 0,11 \\
\hline SOAP & 0,48 & 0,24 & 0,29 & 0,49 & 0,23 & 0,34 & 0,59 & 0,20 & 0,32 & 0,30 \\
\hline SOS & 2,38 & 2,40 & 1,69 & 0,90 & 1,89 & 2,95 & 2,23 & 3,07 & 7,03 & 8,12 \\
\hline
\end{tabular}

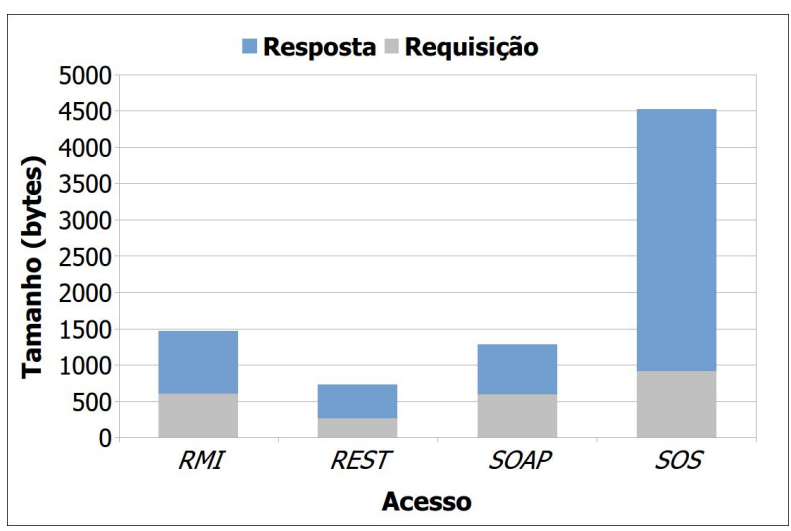

(a) Tamanhos das Mensagens

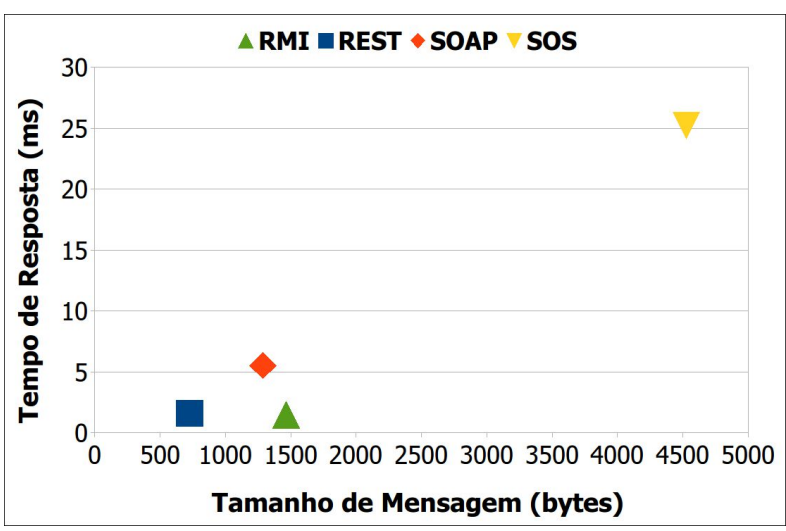

(b) Tempo de Resposta X Tamanho

Figura 4.4: Métodos de acesso: Gráficos de Tamanhos de Mensagens e Tempos de Resposta (F1)

as variações nos tempos de resposta para cada um dos métodos analisados em relação ao aumento no número de threads. Adicionalmente, a Tabela 4.4 mostra os valores dos desvios padrão dos tempos de resposta para os métodos analisados. Esses valores indicam a suscetibilidade e variação nos tempos de resposta de cada um dos métodos no aumento do número de threads. Em geral, os desvios padrão dos métodos de acesso não apresentam grandes variações nas modificações das quantidades de threads. Do mesmo modo, cada um dos métodos mantém constante os desvios pa- 
drão com o aumento no threads, exceto nos cenários de cargas com 180 e 200 threads do serviço SOS. Ou seja, a média geral dos desvios padrão do serviço SOS ficou em 3,26ms. Contudo, os desvios padrão para 180 e 200 threads ficaram em 7,02 e 8,10ms, respectivamente.

Uma análise dos tamanhos das mensagens de requisição e resposta de cada serviço analisado pode ser visto na Figura 4.4(a). Uma característica interessante do gráfico de tamanho das mensagens diz respeito aos tamanhos das mensagens RMI e REST. Embora o RMI seja um mecanismo binário, os tamanhos de suas mensagens de requisição e resposta são maiores que as mensagens dos métodos REST e SOAP que são protocolos textuais. De maneira complementar, o gráfico da Figura 4.4(b) expressa uma relação entre tempos de resposta e tamanhos de mensagens. Em geral, os tempos de resposta aumentam em relação aos aumentos das mensagens dos métodos de acesso, exceto para o método RMI. O RMI mantém baixos tempos de resposta mesmo com tamanhos de mensagens superiores às mensagens dos métodos REST e SOAP. Esses tempos são justificados devido ao custo computacional para a representação dos dados em formatos binários que são mais baixos que o encapsulamento e representação dos dados em formatos textuais como o XML. Em outras palavras, o custo do encapsulamento e processamento dos dados em formatos textuais superam os tempos de transmissão na rede, tendo como consequência tempos de resposta mais elevados. Outro ponto que deve ser destacado são as informações dos sensores que cada um dos mecanismos encapsulam em suas respostas. As informações retornadas por todos os mecanismos de acesso foram definidas em:

- Results: elemento que encapsula os valores das observações realizadas pelos sensores, assim como os horários de aferição das mesmas;

- ProcedureId: elemento que define um identificador para o tipo de sensor que realizou a observação;

- PhenomenonId: elemento que define um identificador do fenômeno observado;

- FeatureOfInterest: elemento que define o objeto do mundo real que está sendo observado.

Por sua vez, o serviço SOS ainda encapsula informações de posicionamento e unidade de medida da observação. Essas informações não foram fornecidas nos demais métodos pelo fato de que esse tipo de dado deve ser associado a uma ontologia de uniformização de dados. Por exemplo, o posicionamento pode ser dado através de diferentes padrões. Contudo, a diferença nos tamanhos das mensagens deve-se principalmente à forma como os dados são encapsulados. Isso pode ser observado mais claramente nos códigos da Seção B.1 do Apêndice B.

Por conseguinte, os resultados obtidos na execução dos experimentos que consideraram requisições que solicitam um dia de observação (F2) estão destacados no gráfico da Figura 4.5. Os gráficos apresentam resultados proporcionalmente semelhantes aos obtidos nos experimentos realizados com o filtro F1, uma vez que SOAP e SOS se mantiveram como métodos de acesso com 


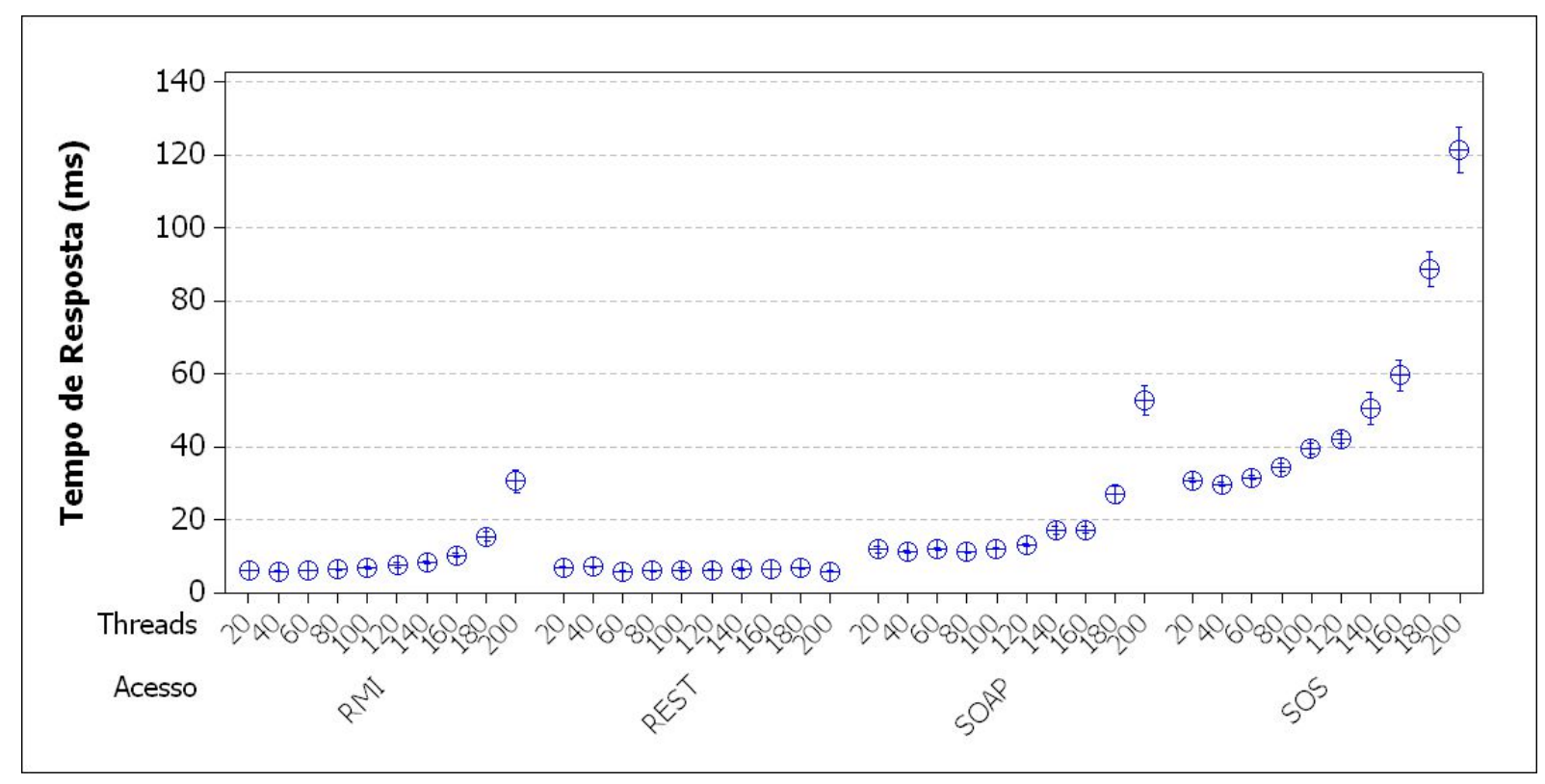

Figura 4.5: Métodos de acesso: Gráfico de Intervalos de Confiança (F2)

Tabela 4.5: Médias dos Tempos de Resposta para o filtro F2

\begin{tabular}{c|c|c|c|c|c|c|c|c|c|c}
\hline & $\mathbf{2 0}$ & $\mathbf{4 0}$ & $\mathbf{6 0}$ & $\mathbf{8 0}$ & $\mathbf{1 0 0}$ & $\mathbf{1 2 0}$ & $\mathbf{1 4 0}$ & $\mathbf{1 6 0}$ & $\mathbf{1 8 0}$ & $\mathbf{2 0 0}$ \\
\hline RMI & 6,17 & 6,00 & 6,17 & 6,45 & 6,88 & 7,67 & 8,40 & 10,34 & 15,53 & 30,72 \\
\hline REST & 7,11 & 7,19 & 5,97 & 6,10 & 6,39 & 6,29 & 6,62 & 6,59 & 6,93 & 6,02 \\
\hline SOAP & 11,98 & 11,34 & 12,07 & 11,33 & 12,22 & 13,17 & 17,17 & 17,33 & 26,95 & 52,78 \\
\hline SOS & 30,84 & 29,85 & 31,63 & 34,35 & 39,64 & 42,20 & 50,39 & 59,60 & 88,68 & 121,29 \\
\hline
\end{tabular}

Tabela 4.6: Desvios Padrão dos Tempos de Resposta para o filtro F2

\begin{tabular}{c|c|c|c|c|c|c|c|c|c|c}
\hline RMI & 0,28 & 0,15 & 0,18 & 0,18 & 0,71 & 1,74 & 0,73 & 1,49 & 3,78 & 8,42 \\
\hline REST & 0,37 & 0,62 & 0,56 & 0,35 & 1,21 & 0,38 & 0,57 & 0,44 & 0,41 & 0,35 \\
\hline SOAP & 2,42 & 0,60 & 0,62 & 0,49 & 0,72 & 0,84 & 2,69 & 2,52 & 5,97 & 10,50 \\
\hline SOS & 1,32 & 1,88 & 1,54 & 3,06 & 3,70 & 3,37 & 11,78 & 11,27 & 12,82 & 16,52 \\
\hline
\end{tabular}

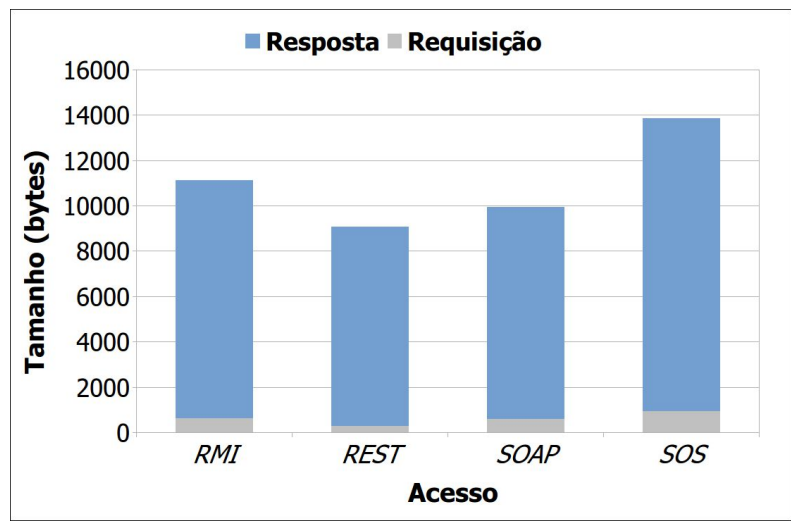

(a) Tamanhos das Mensagens

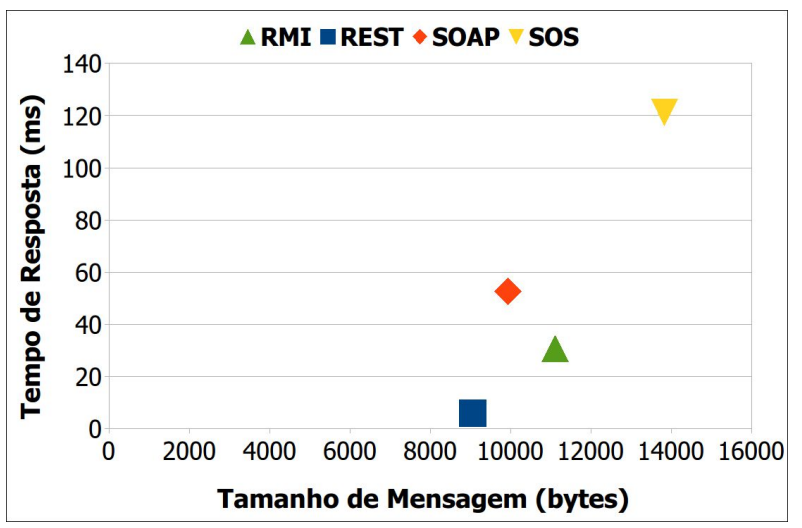

(b) Tempo de Resposta X Tamanho

Figura 4.6: Métodos de acesso: Gráficos de Tamanhos de Mensagens e Tempos de Resposta (F2) 
tempos de resposta mais elevados. Os métodos RMI e REST também tiveram aumentos significativos em referência a utilização do filtro F1. É importante destacar que, no casso do método RMI, esse aumento acentuou-se a partir dos experimentos com 140 threads, como pode ser observado na Tabela 4.5. Os resultados dos experimentos com cargas mais elevadas no método RMI apresentaram aumento substancial nos tempos de resposta. Nesse caso, a elevação acentuada dos tempos de resposta do RMI não pode ser atribuída apenas aos tamanhos das mensagens.

Como pode ser observados na Figura 4.6(a), as mensagens RMI são aproximadamente 30\% maiores que o método REST e $23 \%$ maiores que o método SOAP. O comportamento da relação entre tempo de resposta e tamanho das mensagens, mostrado na Figura 4.6(b), também se manteve proporcionalmente semelhantes ao filtro F1. Outro ponto como o processo de serialização de objetos do RMI pode ter influenciado os resultados. Problemas de desempenho na serialização de objetos são comuns na linguagem Java, como também pode ser observado no trabalho apresentado em (Park e Lee, 2001). No caso dos experimentos apresentados nesta seção, a implementação do serviço RMI definiu um objeto para armazenar as observações e metadados dos sensores. Esse objeto é composto por arrays que armazenam, dentre outras informações (armazenadas em Strings), os tempos e os resultados das observações. Assim, pode-se atribuir os valores mais elevados ao custo de serialização de objetos, que no caso dos experimentos do filtro F2, torna-se mais complexo devido a maior quantidade de objetos serializados. Além disso, é possível que o gerenciamento de threads que expõem os objetos remotos do RMI (implementado pela máquina virtual Java) também tenham influenciado os resultados dos experimentos.

Já a variação dos desvios padrão em relação ao aumento do número de threads para o filtro F2 é mostrado na Tabela 4.6. Nesse caso, é possível observar que apenas o método REST não apresenta variações significativas nos desvios padrão com a elevação da quantidade de threads. Já a maior acentuação no aumento dos desvios padrão é atribuída ao serviço SOS.

Outro tipo de análise é ilustrada nos gráficos das Figuras 4.7, 4.8 e 4.9. Nessa análise são investigadas as interações entre os métodos de acesso RMI, REST e SOAP com o SOS. Para a realização dessa análise foi necessária a configuração de um novo planejamento de experimentos seguindo um projeto fatorial de dois níveis. Dessa forma, foram considerados os extremos dos níveis do fator quantidade de thread (20 e 200). Os níveis de filtros foram mantidos (F1 e F2). Já os níveis do fator métodos de acesso foram tomados dois a dois, mantendo o nível SOS sempre constante. Avaliaram-se as interações entre o método SOS com os demais métodos de acesso. A implementação dessa análise foi realizada com o suporte de um software estatístico chamado de Minitab $^{3}$.

A análise dos métodos RMI e SOS está representada nos gráficos da Figura 4.7. O gráfico de interações (Figura 4.7(a)) mostra que há interações entre todos os fatores considerados na análise, dado que as retas não são paralelas. Por exemplo, é possível observar a ocorrência de interação entre os fatores acesso e filtro, pois ocorre uma modificação no comportamento dos níveis do fator

\footnotetext{
${ }^{3}$ http://www.minitab.com/
} 


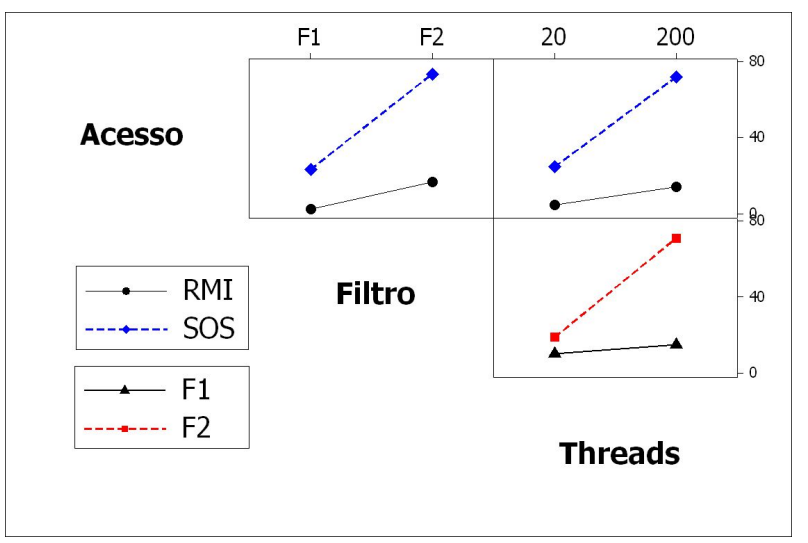

(a) Gráfico de Interações

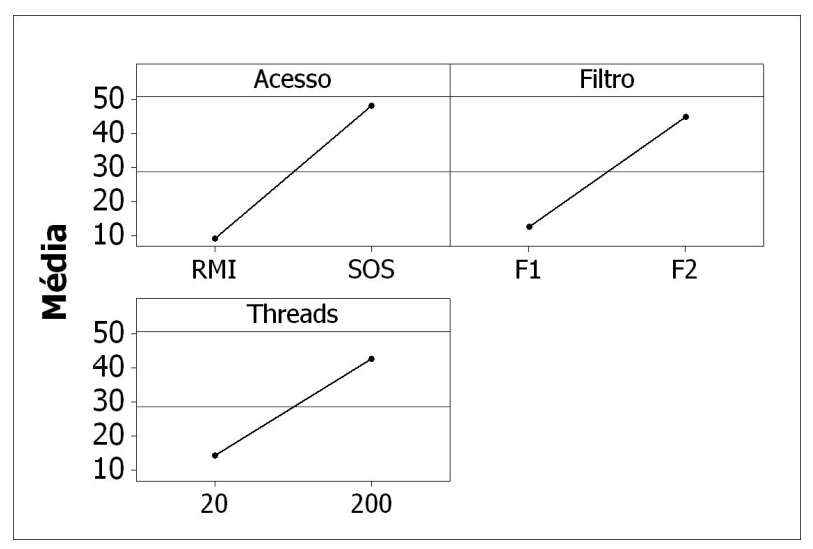

(b) Gráfico de Efeitos Principais

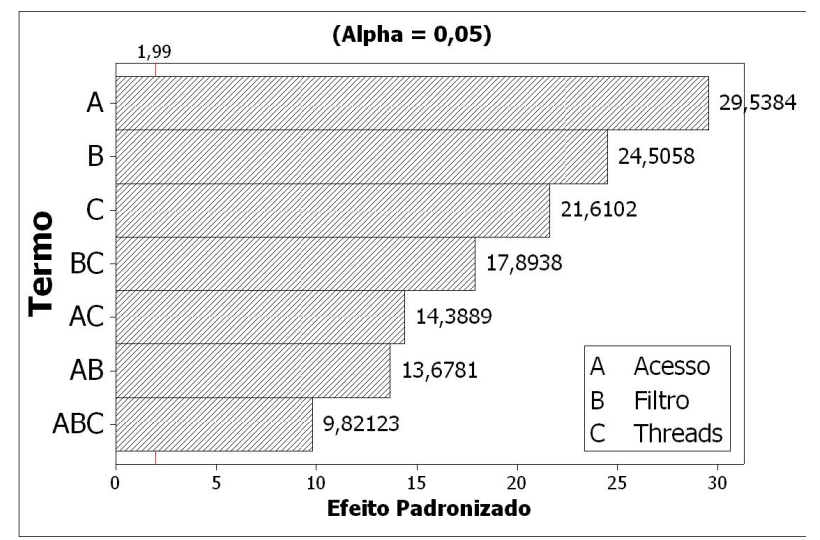

(c) Diagrama de Pareto

Figura 4.7: Métodos de acesso: Gráficos de Análise de Desempenho RMI x SOS

acesso quando ocorre a variação entre os filtros. Como pode ser observado, os comportamentos das retas são distintos, sendo a reta no nível SOS mais inclinada que o nível RMI. O mesmo se repete para as interações entre os fatores acesso e threads, e também, entre filtro e threads. O gráfico de efeitos principais, apresentado na Figura 4.7(b), determina a mudança ocorrida quando se move o nível baixo para o nível alto. À vista disso, pode-se observar que a maior mudança ocorre na variação do fator acesso. O diagrama de Pareto (Figura 4.7(c)) comprova essa diferença mostrando o fator acesso como o mais influente na execução dos experimentos. Todos os fatores que apresentam valores acima da linha vertical com valor de 1,99 , localizada na parte esquerda do diagrama, são significantes. Portanto, a análise dos métodos RMI e SOS, mostra que o fator acesso possui maior influência na execução dos testes seguido pelos fatores filtro e threads. Todas as interações entre fatores também se mostraram significantes.

A Figura 4.8 apresenta os gráficos da análise do projeto fatorial de dois níveis para os métodos de acesso REST e SOS. Assim como a análise realizada sobre os métodos RMI e SOS, o gráfico de interações (Figura 4.8(a)) mostra a ocorrência de interações entre todos os fatores. A Figura 4.8(b), apresenta o gráfico de efeitos principais que mostra uma maior inclinação da reta do fator acesso. Esse comportamento representa uma maior influência desse fator. As demais retas, embora inclinadas, estão mais atenuadas no que concerne à análise RMI e SOS. Essa constatação 


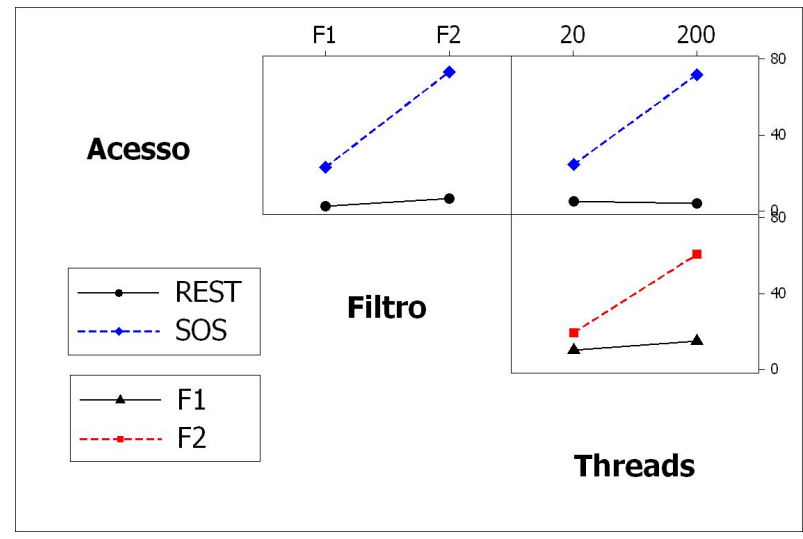

(a) Gráfico de Interações

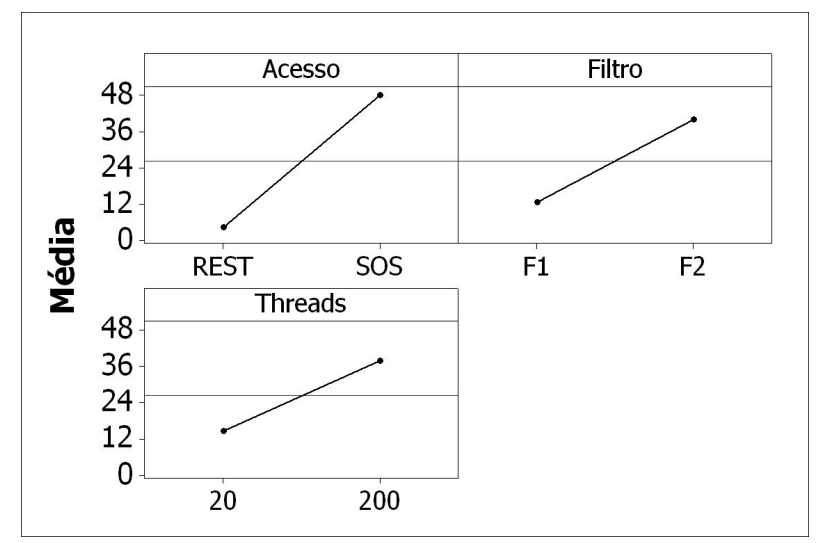

(b) Gráfico de Efeitos Principais

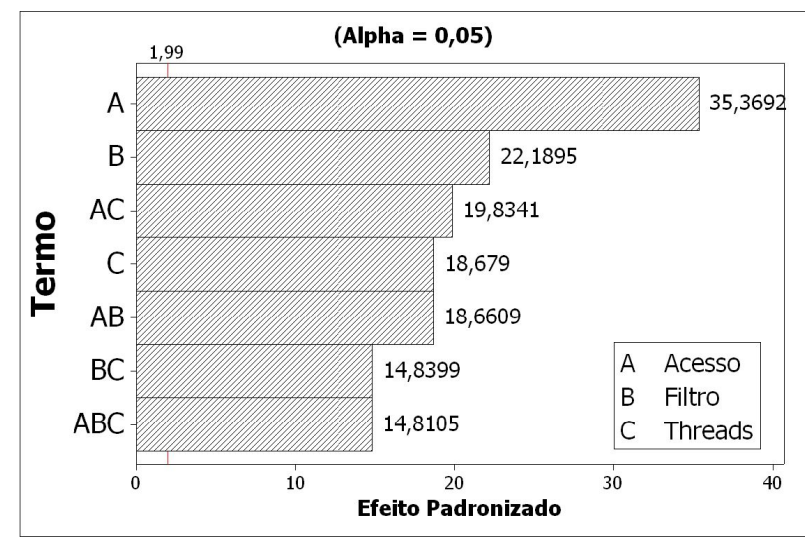

(c) Diagrama de Pareto

Figura 4.8: Métodos de acesso: Gráficos de Análise de Desempenho REST x SOS

é corroborada pelo diagrama de Pareto (Figura 4.8(c)) que mostra uma diminuição nas influências dos fatores filtro e threads, acentuando a significância do fator acesso. A maior influência do fator acesso é justificada pelo fato de que os tempos médios de resposta, quando variados os serviços SOS e REST, possuem diferenças mais significativas que as variações da quantidade de threads e dos tipos de filtros.

Por fim, a Figura 4.9 apresenta os gráficos da análise entre os métodos de acesso SOAP e SOS. Como pode ser observado no gráfico da Figura 4.9(a), as interações entre os fatores acesso e filtro e entre acesso e threads apresentaram diminuições consideráveis. Em contrapartida, a interação entre os fatores filtro e threads aumentou em comparação às outras análises. Considerando o gráfico de efeitos principais (Figura 4.9(b)) observa-se uma maior diferença na variação de níveis para o fator filtro. Diferentemente das outras análises, a maior influência de fatores ocorrida na análise entre os métodos SOAP e SOS é atribuída ao fator filtro, seguido pelos fatores threads e acesso. As influências dos fatores podem ser verificadas no diagrama de Pareto mostrado na Figura 4.9(c). 


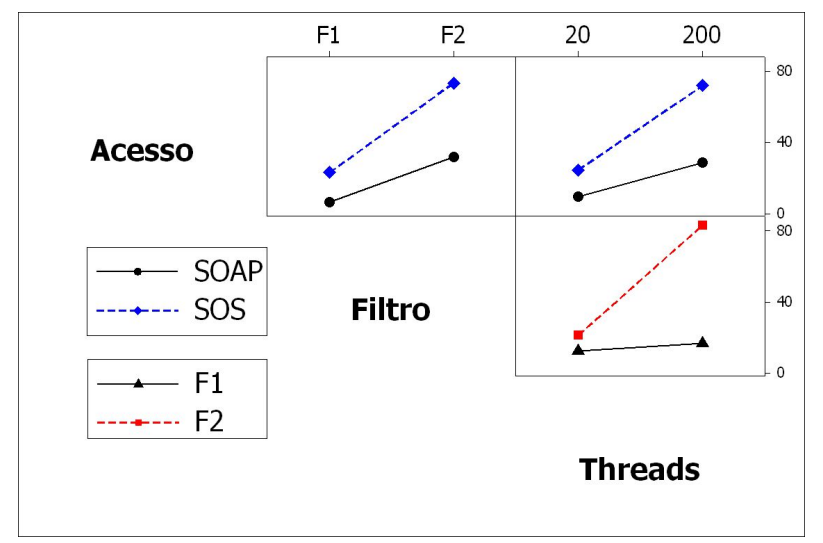

(a) Gráfico de Interações

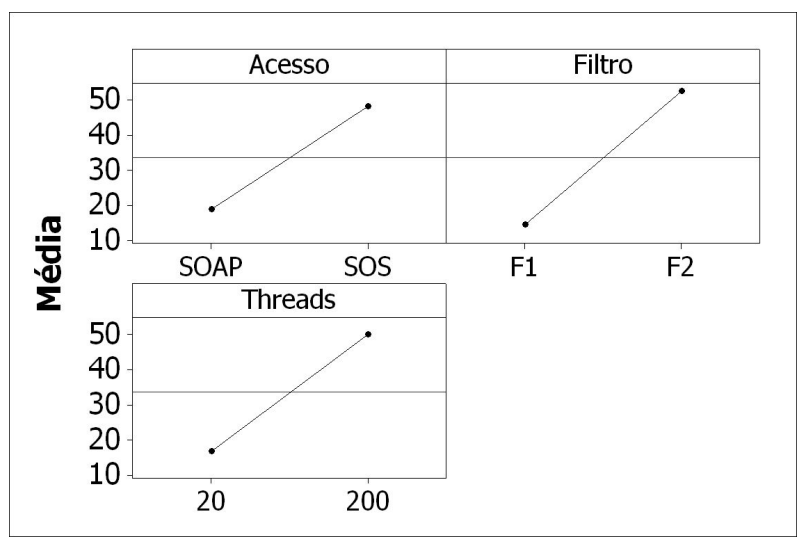

(b) Gráfico de Efeitos Principais

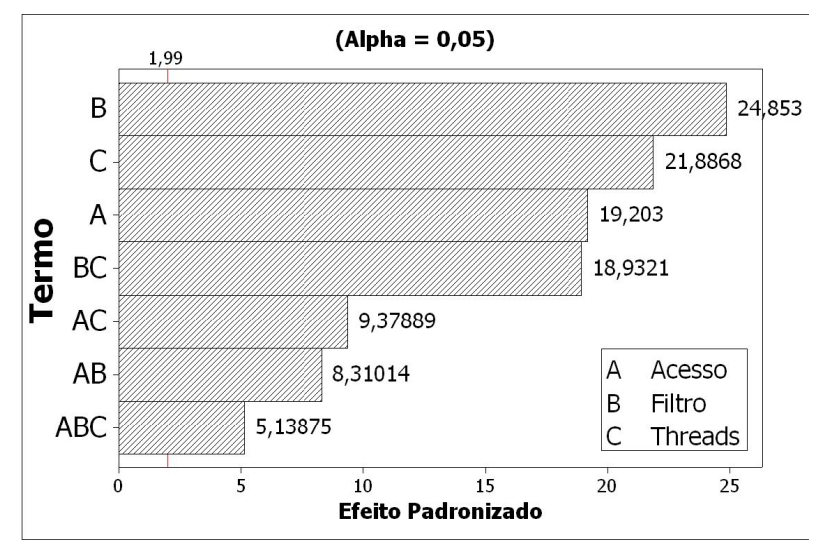

(c) Diagrama de Pareto

Figura 4.9: Métodos de acesso: Gráficos de Análise de Desempenho SOAP x SOS

\subsubsection{Análise da viabilidade de Utilização de SOA para Acesso a Re- des de Sensores}

A avaliação sobre a utilização de diferentes métodos de acesso a redes de sensores evidenciou as diferenças de desempenho entre esses mecanismos. Foram analisados três métodos textuais e um binário. O objetivo principal dessa avaliação visa verificar as diferenças de desempenho do serviço SOS frente a outros métodos de acesso tais como RMI, REST e SOAP. Os resultados obtidos possibilitaram uma constatação importante: métodos binários como o RMI podem apresentar, em determinados cenários, desempenho inferior a mecanismos textuais, como o caso do REST. As análises realizadas sobre as mensagens de cada um dos métodos demonstraram que o processo de serialização de objetos, utilizado pelo RMI, podem produzir mensagens de tamanhos superiores às mensagens dos métodos textuais.

No entanto, o tamanho da mensagem não é o único fator que influencia os tempos de respostas, uma vez que o RMI, comparado ao método SOAP, apresenta melhor desempenho. O resultado obtido na avaliação apresentada nesta seção, no que se refere ao RMI, corrobora com outros estudos que analisam problemas de desempenho na serialização de objetos no Java, e consequentemente do RMI (Kono e Masuda, 2000; Maeda, 2012). Por sua vez, o método REST apresentou excelentes 
tempos de resposta, indicando o seu uso como boa alternativa. Em contrapartida, as observações encapsuladas através desse mecanismo não oferecem os mesmos benefícios de padronização e interoperabilidade do serviço SOS. Outrossim, a inclusão do REST como mecanismo de acesso aos dados do serviço SOS pode ser considerada pelo OGC em novas versões desse serviço, uma vez que atual versão do serviço não considera tal método.

Ademais, os resultados apresentados indicaram degradação de desempenho na abstração de uma rede de sensores através de um serviço SOS com tempos de resposta mais elevados em relação aos demais métodos. É possível ainda realizar um média geral dos tempos de resposta e calcular a média das médias dos tempos de resposta de todas as quantidades de threads consideradas. Nesse caso, pode-se observar que a média geral dos serviços RMI e REST ficaram abaixo de $2 m s$ e abaixo de $6 m s$ para o serviço SOAP. Em contrapartida, o serviço SOS apresentou média de tempos de resposta de, aproximadamente, 18,5ms. Independentemente da quantidade de threads, todos os mecanismos avaliados apresentaram tempos de respostas próximos às médias, exceto o serviço SOS que apresentou valores acima de $20 \mathrm{~ms}$. No caso dos experimentos que consideraram requisições solicitando um dia de observação (F2 - 288 observações), a baixa variação nos tempos de resposta não se mantiveram constantes como ocorrido para o filtro F1, exceto para o método REST. As médias dos tempos de resposta ficaram em 10,43ms, 6,52ms, 18,64ms e 52,85ms para os serviços RMI, REST, SOAP e SOS, respectivamente. Uma informação importante nas análises dos serviços tomados em pares (Figuras 4.7, 4.8 e 4.9) diz respeito ao fator mais influente nas experimentações. O fator acesso foi o mais influente nas análises entre RMI e SOS, assim como na análise REST e SOS. No entanto, esse fator também apresentou uma influência significativa na análise entre SOAP e SOS. Ou seja, a escolha do método de acesso pode interferir no desempenho das aplicações que utilizam os dados de redes de sensores, principalmente na utilização do serviço SOS.

Porém, é necessário considerar os benefícios providos pelo framework SWE quanto a interoperabilidade e padronização que facilitam o desenvolvimento de aplicações que utilizam dados observados por redes de sensores. É possível ainda observar que o intervalo de confiança para os tempos de resposta médio do serviço SOS não ultrapassa o valor de $140 \mathrm{~ms}$, considerando os resultados para o pior caso (filtro F2 e 200 threads). Essas médias são inferiores às frequências de obtenção de observações da maioria das redes de sensores, como apresentado no gráfico de taxa de amostragem exibido na Figura 2.6 da Seção 2.1.3. Esse gráfico mostra uma análise da taxa de amostragem de 21 implementações reais de redes de sensores. Dessas 21 implementações, nove (42\%) não apresentam taxas acima de uma observação por segundo. Além disso, deve-se considerar que nem todas aplicações que utilizam dados de redes de sensores necessitam de informações na mesma frequência da geração de dados pela rede. Por exemplo, a rede de sensores para o sensoriamento de prédios antigos para detecção de avarias estruturais, apresentado em (Ceriotti et al., 2009), possui uma taxa de amostragem de $200 \mathrm{~Hz}$ (são enviados basicamente dados de temperatura e acelerômetros). No entanto, o tempo do envio de relatórios desses dados é feito seis vezes por hora. Ou seja, uma submissão de dados é realizada a cada dez minutos. Assim, os tempos aferidos 
nas experimentações realizadas nesta seção indicam uma tolerância de uma parte significativa das redes de sensores em relação a questões de desempenho. A utilização de mecanismos como o SOS, embora seja inferior em termos de desempenho, é tolerada por uma parcela considerável das redes de sensores encontradas na literatura. Deve-se levar em conta ainda todos os benefícios em relação aos padrões do SWE no que diz respeito a interoperabilidade de tecnologia, a uniformização e homogeneização de dados e metadados, padronização na descrição de algoritmos de processamento e mecanismos de descoberta de serviços, que facilitam o desenvolvimento de aplicações que utilizam redes de sensores.

Contudo, é necessário avaliar de forma mais profunda os serviços e linguagens do framework SWE. O objetivo dessa análise é verificar de uma maneira mais detalhada não apenas o serviço SOS, mas também serviços como o SES e SIR. Essa avaliação visa um melhor entendimento desses serviços para que seja possível a proposição de uma arquitetura de provisão de qualidade de serviço dentro do contexto dos padrões SWE. Mesmo que uma parte das aplicações que utilizam dados de redes de sensores tolerem os problemas de desempenho de serviços SWE como SOS, uma outra parte delas pode exigir certos critérios de qualidade de serviço. Desse modo, a Seção 4.3 apresenta uma avaliação de desempenho incluindo outros tipos de serviços e fatores que podem impactar em diferenças de desempenho no contexto do SWE. Essa análise é utilizada como base para a criação de uma arquitetura de provisão de qualidade de serviço que é mostrada e discutida no Capítulo 5.

\subsection{Avaliação dos Serviços SWE}

Estudos que analisam desempenho no contexto dos serviços SWE podem ser encontrados em (McFerren et al., 2009; Tamayo et al., 2011, 2012; Poorazizi et al., 2012). Todavia, trabalhos que exploram diferentes tipos de serviços, alterações nos filtros utilizados no acesso a esses serviços, variações nas quantidades de clientes e requisições não foram encontrados, sinalizando uma lacuna na literatura.

Esta seção tem o objetivo de apresentar alguns trabalhos relacionados a avaliações qualitativas e quantitativas no contexto dos padrões SWE. O trabalho apresentado em (McFerren et al., 2009) discute as implementações do Sensor Observation Service, destacando características como facilidade de instalação, qualidade da documentação, completude de implementação em relação às definições dos padrões, dentre outras características. Os autores consideram quatro tipos de implementações: $52^{\circ}$ North Initiative, PySOS, MapServer e DeegreeSOS. Os autores não consideram nenhuma análise quantitativa como, por exemplo, uma avaliação de desempenho das implementações no que diz respeito às funcionalidades disponibilizadas.

Em (Poorazizi et al., 2012) é apresentado um estudo complementar ao trabalho realizado em (McFerren et al., 2009). Nesse estudo, são discutidos os desempenhos de várias implementações dos serviços SOS. Os autores fazem uma análise do SOS considerando diferentes tipos de aquisição de dados como quantidade de sensores, localização, tempo e etc. O estudo considera três das 
quatro implementações analisadas em (McFerren et al., 2009) (52 North, Deegree e MapServer). A análise de desempenho realizada levou em consideração duas características: tempo de resposta e tamanho dos documentos retornados pelos serviços. Adicionalmente, em (Tamayo et al., 2012) é apresentada uma avaliação de desempenho dos padrões SWE em um ambiente de computação móvel. Nesse estudo, os autores avaliaram o desempenho de smartphones no processamento de documentos com observações de sensores obtidas através do SOS. Além do processamento, os autores também consideraram o tamanho desses documentos e transmissão dos mesmos através de diferentes tipos de redes como Wi-Fi e 3G. Os autores consideraram ainda diferentes APIs de processamento XML para a plataforma Android.

Por fim, em (Tamayo et al., 2011) é apresentado um estudo empírico das atuais instancias de provedores SOS. Os autores realizaram um trabalho investigativo levantando dezenas de serviços SOS disponibilizados na Web. Esses serviços foram submetidos a diversos testes para verificar, por exemplo, quais partes da especificação são mais frequentes nas implementações do serviço SOS. Eles ainda constataram que muitos dos provedores implementados possuem problemas de validação com os documentos de observações retornados por esses servidores. Muitos dos documentos retornados por esses servidores não puderam ser validados com o XML Schema que os definem.

Diversos estudos na literatura analisam o serviço SOS. No entanto, diversos outros serviços do modelo de interfaces do SWE não são considerados. Por exemplo, o SES é um serviço importante dentro do modelo de interfaces e que não vem sendo tratado na literatura em estudos de avaliação de desempenho. Serviços de alerta são importantes ferramentas para o desenvolvimento de aplicações de sistemas críticos onde atrasos na entrega de alertas podem inviabilizar a eficiência dessas aplicações. Por conseguinte, o serviço de registro (SIR) fornecido pelo SWE também não é considerado nos estudos de avaliação de desempenho encontrados. O SIR figura como importante serviço de descoberta de sistemas de sensores mesmo não sendo ainda um padrão do SWE. Atualmente, o SIR é tratado como um "discussion paper". Contudo, já se encontram disponíveis implementações desse serviço, como a disponibilizada no site da $52^{\circ}$ North Initiative ${ }^{4}$.

\subsubsection{Planejamento de Experimentos}

O planejamento de experimentos para a avaliação de desempenho dos serviços SOS, SES e SIR tem o objetivo de verificar as diferenças de desempenho na utilização de diferentes tipos de filtros. A avaliação proposta considera um projeto de experimentos fatorial completo com 3 fatores e 2 níveis: Quantidade de Threads, Taxa de Submissão e Tipos de Filtros $\left(2^{3}\right.$, totalizando 8 experimentos). Em relação à métrica utilizada para a realização dos experimentos, determinou-se o tempo de resposta como parâmetro de avaliação, assim como ocorrido na avaliação dos métodos de acesso. Esse planejamento é aplicado para cada um dos serviços avaliados e está definido na Tabela 4.7 .

\footnotetext{
${ }^{4}$ Sensor Instance Registry Implementation: http://52north.org/downloads/sensor-web/sir
} 
Tabela 4.7: Fatores da Avaliação de Desempenho dos Serviços SWE

\begin{tabular}{c|c|c|c}
\hline Serviços & threads & Taxa de Submissão & Tipos de Filtros \\
\hline SOS & $50 / 100$ & $120 / 240$ & 1 Obs (F1)/288 Obs (F2) \\
\hline SES & $50 / 100$ & $120 / 240$ & Level1/Level2 \\
\hline SIR & $50 / 100$ & $120 / 240$ & Phenomenon/ID \\
\hline \multicolumn{3}{|c}{ Métrica de Avaliação } \\
\hline \multicolumn{3}{c}{ Tempo de Resposta } \\
\hline
\end{tabular}

Os fatores quantidade de threads e taxa de submissão possuem os mesmos níveis para todos os serviços avaliados. Assim como na avaliação de desempenho dos métodos de acesso, a variação na quantidade de threads simula a variação da quantidade de clientes acessando os serviços. Por sua vez, o fator taxa de submissão simula a quantidade de requisições submetidas aos serviços seguindo uma função exponencial com médias de 120 e 240 requisições por minuto. No caso das experimentações sobre os serviços SWE, cada thread realiza dez requisições ao serviço utilizando as duas médias consideradas (120 e 240). Por sua vez, o fator tipos de filtros possui diferentes níveis, respeitando a especificidade de cada serviço. No caso do serviço SOS, são realizados experimentos que utilizam as mesmas variações de filtros utilizadas na avaliação dos métodos de acesso apresentada na Seção 4.2, no que concerne a quantidade de dados retornados nas requisições. Foram consideradas requisições que retornam somente uma observação e requisições que retornam 288 observações. É importante destacar ainda que o serviço SOS configurado contém o mesmo banco de dados utilizado na avaliação dos métodos de acesso.

No caso do serviço SES são utilizados dois dos três tipos de níveis possíveis para esse tipo de serviço. Na avaliação do serviço SES são utilizados os níveis denominados Level 1 e Level 2, definindo diferentes critérios de disparo de notificações. Como mencionado, na Seção 3.3.2, o Level 1 considera uma expressão XPath que verifica o valor do elemento om:procedure, enquanto que o Level 2 leva em conta critérios como localização do sensor, valor da observação e etc. No caso dos experimentos executados nesta avaliação de desempenho é considerado um critério de disparo por localização. Ou seja, haverá o disparo de um alerta quando o SES receber dados de sensores que estão localizados em uma determinada área. Exemplos de mensagens de subscription dos níveis 1 e 2 do serviço SES podem ser encontradas nos Códigos B.9 e B.10 do Apêndice B.

A avaliação do serviço SES se diferencia das demais avaliações, pois trata-se de um serviço assíncrono. Na prática, sensores enviam notificações ao serviço SES que se encarrega por encaminhá-las aos consumidores cadastrados. Dessa forma, o gerador de carga implementado para os testes do serviço SES é o componente responsável por simular a geração das notificações. Um exemplo de mensagem de notificação é apresentada no Código B.11 do Apêndice B. Avaliar os tempos de entrega das mensagens de notificação é uma tarefa complexa, uma vez que é necessário ter uma sincronização de relógio que permita identificar os horários de envio e recebimento dessas mensagens. Essa medição foi possível pelo fato de que o gerador de carga envia e recebe a notificação na mesma máquina (host). O gerador envia a notificação para o serviço SES, simulando 
a ação de um sensor. Essa notificação é recebida pelo serviço SES que encaminha novamente a notificação ao gerador de carga.

Por fim, os experimentos realizados sobre o SIR consideram dois tipos de critérios de busca: pelo nome de um fenômeno observado e pelo identificador (Id) do sensor no serviço de registro. É importante destacar que cada sistema de sensor cadastrado no SIR recebe um número que o identifica univocamente. A configuração do SIR para esta avaliação possui 12 sistemas de sensores cadastrados que oferecem a mesma informação de sensoriamento. Assim, os experimentos que utilizam um filtro pelo nome do fenômeno retornam 12 descrições de sensores (SensorML). Por outro lado, a utilização do Id no filtro de busca retorna apenas uma descrição. A Seção 4.3.2 apresenta o ambiente de testes implementado para a execução dos experimentos.

\subsubsection{Ambiente de Testes}

A infraestrutura de hardware utilizada para a execução da avaliação de desempenho dos serviços SWE possui a mesma configuração empregada na avaliação dos métodos de acesso. Assim, a Tabela 4.2 também descreve o ajuste das máquinas virtuais para a avaliação apresentada nesta seção. A Figura 4.10 apresenta o modelo arquitetural utilizado na condução dos experimentos que avaliaram os serviços SWE. As implementações dos componentes de software também foram realizadas através de ferramentas e APIs fornecidas pela $52^{\circ}$ North (52North, 2014a).

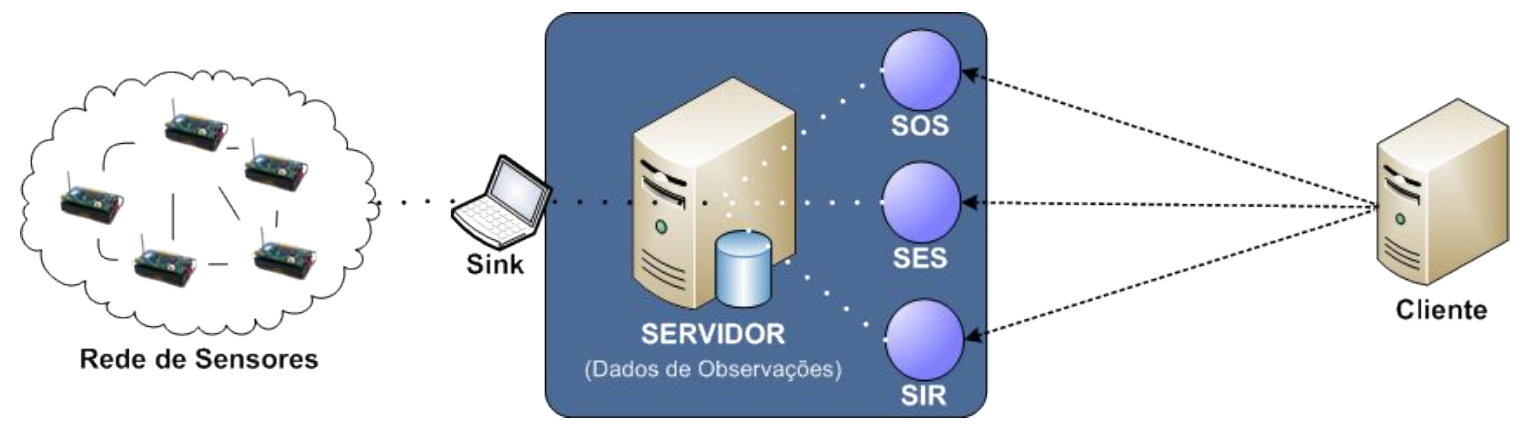

Figura 4.10: SWE: Arquitetura do Ambiente de Testes

\subsubsection{Execução dos Experimentos}

A execução dos testes seguiu um modelo fatorial completo de dois níveis $\left(2_{\text {threads }} * 2_{\text {TaxaSub }} *\right.$ $2_{\text {Filtros }}$ ). Esse modelo foi aplicado para cada um dos serviços considerados (SOS, SES e SIR). Dessa forma, 8 tipos de experimentos foram executados para cada um dos serviços, com um total de 24 experimentos. Tal qual para os experimentos dos métodos de acesso, cada um desses 24 testes foram replicados 30 vezes. O script em Perl utilizado para automatizar o processo de avaliação dos serviços SWE possui os seguintes parâmetros de entrada:

\section{- Parâmetros de controle dos experimentos:}


- Serviço: define o serviço a ser avaliado (SOS, SES ou SIR);

- Número de threads: define a quantidade de threads executadas nos experimentos;

- Número de Requisições: define a quantidade de requisições enviadas por cada thread;

- Replicações: define a quantidade de replicações dos testes para a obtenção de uma validade estatística;

- Endereço do Serviço: define o endereço (URL) onde está localizados os servidores dos métodos de acesso;

- Caminho do Arquivo de Resultados: define o local no sistema de arquivos onde serão armazenado os resultados dos testes;

\section{- Parâmetros de definição de consulta aos sensores:}

- Nome do Sensor: define o nome do sensor pelo qual deseja-se receber observações;

- filtro: define o tipo de filtro que será utilizado no experimento. O tipo do filtro depende do tipo de serviço testado.

Uma vez executados os experimentos, coletaram-se os dados dessas experimentações possibilitando que a fase de análise dos resultados definida fosse cumprida. Assim, uma análise individual de cada um dos serviços SWE considerados é apresentada nas Seções 4.3.4, 4.3.5 e 4.3.6 para os serviços SOS, SES e SIR, respectivamente.

\subsubsection{Análise dos Resultados para o serviço SOS}

Diferentemente dos experimentos do serviço SOS mostrados na Seção 4.2, a avaliação apresentada nesta seção utiliza um fator distinto que considera a taxa de submissão de requisições por cada uma das threads. A análise dos resultados dos experimentos sobre o serviço SOS é apoiada por um conjunto de gráficos. O gráfico da Figura 4.11 apresenta que o maior aumento nos tempos de resposta ocorre na mudança do filtro que retorna apenas uma observação para um filtro que retorna 288 observações (um dia de observação). Aumentos significativos nos tempos de resposta, considerando o aumento de clientes, ocorrem para o filtro de um dia. Os tempos de resposta são próximos na variação no número de threads para os experimentos com requisições que retornam apenas uma observação, ou seja, não ocorrem aumentos significativos nos tempos de resposta para o filtro F1 no aumento do número de threads de 50 para 100.

Uma análise sobre os tamanhos das mensagens no que concerne aos filtros utilizados nos experimentos sobre o serviço SOS é apresentada na Figura 5.1. O gráfico da Figura 4.12(a) mostra que as mensagens em resposta que solicitam um dia de observações (F2) são aproximadamente 3,5 vezes maiores que as repostas que solicitam apenas uma observação. Por conseguinte, o gráfico da Figura 4.12(b) mostra uma relação entre os tamanhos das mensagens de resposta para os filtros considerados no serviço SOS com os tempos de resposta médios. Os tempos de reposta médios 
considerados levam em conta os experimentos com 100 threads e taxa de 240 requisições por minuto. Nesse caso, as mensagens que consideraram o filtro de um dia de observação apresentaram tempos de reposta 3,8 vezes mais altos que as mensagens que retornaram apenas uma observação.

Já a interação entre os fatores pode ser observada na Figura 4.13(a). Pode-se concluir que todos os fatores interagem entre si, dadas as retas não paralelas do gráfico de interações. Contudo, é possível observar uma maior interação entre os fatores filtro e taxa de submissão. O gráfico de efeitos principais, demonstrado na Figura 4.13(b), define o fator tipo de filtro com a maior variação nos tempos de resposta, no que concerne a alteração dos seus níveis. Assim, a reta do fator filtro expressa inclinação mais acentuada, definindo esse fator com o maior variação nos tempos de resposta. Por fim, o gráfico de Pareto, apresentado na Figura 4.13(c), confirma a análise apresentada nos gráficos de interações e efeitos principais mostrando que todos os fatores influenciaram os tempos dos experimentos. Em resumo, o filtro corresponde ao fator de maior influência seguido pela taxa de submissão e quantidade de threads. Embora o tipo de filtro utilizado tenha maior impacto nos tempos de resposta é necessário atenção à quantidade de threads e a taxa de submissão de requisições, principalmente para filtros que retornam muitas observações.

\subsubsection{Análise dos Resultados para o serviço SES}

Os resultados obtidos para o SES estão apresentados nos gráficos das Figuras 4.14, 4.15 e 4.16. No gráfico da Figura 4.14 é possível observar que a grande diferença nos tempos de resposta se dá na variação da quantidade de threads. Adicionalmente, os níveis de filtros também exercem influência significativa nos tempos de resposta, principalmente para os experimentos com a taxa média de 240 requisições por minuto e para os experimentos com 100 clientes. Nesses casos, os

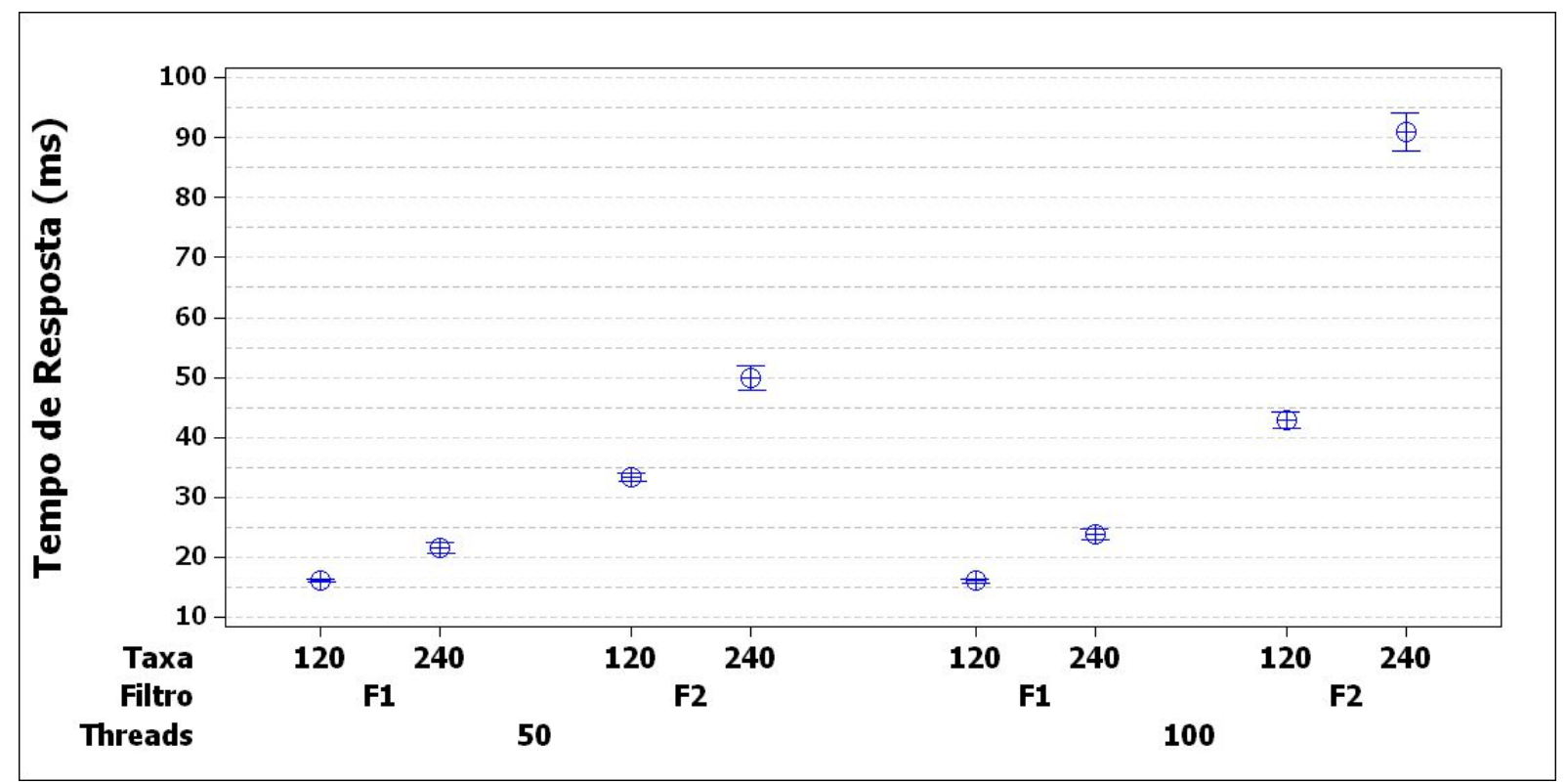

Figura 4.11: Métodos de acesso: Gráfico de Intervalos de Confiança (SOS) 


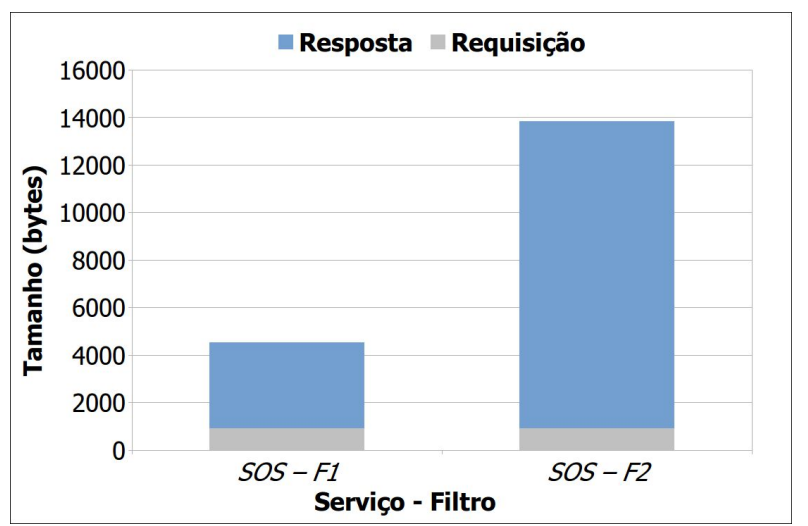

(a) Tamanhos das Mensagens

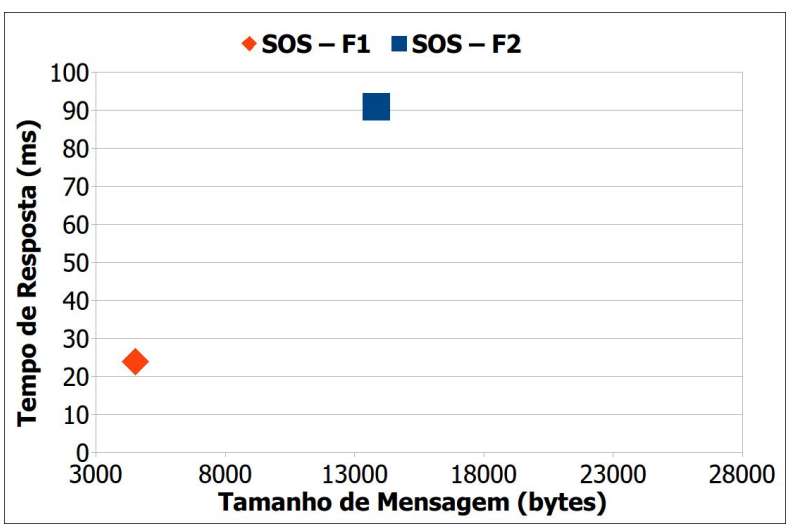

(b) Tempo de Resposta X Tamanho

Figura 4.12: SWE: Gráficos de Tamanhos de Mensagens e Tempos de Resposta (SOS)

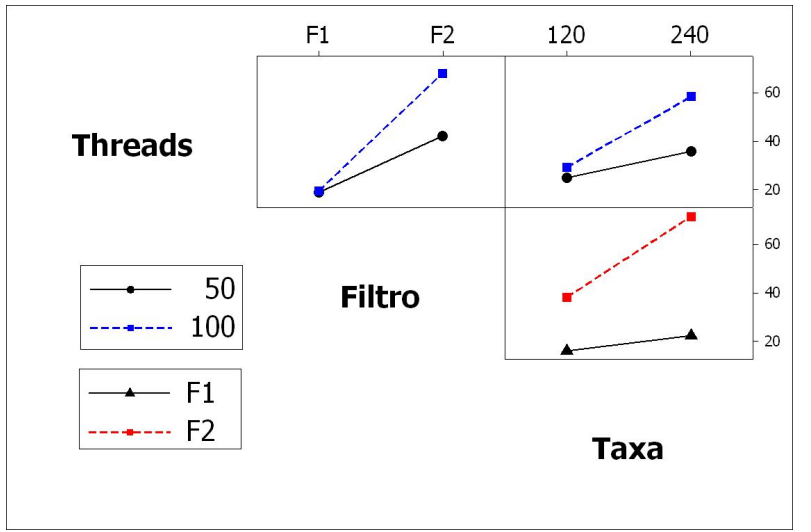

(a) Gráfico de Interações

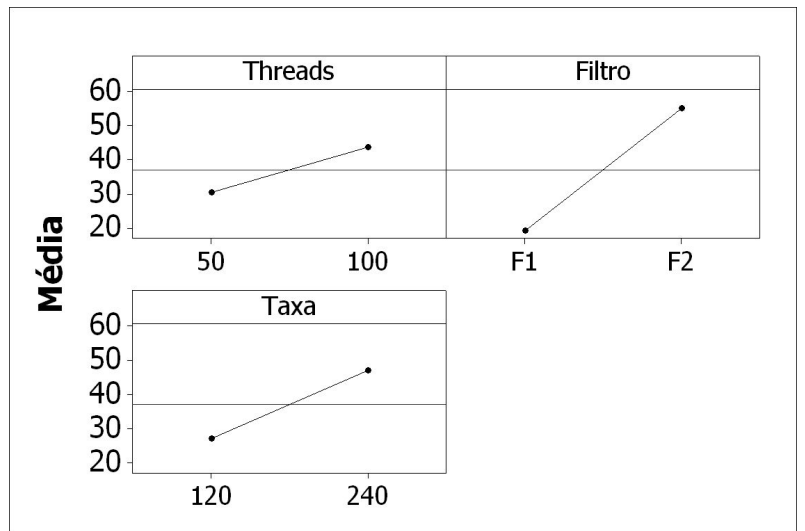

(b) Gráfico de Efeitos Principais

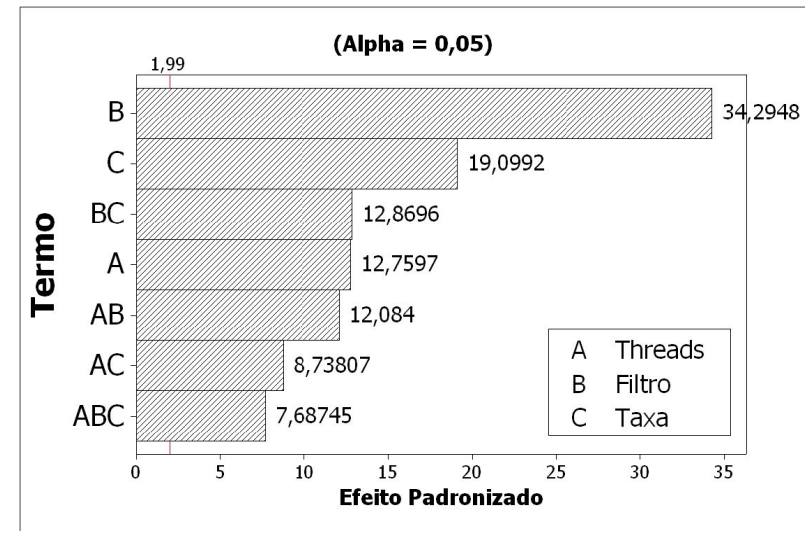

(c) Diagrama de Pareto

Figura 4.13: SWE: Gráficos de Análise de Desempenho (SOS)

experimentos que consideram o Level 2 possuem tempos de resposta consideravelmente superiores em relação aos tempos obtidos para o Level 1.

A análise dos tamanhos das mensagens dos diferentes filtros utilizados no serviço SES é apresentada na Figura 4.15. O gráfico da Figura 4.15(a) mostra que praticamente não há diferenças de tamanho de notificações geradas por ambos os níveis. Esse comportamento era esperado uma 


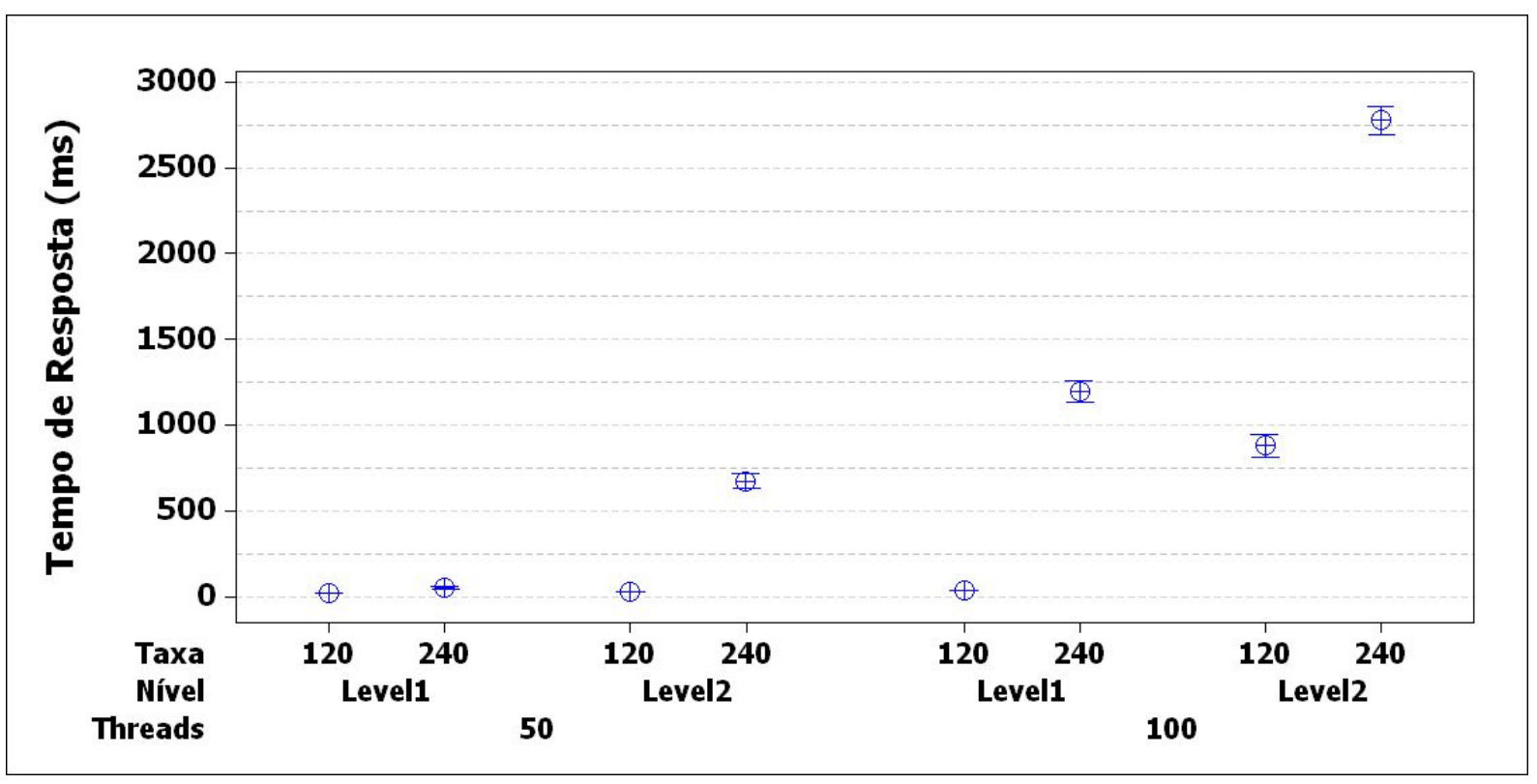

Figura 4.14: Métodos de acesso: Gráfico de Intervalos de Confiança (SES)

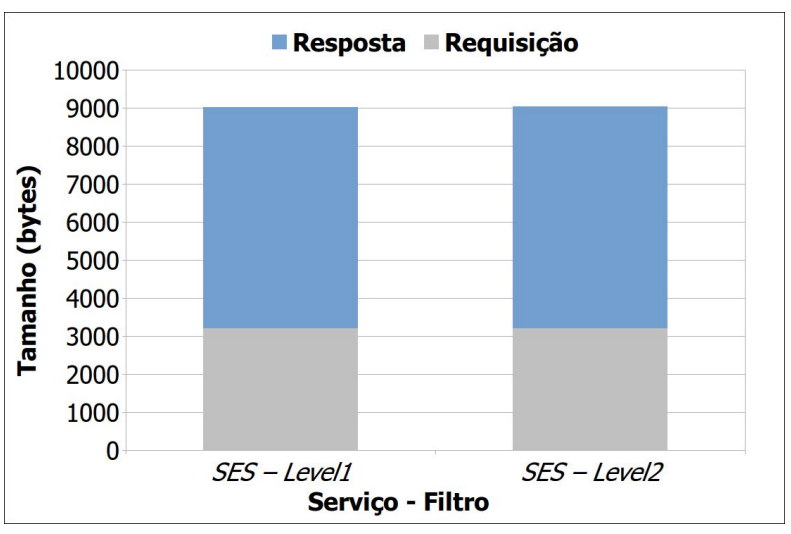

(a) Tamanhos das Mensagens

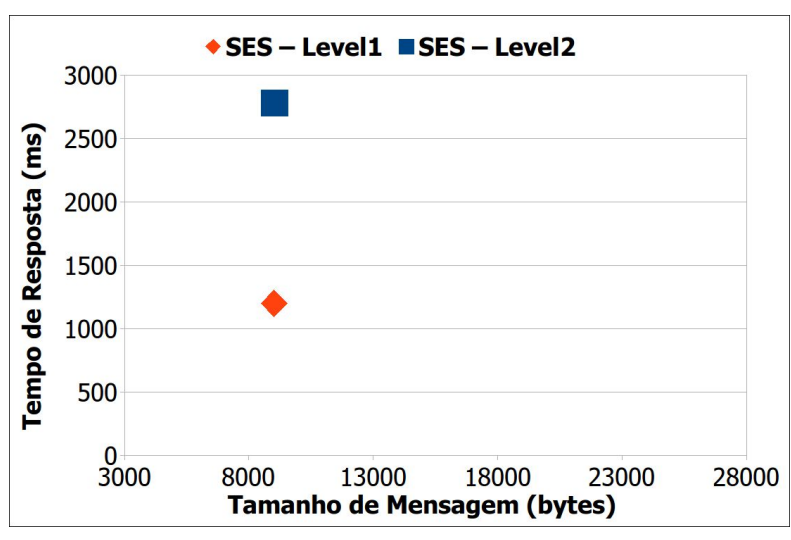

(b) Tempo de Resposta X Tamanho

Figura 4.15: SWE: Gráficos de Tamanhos de Mensagens e Tempos de Resposta (SES)

vez que o envio das notificações enviadas pelos sensores são iguais. O que muda é o elemento XML utilizado pelo serviço SES no disparo da notificação. No caso do Level 1, é utilizada uma expressão Xpath, enquanto que no Level 2 é utilizado um elemento de posicionamento. No caso do serviço SES, a relação entre os tamanhos das mensagens e os tempos de resposta, apresentada na Figura 4.15(b), mostra que não há uma associação direta entre esses parâmetros. Os tamanhos das mensagens não influenciam os tempos de resposta. O filtro que utiliza o Level 2 apresenta tempos de resposta 2,3 vezes superiores ao filtro Level 1, mesmo com tamanhos de mensagens semelhantes. Isso se deve ao fato de que no filtro Level 2, o serviço SES realiza um cálculo de localização para verificar se a notificação recebida foi enviada por um sensor que se encontra na área de localização definida no cadastro do filtro (subscription) .

O gráfico de interações, mostrado na Figura 4.16(a), revela que a maior interação ocorre para os fatores threads e taxa de submissão. Por conseguinte, a Figura 4.16(b) exibe o gráfico de efeitos 


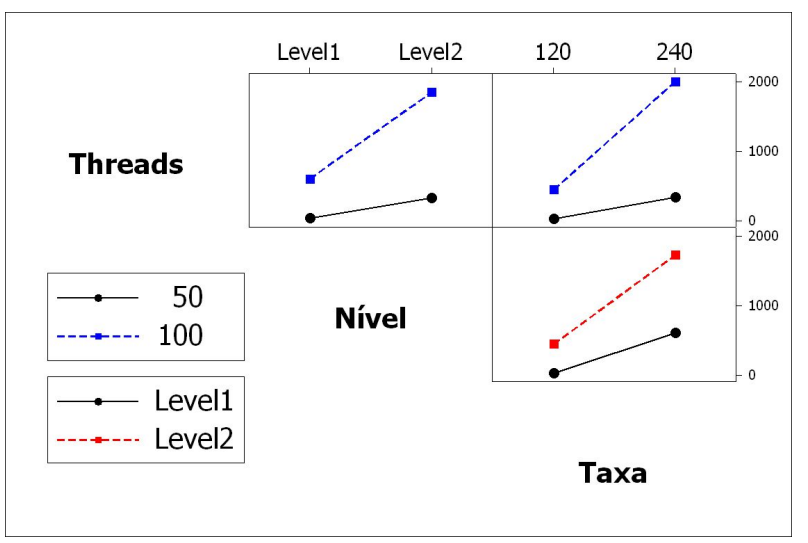

(a) Gráfico de Interações

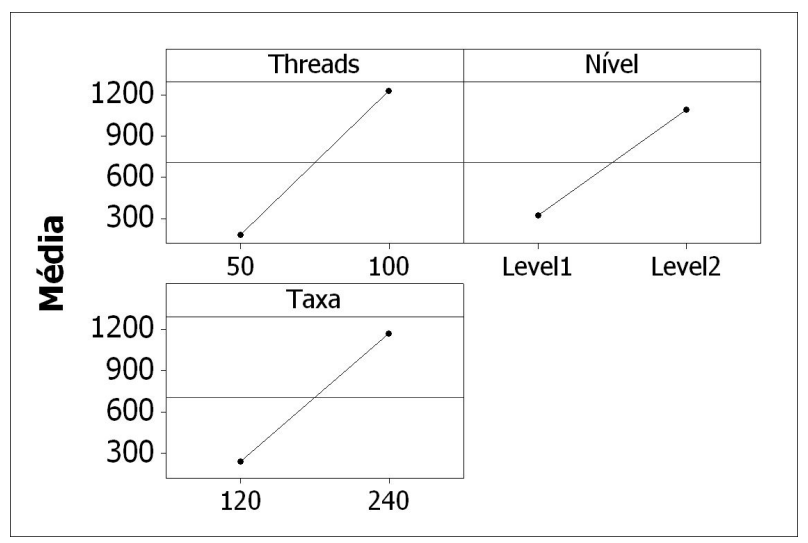

(b) Gráfico de Efeitos Principais

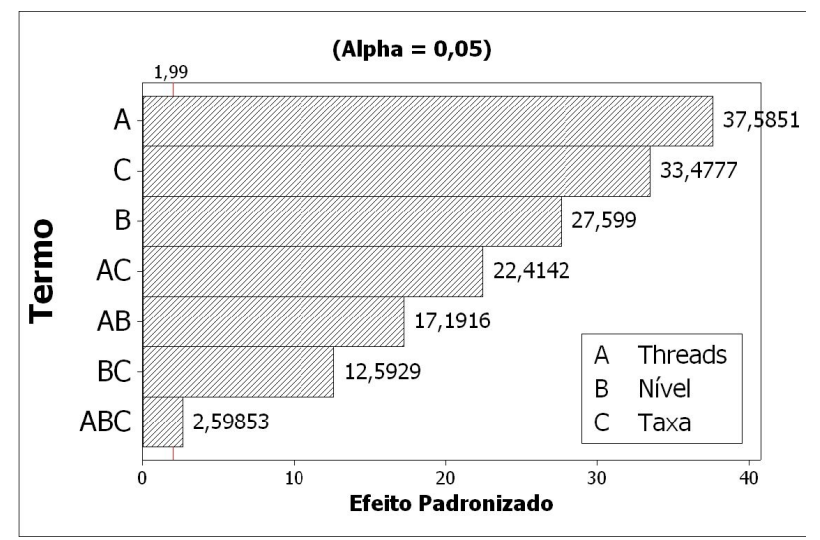

(c) Diagrama de Pareto

Figura 4.16: SWE: Gráficos de Análise de Desempenho (SES)

principais onde pode ser observado o fator threads com maior variação nos tempos de resposta, considerando a variação dos níveis de filtros utilizados. Já o gráfico de Pareto, apresentado na Figura 4.16(c), mostra que a quantidade de clientes é o fator de maior destaque nos experimentos, seguido dos fatores nível de filtros e taxa de requisições. É possível ainda verificar que a interação entre os fatores também representam influências significativas. Uma das principais constatações obtidas nas execuções dos experimentos é com relação à influência dos níveis de filtros utilizados no serviço SES. Aplicações que utilizam o SES podem utilizar os resultados obtidos nos experimentos desse serviço para balizar a utilização dos tipos de filtros do SES. Por exemplo, determinadas aplicações que utilizam dados de redes de sensores e que reagem às mensagens de alertas podem optar, caso seja possível, por filtros computacionalmente mais leves, como é o caso do Level 1. Como demonstrado nos experimentos, a definição adequada dos filtros pode melhorar o desempenho no processo de emissão de alertas. 


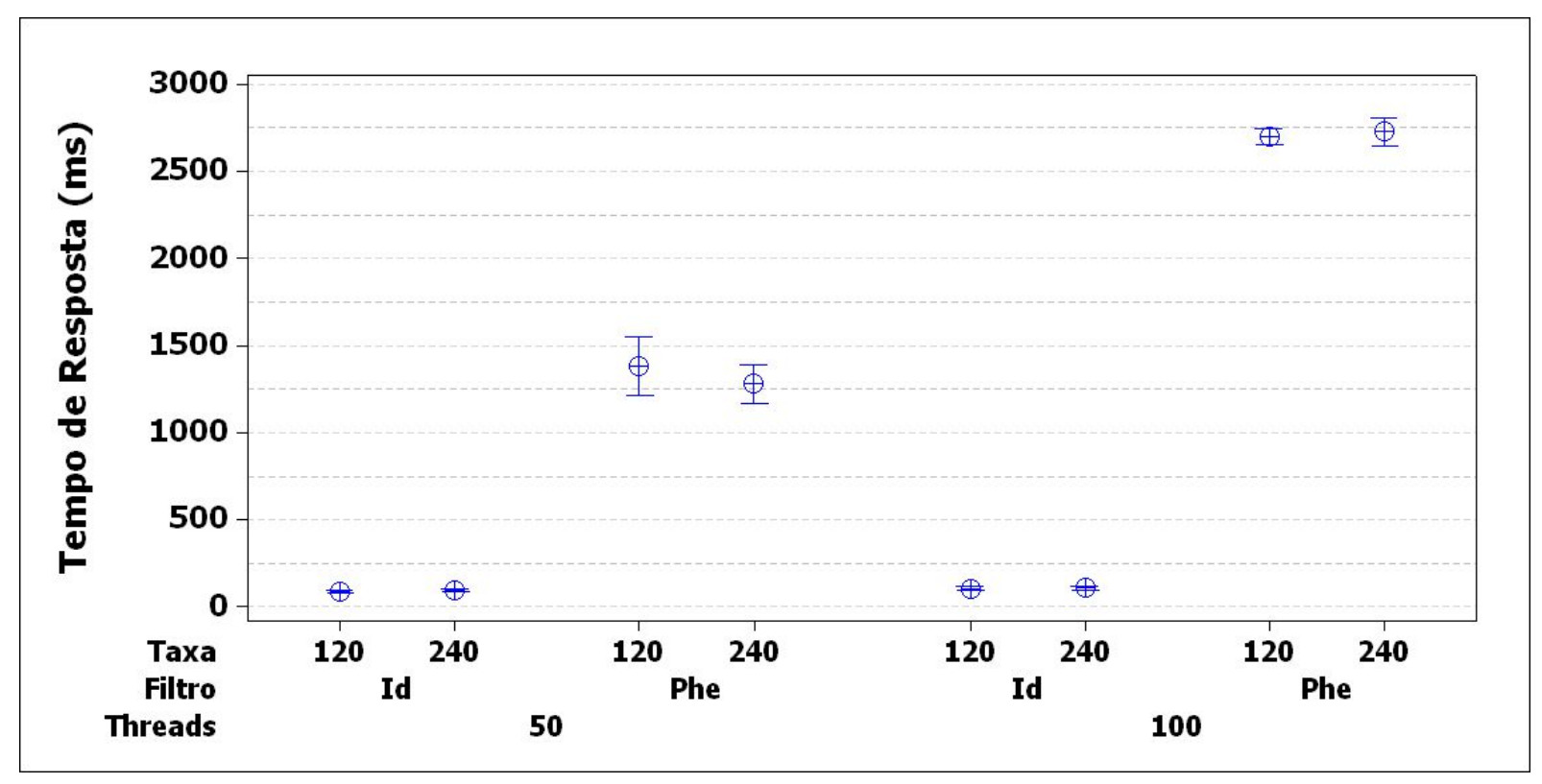

Figura 4.17: Métodos de acesso: Gráfico de Intervalos de Confiança (SIR)

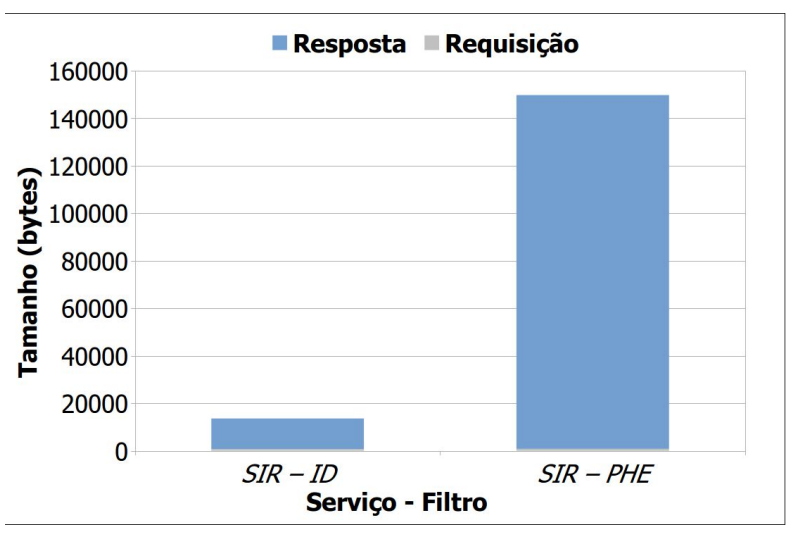

(a) Tamanhos das Mensagens

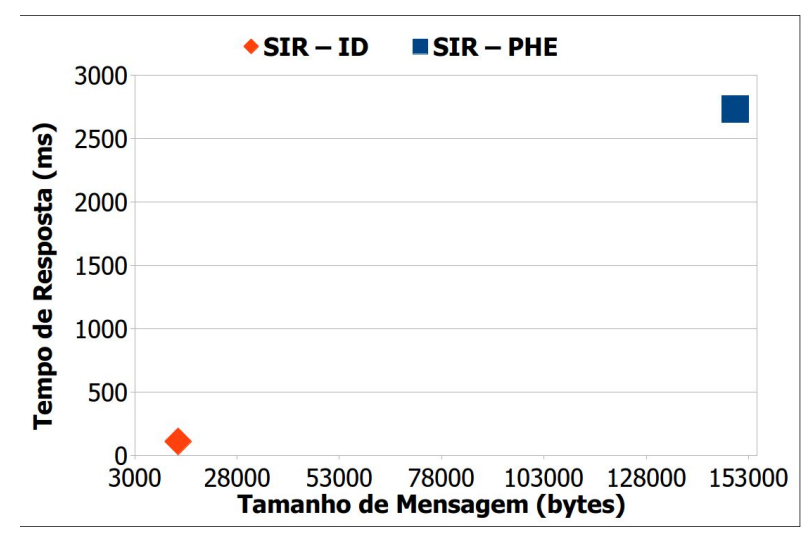

(b) Tempo de Resposta X Tamanho

Figura 4.18: SWE: Gráficos de Tamanhos de Mensagens e Tempos de Resposta (SIR)

\subsubsection{Análise dos Resultados para o serviço SIR}

Por fim, os resultados dos experimentos relacionados ao serviço SIR estão demonstrados nas Figuras 4.17, 4.18 e 4.19. O gráfico da Figura 4.17 mostra que os tempos de resposta possuem diferenças significativas para o fator filtro.

A Figura 4.18 mostra uma análise para os tamanhos das mensagens dos experimentos do serviço SIR. No gráfico da Figura 4.18(a), é possível observar que mensagem de resposta a uma busca por fenômeno (Phenomenon) é aproximadamente duas vezes maior que uma busca por Id. Não obstante, a Figura 4.18(b) mostra que os tempos de resposta das requisições que submetem buscas por fenômeno podem ser até 25 vezes piores em relação às buscas por Id. Esses resultados configuraram a maior diferença de desempenho encontrada nas avaliações dos serviços SWE. Pode-se concluir que não apenas os tamanhos das mensagens influenciam os tempos de resposta, 


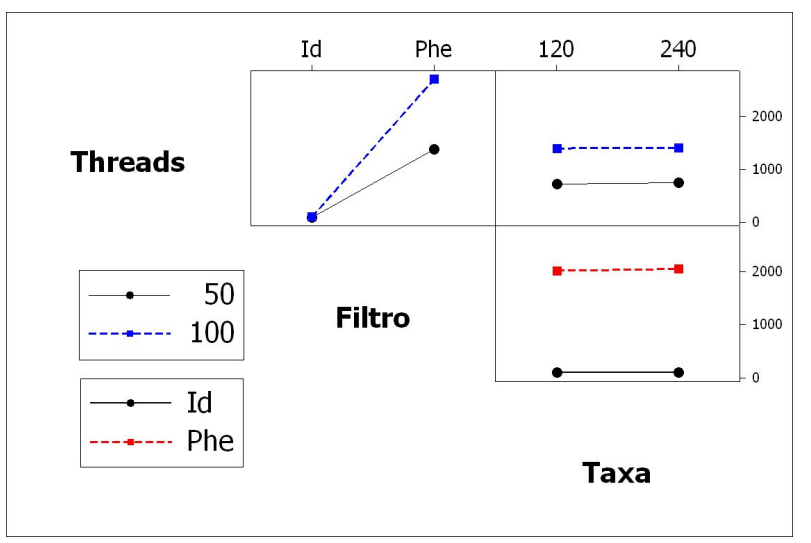

(a) Gráfico de Interações

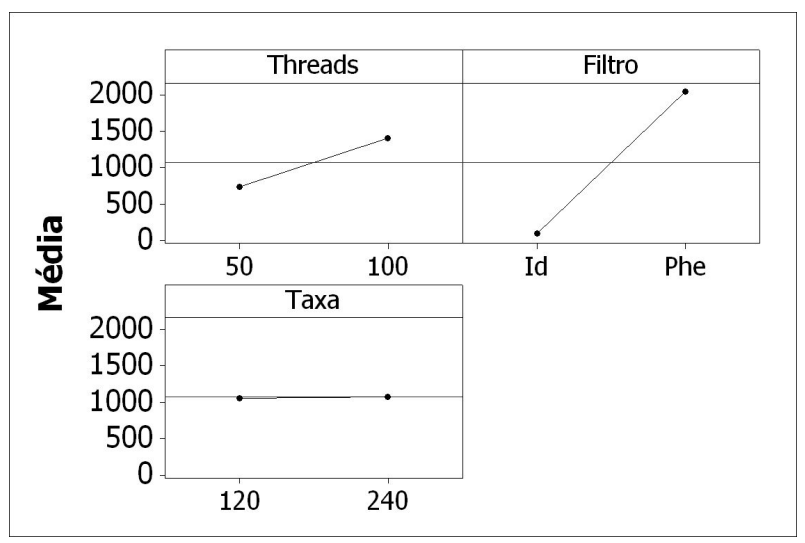

(b) Gráfico de Efeitos Principais

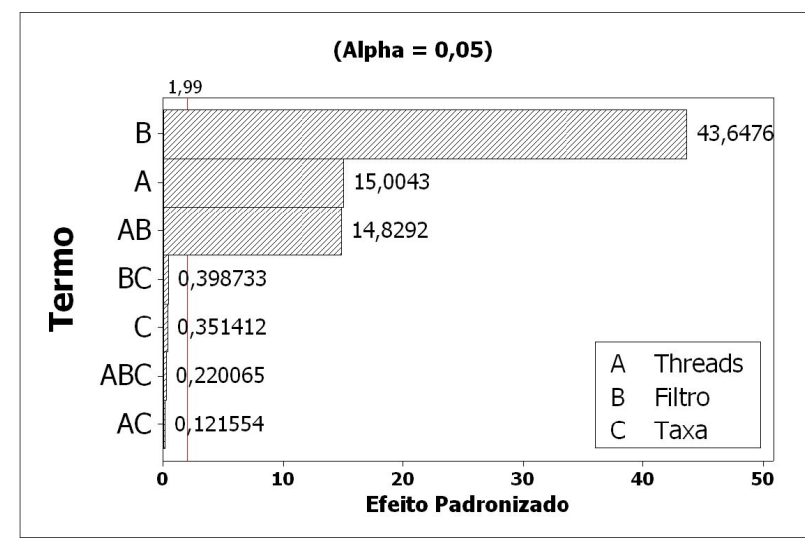

(c) Diagrama de Pareto

Figura 4.19: SWE: Gráficos de Análise de Desempenho (SIR)

mas também o custo de acesso a banco de dados realizado pelo serviço SIR na provisão dos dados dos sistemas de sensores. Essa conclusão pôde ser feita através da análise dos tamanhos das mensagens em relação ao aumento dos tempos de resposta. Ou seja, os tempos de resposta não aumentaram na mesma proporção que os tamanhos das mensagens.

A interação entre os fatores pode ser observada no gráfico da Figura 4.19(a). Diferentemente dos outros serviços, o SIR possui apenas interação entre os fatores threads e filtro. Além disso, observa-se, na Figura 4.19(b), que o fator taxa de submissão não apresenta diferenças significativas. A busca por informações de sensores utilizando seu Id no serviço é consideravelmente mais eficiente, uma vez que há apenas uma única descrição de sensor. Esse comportamento faz com que o fator mais influente nos experimentos seja o tipo de filtro, como pode ser observado na Figura 4.19(c).

Contudo, é impossível conhecer o Id do sensor sem realizar uma busca mais genérica, como por exemplo, nome do fenômeno observado. Nesse sentido, caso a aplicação necessite checar, frequentemente, possíveis atualizações na descrição do sensor utiliza-se primeiramente uma busca, por exemplo, pelo fenômeno observado e as buscas subsequentes pelo Id obtido na primeira interação. Outro mecanismo que pode ser utilizado para otimizar as buscas de sistemas de sensores no SIR é inserção de um Broker que faz um cache das mensagens de busca enviadas ao SIR. 
Nesse caso, o Broker pode relacionar as mensagens de busca com Ids de sensores retornados pelo SIR. Assim, o Broker pode utilizar os identificadores através das mensagens de busca armazenadas no cache. Por exemplo, um cliente faz uma busca por sensores que medem a velocidade do vento e submete essa busca ao Broker. O Broker recebe essa mensagem de busca e encaminha ao SIR. A resposta do SIR é armazenada em um tupla com a mensagem de busca e o Id do sensor (search_msg, sensor_id) no cache Broker. Assim, quando outros clientes submeterem a mesma mensagem de busca, pode-se substituir essa mensagem por uma mensagem de busca pelo Id do sensor, reduzindo o tempo de acesso ao serviço de registro.

\subsubsection{Análise Geral dos Serviços SWE}

A avaliação de desempenho desenvolvida sobre o modelo de interfaces do SWE destacou, especialmente, os serviços SOS, SES e SIR. A avaliação considerou a quantidade de clientes, tipo de filtros e taxas de submissão de requisições como fatores de influência nos tempos de resposta no acesso aos serviços destacados. Os resultados obtidos demostraram uma influência importante dos tipos de filtros nos tempos de respostas dos serviços. As análises realizadas indicaram que os desenvolvedores de aplicações que utilizam esses serviços devem examinar cuidadosamente a definição dos filtros, uma vez que os mesmos podem impactar significativamente no desempenho dessas aplicações. Esse comportamento é evidenciado principalmente para os serviços SES e SIR que apresentam grandes diferenças de desempenho na variação dos filtros. Além disso, quantidade de cliente e taxa de submissão de requisições também provocaram grandes variações de desempenho. Diferentemente do serviço SOS, que apresentou médias de tempos de resposta inferiores a $100 \mathrm{~ms}$, os serviços SES e SIR obtiveram tempos de resposta superiores a 2,5s para determinados tipos de cargas e filtros. Tais resultados podem parecer altos quando comparados aos valores obtidos para o serviço SOS. Entretanto, não foram encontrados na literatura trabalhos que caracterizem limites de desempenho no contexto desses serviços. Logo, os desenvolvedores de aplicações que necessitem obter informações desses serviços devem considerar os resultados apresentados nesta seção avaliando se os problemas de desempenho demonstrados podem ou não inviabilizar a utilização dos mesmos.

Além disso, métodos como os serviços SES e SIR também podem ser implementados através de mecanismos binários ou outros tipos de mecanismos que implementam serviços nos moldes das arquiteturas orientadas a serviço como o caso do REST. Contudo, tais tipos de serviços são ainda mais dependentes de tecnologias de homogeneização e ontologias. Por exemplo, a definição de critérios de disparo devem seguir regras definidas por padrões e linguagens de descrição. Nesse tipo de serviço não se aplica apenas a utilização de formatos XML na codificação dos dados. Um desenvolvedor de uma aplicação de alertas não deseja somente receber notificações, mas também definir critérios de disparo que atendam às exigências da sua aplicação. Dessa forma, o mecanismo que oferece esse tipo de serviço deve fornecer condições para que esses critérios sejam definidos. Isso deve ser feito através da especificação de linguagens e ontologias que flexibilizem esse tipo 
de funcionalidade. Caso contrário, a utilização do serviço de alerta pode ficar comprometida. O mesmo acontece para serviços de registro como o SIR. A falta de padronização pode comprometer a leitura e processamento de informações de descrição de sensores, caso esses requisitos não sejam fornecidos por outros tipos de mecanismos.

Os resultados apresentados nas avaliações de desempenho dos serviços SWE considerados neste capítulo fornecem indicativos de desempenho que podem auxiliar no desenvolvimento de aplicações sobre o arcabouço de especificações e linguagens desse paradigma. Esses resultados proporcionam melhor entendimento do funcionamento dos serviços SWE no que diz respeito à identificação dos pontos que sofrem maior suscetibilidade em relação a desempenho. Toda essa avaliação possibilitou que uma proposta de provisão de qualidade de serviço fosse elaborada, visando responder a questão número quatro que foi definida na Seção 1.3.

\subsection{Considerações Finais}

Este capítulo investigou e quantificou os problemas de desempenho da utilização de arquiteturas orientadas a serviço no contexto das redes de sensores quanto à avaliação de desempenho de diferentes tipos de implementações de serviços Web, assim como comparou tais implementações com um mecanismo binário. Os experimentos executados demonstraram uma notória diferença nos desempenhos, destacando o modelo REST como o mecanismo de maior eficiência. Além disso, foi possível verificar uma diminuição de desempenho dos serviços SOS frente aos demais mecanismos. Contudo, essa degradação pode não comprometer a utilização desse serviço à medida que a grande parte das aplicações de redes de sensores não demandam alto desempenho, tomando como referência a frequência de aferição de observações.

No que concerne aos resultados das avaliações efetuadas apenas sobre os serviços SWE, pôdese examinar as diferenças de desempenho entre os serviços, e também, mensurar distinções nos tempos de resposta na utilização de diferentes tipos de filtros e cargas de trabalho. Em suma, o emprego dos serviços SWE compromete o desempenho do acesso a dados observados por redes de sensores. Todavia, esses problemas de desempenho não inviabilizam sua utilização, posto que a tolerância em relação a desempenho depende do tipo de aplicação. Dessa forma, os resultados das avaliações de desempenho tratados neste capítulo contribuem no sentido de apresentar indicadores de desempenho que norteiam a utilização desse tipo de abordagem. Além disso, aplicações que exigem maior desempenho e impõem restrições em relação à qualidade de serviço podem se amparar em uma proposta de arquitetura de provisão de qualidade de serviço (da sigla em inglês QoS, Quality of Service), apresentada no Capítulo 5. 

ados os problemas de desempenho dos serviços SWE encontrados através das avaliações apresentadas no Capítulo 4, este capítulo tem o objetivo de propor uma arquitetura de provisão de qualidade serviço que visa à redução de tais problemas. A proposição dessa arquitetura executa a etapa 5 da metodologia proposta na Seção 1.4. A arquitetura, denominada Sensor Web Architecture (SWARCH), visa reduzir os problemas de desempenho dos serviços SWE através da inclusão de um componente que monitora constantemente os serviços cadastrados no registro de sensores. A proposta dessa arquitetura visa preencher uma lacuna encontrada no conjunto de especificações do SWE, no que se refere ao não tratamento de requisitos de qualidade de serviço. A própria OGC assume essa lacuna tendo essa questão como um desafio a ser superado: "OGC standards provide an important framework for addressing semantics, but more work needs to be done to enable fusion of data from diverse sensor types. Data quality and quality of service are important issues to address in sensor web standards development activities" (OGC, 2014c).

Um trabalho sobre provisão de critérios de qualidade de serviço no contexto dos padrões do SWE é apresentado em (Parhi et al., 2011). Nesse trabalho, os autores fornecem um serviço de busca que considera requisitos funcionais e não funcionais na seleção do serviço. Ao realizar um registro, o provedor do serviço deve fornecer tanto os parâmetros funcionais quanto não funcionais. O mecanismo de busca utilizado pelos autores é interessante. No entanto, não realiza uma associação direta com a especificação dos serviços disponibilizados pelo SWE, tais como os serviços SIR, SOS e SES. Os autores propõem um registro abstrato que é utilizado para armazenar os requisitos funcionais e não funcionais. A proposta de provisão de qualidade de serviço apresentada neste capítulo difere em diversos aspectos em relação à proposta apresentada em (Parhi et al., 2011). O mecanismo de provisão de qualidade de serviço apresentado neste capítulo propõe 
um Broker que utiliza as interfaces existentes no conjunto de serviços do SWE. Outro ponto importante é que alguns critérios de qualidade de serviço, tais como tempo de resposta, são voláteis e precisam ser constantemente verificados. Esse tipo de verificação constante é implementado pelo Broker, onde parâmetros de qualidade de serviço podem ser adicionados ou retirados de acordo com a necessidade das aplicações. A Seção 5.3 descreve a arquitetura de provisão de qualidade de serviço detalhando cada um dos componentes que a compõem. Contudo, é necessário discutir previamente algumas questões relacionadas à qualidade de serviço no contexto do SWE. Essa discussão é apresentada na Seção 5.1, onde se estabelece uma associação entre requisitos e parâmetros de qualidade de serviços com o modelo de interface do SWE.

\subsection{Qualidade de Serviço em Redes de Sensores}

Qualidade de serviço em redes de sensores compreende duas perspectivas distintas: QoS da camada de aplicação e QoS da camada rede. A QoS da camada de aplicação está relacionada à qualidade e precisão das medições dos sensores, erros nas medições, disposição dos sensores, cobertura e número de sensores ativos. A QoS da camada de rede tem o objetivo de prover o suporte necessário ao atendimento dos critérios de qualidade definidos na camada de aplicação no que diz respeito a banda disponível e ao consumo de energia (Chen e Varshney, 2004). Em (Chen et al., 2011) é apresentada uma classificação de diferentes parâmetros de QoS aplicados às redes de sensores. Nessa classificação, existe uma divisão entre parâmetros específicos do usuário (userspecified) e parâmetros de baixo nível (low-level) para Critical Infrastructure Protection (CIPs). Infraestruturas críticas são caracterizadas como infraestruturas onde uma falha pode acarretar impactos catastróficos nos domínios em que elas se aplicam. Sistemas de emergências, serviços de governos, telecomunicações e energia são exemplos de sistemas críticos. No entanto, essa classificação pode ser estendida para a maioria dos requisitos de QoS em redes de sensores, adicionandose os parâmetros de QoS definidos em (Xia, 2008). Parâmetros específicos dos usuários podem ser descritos da seguinte forma:

- Prioridade: define a forma de se obter diferentes níveis de importância para o fluxo de dados. O objetivo desse parâmetro é priorizar um determinado tipo de dado. Por exemplo, dados de monitoramento não possuem o mesmo nível de importância que notificações de ataques ou falhas;

- Periodicidade: refere-se à qualidade das ações executadas em um determinado período de tempo. Esse comportamento é comum em aplicações de monitoramento que reportam leituras de medições de forma periódica às suas estações base;

- Tempo de Resposta: tempo necessário para submeter uma requisição e receber uma resposta; 
- Deadline: também conhecida como latência máxima, o deadline define o limite máximo de tempo em que uma determinada tarefa deve ser executada. Certas medições em uma rede de sensores somente fazem sentido se forem recebidas em um período específico de tempo;

- Disponibilidade: mede o tempo de funcionamento do sistema. Esse parâmetro é importante, pois ele pode indicar, entre outros aspectos, a segurança do sistema. Por exemplo, em um sistema de segurança residencial, o usuário estará seguro caso o índice de disponibilidade do sistema seja alto. Caso ocorra uma invasão em sua residência, o usuário terá a confiança de que o sistema está funcionando apropriadamente;

- Confiabilidade: especifica a habilidade da rede em assegurar a transmissão de dados entre os nós, notificando a ocorrência de eventuais erros ou falhas.

Por sua vez, os parâmetros de baixo nível podem ser descritos como:

- Confidencialidade: envolve assegurar que apenas partes autorizadas tenham acesso às informações geradas pela rede de sensores;

- Integridade: refere-se à ausência de alterações não permitidas no sistema;

- Manutenibilidade: especifica a habilidade do sistema em submeter-se a modificação e reparos. Redes de sensores são sistemas dinâmicos, onde topologias e as quantidades de sensores são modificados constantemente. Por exemplo, o sistema deve estar preparado para a substituição de um determinado nó sensor sem que haja prejuízos à execução do sistema como um todo;

- Eficiência em energia: conduz eficientemente a utilização de energia nos nós. As redes de sensores são limitadas em relação ao fornecimento de energia. Dessa forma, é necessário que se tenha uma utilização onde haja um consumo mínimo desse recurso;

- Escalabilidade: indica a habilidade de aumentar a rede de maneira eficiente. Redes de sensores devem ser escaláveis para eventuais adições de nós que possam auxiliar o crescimento da qualidade da rede, como por exemplo, o aumento da área observável;

- Vazão: mede a quantidade de fluxo de dados transportado em um determinado período de tempo. Aplicações de monitoramento geralmente não geram grandes tráfegos. No entanto, aplicações de infraestrutura crítica são um pouco mais rigorosas nesse sentido, devido à grande disponibilidade exigida e pela natureza do sistema que está sendo monitorado. Assim, plataformas de sensores devem lidar com picos de demanda de recursos;

- Responsividade: mede a habilidade da rede em se adaptar às mudanças de sua topologia. A falta de responsividade afeta negativamente a confiabilidade da rede. Ou seja, falhas em nós da rede, assim como no próprio sistema, não devem prejudicar o comportamento da rede; 
- Recuperação a falhas: define a habilidade da rede na recuperação de falhas em um ou mais nós da rede;

- Atraso (delay): mede o atraso no sistema quando esse executa uma determinada ação. Por exemplo, atraso na entrega de pacotes. Requisitos relacionados a atrasos dependem dos requisitos da aplicação e devem ser minimizados;

- Variação no delay (jitter): definido como a variação nos atrasos entre pacotes dentro de um determinado fluxo de dados. Informações oferecidas por uma estação base sobre a leitura da rede de sensores devem ser sincronizadas. Por exemplo, um evento produzido por um aumento de temperatura em rede de sensores deve ser reportado ao mesmo tempo por nós mais próximos do evento;

- Perda de pacotes e taxa de erro: esses dois parâmetros são frequentemente utilizados quando a comunicação da rede é suscetível a erros.

Esta seção apresentou uma discussão sobre os critérios de qualidade de serviço que são geralmente empregados em redes de sensores. A Seção 5.2 discute uma associação desses critérios com os serviços SWE.

\subsection{Qualidade de Serviço nos Padrões SWE}

A qualidade de serviço de aplicações de redes de sensores é determinada pela exigência da lógica da aplicação, e em muitos casos, definida pelo modelo de entrega de dados. Como discutido na Seção 2.1.1, as aplicações em redes de sensores podem ser classificadas pelo modelo de entrega dos dados que são definidos como dirigido a evento, dirigido a consulta ou contínuo. O modelo de interfaces do SWE pode ser expressado seguindo essa classificação. Assim, dentro do contexto dos serviços SWE, uma aplicação dirigida a evento pode ser exemplificada em um sistema de monitoramento de incêndios, onde uma rede de sensores deve informar a ocorrência de um foco de incêndio. Nesse caso, um serviço SES pode ser utilizado para acionar atuadores de combate ao fogo. Assim, no que tange à qualidade de serviço, a aplicação deve cumprir um tempo específico de reação (deadline) sendo não tolerante a atrasos, uma vez que atrasos no acionamento de atuadores comprometem o sucesso da aplicação. Esse tipo de aplicação também é definido na literatura como de missão crítica, ou seja, não tolera falhas. Aplicações dirigidas a eventos ainda exigem outros critérios como, por exemplo, disponibilidade, confiabilidade e perda de pacotes.

Por sua vez, aplicações dirigidas à consulta podem ser implementadas utilizando um serviço SOS. Uma aplicação dirigida a consulta pode ser exemplificada em um sistema de monitoramento climático de uma determinada cidade, onde um usuário faz uma consulta e recebe, por exemplo, o valor da temperatura ambiente. Nesse cenário, o sistema é definido como interativo, pois há interação com um usuário. Em relação à QoS, diversos critérios podem ser utilizados como vazão, tempo de resposta e atraso. O serviço SIR também possui um modelo de entrega dirigido a 
consulta, uma vez que consumidores buscam informações de sensores nesse serviço por um modo requisição/reposta. Aplicações contínuas também podem ser implementadas utilizando um serviço SOS. Por exemplo, uma aplicação pode solicitar periodicamente a um serviço SOS, imagens de uma câmera em determinado sensor. Para esse tipo de aplicação uma largura de banda mínima é exigida, pois dados multimídia geralmente utilizam uma vazão mínima para o tráfego de seu fluxo de dados. Outro tipo de aplicação contínua, construída através de um serviço SOS, é exemplificado na monitoração de dados vitais de pacientes em hospitais. Nesse caso, um sensor que afira o ritmo cardíaco de uma determinada pessoa envia, de tempos em tempos, esse dado para um observador. O serviço SOS nesse exemplo pode exigir diferentes critérios de QoS como deadline, prioridade, confiabilidade, disponibilidade, atraso e jitter.

As especificações definidas pela Sensor Web Enablement não definem requisitos de qualidade de serviço para os tipos de entrega dos dados. A linguagem de descrição de sensores (SensorML), por exemplo, define em sua especificação uma propriedade de qualidade nas medições que são realizadas pelo sensor. Essa propriedade é atribuída ao tipo de dado para oferecer uma indicação de confiabilidade na medição. Por exemplo, o tipo booleano no padrão SensorML representa uma propriedade que é verdadeira ou falsa. No entanto, a qualidade de um tipo booleano define o nível de confiança do valor verdadeiro ou falso, podendo ser expressado como uma quantidade (p.e. 85\%) ou uma categoria (p.e. Alta). Portanto, não há definição de parâmetros de qualidade de serviço no modelo de entrega dos dados no contexto dos padrões do SWE. Esses requisitos de qualidade de serviço no nível da entrega dos dados impactam significativamente no desempenho das aplicações construídas a partir dos serviços do SWE, pois essas aplicações são consumidoras dos dados disponibilizados por serviços como SOS, SES e SIR.

A Tabela 5.1 apresenta uma possível associação dos requisitos de QoS mais utilizados em redes de sensores com os serviços definidos no modelo de interfaces do SWE. Nessa associação, leva-se em conta o tipo de entrega de dados de cada um dos serviços e suas restrições em relação aos requisitos de qualidade de serviço. Em geral, pode-se dizer que o SOS e SIR são dirigidos à consulta, sendo que o SOS também pode ser considerado contínuo uma vez que uma aplicação pode solicitar periodicamente informações a esse serviço. O SES é dirigido a evento (alerta), onde usuários definem critérios de disparo para que sejam enviadas notificações aos consumidores cadastrados no serviço. Na maioria das vezes, aplicações que utilizam sistemas de alerta estabelecem um tempo máximo (deadline), dentre outros requisitos, para que as notificações cheguem aos clientes. No entanto, é importante destacar que os critérios de qualidade de serviço variam dependendo do tipo de aplicação. Em outras palavras, um cliente de um serviço SOS pode exigir diferentes critérios de QoS para perfis de aplicações distintos. Outro ponto importante em relação à Tabela 5.1 diz respeito a não atribuição de determinados parâmetros tais como eficiência em energia, responsividade e perda de pacotes a nenhum dos serviços SWE destacados. Em geral, esses parâmetros são utilizados apenas no âmbito interno das plataformas de sensoriamento e dos protocolos de comunicação utilizados na troca de dados entre nós sensores dentro da rede. 
Tabela 5.1: Requisitos de QoS para os Serviços SWE

\begin{tabular}{c|c|c|c}
\hline Parâmetros & SIR & SOS & SES \\
\hline Prioridade & & & $\mathbf{X}$ \\
\hline Periodicidade & $\mathbf{X}$ & $\mathbf{X}$ & \\
\hline Tempo de Resposta & $\mathbf{X}$ & $\mathbf{X}$ & $\mathbf{X}$ \\
\hline Deadline & & $\mathbf{X}$ & $\mathbf{X}$ \\
\hline Disponibilidade & $\mathbf{X}$ & $\mathbf{X}$ & $\mathbf{X}$ \\
\hline Confiabilidade & $\mathbf{X}$ & $\mathbf{X}$ & $\mathbf{X}$ \\
\hline Confidencialidade & $\mathbf{X}$ & $\mathbf{X}$ & $\mathbf{X}$ \\
\hline Integridade & $\mathbf{X}$ & $\mathbf{X}$ & $\mathbf{X}$ \\
\hline Segurança & $\mathbf{X}$ & $\mathbf{X}$ & $\mathbf{X}$ \\
\hline Manutenibilidade & $\mathbf{X}$ & $\mathbf{X}$ & $\mathbf{X}$ \\
\hline Eficiência em energia & & & \\
\hline Escalabilidade & $\mathbf{X}$ & $\mathbf{X}$ & $\mathbf{X}$ \\
\hline Vazão & $\mathbf{X}$ & $\mathbf{X}$ & $\mathbf{X}$ \\
\hline Responsividade & & & \\
\hline Recuperação a falhas & $\mathbf{X}$ & $\mathbf{X}$ & \\
\hline Atraso & $\mathbf{X}$ & $\mathbf{X}$ & $\mathbf{X}$ \\
\hline Variação no delay (jitter) & $\mathbf{X}$ & $\mathbf{X}$ & $\mathbf{X}$ \\
\hline Perda de pacotes e erros & & & \\
\hline
\end{tabular}

Nas próximas seções são apresentados o projeto, implementação e um estudo de caso da SWARCH (Sensor Web Architecture), uma arquitetura que visa prover QoS aos serviços oferecidos pelo SWE. A Seção 5.3 apresenta uma descrição dos componentes e do funcionamento da SWARCH.

\subsection{Descrição da Arquitetura}

O objetivo da SWARCH pode ser caracterizado como uma proposta de arquitetura para provisão de QoS aos serviços definidos no modelo de interfaces da Sensor Web Enablement. A arquitetura tradicional dos serviços SWE funciona seguindo o modelo apresentado na Figura 5.1(a). Nessa arquitetura estão presentes um consumidor, um registro e um provedor de serviços. Nesse modelo, o consumidor realiza a descoberta de um sistema de sensores que o atende funcionalmente, através do registro de serviços. Por sua vez, o consumidor, após descobrir o serviço que o atende, realiza alguma interação com o serviço descoberto. Essa interação pode ser uma inscrição em um sistema de alerta (Subscribe - SES), ou então, uma requisição de informações de observações aferidas pelo sistema de sensores através do serviço SOS (GetObservation). Por outro lado a arquitetura da SWARCH é demonstrada na Figura 5.1(b). O objetivo da arquitetura proposta neste capítulo soma às funcionalidades da arquitetura tradicional do SWE um elemento que provê a seleção de serviços através de critérios de QoS. Esses critérios de qualidade são definidos por aplicações construídas sobre os padrões do SWE. Por exemplo, uma aplicação pode exigir que um 


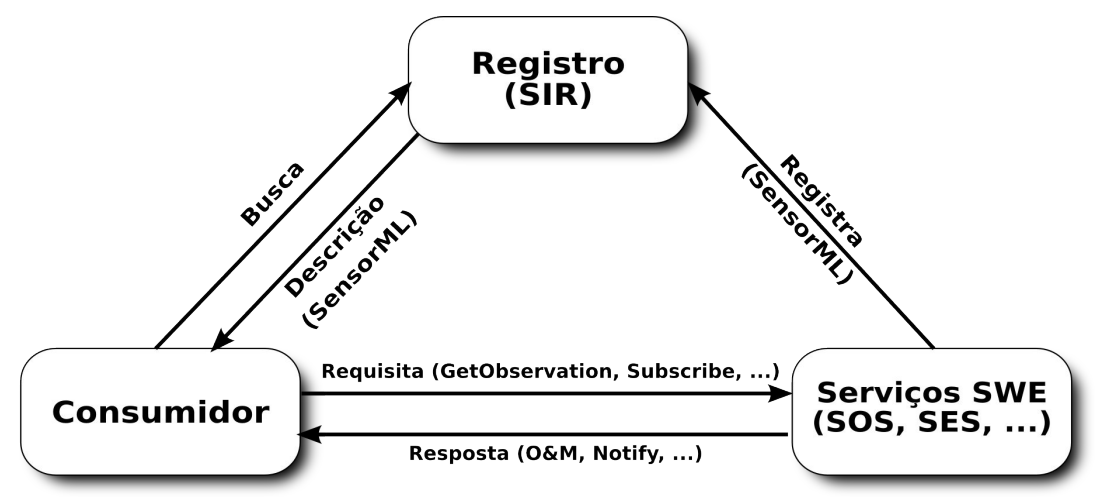

(a) SWE Tradicional

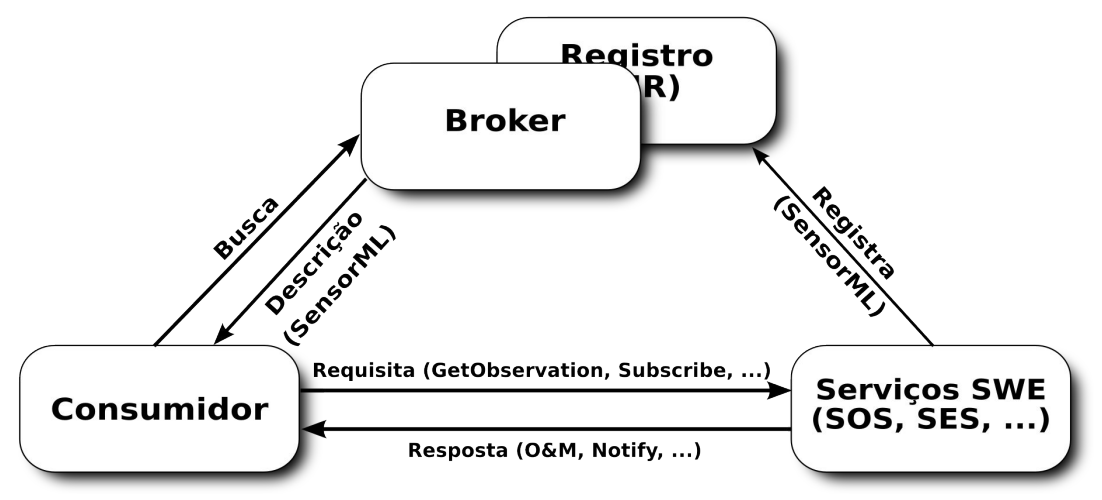

(b) SWARCH

Figura 5.1: Arquitetura Tradicional SWE X SWARCH

serviço SOS atenda sua solicitação em um tempo de resposta específico, ou ainda, determina que a disponibilidade do sistema esteja dentro de um determinado índice. Os componentes da SWARCH podem ser definidos da seguinte forma:

- Registro: componente responsável por armazenar descrições dos sistemas de sensores, implementado pelo serviço SIR;

- Serviços: serviços SWE para notificação de alertas e obtenção de observações. É importante lembrar que o serviço SOS é utilizado como uma interface de acesso a dados de observações realizadas pela rede de sensores, enquanto o SES fornece um serviço de alertas;

- Broker: componente responsável pela realização dos testes e aferição dos parâmetros de qualidade dos serviços cadastrados no registro;

- Consumidor: são as aplicações ou usuários que seguem o modelo arquitetural original do SWE e que podem fazer a busca por sistemas de sensores em um registro ou um catálogo de sensores (SIR). No caso da SWARCH, o consumidor submete requisições ao Broker, ao invés do registro.

Quando um consumidor realiza uma solicitação de observações realizadas por um sensor ou por uma rede de sensores, a SWARCH deve fazer uma busca e selecionar quem atenderá a solicitação. 
Para realizar esse tipo de seleção, o consumidor envia uma mensagem de busca podendo determinar diversos critérios de filtragem de maneira a selecionar o sistema de sensores mais adequado. Os critérios de filtragem podem ser o tipo de fenômeno observado, a localização dos sensores que compõem o sistema ou ainda o tipo de serviço SWE (SOS, SES, SPS, etc.). No caso da SWARCH, o consumidor acrescenta parâmetros de QoS aos critérios de filtragem. Esses critérios de qualidade de serviço são utilizados por um módulo de seleção do Broker para determinar os serviços que atendem as restrições impostas pelo consumidor.

O Broker, dentro da arquitetura, tem três funções principais: (1) receber as requisições dos usuários através de um serviço Web, (2) fazer a seleção dos serviços que atendem restrições de qualidade e (3) retornar as descrições desses serviços ao consumidor. O Broker é dividido em quatro módulos principais: WSModule, SearchModule, TestModule e SelectionModule. As mensagens trocadas na SWARCH, assim como os módulos implementados para a composição do Broker estão detalhados nas Seções 5.3.1 e 5.3.2, respectivamente.

\subsubsection{Mensagens na Arquitetura}

O processo de busca de serviços no modelo arquitetural tradicional do SWE (Figura 5.1(a)) é realizado no registro de serviço que pode ser implementado pelo serviço SIR. No caso da SWARCH, essa mensagem é enviada ao Broker da arquitetura (Figura 5.1(b)).

A Figura 5.2 enumera todas as mensagens trocadas entres os componentes da SWARCH. A Sensor Web Architecture utiliza um conjunto de mensagens que são, em sua maioria, definidas pelos padrões do SWE. A mensagem 1 (InsertSensorInfoRequest ${ }^{1}$ ) representa uma requisição de inserção da descrição de um sistema de sensores que é utilizada pelo provedor do serviço. Essa mensagem de inserção carrega um documento SensorML com os metadados dos sensores. Por sua vez, a mensagem 2 pode ser definida como uma composição de uma mensagem de busca, utilizada para acessar o serviço SIR, com um elemento que define critérios de qualidade de serviço. A mensagem 2, exemplificada no Código 5.1, apresenta um exemplo da estrutura dessa mensagem.

O elemento de busca da mensagem 2 está encapsulado entre as linhas 3 e 14 do Código 5.1. Vale lembrar que essa parte da mensagem faz parte da especificação de acesso ao serviço SIR (OGC, 2010b). Além disso, o elemento de qualidade de serviço está codificado na linha 16 . O elemento de qualidade é uma proposta de mecanismo de definição de critérios de qualidade de serviço da SWARCH, ou seja, não faz parte de nenhum dos padrões do SWE. A mensagem 3 (searchSensor ${ }^{2}$ ) corresponde à mensagem de busca que é submetida ao registro. Essa mensagem de busca é extraída da mensagem 2. As mensagens 4 e 5 são mensagens de requisição de aferições de sensores (GetObservation $\left.{ }^{3}\right)$ e notificação de alertas (Notify $\left.{ }^{4}\right)$, respectivamente.

\footnotetext{
${ }^{1}$ InsertSensorInfoRequest Schema: http://52north.org/schema/sir/0.3.2/sirInsertSensorInfo.xsd

${ }^{2}$ searchSensor Schema: http://52north.org/schema/sir/0.3.2/sirSearchSensor.xsd

${ }^{3}$ GetObservation Schema: http://schemas.opengis.net/om/1.0.0/observation.xsd

${ }^{4}$ Notify Schema: http://docs.oasis-open.org/wsn/b-2.xsd
} 


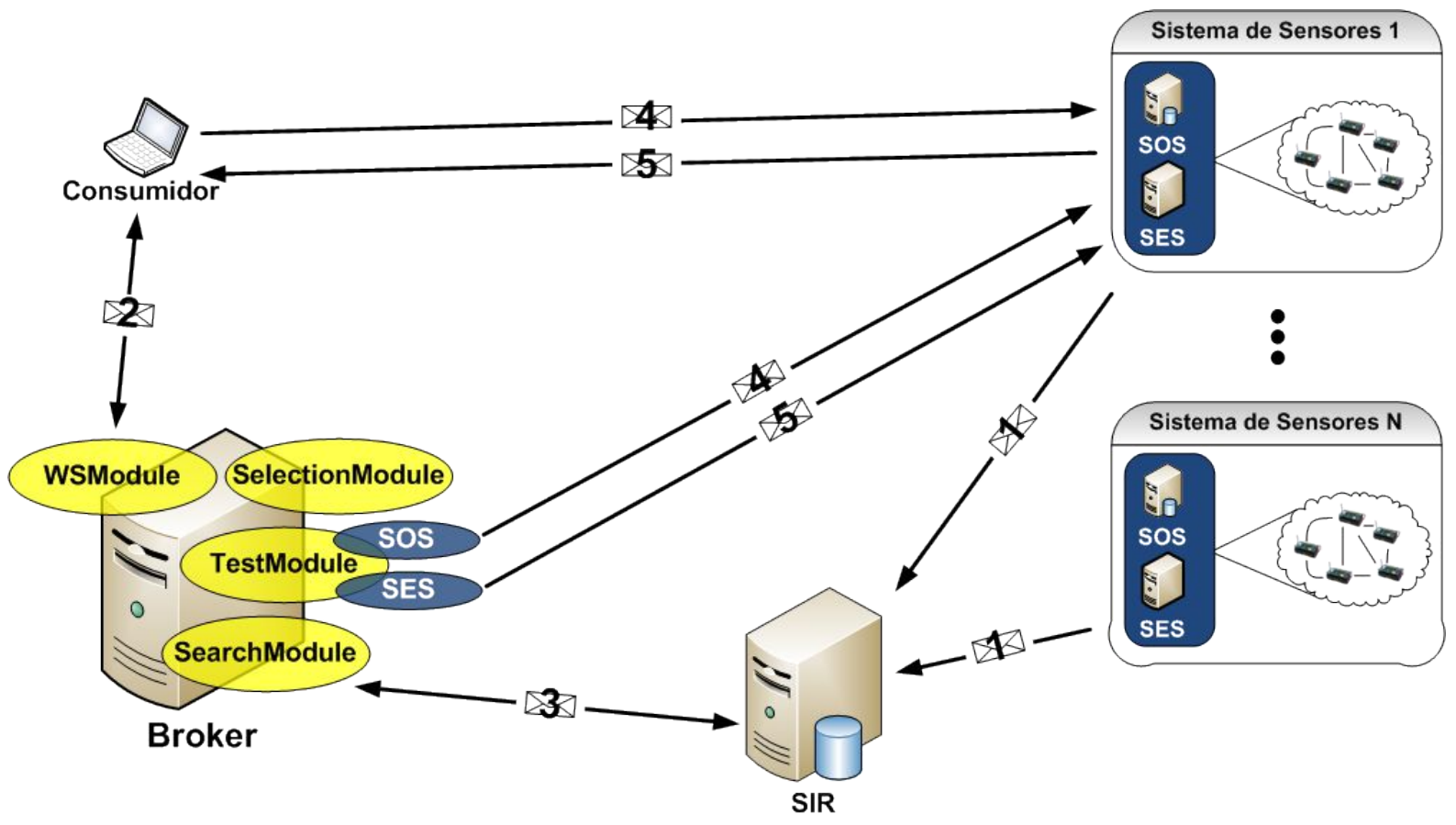

Figura 5.2: Elementos da SWARCH

\subsubsection{Broker}

O funcionamento do Broker está detalhado através de diagramas de classe e sequência. Vale ressaltar que a modelagem de sistemas computacionais é parte importante dentro do desenvolvimento de um software. Ela é importante no sentido de facilitar a compreensão dos problemas que devem ser solucionados pelo software. A modelagem, dentro do contexto da implementação do Broker tem o intuito de oferecer uma forma simplificada de entendimento da estrutura desse componente. Além disso, a modelagem é essencial para a continuação do desenvolvimento e manutenção da ferramenta. Para realizar a modelagem foi utilizada a UML (Unified Modeling Language). A UML pode ser definida como um formalismo gráfico para análise e projeto de software. Ela

Código 5.1: Mensagem de Busca na SWARCH

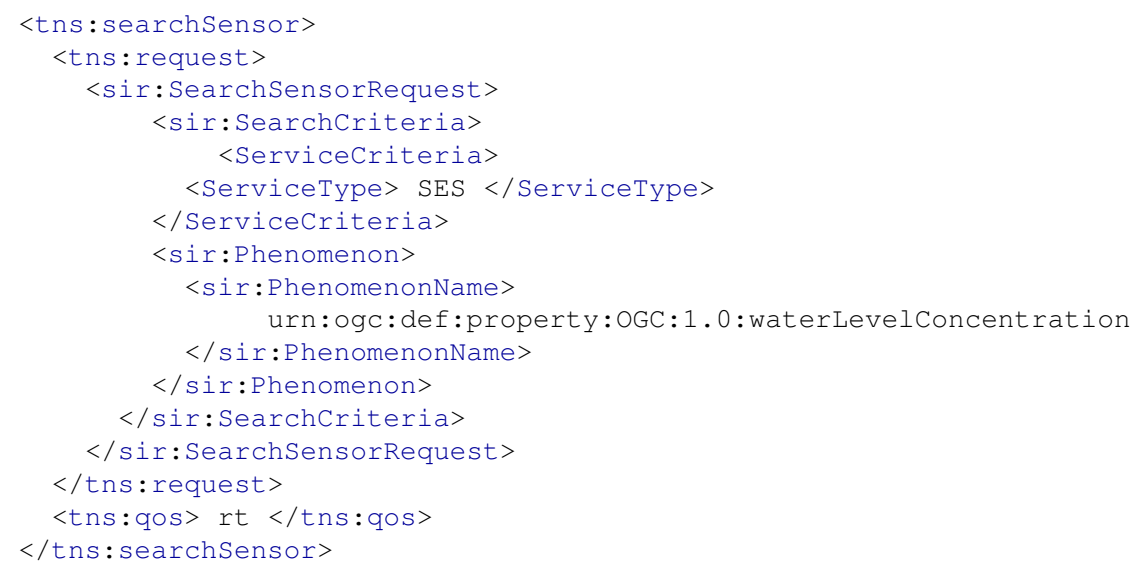




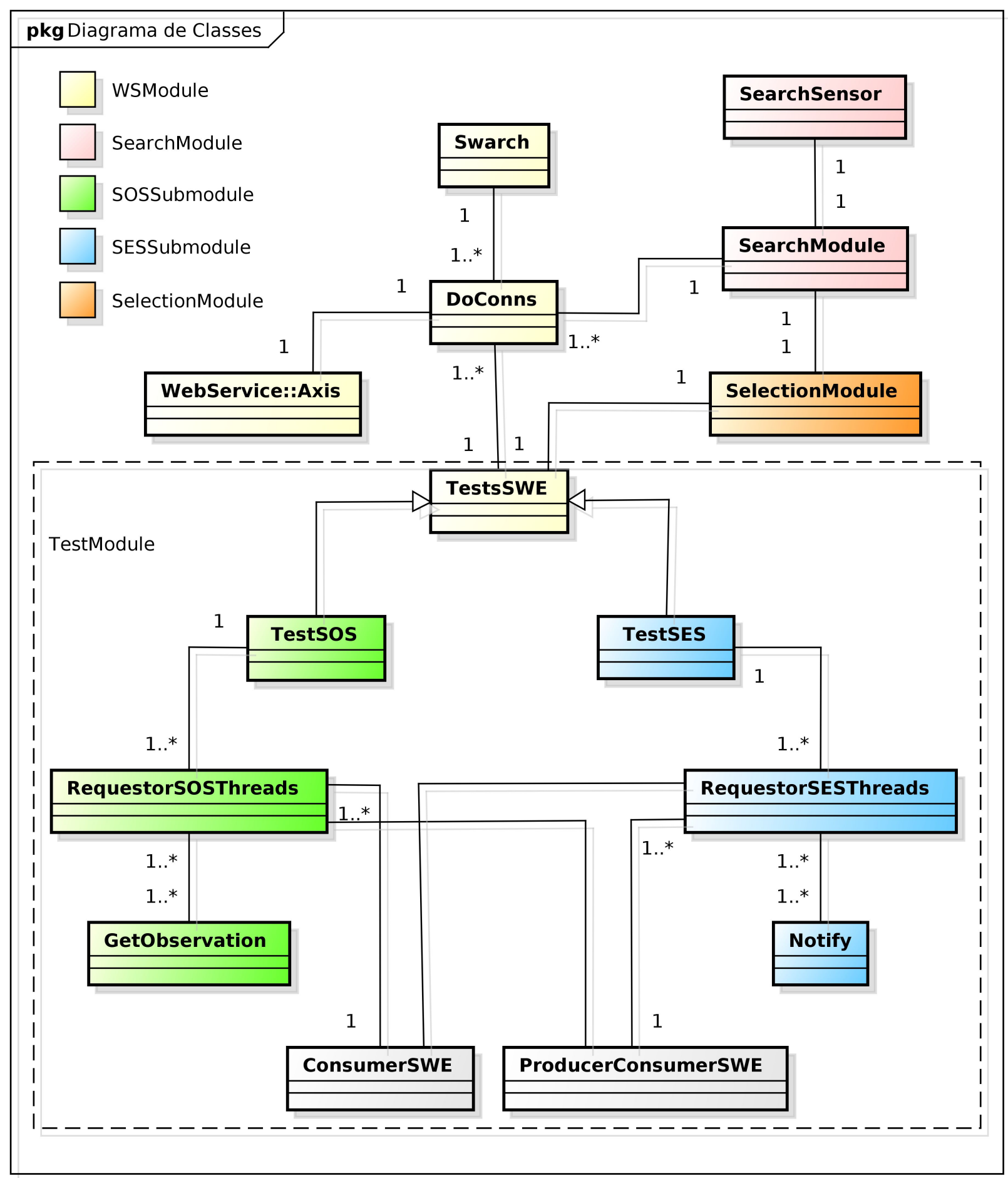

Figura 5.3: Diagrama de Classes do Broker

apresenta um conjunto de diagramas para a definição da estrutura e comportamento de um sistema computacional. No entanto, não foram utilizados todos os recursos fornecidos pela UML. O principal objetivo desta seção é determinar, da forma mais simplificada possível, os componentes implementados e os seus relacionamentos. 


\section{Diagrama de Classes do Broker}

O diagrama de classes apresentado na Figura 5.3 define uma parte das classes implementadas para a composição do Broker, uma vez que classes secundárias, que oferecem suporte as classes principais, não estão representadas do diagrama. O diagrama apresenta os seguintes elementos:

- WSModule: implementado através da composição de três classes principais: Swarch, DoConns e TestsSWE. Essas três classes são responsáveis por receber as requisições dos consumidores. A classe DoConss implementa um servidor de sockets que atende às requisições vindas de um serviço Web (classe WebService::Axis) que expõe uma interface de acesso ao Broker. A WebService::Axis é uma classe externa ao Broker que fica publicada dentro do servidor de aplicação Axis2 (Apache, 2014a). Ou seja, ocorre uma comunicação entre o serviço Web publicado no Axis2 com a classe DoConns através de sockets. Após essa etapa ocorre a extração das informações de busca e qualidade de serviço definidas em uma mensagem como a apresentada no Código 5.1. Tais informações são enviadas aos módulos SearchModule e SelectionModule;

- SearchModule: implementado basicamente por duas classes: SearchModule e SearchSensor. A classe SearchModule é responsável basicamente por realizar as buscas no repositório de serviços (SIR) e atualizar as informações obtidas em um cache da classe TestModule. A classe SearchSensor oferece os métodos necessários para realizar a interação com o registro do serviço através do fornecimento de interfaces que possibilitam a criação de mensagens dentro do padrão SIR;

- TestModule: implementado por um conjunto de classes que avaliam tanto serviços SOS quanto SES. A fase atual de implementação desse módulo considera tempo de resposta e disponibilidade como critérios de qualidade de serviço. A TestsSWE é a principal classe desse módulo. Ela fornece os principais métodos no processo de avaliação dos serviços que são herdados pelas classes TestSOS e TestSES que compõem os seguintes submódulos:

- SOSSubmodule: além da classe TestSOS, o SOSSubmodule é composto por outras duas classes: RequestorSOSThreads e GetObservation. A classe RequestorSOSThreads implementa as threads utilizadas no processo de avaliação do serviço SOS. Por sua vez, a classe GetObservation fornece os métodos necessários para a criação de mensagens no padrão SOS. As classes ConsumerSWE e ProducerSWE são outras duas importantes classes no SOSSubmodule que também são utilizadas no SESSubmodule. Durante o processo de avaliação dos serviços SWE, várias threads acessam simultaneamente os serviços. No entanto, esses acessos devem possuir um sincronismo para que haja uma garantia da quantidade de threads acessando o serviço em determinado período de tempo. Assim, as classes ConsumerSWE e ProducerSWE fornecem um mecanismo para implementar um padrão produtor consumidor. Nesse caso, a ProducerSWE 
produz um servidor, que na realidade é um URL do serviço que deve ser testado. Uma vez produzido o servidor, utiliza-se um método ( $p u t$ ) da classeProducerConsumerSWE que controla a ativação das threads. Por outro lado, todas as threads, instâncias da classe RequestorSOSThreads utilizam um outro método (get) para consumir o URL gerado pela classe ProducerSWE. Vale ressaltar que todo esse processo tem o objetivo de manter uma determinada quantidade de threads acessando simultaneamente um determinado serviço. Por exemplo, esse processo garante que 50 threads acessem o serviço SOS em determinado período de tempo, caso essa quantidade tenha sido definida pelo administrador da arquitetura;

- SESSubmodule: esse submódulo é composto pelas classes TestSES, RequestorSESThreads e Notify. A classe Notify provê os métodos para o acesso e submissão de notificações ao serviço SES. Já a classe RequestorSESThreads opera de maneira semelhante a classe RequestorSOSThreads em relação ao controle e sincronismo das threads instanciadas para realizar os testes no serviço SES. Devido ao caráter assíncrono do serviço SES, o detalhamento da operação do SESSubmodule é realizado posteriormente nesta seção;

- SelectionModule: implementado basicamente pela classe SelectionModule que tem como principal função o ranqueamento dos melhores serviços testados pelo Broker considerando os critérios de QoS definidos pelos consumidores. Essa classe tem a responsabilidade de associar as informações aferidas pelos módulos de testes com os parâmetros de qualidade definidos pelo consumidor. Além disso, essa classe tem uma associação com o módulo de busca para processar as descrições dos sistemas de sensores que possuem o melhor oferecimento de qualidade de serviço.

\section{Diagramas de Sequência do Broker}

O diagrama de sequência, mostrado na Figura 5.4, permite um melhor entendimento de cada um dos elementos de software que compõem a implementação do Broker. Cada módulo implementado no Broker é representado pela instância de um objeto no diagrama. Os módulos pertencentes ao Broker estão destacados no diagrama. A primeira interação entre os componentes da SWARCH é realizada entre os objetos Consumidor e WSModule. Nessa interação o consumidor envia uma mensagem SOAP que contém duas informações. A primeira informação define a mensagem de busca que será utilizada para a realização da consulta no SIR e a segunda informação define os parâmetros de QoS que serão utilizados na seleção do serviço.

O WSModule recebe a mensagem SOAP do Consumidor e extrai as duas informações encapsuladas, repassando-as ao SeachModule. O SearchModule utiliza a mensagem de busca para fazer a consulta no SIR. Uma vez concluída a consulta, o SearchModule processa a mensagem de resposta enviada pelo registro em um array que contém os documentos de descrição de sensores 


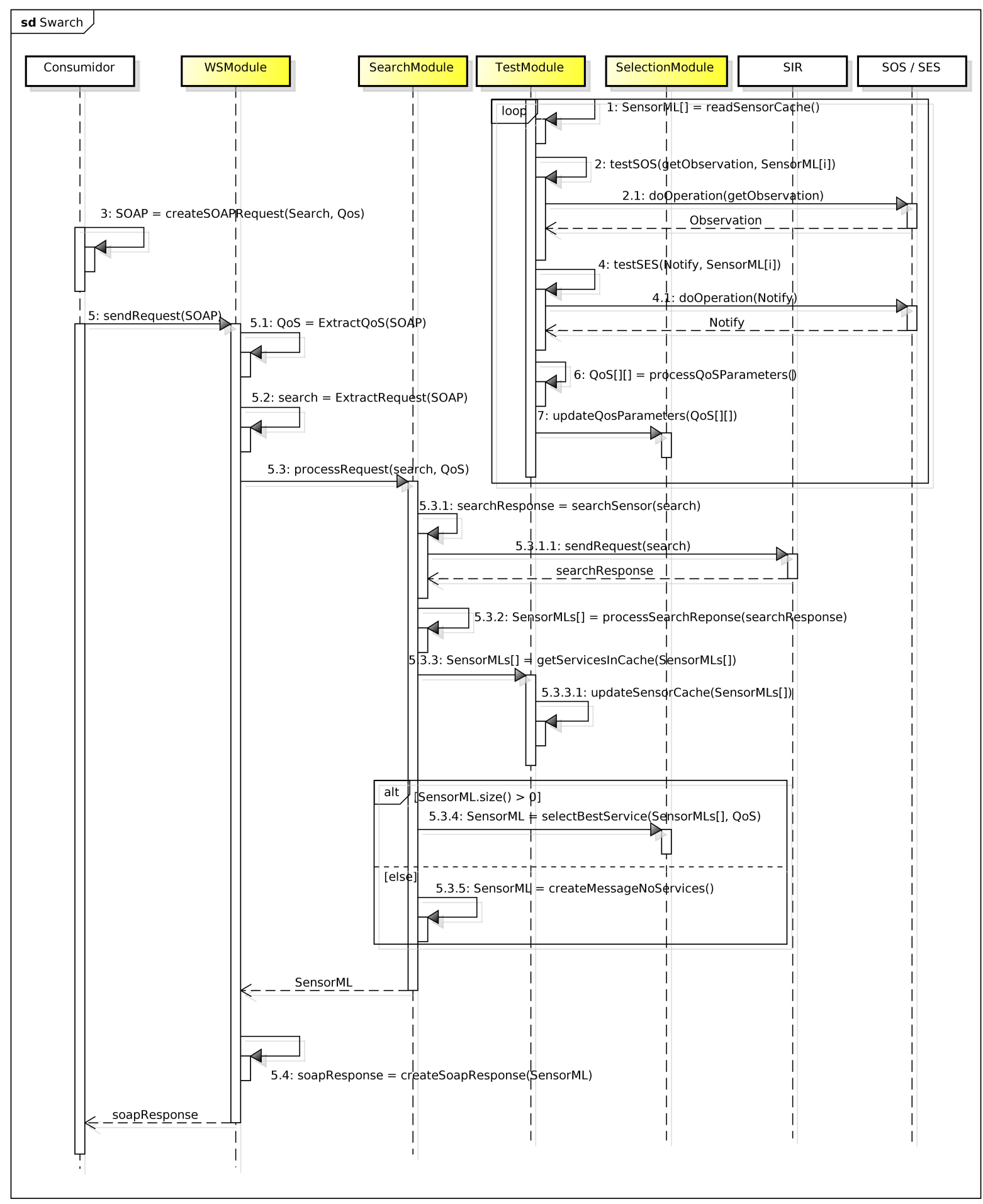

Figura 5.4: Diagrama de Sequência da SWARCH

(SensorML) dos serviços retornados pelo SIR. Em seguida, o SearchModule atualiza um outro array com as descrições dos sensores que estão em cache no TestModule. O TestModule, ao receber essa consulta, atualiza as informações dos sensores que ainda não estavam inseridas no cache. Contudo, o TestModule retorna apenas os sensores que estavam presentes no cache antes da recepção dessa nova atualização. Isso deve ser feito devido ao fato de que não há tempo hábil para 
retornar informações de QoS dos sensores que não estavam no cache. Assim, o SearchModule verifica se existiam sensores cadastrados no cache gerenciado pelo TestModule. Se o tamanho do array retornado pelo TestModule for maior que zero significa que havia informações de qualidade de serviço para pelo menos um dos sensores retornados pelo serviço de registro. Dessa forma, o SearchModule solicita ao SelectionModule que retorne o serviço que melhor atende os parâmetros de QoS especificados pelo Consumidor. Caso o tamanho do array seja zero, é criada uma mensagem informando que nenhum dos serviços cadastrados no registro atende aos critérios de qualidade de serviço definidos pelo Consumidor. O Broker conterá informações de qualidade de serviço desses serviços em uma próxima busca. Por fim, o SearchModule encapsula o documento de descrição do serviço em uma mensagem SOAP de resposta e o envia ao Consumidor.

O funcionamento do TestModule está representado no lado superior direito da Figura 5.4. Os testes implementados pelo TestModule utilizam um laço (loop) que avalia constantemente os serviços cadastrados no cache de serviços. O TestModule insere os sensores recebidos do SearchModule em uma lista de serviços que devem ser avaliados. Essa verificação é realizada periodicamente pelos submódulos chamados de SESSubmodule e SOSSubmodule. A divisão em submódulos é necessária devido à natureza de cada um dos serviços. É importante destacar que a fase atual de implementação da SWARCH considera apenas os serviços SOS e SES. No entanto, futuras implementações pretendem considerar outros serviços como o SPS.

A implementação do SESSubmodule merece destaque uma vez que o serviço SES é assíncrono e, dessa forma, apresenta maior complexidade. A Figura 5.5, mostra um diagrama de sequência com uma sumarização das instâncias de classes implementadas para a composição do SESSubmodule. A primeira etapa no processo de avaliação do serviço SES consiste na instanciação de um consumidor (classe Consumer) que é responsável por receber as notificações do serviço SES. Após essa etapa, várias instancias da classe RequestorSESThreads são criadas. Cada um dos objetos instanciados simula um sensor enviando notificações ao serviço SES. Por se tratar de um serviço assíncrono, a medição do tempo entre enviar e receber uma notificação torna-se mais complexa que um serviço síncrono como SOS.

Dessa forma, os objetos da classe RequestorSESThreads executam a sequência de mensagens numeradas de três a sete, no diagrama da Figura 5.5. Primeiramente, é criado um objeto da classe Date do Java que define o horário em que a notificação foi gerada. Esse horário é encapsulado em uma mensagem de notificação padrão do serviço SES (mensagem 4). Posteriormente, o tempo anterior ao envio da submissão da notificação é tomado para que seja utilizado, futuramente, para contabilizar o tempo de resposta do envio da notificação. Além disso, a tupla <date,start> é armazenada em uma tabela hash (classe HashTable do Java). O elemento date da tupla é utilizado como chave na tabela, enquanto que start armazena o horário anterior a submissão da notificação. Quando o objeto Consumer recebe a notificação do serviço SES, o horário de recepção da mensagem de notificação é armazenado em uma variável chamada de end. Então, é realizada a extração do elemento date que é utilizado para recuperar o valor do horário anterior a submissão da notificação realizada pelo objeto da classe RequestorSESThreads. Assim, tendo o valor do horário 


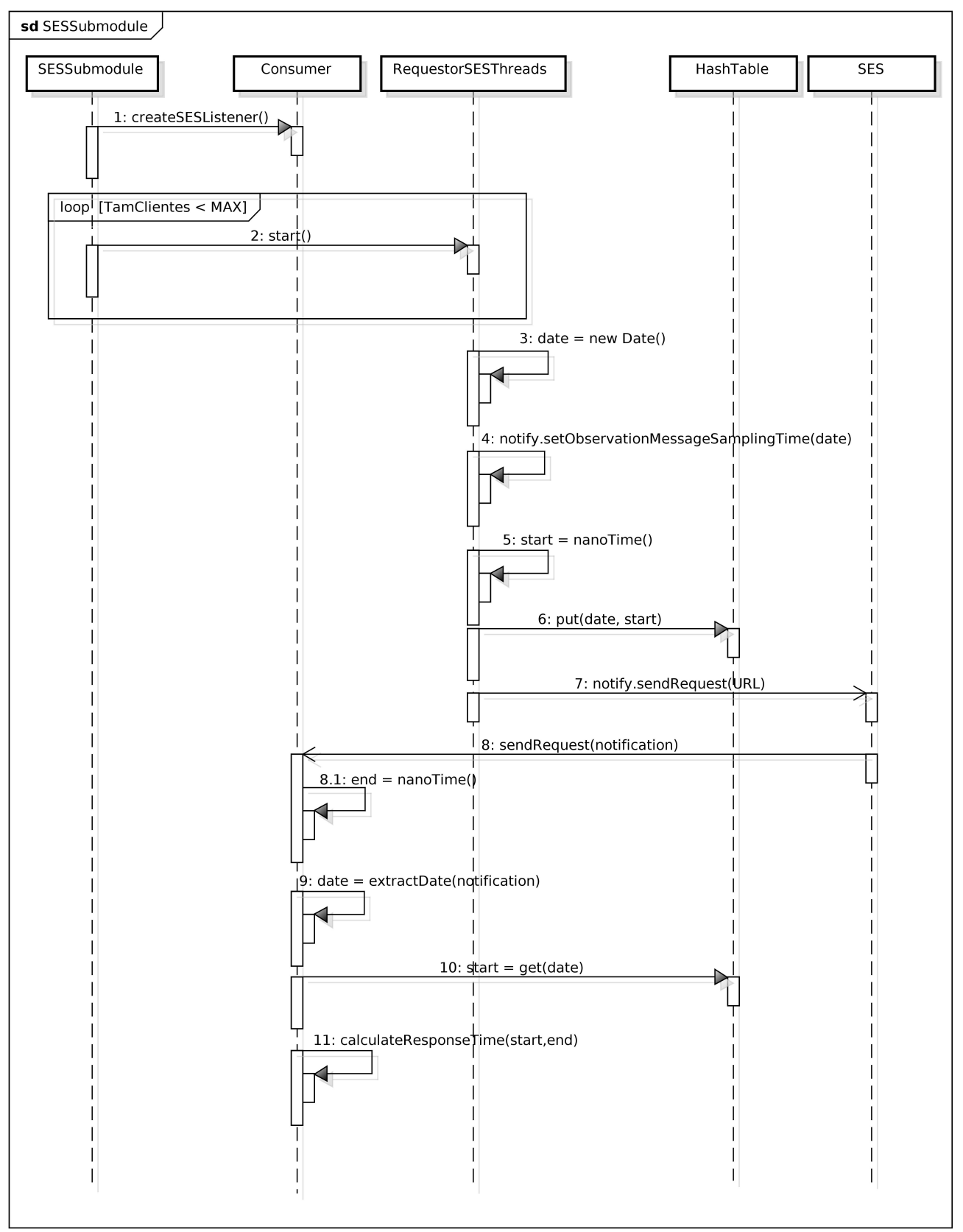

Figura 5.5: Diagrama de Sequência da SESSubmodule

anterior a submissão da notificação (start) e o valor do horário posterior ao recebimento da mesma, pode-se calcular o tempo gasto entre enviar e receber uma notificação para/de o serviço SES.

Diversos parâmetros de qualidade de serviço podem ser verificados pelo TestModule, por exemplo, tempo de resposta médio. O tempo de resposta médio é calculado por meio de requisições submetidas aos serviços através de threads. Como mencionado no Capítulo 4, a utilização de threads na execução dos testes é necessária para imitar o comportamento de vários clientes acessando os serviços. O número de threads e a quantidade de requisições que cada uma delas submete aos serviços é customizável e o administrador da arquitetura pode ajustar esses parâmetros de configuração da maneira mais adequada. Assim como a quantidade de threads, o período entre os 
testes também pode ser ajustado. A definição do período entre as realizações dos testes executados pelos módulos SOSSubmodule e SESSubmodule deve ser realizada com cuidado. Isso se deve ao fato de que períodos muito curtos sobrecarregam o sistema, enquanto que períodos muito longos não aferem os parâmetros de QoS apropriadamente.

Outros parâmetros de qualidade de serviço como confiabilidade e disponibilidade também são verificados pelo TestModule. Por exemplo, a confiabilidade do sistema é realizada através do cálculo de desvio padrão dos tempos de resposta. $\mathrm{O}$ valor do desvio padrão dos tempos de resposta indica a variação do atendimento do sistema testado. Por sua vez, a disponibilidade do sistema é verificada através de um heartbeat que monitora possíveis falhas de disponibilidade dos sistemas analisados. A disponibilidade do sistema é tratada em porcentagem. Após a realização das verificações dos serviços SOS e SES, ocorre uma atualização dos parâmetros de QoS no SelectionModule. Como comentado anteriormente, o SelectionModule é responsável por realizar o ranqueamento dos serviços de acordo com os critérios de qualidade de serviço.

A arquitetura apresentada neste capítulo é implementada em um protótipo construído para validar a proposta de inserir um Broker de tratamento de QoS no contexto do SWE. O protótipo foi implementado através das APIs providas pela $52^{\circ}$ North Initiative. Um estudo de caso que valida o protótipo da Sensor Web Architecture é apresentado na Seção 5.4.

\subsection{Estudo de Caso}

Esta seção visa apresentar um estudo de caso que demonstre e valide a utilização da SWARCH. A utilização de um mecanismo intermediário que oferece suporte à descoberta de serviços com base em critérios qualidade de serviço é justificada para o cenário apresentado.

A estação das chuvas no Brasil ocorre sempre no verão entre o período de dia 21 dezembro a 20 de março. Nesse período acontece a maior parte da precipitação média anual no país. Por conta dessas chuvas, o Brasil tem sofrido constantemente com desastres naturais como enchentes e deslizamentos de terras. A região Serrana do Rio de Janeiro, por exemplo, sofre recorrentemente com esse tipo de problema. Uma medida para evitar a perda de vidas humanas é utilização de sistemas de sensoriamento que monitorem constantemente regiões de risco. Em um futuro próximo, pode-se imaginar que empresas especializadas em sensoriamento instalem suas infraestruturas de sensoriamento em regiões com propensão a desastres naturais. Essas empresas podem disponibilizar os dados de sensoriamento pela Web utilizando os padrões do SWE. Dessa forma, desenvolvedores podem implementar diversos tipos de aplicações com diferentes restrições em relação à qualidade de serviço. As empresas fornecerão diferentes infraestruturas com o oferecimento de qualidade de serviço também distintos. Nesse caso, uma arquitetura como a apresentada neste trabalho é importante, uma vez que ela seleciona não somente aspectos funcionais do sistema de sensoriamento, mas também aspectos não funcionais. 


\subsubsection{Planejamento de Experimentos}

O planejamento de experimentos para a validação da SWARCH está apresentado na Tabela 5.2. Dois fatores são considerados nesse planejamento: Utilização do Broker e Quantidade de Threads. Esses dois fatores conduzem a execução de dois tipos de experimentos. O primeiro experimento considera o acesso aos serviços SOS e SES sem a intermediação do Broker. A busca dos sensores é submetida diretamente ao serviço SIR. É importante ressaltar que o consumidor faz a busca por propriedades de observação que estão cadastradas em todas as máquinas virtuais configuradas para a execução da validação. Assim, para o primeiro experimento, o serviço SIR retorna uma lista com todas as possibilidades de serviços para os quais os consumidores podem submeter requisições para a obtenção de alertas ou observações. Então, o consumidor, seleciona aleatoriamente um serviço para submeter requisições.

O segundo tipo de experimento leva em consideração a utilização do Broker no processo de descoberta de serviço. Nesse caso, um parâmetro de QoS é enviado conjuntamente com a mensagem de busca. Diferentemente do primeiro experimento, a mensagem de retorno do Broker informa apenas um serviço. Ou seja, o Broker retorna o melhor serviço em relação ao critério de qualidade serviço estabelecido pelo cliente. Além disso, é importante ressaltar que dez variações para a quantidade de threads são consideradas para essa validação.

Tabela 5.2: Fatores para a Validação da SWARCH

\begin{tabular}{c|c|c}
\hline & Utilização do Broker & Qtd. De Threads \\
\hline 1 & Sem Broker & $10,20,30,40,50,60,70,80,90$ e 100 \\
\hline 2 & Broker & $10,20,30,40,50,60,70,80,90$ e 100 \\
\hline
\end{tabular}

\subsubsection{Ambiente de Testes}

Baseado no contexto de sensoriamento para a prevenção de desastres naturais, a validação da arquitetura proposta neste trabalho é desenvolvida simulando um cenário onde 12 empresas fornecem informações de sensoriamento sobre o nível de concentração de água para uma determinada região. Considera-se, para essa validação, que cada empresa oferece os mesmos serviços e o mesmo tipo de dado. A validação desenvolvida utiliza um gerador de carga de trabalho que está configurado para realizar requisições para ambos os serviços considerados na arquitetura (SES e SOS). Os testes de validação consideram diversas cargas de trabalho imitando o comportamento de consumidores acessando, ao mesmo tempo, o sistema. O tempo de resposta no atendimento das requisições é o parâmetro de qualidade de serviço utilizado nessa validação. Os 12 sistemas foram instanciados em 12 máquinas virtualizadas. Essas 12 máquinas virtuais utilizam três máquinas reais em um cluster de computadores. Por sua vez, as 12 máquinas virtuais possuem diferentes configurações, seguindo as características definidas na Tabela 5.3. 
Tabela 5.3: SWARCH: Configurações de Hardware

\begin{tabular}{c|c|c|c|c}
\hline \multicolumn{5}{c}{ Configuração dos Nós Físicos } \\
\hline \multicolumn{5}{c}{ Intel(R) Core(TM)2 Quad CPU Q9400 of 2.66GHz; } \\
Memória: 8 GB RAM DDR 3. \\
\hline \multicolumn{5}{c}{ Máquinas Virtuais } \\
\hline Capacidade & Quantidade & Qtd. de Processadores & Memória & Disco \\
\hline Baixa & 4 & 1 & $512 \mathrm{MB}$ & $15 \mathrm{~GB}$ \\
\hline Média & 4 & 1 & $1 \mathrm{~GB}$ & $15 \mathrm{~GB}$ \\
\hline Alta & 4 & 2 & $2 \mathrm{~GB}$ & $15 \mathrm{~GB}$ \\
\hline
\end{tabular}

Os serviços SOS configurados nas máquinas contém um banco de dados com observações de nível de concentração de água. O banco de dados utilizado nas avaliações de desempenho apresentadas no Capítulo 4 também foi utilizado neste estudo de caso. A inserção das observações no banco de dados imita o comportamento de uma rede de sensores enviando uma observação a cada 5 minutos ao serviço SOS durante um mês, com um total de 8640 observações. Essa base de dados foi replicada em cada uma das máquinas virtuais destacadas na Tabela 5.3. Diferentemente das avaliações do Capítulo 4, os testes de validação da SWARCH utilizam um filtro de observações para um período de 3 dias. Assim, os testes ao serviço SOS retornam um total de 864 observações. Decidiu-se realizar essa modificação no filtro para aumentar a sobrecarga sobre os servidores que executam os serviços de modo a evidenciar o suporte do Broker nas avaliações.

\subsubsection{Execução dos Experimentos}

A execução dos experimentos na validação da arquitetura seguiu a seguinte metodologia:

- Um ciclo de teste é executado a cada 8 segundos;

- Cada um dos experimentos considera 10 tipos de carga de trabalho variando o número de threads (clientes). A quantidade de threads varia de 10 a 100 (10, 20, 30 ... 100);

- 10 ciclos de testes são executados. Em cada um desses ciclos as threads enviam uma única requisição aos serviços;

- Quatro experimentos foram realizados. Experimentos de avaliação do serviço SOS com e sem a intermediação do Broker. Experimentos do serviço SES com e sem a intermediação do Broker;

- Cada experimento é replicado 30 vezes para a obtenção de uma validade estatística.

\subsubsection{Análise dos Resultados}

Os resultados obtidos na realização da validação da SWARCH também são apresentados com o suporte de gráficos de intervalos de confiança, de interações, efeitos principais e Pareto. Exceto 


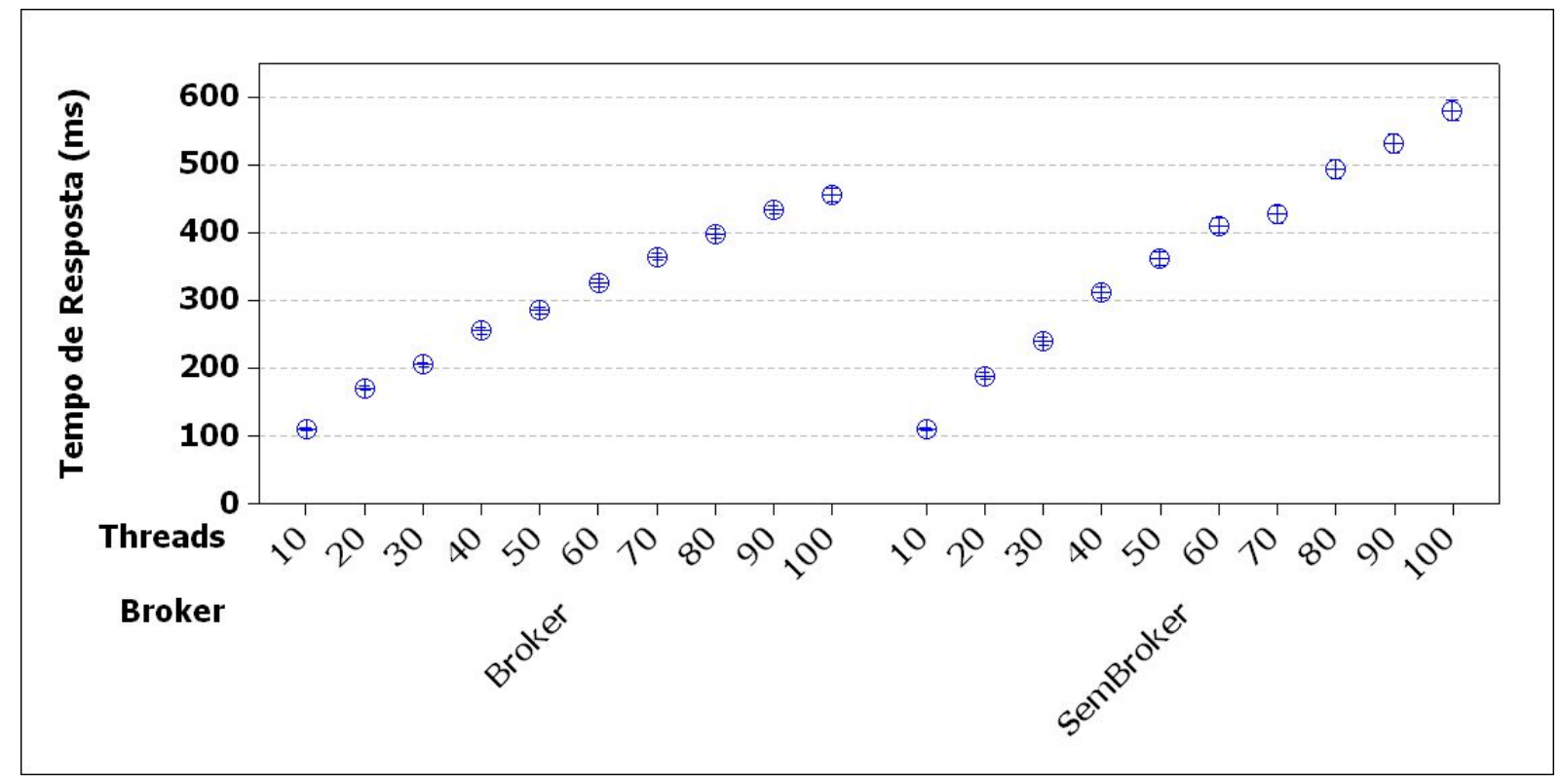

Figura 5.6: SWARCH: Gráfico de Intervalos de Confiança (SES)

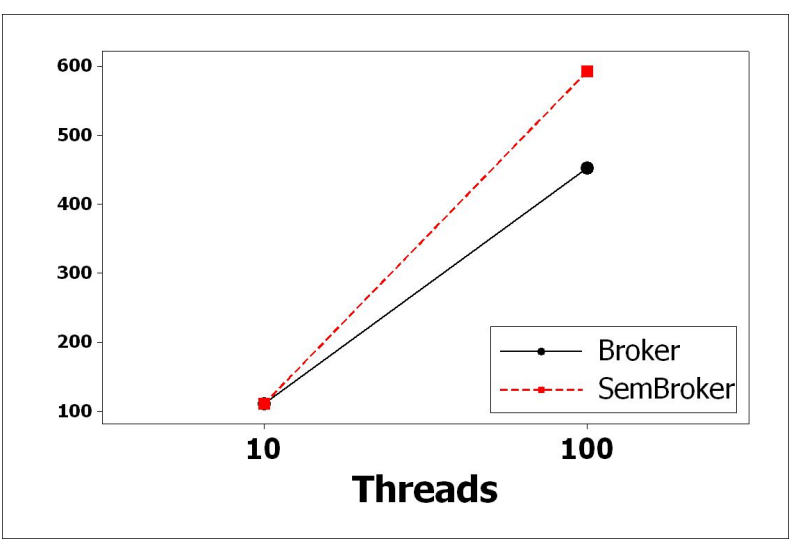

(a) Gráfico de Interações

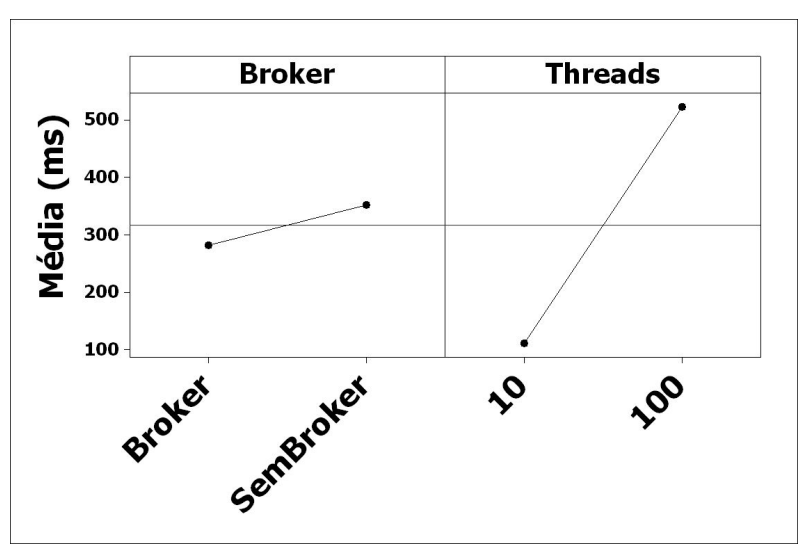

(b) Gráfico de Efeitos Principais

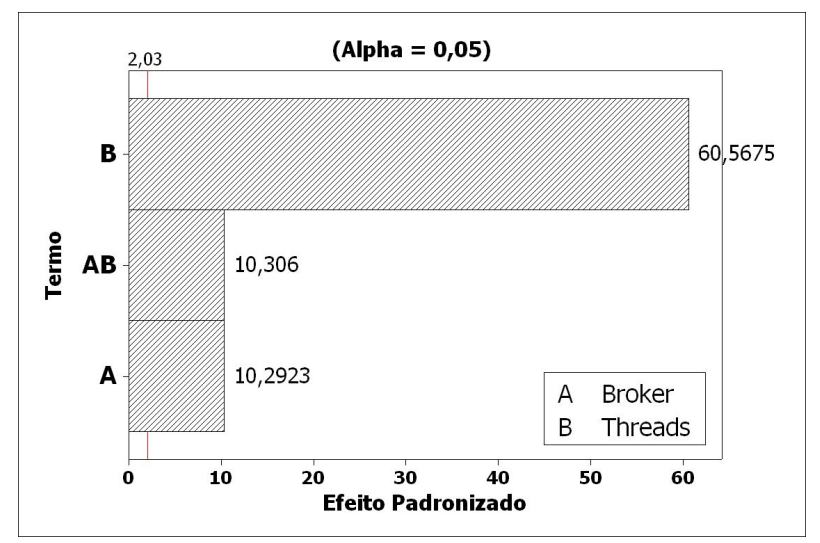

(c) Diagrama de Pareto

Figura 5.7: SWARCH: Gráficos de Análise de Desempenho (SES)

para os gráficos de intervalos de confiança, os demais gráficos mostram uma análise considerando apenas as cargas com 10 e 100 threads. 


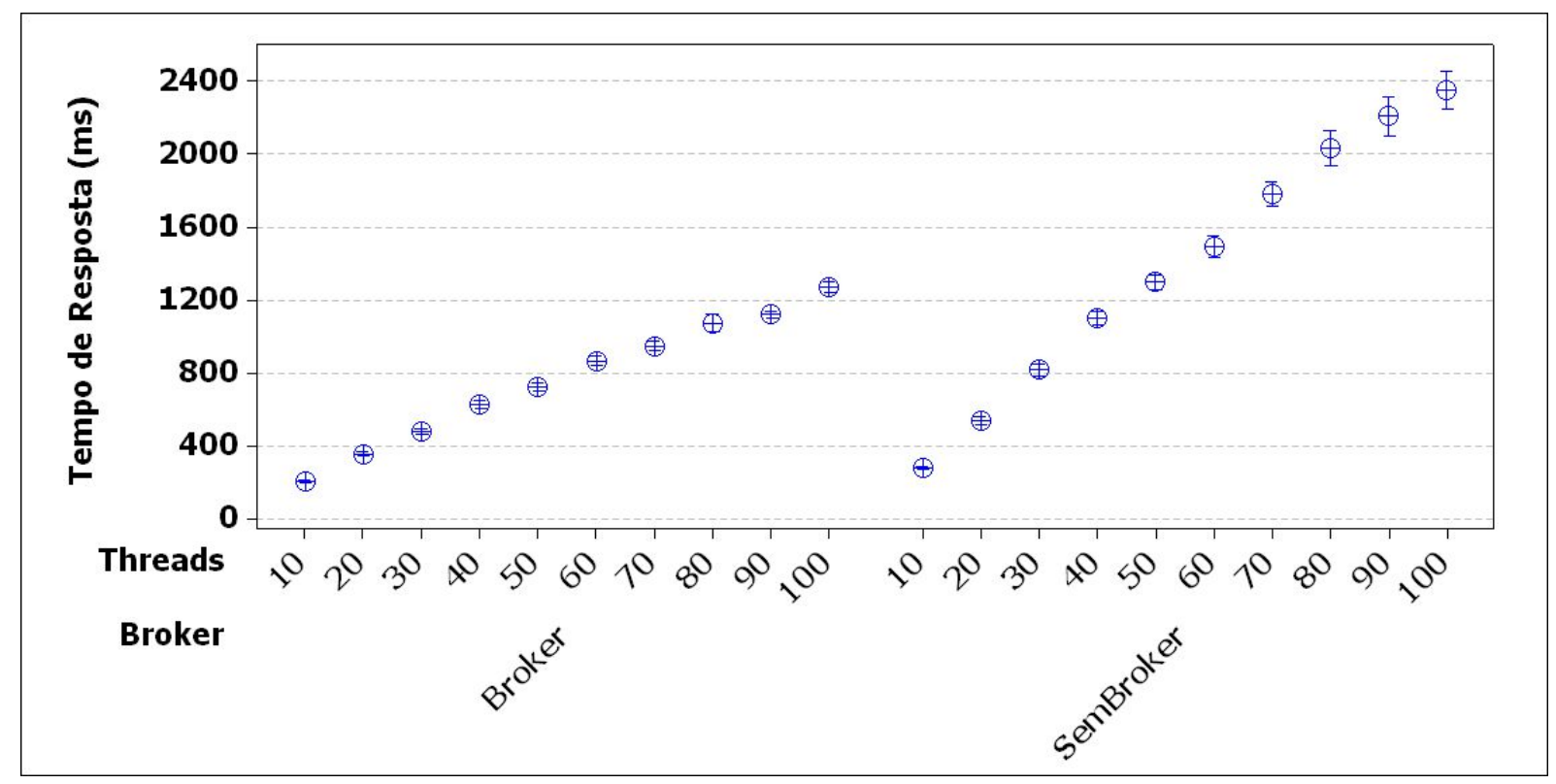

Figura 5.8: SWARCH: Gráfico de Intervalos de Confiança (SOS)

O gráfico da Figura 5.6 mostra os resultados dos experimentos realizados sobre o serviço SES. Para os experimentos realizados sobre o serviço SES, obteve-se uma melhora nos tempos de resposta de até $21,6 \%$, na utilização do Broker em relação aos experimentos sem esse elemento. Embora pequena, é possível observar no gráfico da Figura 5.7(a) uma interação entres os fatores quantidade de threads e utilização do Broker. O gráfico da Figura 5.7(b) evidencia que a maior acentuação dos tempos de resposta ocorre na troca do fator quantidade de threads de 10 para 100. Contudo, há também uma diferença significativa na utilização do Broker em contrapartida a sua não utilização. Por fim, a Figura 5.7(c) mostra um gráfico de Pareto que define a quantidade de threads como o fator mais influente nos testes, seguido do fator utilização do Broker. A utilização do Broker teve influência significativa nos experimentos uma vez que os valores para o Broker no gráfico de Pareto ultrapassou o valor 2.03 que delimita os fatores que não influenciam daqueles que influenciam os tempos de resposta.

Os resultados obtidos para os experimentos realizados sobre o serviço SOS se assemelham proporcionalmente aos experimentos do serviço SES. Nesse caso, o gráfico da Figura 5.8 apresenta os tempos de resposta obtidos para o serviço SOS. Nos experimentos é possível observar que a melhora nos tempos de resposta, utilizando a intermediação do Broker, é superior em relação ao serviço SES. O Broker, utilizado como intermediário na seleção do serviço SOS, fez com que houvesse uma queda nos tempos de resposta de aproximadamente $46 \%$ em relação a sua não utilização. O gráfico de interações entre os fatores (Figura 5.9(a)) demonstra que a variação nos níveis do fator utilização do Broker, para o serviço SOS, acentua as diferenças nos tempos de resposta em comparação aos experimentos do serviço SES. Esse comportamento mostra a ocorrência de uma interação significativa entre os fatores. Ou seja, a modificação da quantidade de threads possui impacto na utilização ou remoção do Broker. 


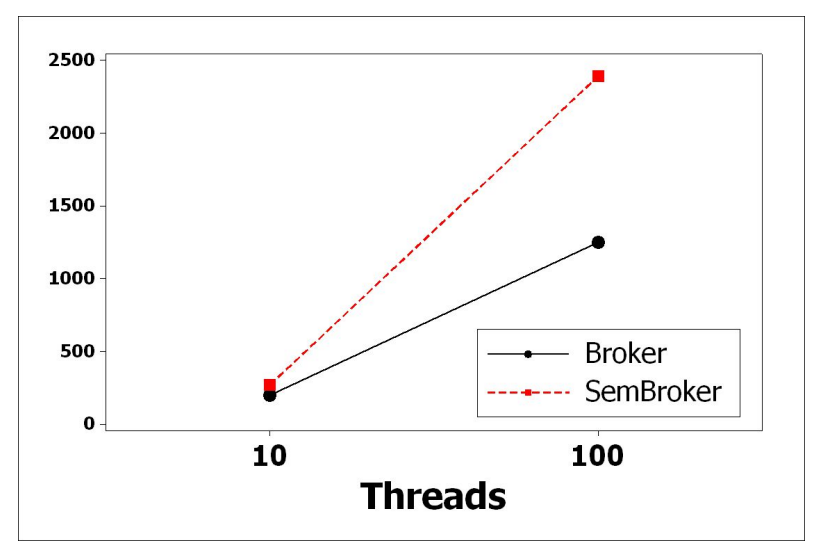

(a) Gráfico de Interações

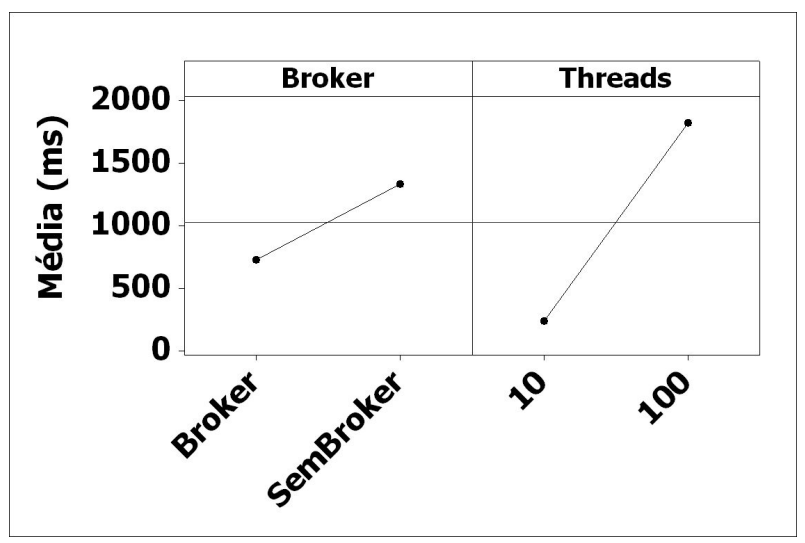

(b) Gráfico de Efeitos Principais

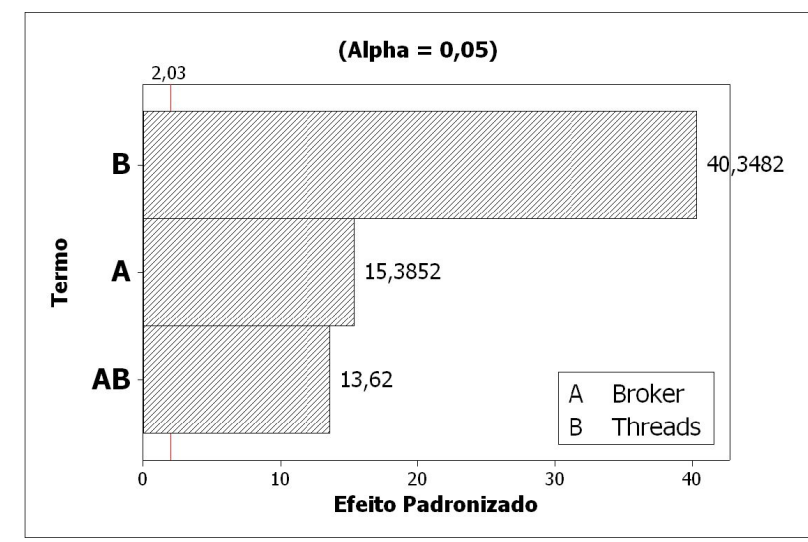

(c) Diagrama de Pareto

Figura 5.9: SWARCH: Gráficos de Análise de Desempenho (SOS)

O gráfico da Figura 5.9(b) apresenta uma maior inclinação da reta dos tempos de reposta para o fator quantidade de threads, evidenciando também um maior aumento na variação dos níveis da quantidade threads em relação à utilização do Broker. Já a quantificação da influência dos fatores é dada através do gráfico de Pareto apresentado na Figura 5.9(c), onde pode ser observado que a quantidade de threads é o fator mais influente nos experimentos. Não obstante, a intermediação do Broker é mais influente nos tempos de resposta quando comparada ao serviço SES. Ou seja, para o serviço SOS, houve uma diminuição da influência do fator quantidade de threads e um aumento da influência do fator utilização do Broker. Entretanto, ambos os experimentos sobre os serviços SES e SOS demonstram uma manipulação mais eficiente do Broker em relação a cargas de trabalho.

Uma informação que deve ser destacada tanto para os serviços SOS quanto para o serviço SES é com relação aos intervalos de confiança obtidos nos experimentos realizados com a utilização do Broker. Os desvios padrão dos experimentos sem o Broker se mostraram mais elevados quando comparados aos desvios padrão dos experimentos incluindo o Broker. Esses resultados mostram que a utilização do Broker torna mais estável os tempos de resposta. Não obstante, os intervalos de confiança mostrados nos gráficos das Figuras 5.8 e 5.6 não se sobrepõem, demonstrando que as diferenças entre os tempos de resposta são estatisticamente distintas. 


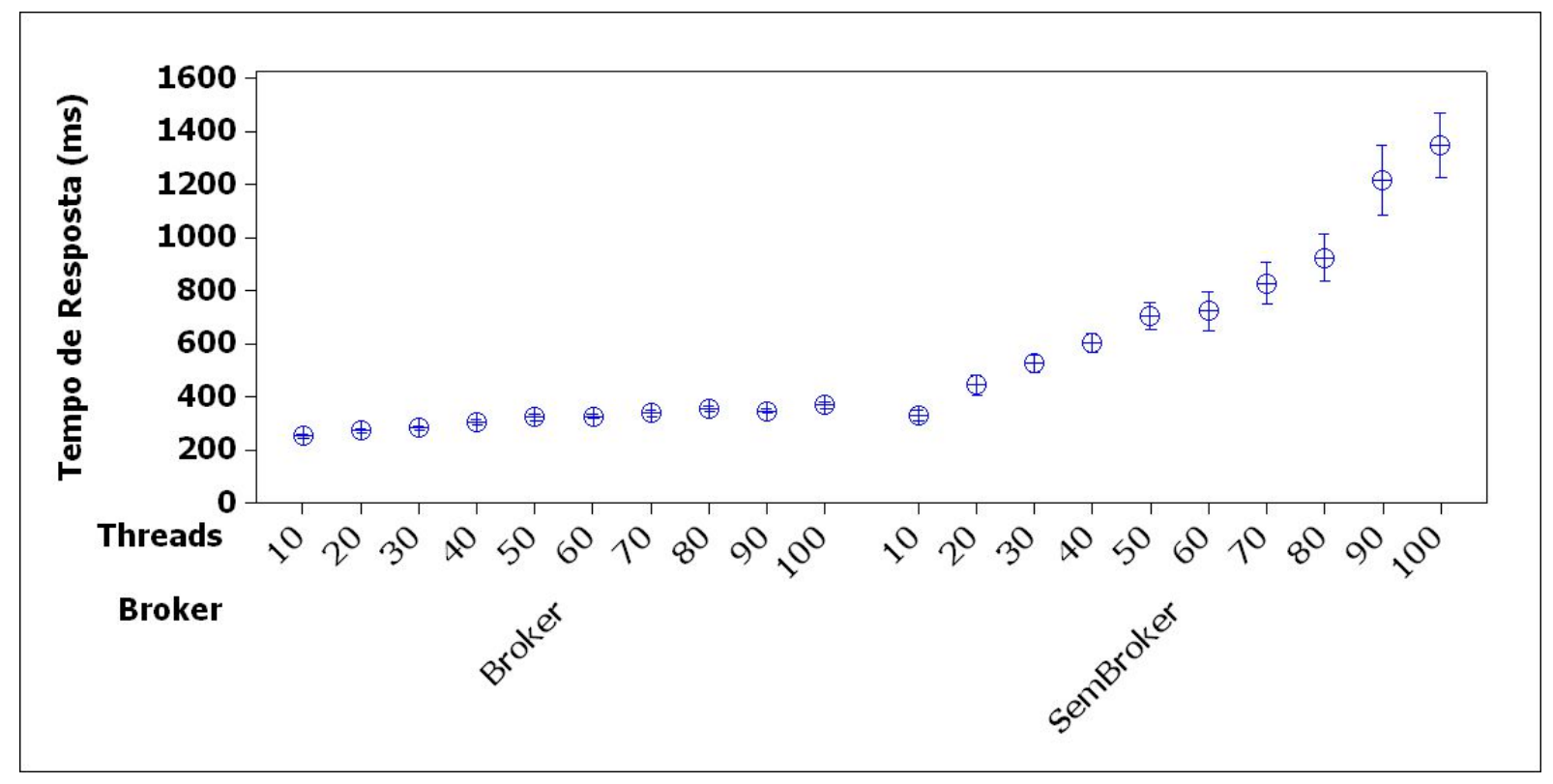

Figura 5.10: SWARCH: Gráfico de Intervalos de Confiança (SIR)

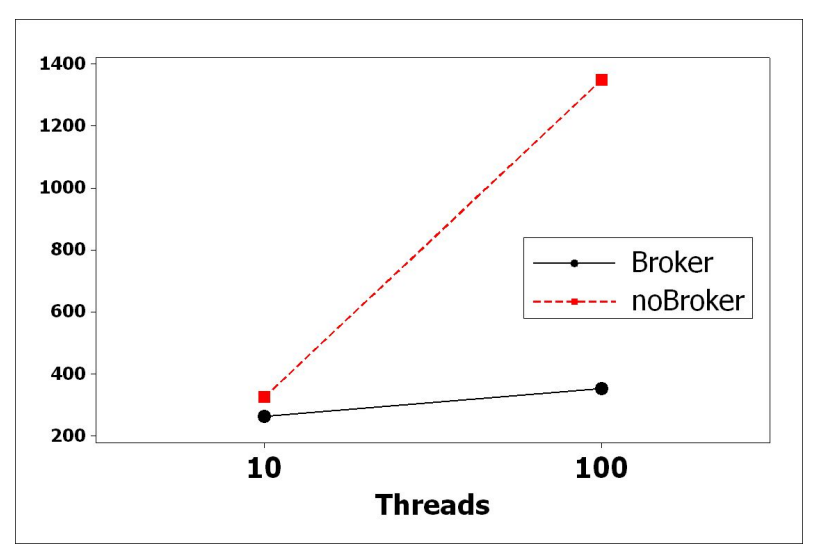

(a) Gráfico de Interações

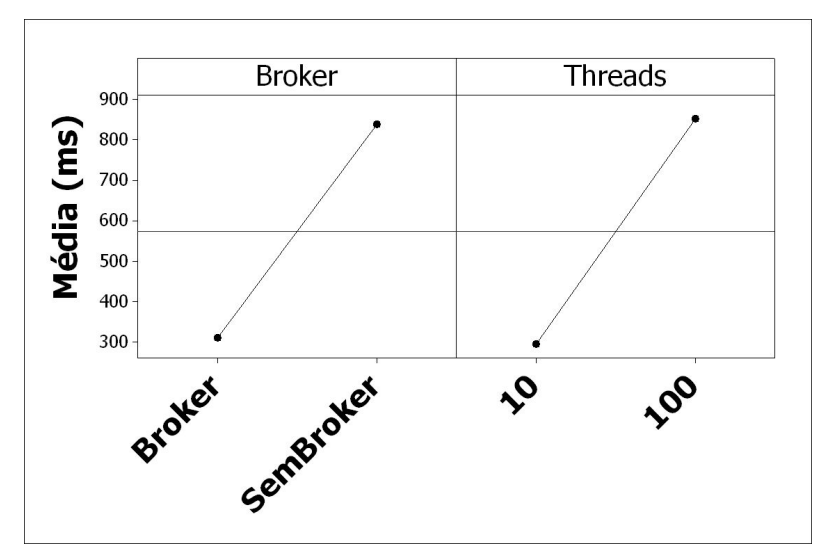

(b) Gráfico de Efeitos Principais

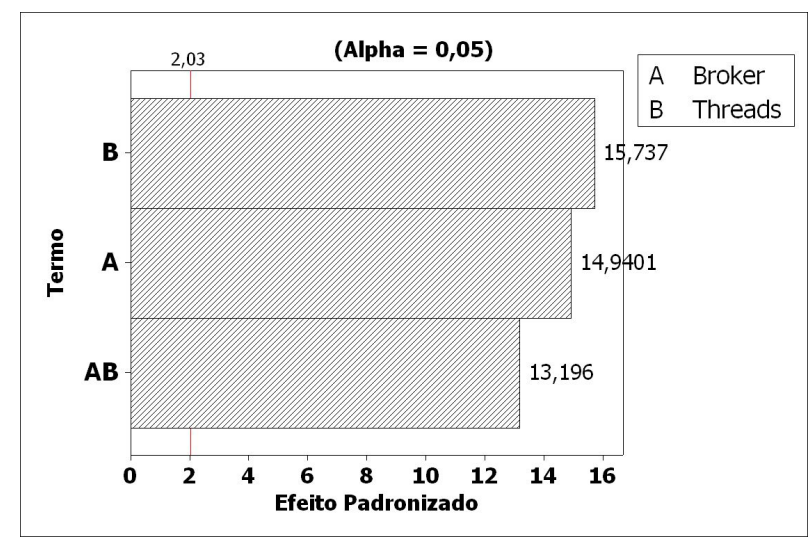

(c) Diagrama de Pareto

Figura 5.11: SWARCH: Gráficos de Análise de Desempenho (SIR)

Finalmente, foram definidos experimentos para verificar a influência do Broker no processo de seleção do serviço. Esses experimentos consideram o tempo de resposta na seleção do serviço 
através da intermediação do Broker, e também, do acesso direto ao serviço SIR. Nesse caso, não é contabilizado o tempo de acesso aos serviços SOS e SES. O Broker possui um sistema de cache que otimiza buscas no SIR. Isso é feito através do armazenamento de mensagens de busca na memória. Cada sistema de sensor possui uma identificação no serviço SIR. Então, a mensagem de busca pode retornar um ou mais identificadores de sensores. Quando uma mensagem de busca chega ao Broker, e essa mensagem está armazenada no cache, o Broker a modifica por uma busca pelo identificador. Como constatado na avaliação de desempenho do serviço SIR apresentada na Seção 4.3, as buscas por identificadores são mais rápidas que as buscas por outros critérios. Entretanto, considerou-se para os experimentos uma taxa de acerto no cache de $40 \%$. Os experimentos foram divididos em dois tipos.

O primeiro tipo leva em conta a intermediação do Broker na seleção do serviço. Em contraste, o segundo experimento considera a seleção pelo serviço SIR. Em outras palavras, o acesso é feito diretamente ao serviço SIR. O gráfico da Figura 5.10 demonstra os tempos de resposta para seleção do serviço. É possível observar que os tempos de resposta para os experimentos realizados com a intermediação do Broker são menores e mais estáveis. Já o gráfico de interações entre os fatores, mostrado na Figura 5.11(a), demonstra que ocorre uma interação entre os fatores considerados. O aumento no número de threads tem impacto no comportamento dos níveis do fator Utilização do Broker. A influência de cada um dos fatores pode ser observada nos gráficos das Figuras 5.11(b) e 5.11(c). A Figura 5.11(b) mostra que as retas de ambos os fatores são semelhantes, mostrando que uma semelhança no percentual de influencia de ambos os fatores. Esse comportamento é confirmado no diagrama de Pareto da Figura 5.11(c). A utilização do Broker teve influência significativa nos resultados dos experimentos, uma vez que essa avaliação considerou apenas os extremos das quantidades de threads (10 e 100 threads). Isso demonstra que a utilização do Broker é bastante influente nos resultados obtidos, mesmo com as diferenças nos tempos de resposta desses dois tipos de carga de trabalho.

\subsection{Considerações Finais}

Este capítulo apresentou uma arquitetura para provisão de qualidade de serviço no contexto dos padrões do SWE, destacando principalmente os serviços SOS e SES. A arquitetura proposta possui, como elemento principal, um Broker que monitora periodicamente parâmetros de QoS nos serviços SWE. O provisionamento de QoS foi implementado através da inserção de um elemento na mensagem de busca do SIR. Esse elemento é utilizado para guiar o Broker na seleção do serviço que cumpre com as exigências definidas pelos consumidores ou aplicações finais. A validação da arquitetura proposta avaliou os tempos de resposta no acesso aos serviços utilizando o Broker como componente intermediário na seleção do serviço. Além disso, um planejamento de experimentos foi definido para avaliar a influência do Broker no processo de seleção. Os resultados demonstraram uma maior eficiência na seleção de serviços realizada pelo Broker, uma vez que os 
tempos de respostas foram estatisticamente inferiores e mais estáveis quando comparados com os resultados obtidos no acesso direto ao registro do serviço (SIR).

Os resultados demostraram que a utilização do Broker pode diminuir os tempos de resposta em até $46 \%$, como apresentado para o serviço SOS. Além disso, a variação dos tempos de resposta tornam-se mais estáveis com a utilização do Broker. Isso foi demonstrado através do cálculos dos desvios padrão e intervalos de confiança. Os tempos de resposta, nos experimentos que utilizaram a intermediação do Broker, apresentaram intervalos de confiança menores. Outro ponto positivo na utilização do Broker foi em relação a inserção de um cache que mantém em memória as descrições de serviços mais requisitados. A taxa de acerto no cache foi estabelecida em $40 \%$ nas experimentações. Nesse cenário, o Broker reduziu significativamente os tempos de resposta. Portanto, pode-se afirmar que a modificação da arquitetura tradicional do SWE, através da inserção de um Broker que monitora constantemente os serviços SWE, melhora os tempos de resposta no acesso a esses serviços. Ainda que a atual fase de implementação da SWARCH não tenha considerado outros parâmetros de qualidade de serviço, é possível que diferentes requisitos sejam incorporados a arquitetura.

O Capítulo 6 apresenta as conclusões desta tese, destacando as respostas às questões definidas na Seção 1.3. Adicionalmente, as contribuições, produção científicas e trabalhos futuros também são destacados. 
trabalho desenvolvido nesta tese aborda a lacuna que diz respeito a estudos que analisem de maneira criteriosa os impactos causados no desempenho das aplicações construídas sobre o paradigma de utilização de arquiteturas orientadas a serviço para acesso à redes de sensores.

Quatro questões coordenam a definição de uma metodologia para a confirmação da hipótese de que os problemas de desempenho não comprometem a utilização de SOA para a exposição de redes de sensores. Todas as avaliações de desempenho executadas neste estudo, assim como a proposição de uma arquitetura de provisão de qualidade de serviço, possibilitaram que os quatro questionamentos fossem respondidos.

A primeira questão refere-se à existência ou não de grandes variações de desempenho na utilização de SOA em relação a outros métodos de acesso, como por exemplo mecanismos binários. Por meio dos experimentos apresentados na Seção 4.2 pode-se concluir que o desempenho desses mecanismos podem variar significantemente. Questões relacionadas a tamanhos das mensagens de requisição e resposta bem como os métodos de encapsulamento utilizados pelos diferentes métodos na manipulação dos dados de sensoriamento impactam diretamente o desempenho no acesso aos serviços. Os resultados obtidos durante a condução dos experimentos mostraram, por exemplo, que métodos de acesso como o serviço SOS podem apresentar tempos de resposta até 17 vezes superiores à utilização de RMI, como pôde ser observado nos resultados dos experimentos que utilizaram filtros que retornavam apenas uma observação (F1) através de solicitações enviadas por duzentas threads.

A segunda questão refere-se à existência de diferenças significativas em relação a desempenho quando se utilizam diferentes formas de implementação de arquiteturas orientadas a serviço que 
abstraem redes de sensores. Os experimentos descritos na Seção 4.2 também mostraram que diferentes implementações de arquiteturas orientadas a serviço possuem diferentes desempenhos. Os serviços SWE, por exemplo, agregam um conjunto de metadados que aumentam os tamanhos e o custo de processamento das mensagens quando comparados com outros mecanismos tais como REST e SOAP. Embora seja um mecanismo não binário, o REST se mostrou bastante eficiente, apresentando valores de tempo de resposta mais baixos e estáveis. Esses resultados podem encaminhar futuras atualizações no que concerne a recomendação de estilos arquiteturais mais eficientes no acesso a redes expostas pelos serviços SWE. Contudo, outros estudos em relação aos impactos causados em uma possível adoção de outros mecanismos de acesso, na manutenção da padronização e interoperabilidade, devem ser conduzidos.

O terceiro questionamento apresentado na introdução refere-se a viabilidade de utilização das arquiteturas orientadas a serviço em aplicações de redes de sensores, devido aos possíveis problemas de desempenho. Pode-se concluir, nesse caso, que a viabilidade depende do tipo de aplicação. Os resultados obtidos nas avaliações de desempenho realizadas neste trabalho de doutorado mostraram que as aplicações que utilizam dados de redes de sensores suportam os problemas de desempenho das arquiteturas orientadas a serviço, uma vez que essas redes, na maioria das vezes, não realizam observações em altas frequências. Ou seja, na maioria dos casos, a periodicidade de medições das redes de sensores permite que métodos tais como os serviços SWE sejam utilizados. Contudo, é importante destacar que redes que exigem maior desempenho podem adotar mecanismos mais eficientes como REST, ou então, técnicas de seleção de serviços computacionalmente mais capacitados.

Finalmente, questiona-se se existe alguma forma de redução dos possíveis problemas de desempenho no contexto de redes de sensores abstraídas por SOA. Essa questão foi tratada por meio da proposta, implementação e avaliação de uma arquitetura de provisão de qualidade de serviço como a apresentada no Capítulo 6, denominada SWARCH. Essa arquitetura pode reduzir os problemas de desempenho, por exemplo, dos serviços SWE. A proposição dessa arquitetura, no contexto do SWE, tem o objetivo de alcançar melhores parâmetros de desempenho com a manutenção dos aspectos de interoperabilidade e padronização. Os resultados de um estudo de caso realizado sobre a SWARCH confirmaram a possibilidade de seleção de serviços que ofertam melhores condições de desempenho em um ambiente onde há oferecimento de dados de sensoriamento, por exemplo, através de várias empresas.

As repostas às perguntas definidas no primeiro capítulo desta tese corroboram com a hipótese defendida neste trabalho de doutorado. Ou seja, pode-se considerar correta a seguinte afirmação: "É possível aplicar arquiteturas orientadas a serviço sem degradar, a ponto de inviabilizar o seu uso, o desempenho no acesso às observações geradas por redes de sensores. A adoção desse modelo arquitetural não compromete os requisitos de qualidade definidos pelos consumidores finais, mesmo que esse tipo de arquitetura adicione uma sobrecarga no desempenho das aplicações construídas sobre ela". Não obstante, a utilização de arquiteturas orientadas a serviço no contexto das redes de sensores pode ser considerada uma alternativa interessante visto que esse paradigma 
carrega os benefícios do provisionamento de interoperabilidade e padronização. A constatação e quantificação dos problemas de desempenho desse paradigma não inviabilizam sua utilização.

\subsection{Dificuldades Encontradas}

Todos os experimentos realizados durante a execução deste projeto de doutorado foram implementados em um ambiente real, com um total de 124 tipos de experimentos. Contabilizando as replicações foram executados mais de 3500 experimentos. Por se tratar de experimentos em ambiente real, muitos problemas ocorreram durante as avaliações, tais como: falhas de software e hardware, quedas de energia e dificuldades de acesso ao ambiente de testes. Além disso, a utilização de algumas APIs e ferramentas utilizadas nas implementações dos experimentos dos serviços SWE, apresentaram alguns problemas, sendo necessário recorrer ao fórum de discussões dessas ferramentas no intuito de encontrar soluções, pois a documentação das mesmas era bastante escassa. É importante também destacar que alguns dos erros encontrados nas APIs foram corrigidos durante o desenvolvimento dos testes, sendo as correções submetidas aos desenvolvedores, como pode ser observado no fórum de discussão da SensorWeb ${ }^{1}$.

\subsection{Contribuições}

As contribuições obtidas com a realização deste projeto de doutorado podem ser destacadas da seguinte forma:

- Estudo e avaliação de diferente mecanismos de acesso a dados aferidos por redes de sensores. Essa avaliação permitiu identificar as diferenças de desempenho entre os diferentes métodos de acesso considerados (um método binário e três tipos de implementações de serviços Web);

- Estudo e avaliação dos serviços SES, SOS e SIR que representam parte do modelo de interface criada pelo SWE. Nessa avaliação verificou-se a influência no desempenho de vários tipos de filtros que podem ser utilizados no acesso a esses serviços;

- Indicação a OGC sobre uma possível inclusão de um mecanismo REST no contexto dos padrões do SWE;

- Criação de um material de referência do framework SWE. O conjunto de padrões e linguagens SWE é extensa e exaustiva. Dessa forma, a presente tese de doutorado contribui no sentido de prover uma material sintetizado sobre oframework;

- Proposição e implementação de um protótipo de provisão de qualidade de serviço para os padrões do SWE. Essa arquitetura, chamada de SWARCH, apresentou bons resultados em uma validação que considerou os tempos de resposta aos serviços como métrica de avaliação;

\footnotetext{
${ }^{1}$ http://sensorweb.forum.52north.org/InsertObservation-Problem-tt4025166.html
} 
- Correção de falhas (bugs) das APIs fornecidas pela 52 North. É importante destacar que essas APIs são disponibilizadas como software livre, podendo ser modificadas ou redistribuídas sob termos da GNU General Public Licence;

- Revisão de literatura que investigou as diferentes possibilidades de acessar redes de sensores, permitindo encontrar as lacunas no contexto de avaliação de desempenho e tratamento de requisitos de qualidade de serviço. Além disso, a revisão bibliográfica permitiu a definição de outros projetos que podem ser executados no futuro, como pode ser observado na Seção 6.4.

\subsection{Produção Científica}

Esta seção apresenta a produção científica produzida durante o desenvolvimento deste projeto de doutorado.

\subsubsection{Artigos Diretamente Relacionados à Tese}

Os seguintes artigos foram publicados no ano de 2013 como resultados do desenvolvimento desse projeto de doutorado:

- Submissão - Sensors Journal - (Qualis A2):

- TAVARES, T. C.; SANTANA, Regina Helenna Carlucci; SANTANA, Marcos José; ESTRELLA, Júlio Cezar; REIFF-MARGANIEC, Stphan. Identifying and Addressing Performance Issues in Sensor Networks based on Service-oriented Architecture. Sensors 2014.

- Publicação - 11th International Conference on Service Oriented Computing (ICSOC 2013) - Qualis A2:

- TAVARES, T. C.; SANTANA, Regina Helenna Carlucci; SANTANA, Marcos José; ESTRELLA, Júlio Cezar. An architecture to provide quality of service in OGC SWE context. Lecture Notes in Computer Science. 1ed.Germany: Springer Berlin Heidelberg, 2013, v. 8274, p. 592-599.

- Publicação - Eighth International Conference on Systems and Networks Communications (ICSNC 2013) - Qualis B3:

- TAVARES, T. C.; SANTANA, Regina Helena Carlucci; SANTANA, Marcos José; ESTRELLA, J. C.. Performance Evaluation on OpenGIS Consortium for Sensor Web Enablement Services. In: The Eighth International Conference on Systems and Networks 
Communications (ICSNC 2013), 2013, Venice. Proceedings of The Eighth International Conference on Systems and Networks Communications. Wilmington, DE: IARIA XPS Press, 2013.

\subsubsection{Artigos Publicados em Coautoria}

Os seguintes artigos foram escritos em coautoria com outros alunos do Laboratório de Sistemas Distribuídos e Programação Concorrente:

- Publicação- International Conference on Telecommunications (IEEE ICT 2010) - Qualis B2:

- PEIXOTO, M. L. M.; SANTANA, Marcos José; ESTRELLA, J. C.; TAVARES , T. C.; KUEHNE, B. T.; SANTANA, Regina H. C.; A Metascheduler Architecture to provide QoS on the Cloud Computing. In: IEEE ICT - International Conference on Telecommunications, 2010, Doha. Track in Networking and Internet Computing, 2010.

- Publicação - IEEE Congress on Services (SERVICES 2010) - (Qualis B2):

- ESTRELLA, JULIO CEZAR; TOYOHARA, RUBENS KENJI T.; KUEHNE, BRUNO TARDIOLE; TAVARES, T.C.; SANTANA, REGINA H.C.; SANTANA, MARCOS J.; BRUSCHI, SARITA MAZZINI. A Performance Evaluation for a QoS-Aware Service Oriented Architecture. In: 2010 IEEE Congress on Services (SERVICES), 2010, Miami. 2010 6th World Congress on Services. p. 260-267.

\subsection{Trabalhos Futuros}

O presente trabalho de doutorado não finaliza as possibilidades de estudo no que tange avaliações de desempenho e provisão de qualidade de serviços para redes de sensores expostas como serviços. Outros estudos podem ser conduzidos a partir dos resultados e constatações encontradas durante o desenvolvimento desta tese. Dentre as possíveis ramificações de trabalhos futuros, destacam-se os seguintes estudos:

- Avaliação de desempenho considerando disponibilidade: disponibilidade pode ser considerada um importante requisito de qualidade de serviço, posto que a maioria dos contratos de prestação de serviços na área de tecnologia da informação consideram tal parâmetro. Embora a SWARCH tenha implementado um módulo de verificação de disponibilidade, um estudo de caso utilizando esse requisito não foi realizado. A realização de estudos de disponibilidade em ambientes reais não é uma tarefa trivial, uma vez que eles devem "simular" o comportamento de um sistema em funcionamento. A literatura trata essa questão através da 
investigação, por exemplo, de distribuições de probabilidade que imitam o comportamento de sistemas reais através da análise de $\log s$, como pode ser observado em (Nurmi et al., 2005). Essas distribuições de probabilidade são facilmente utilizadas em estudos de simulação tradicionais. No entanto, a realização desse tipo avaliação em ambientes reais deve ser investigada com mais profundidade. Isso se deve ao fato de que as falhas de disponibilidade são regidas por distribuições de probabilidade encontradas através de logs reais, considerando meses ou até anos de funcionamento de sistemas reais.

- Adição de novos módulos a SWARCH: a implementação de um protótipo da arquitetura de provisão de qualidade de serviço apresentada no Capítulo 5 pode ser estendida para atender outros serviços do SWE como o SPS. Além disso, outros módulos podem ser criados para o monitoramento de outros tipos de parâmetros de qualidade de serviço, tais como segurança. Requisitos de segurança são importantes no contexto de redes de sensores, e consequentemente, na aplicação dos serviços SWE. Assim, avaliações de desempenho que consideram a adição de mecanismos de segurança podem ser conduzidas com o objetivo de analisar o impacto desse tipo de requisito no SWE.

- Sensores reais: tanto as avaliações de desempenho quanto a validação da SWARCH foram implementadas utilizando um banco de dados previamente populado com observações de sensoriamento que simularam uma rede de sensores enviando aferições. No entanto, a realização de testes e utilização da SWARCH, tendo como plano de fundo uma rede de sensores real, configura uma possibilidade de trabalho futuro. Esse trabalho deverá ser executado no IFSULDEMINAS-Câmpus Inconfidentes, onde uma infraestrutura com equipamentos foi adquirida recentemente para o monitoramento de resíduos sólidos urbanos aterrados em um lisímetro;

- Internet das Coisas (Internet of Things): trabalhos que consideram a avaliação de desempenho e provisão de qualidade de serviços da aplicação dos padrões e linguagens do SWE para o contexto da Internet das coisas representam uma possibilidade de trabalhos futuros. A utilização dos padrões do SWE nesse contexto já vem sendo matéria de estudo no OGC. Além disso, o OGC criou um novo grupo, denominado de Sensor Web for IoT (SWIOT), que é responsável pela definição de novos padrões que visam um melhor ajuste na aplicação de uma arquitetura orientada a serviço para atender às características da Internet das coisas. Essa movimentação do consórcio em relação aplicação dos conceitos do SWE no âmbito da Internet da coisas indica que a pesquisa nesse cenário começa a se tornar uma realidade. 


\section{Exemplo de um documento SensorML}

Esta seção apresenta um exemplo simples de como um documento SensorML deve ser descrito. A linguagem básica pra descrever um documento SensorML é o XML. Uma estação meteorológica é utilizada pra exemplificar os detalhes de um documento SensorML básico. O exemplo contém um conjunto básico de metadados que podem ser utilizados para descrever um sistema de sensoriamento. Os elementos keywords e identifier estão descritos, respectivamente, nas linhas 2 e 11 do Código A.1. Essas propriedades permitem determinar diferentes termos de descrição e identificação da estação meteorológica em questão, facilitando a busca desse sistema por motores de busca. No caso do elemento identification, são definidos três identificadores diferentes: uniqueID (definido por um URN), longName e shortName.

Por sua vez, elementos de classificação e definição de tempo, pelo qual as observações obtidas dos sensores são válidas, estão demonstrados no Código A.2. O exemplo fornece informações sobre qual tipo de aplicação o sensor se destina (classificação). Além disso, pode-se observar que os sensores são expostos para a criação de aplicações climáticas (clima - linha 6) e possui observações válidas entre os dias 15 e 20 de janeiro de 2014 (linhas 14 e 15).

O fragmento de código apresentado no Código A.3 demonstra dois elementos: capabilities e contact. O primeiro é composto por dois itens principais: status (linha 4) e observedBBOX (linha 10). O status define a condição de operação do sistema. No exemplo, a estação está definida como ativa. Adicionalmente, o elemento (observedBBOX) é utilizado para especificar a área observada pela estação meteorológica. A definição da área se dá através de duas coordenadas (lowerCorner e upperCorner). Já o elemento contact (linha 18), informa o contato do operador da estação meteorológica. No exemplo, a estação meteorológica está sob a responsabilidade do Laboratório de Sistemas Distribuídos e Programação Concorrente do ICMC. 
Código A.1: Elementos keywords e identification

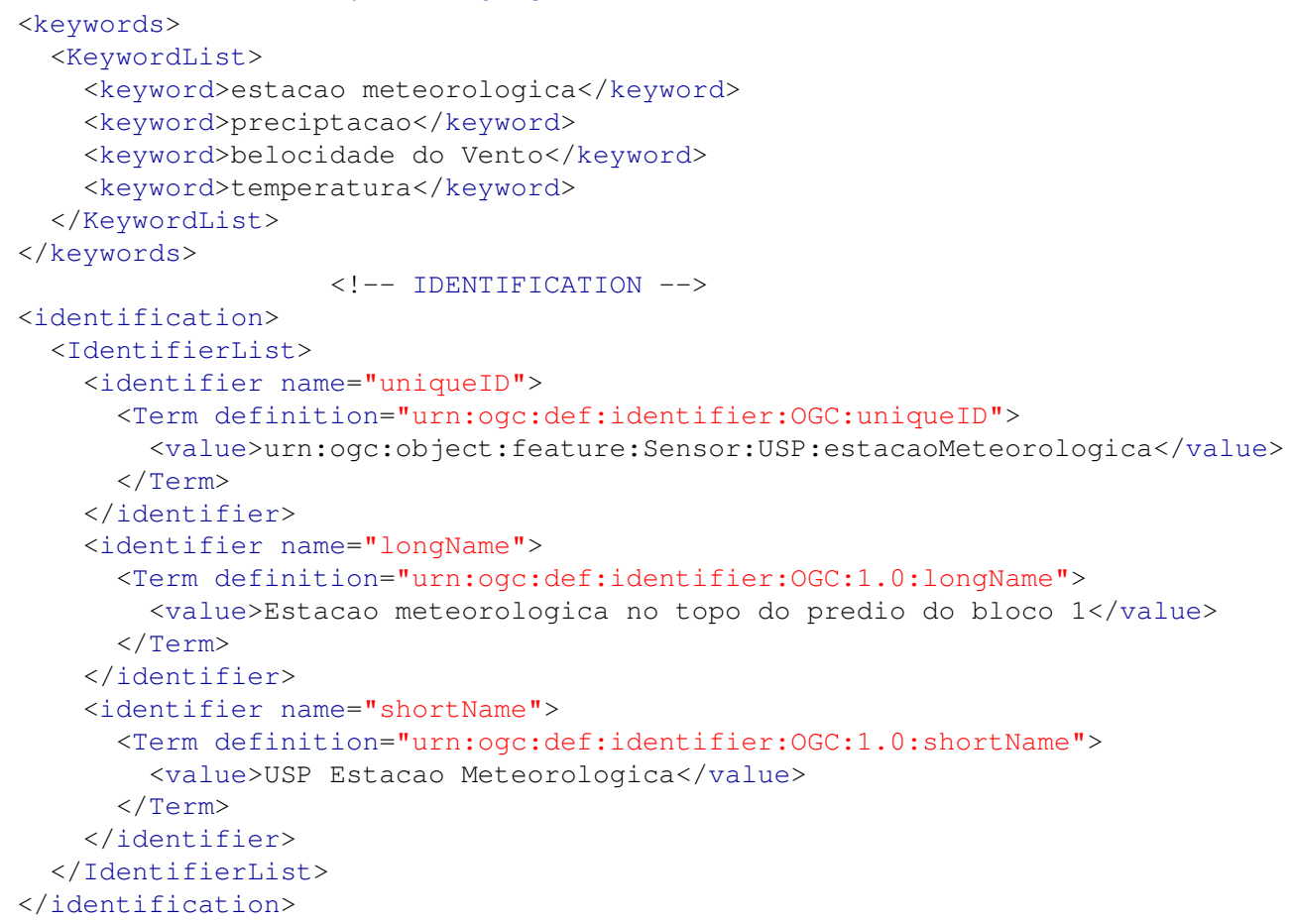

\section{Código A.2: Elementos classification e validTime}

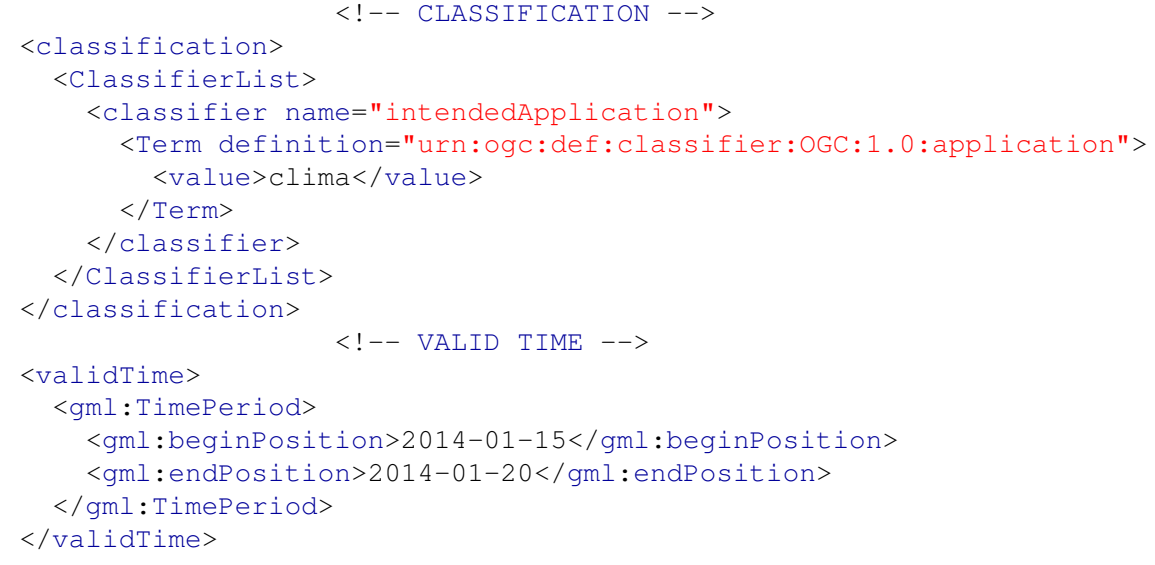


Código A.3: Elemento capabilities

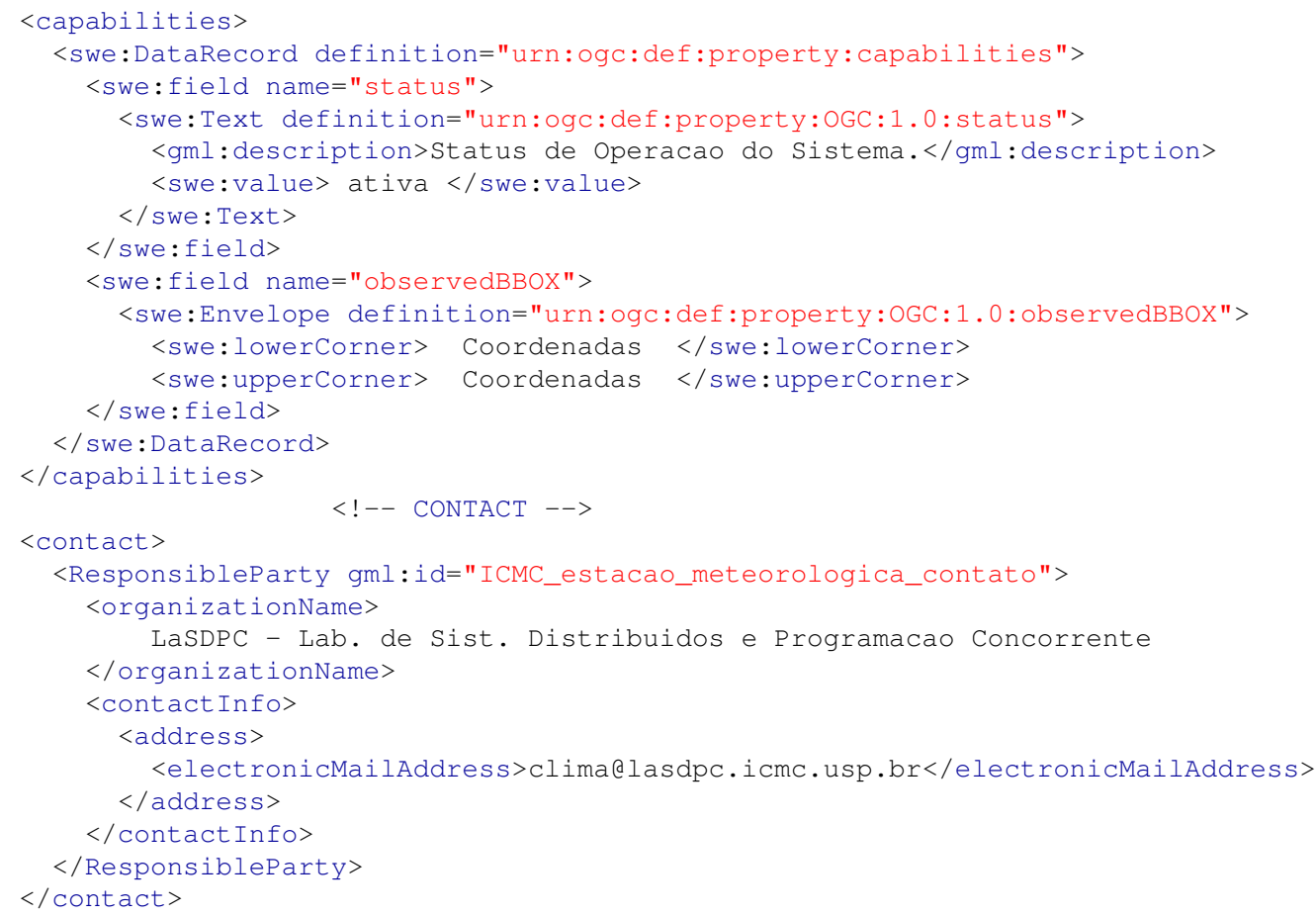

Uma outra informação importante dentro de um documento SensorML é descrita na seção de posicionamento. Para definir a localização do sistema de sensoriamento é necessário utilizar o elemento position. No exemplo do Código A.4, o posicionamento da estação meteorológica pode ser idêntica àquela definida na seção observedBBOX. O posicionamento depende do tipo de sensor que está sendo definido pelo documento SensorML. Em geral, sensores in-situ, discutidos na Seção 2.1, possuem a mesma localização definida na seção bouding box, enquanto que essas informações são diferentes para sensores remotos.

Os parâmetros de entrada e saída são definidos através dos elementos input e output. Um exemplo de definição desses parâmetros é apresentado no Código A.5 onde estão definidos três fenômenos (entradas) observados por uma estação meteorológica: precipitação, vento e temperatura. Por outro lado, os parâmetros de saída são definidos no elemento output. Dadas as entradas, apresenta-se o resultado do processamento das mesmas resultando na geração de quatro valores de saída: precipitação, direção e velocidade do vento e temperatura. Ou seja, o parâmetro de entrada vento possibilitou a geração de dois valores distintos: direção e velocidade do vento.

Como discutido na Seção 3.2.2, o elemento component é utilizado pra descrever um processo físico. Exemplos de componentes podem ser representados por transdutores (detectores e atuadores), clocks, baterias e etc. Um exemplo de código de um componente é apresentado no Código A.6. Nesse caso, é apresentado a descrição de um termômetro. 
Código A.4: Elemento position

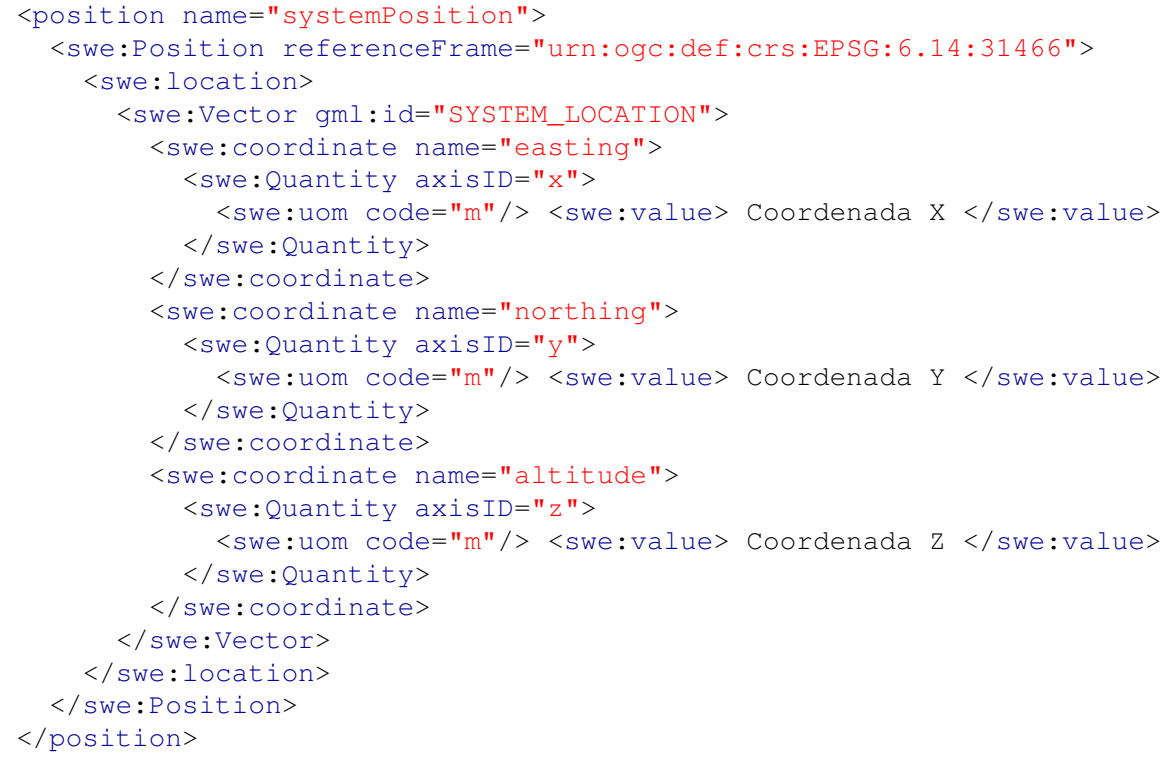

Código A.5: Elemento inputs

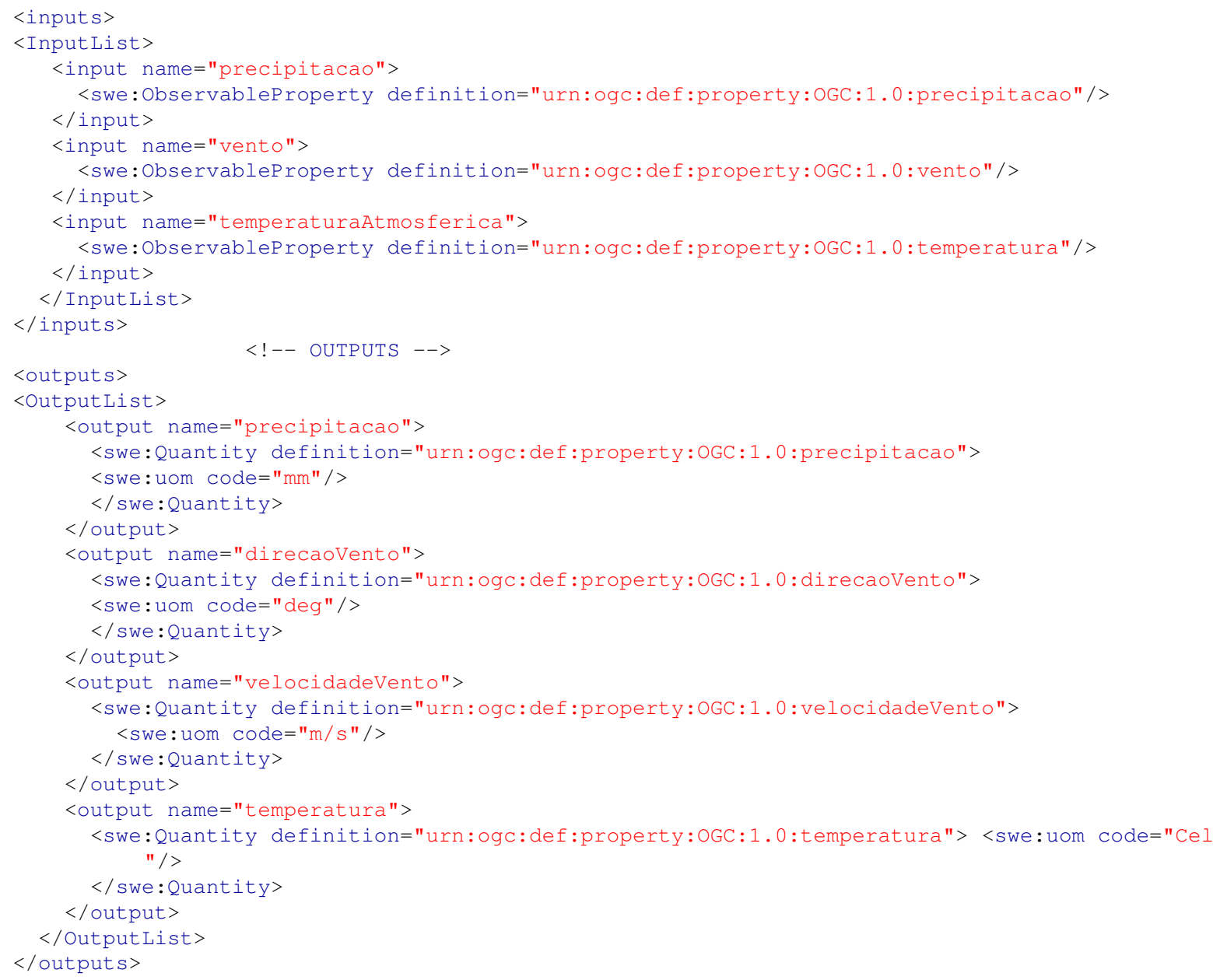


Código A.6: Elemento component

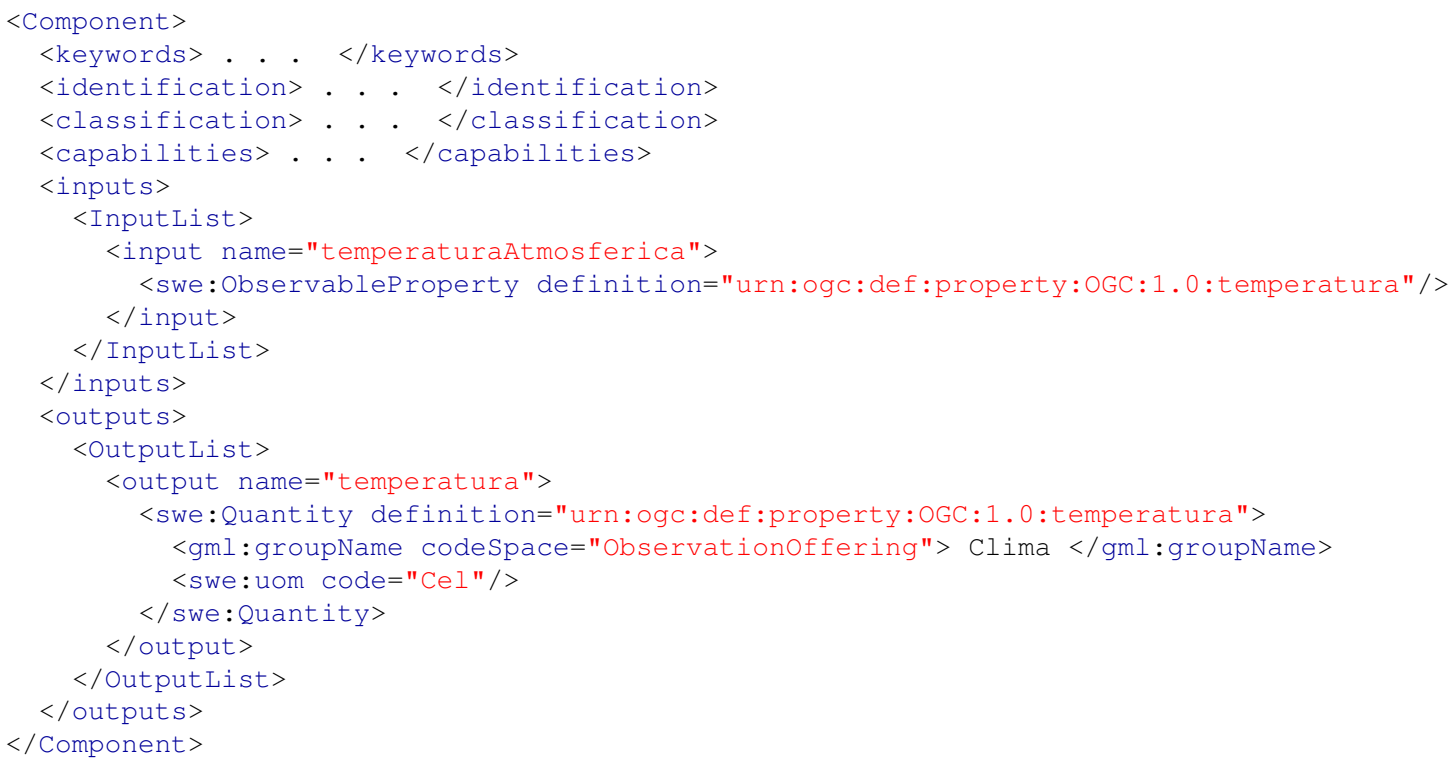



APÊNDICE

\section{$B$}

\section{Códigos Complementares}

\section{B.1 Métodos de Acesso}

Esta seção apresenta os códigos das mensagens trocadas pelos métodos de acesso na avaliação de desempenho discutida na Seção 4.2. Todos os códigos apresentados nesta seção foram obtidos através do software Wireshark ${ }^{1}$.

Código B.1: Métodos de Acesso: Requisição RMI

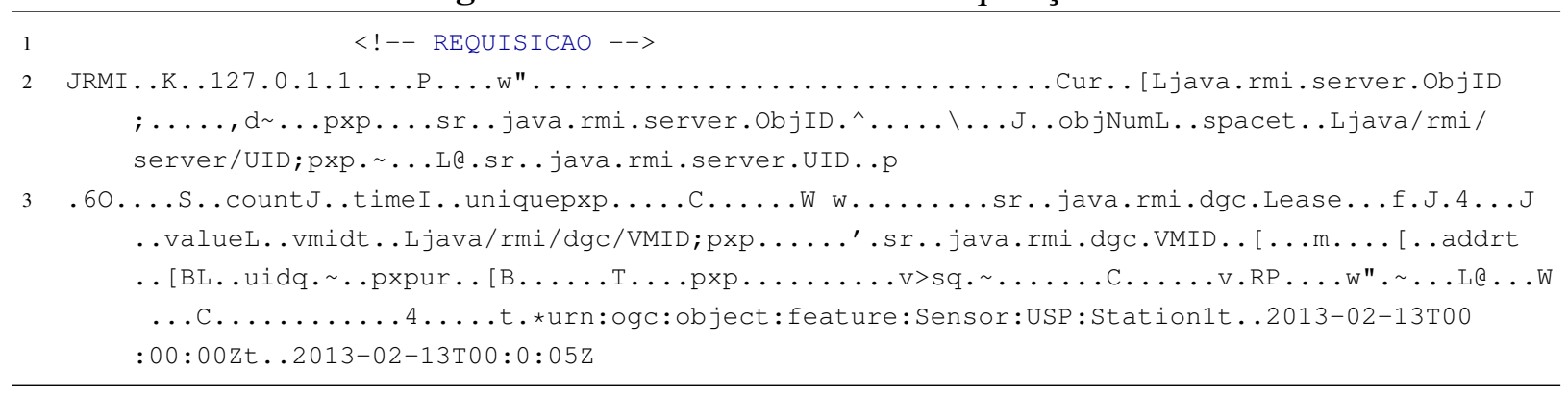

Código B.2: Métodos de Acesso: Resposta RMI

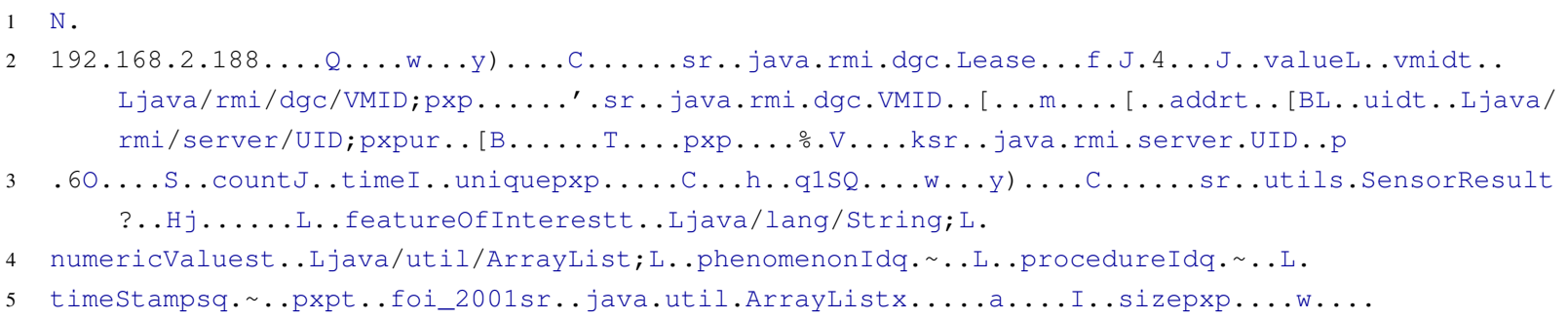

${ }^{1}$ Wireshark é um analisador de protoloco de rede que pode ser encontrado em http://www.wireshark.org/ 
6 sr..java.lang.Double...J)k.......valuepxr..java.lang.Number........pxp@.333333xt.4urn:ogc : def:property:OGC:1.0:waterLevelConcentrationt.*urn:ogc:object:feature: Sensor:USP:

Station1sq. ...........

7 sr..java.sql.Timestamp\&....S.e...I..nanospxr..java.util.Datehj..KYt....pxpw.....H..x..".x

\section{Código B.3: Métodos de Acesso: Requisição REST}

$1 \mathrm{GET} / \mathrm{com}$.usp.sensor.jaxb/rest/sensor?startTime=2013-02-13T00:00:00Z\&endTime=2013-02-13T00 :05:59Z\&procedure=urn:ogc:object: feature: Sensor:USP: Station 1 HTTP/1.1

2 Accept: application/xml

3 User-Agent: Java/1.7.0_51

4 Host: $192.168 .2 .127: 8080$

5 Connection: keep-alive

\section{Código B.4: Métodos de Acesso: Resposta REST}

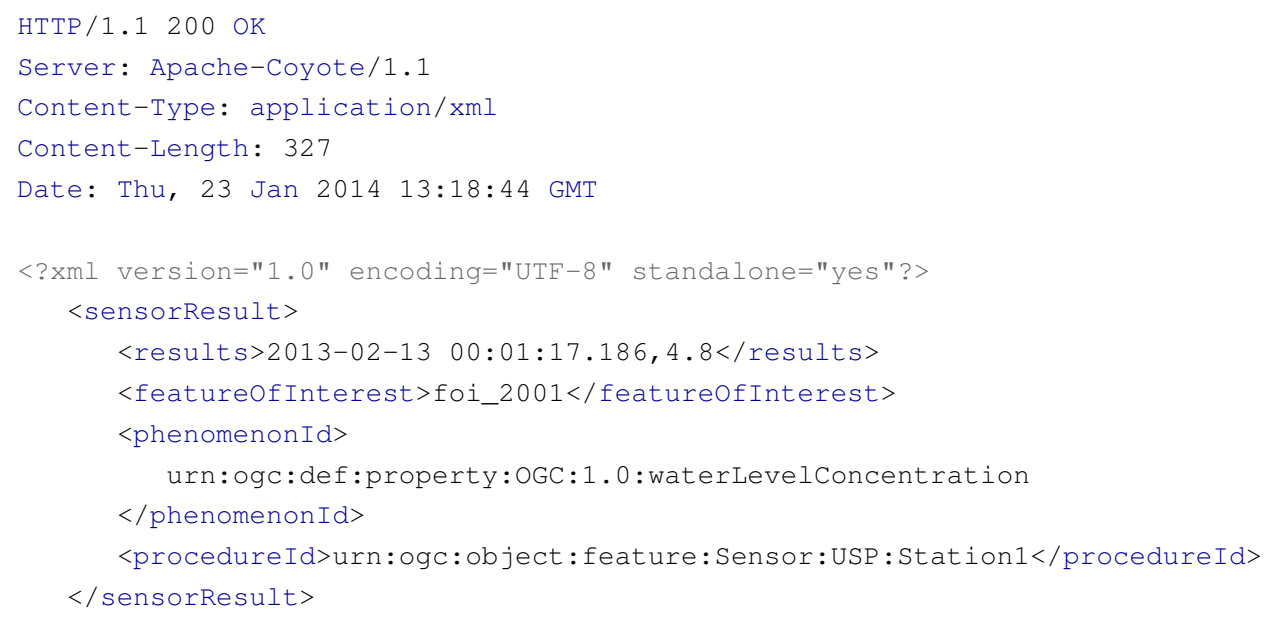

Código B.5: Métodos de Acesso: Requisição SOAP

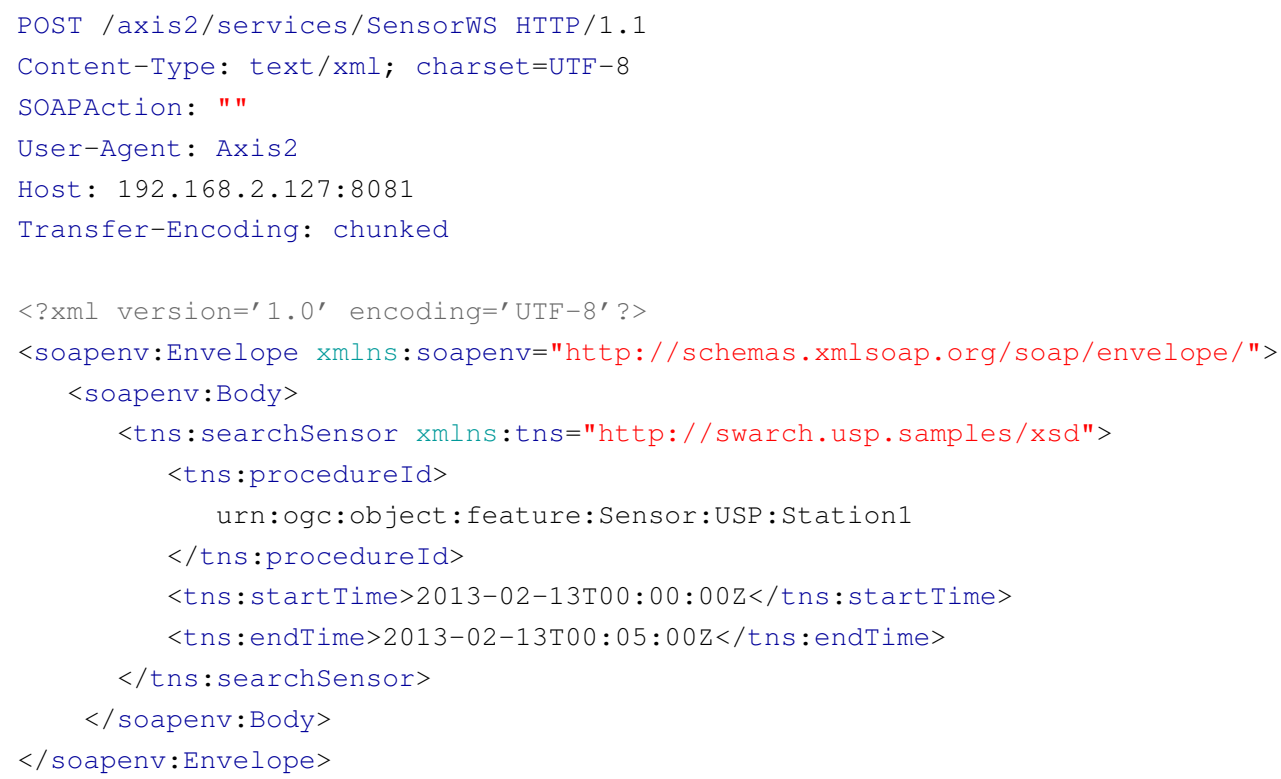

Código B.6: Métodos de Acesso: Resposta SOAP

\footnotetext{
$1 \quad \mathrm{HTTP} / 1.1200$ OK

2 Date: Mon, 03 Feb 2014 16:56:49 GMT
} 


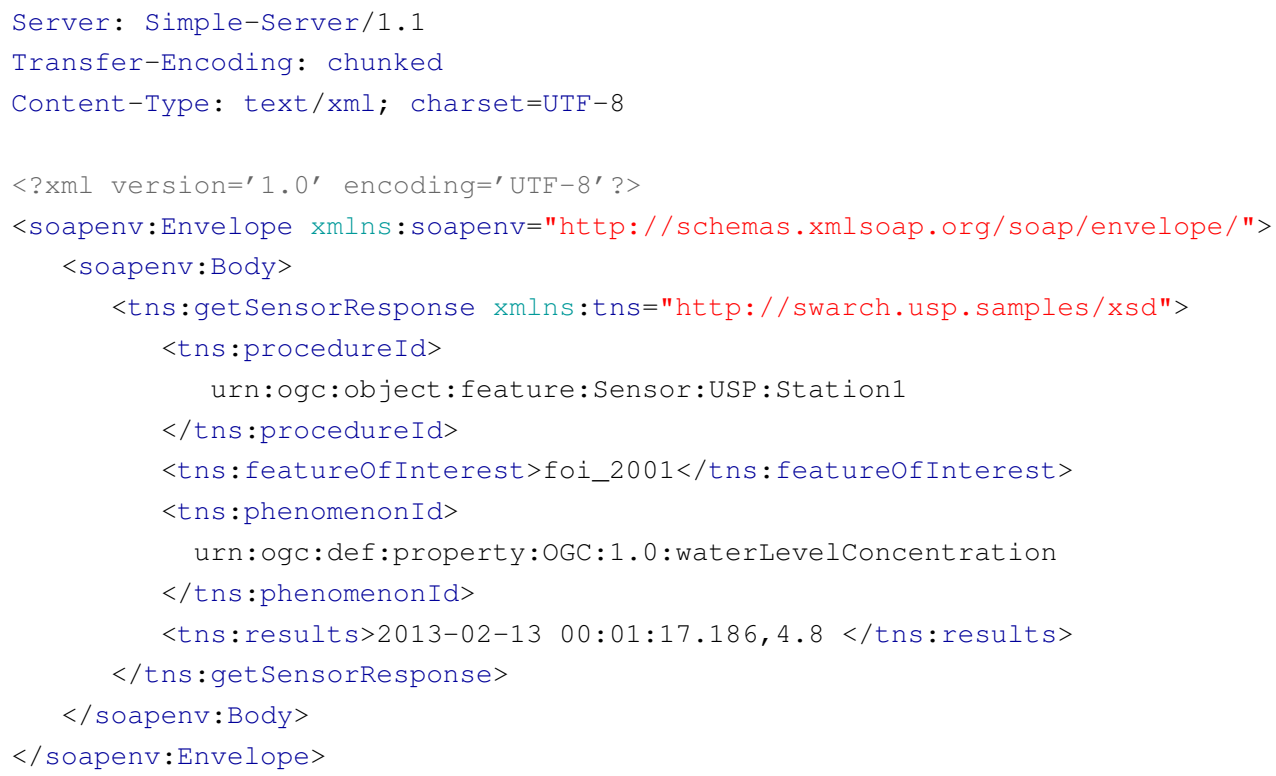

Código B.7: Métodos de Acesso: Requisição SOS

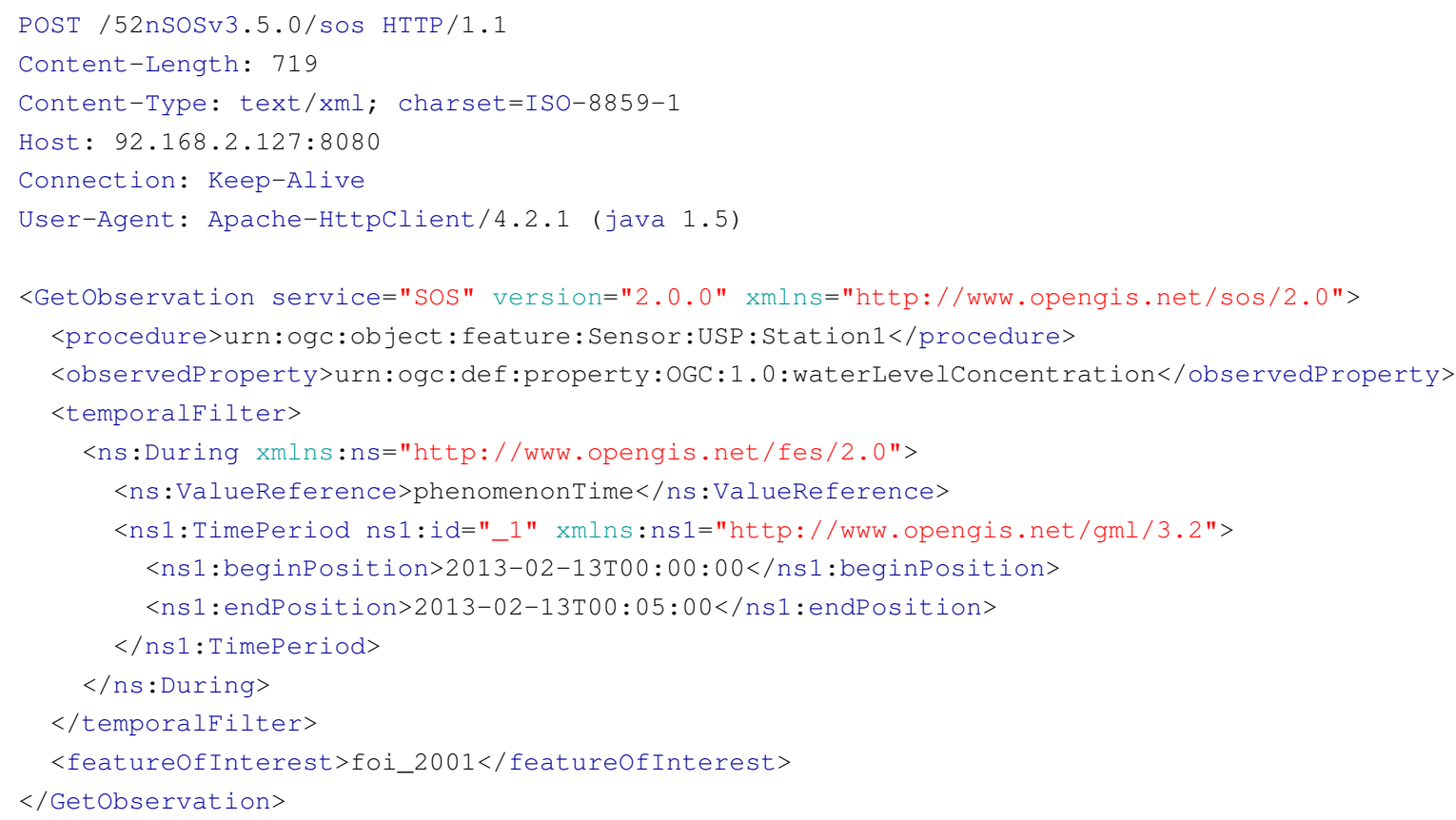

Código B.8: Métodos de Acesso: Resposta SOS

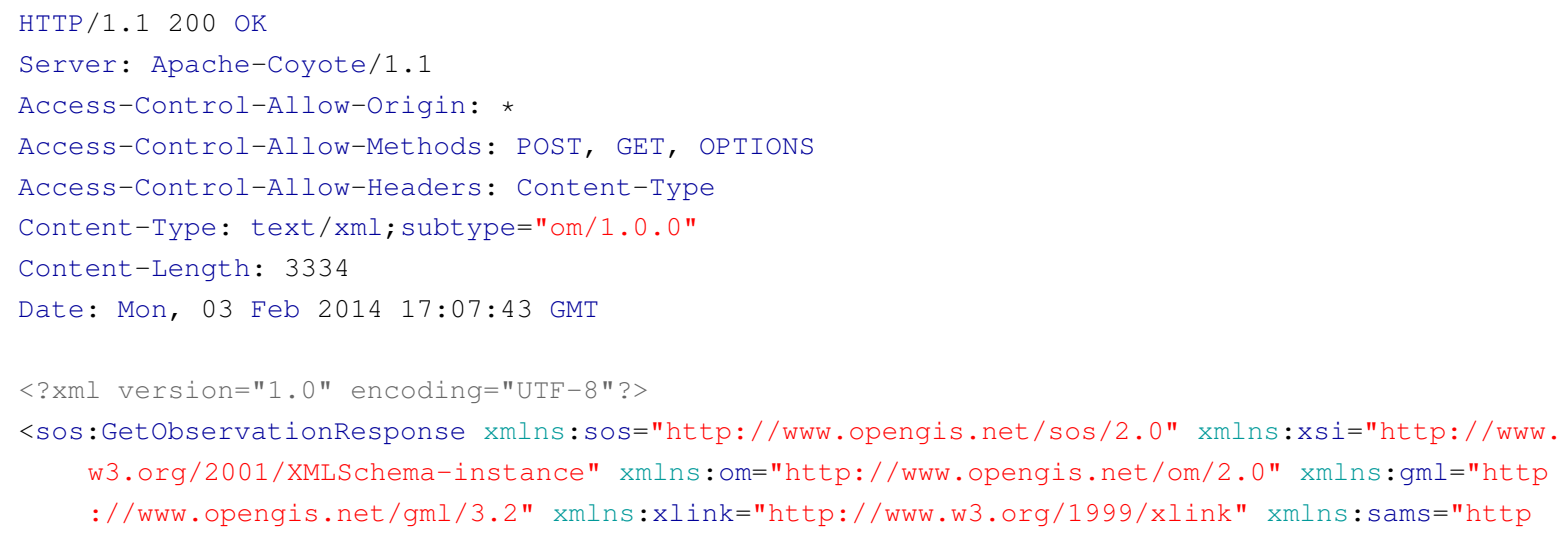


://www.opengis.net/samplingspatial/2.0" xmlns:sf="http://www.opengis.net/sampling/2.0" xsi:schemaLocation=" http://www.opengis.net/sos/2.0 http://schemas.opengis.net/sos/2.0/ sos.xsd http://www.opengis.net/om/2.0 http://schemas.opengis.net/om/2.0/observation.xsd http://www.opengis.net/sampling/2.0 http://schemas.opengis.net/sampling/2.0/ samplingFeature.xsd http://www.opengis.net/samplingspatial/2.0 http://schemas.opengis.net / samplingSpatial/2.0/spatialSamplingFeature.xsd">

<sos:observationData>

<om:OM_Observation gml:id="o_1374695629488">

<om:type xlink:href="http://www.opengis.net/def/observationType/OGC-OM/2.0/

OM_SWEObservation"/>

$<$ om: phenomenontime>

<gml:TimeInstant gml:id="phenomenonTime_o_1374695629488">

<gml:timePosition>2013-02-13T00:01:17.186z</gml:timePosition>

$</$ gml:TimeInstant $>$

$</ o m:$ phenomenonTime>

<om:resultTime xlink:href="\#phenomenonTime_o_1374695629488"/>

<om:procedure xlink:href="urn:ogc:object:feature:Sensor:USP:Station1"/>

<om:observedProperty xlink:href="urn:ogc:def:property:oGC:1.0:waterLevelConcentration"/

<om:featureofInterest xlink:title="foi_2001">

<sams:SF_SpatialSamplingFeature gml:id="sf_o">

<gml:identifier codeSpace=" ">foi_2001</gml:identifier>

<sf:type xlink:href="http://www.opengis.net/def/samplingFeatureType/OGC-OM/2.0/ SF_SamplingPoint"/>

<sf:sampledFeature xlink:href="urn:ogc:def:nil:oGC:unknown"/>

$<$ sams:shape>

<gml:Point gml:id="point_sf_o">

<gml:pos srsName="http://www.opengis.net/def/crs/EPSG/0/4326">51.77 7.3</gml: pos>

$</$ gml: Point $>$

$</$ sams: shape $>$

$</$ sams:SF_SpatialSamplingFeature $>$

$</$ om: featureofInterest $>$

<om:result xmlns:swe="http://www.opengis.net/swe/2.0" xsi:type="swe:

DataArraypropertyType">

$<$ swe:DataArray>

$<$ swe:elementCount>

$<$ swe: Count $>$

$<$ swe: value $>1</$ swe:value $>$

$</$ swe: Count $>$

$</$ swe:elementCount $>$

$<$ swe:elementType name="Components">

$<$ swe: DataRecord >

<swe:field name="phenomenonTime">

<swe:Time definition="http://www.opengis.net/def/property/oGC/0/

PhenomenonTime">

<swe:uom xlink:href="http://www.opengis.net/def/uom/ISO-8601/0/Gregorian"/>

$</$ swe:Time $>$

$</$ swe:field $>$

<swe:field name="waterLevelconcentration">

<swe:Quantity definition="urn:ogc:def:property:OGC:1.0: waterLevelconcentration">

<swe:uom code $=" \mathrm{~cm} " />$

$</$ swe: Quantity $>$

$</$ swe:field $>$

$</$ swe: DataRecord $>$

$</$ swe:element Type $>$

$<$ swe: encoding >

<swe:TextEncoding decimalSeparator="." tokenSeparator="," blockSeparator=" ;"/> 


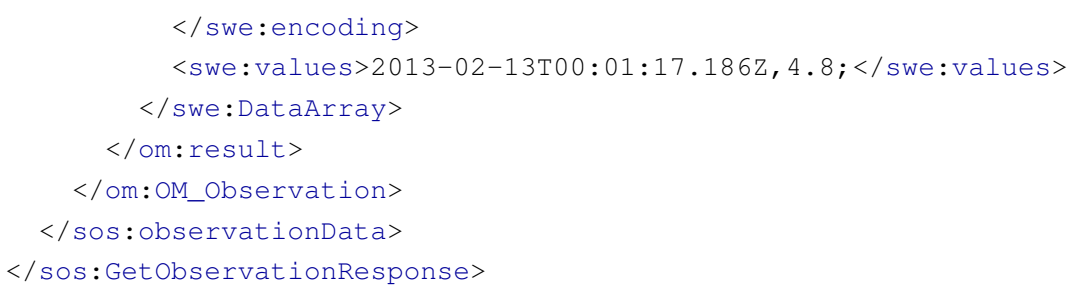

\section{B.2 SWE}

Código B.9: SWE: Level1 Subscription

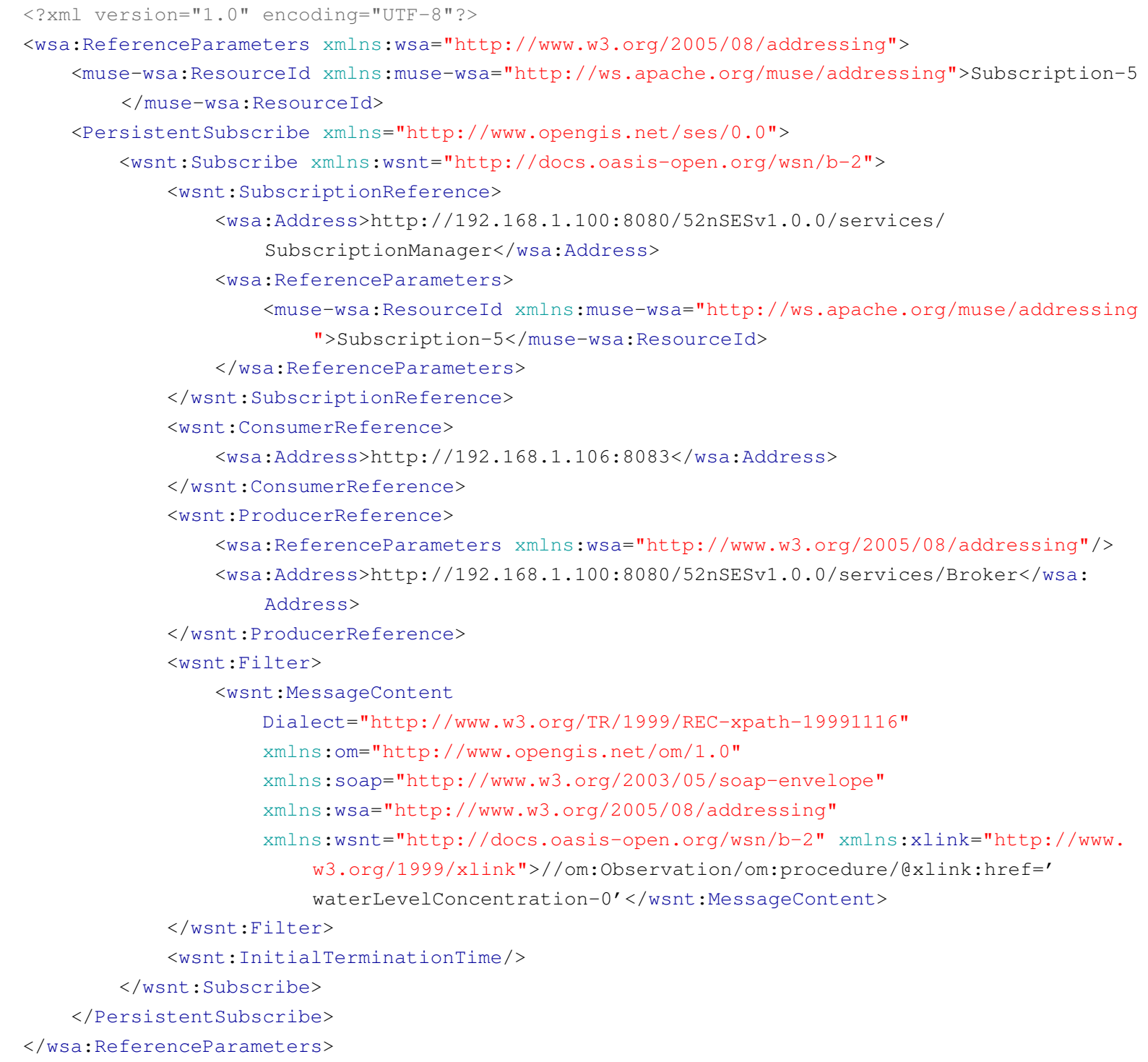

Código B.10: SWE: Level2 Subscription

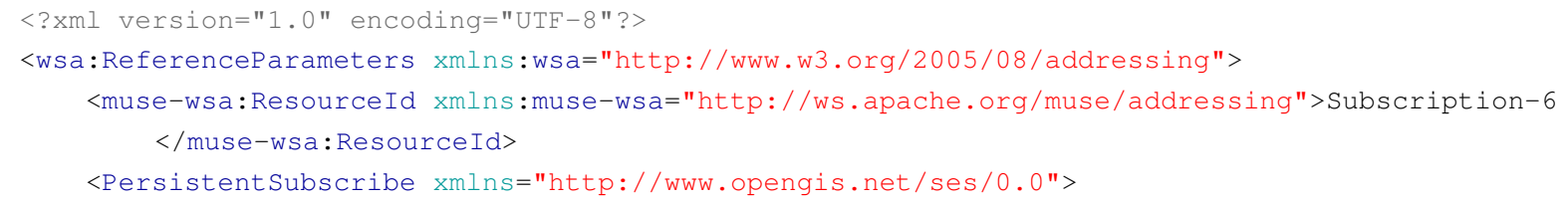


<wsnt:Subscribe xmlns:wsnt="http://docs.oasis-open.org/wsn/b-2">

<wsnt:SubscriptionReference>

<wsa:Address>http://192.168.1.100:8080/52nSESv1.0.0/services/

SubscriptionManager $</$ wsa: Address $>$

$<w s a:$ ReferenceParameters>

<muse-wsa:ResourceId xmlns:muse-wsa="http://ws.apache.org/muse/addressing

">Subscription-6</muse-wsa: ResourceId>

$</$ wsa: ReferenceParameters $>$

$</$ wsnt: SubscriptionReference>

<wsnt:ConsumerReference>

<wsa:Address>http://192.168.1.106:8082</wsa:Address>

$</$ wsnt: ConsumerReference $>$

<wsnt:ProducerReference>

<wsa:ReferenceParameters xmlns:wsa="http://www.w3.org/2005/08/addressing"/>

<wsa:Address>http://192.168.1.100:8080/52nSESv1.0.0/services/Broker</wsa:

Address>

$</$ wsnt:ProducerReference $>$

$<$ wsnt:Filter $>$

<wsnt:MessageContent Dialect="http://www.opengis.net/ses/filter/level3">

<EML xmlns="http://www.opengis.net/eml/0.0.1">

$<$ SimplePatterns>

<SimplePattern inputName="sensorStream" patternID="

defaultsimplepattern">

$<$ SelectFunctions $>$

<SelectFunction newEventName=" " outputName="output ">

$<$ SelectEvent eventName="sensorStream"/>

$</$ SelectFunction $>$

$</$ SelectFunctions $>$

$<$ View $>$

$<$ LengthView $>$

$<$ EventCount $>1</$ EventCount $>$

$</$ LengthView $>$

$</$ View $>$

$<$ Guard $>$

$<$ fes:Filter

xmlns="http://www. opengis.net/wfs"

xmlns:fes="http: //www. opengis.net/fes/2.0"

xmlns: gml="http://www. opengis.net/gml/3.2"

xmlns:ows="http://www.opengis.net/ows" xmlns:swe="http:// www. opengis.net/swe/1.0.1">

$<$ fes:Within>

<fes:ValueReference>input/geometry</fes:ValueReference>

$<$ fes:Literal>

<gml:Polygon gml:id="aoi_01">

$<$ gml: exterior>

$<$ gml: LinearRing>

<gml:posList>58.0 $10.0 \quad 40.0 \quad 10.0 \quad 40.0 \quad 3.0 \quad 58.0 \quad 3.0</ g m l:$ posList>

$</$ gml: LinearRing $>$

$</$ gml :exterior $>$

$</$ gml: Polygon>

$</$ fes:Literal>

$</$ fes:Within $>$

$</$ fes:Filter $>$

$</$ Guard $>$

$<$ PropertyRestrictions/>

$</$ SimplePattern $>$

$</$ Simplepatterns $>$

$<$ Complexpatterns/> 


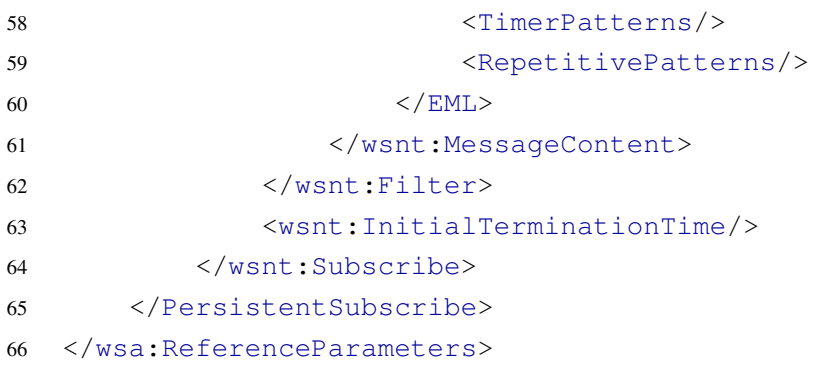

\section{Código B.11: SWE: SES Notification}

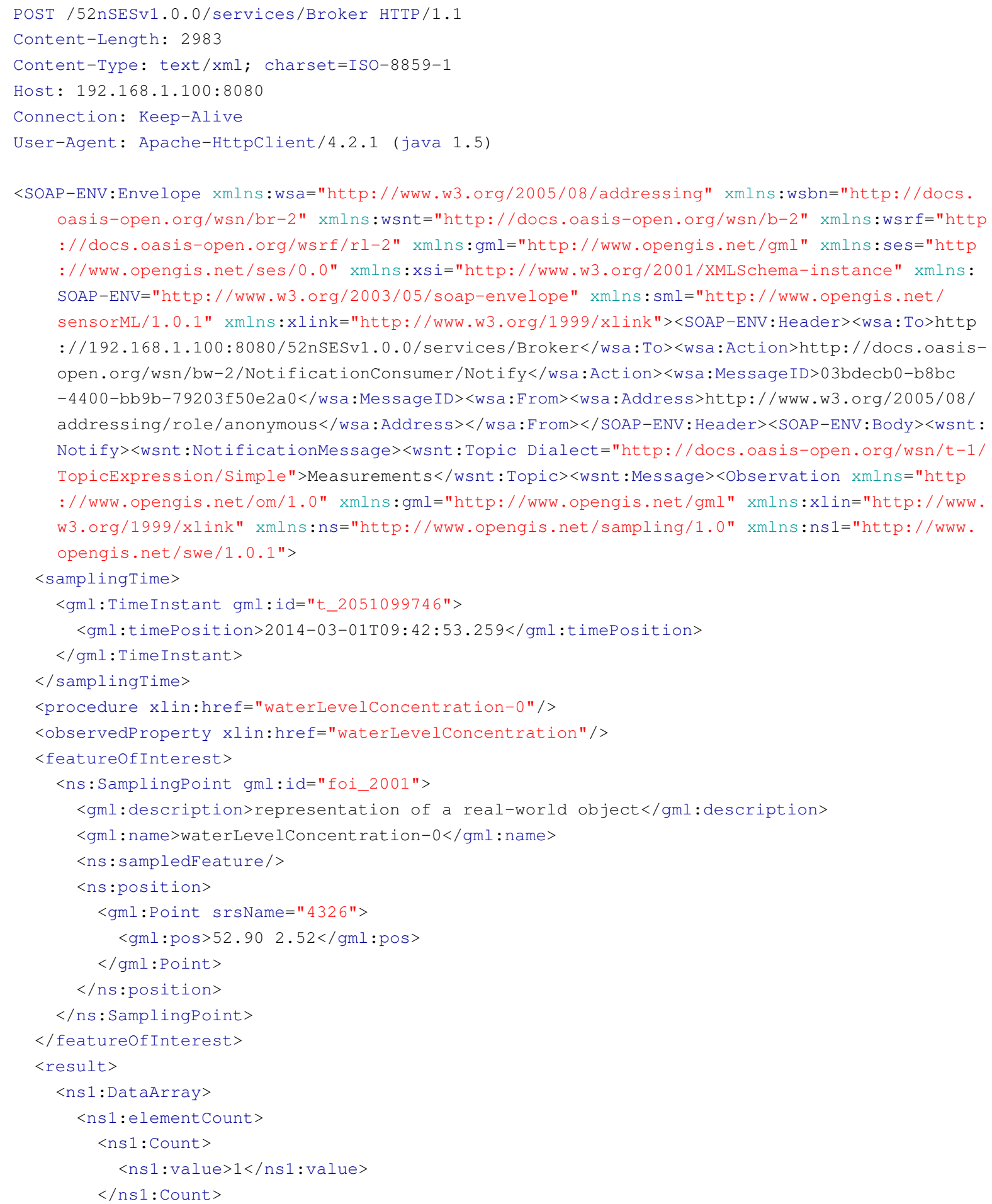


$34</$ ns1:elementcount $>$

$35<$ ns1:element Type name="Components">

$36<$ ns1:DataRecord $>$ 
52NoRTH 52north - exploring horizons. Disponível em: http://52north.org/. Último acesso: 21/01/2014, 2014a.

52NORTH Ox-framework. Disponível em: http://52north.org/communities/ sensorweb/oxf/. Último acesso: 28/01/2014, 2014b.

Aberer, K.; Hauswirth, M.; SAlehi, A. Infrastructure for data processing in large-scale interconnected sensor networks. In: Mobile Data Management, 2007 International Conference on, 2007, p. 198-205.

AKYILDIZ, I.; Vuran, M. C. Wireless sensor networks. New York, NY, USA: John Wiley \& Sons, Inc., 2010.

AmeEn, M.; LiU, J.; KwAK, K. Security and privacy issues in wireless sensor networks for healthcare applications. Journal of Medical Systems, v. 36, n. 1, p. 93-101, 2012.

Disponível em: http://dx.doi.org/10.1007/s10916-010-9449-4

APACHE Apache axis2. Disponível em: http://ws.apache.org/axis2/.. Último acesso: 21/10/2014, 2014a.

APACHE Apache tomcat. Disponível em: http://tomcat.apache.org/.. Último acesso: 21/01/2014, 2014b.

Bröring, A.; EChTERHOFF, J.; JiRKA, S.; Simonis, I.; EVERding, T.; StAsCh, C.; LiAnG, S.; Lemmens, R. New generation sensor web enablement. Sensors, v. 11, n. 3, p. 2652-2699, 2011.

Disponível em: http: / /www . mdpi . com/1424-8220/11/3/2652

Burrell, J.; Brooke, T.; Beckwith, R. Vineyard computing: Sensor networks in agricultural production. IEEE Pervasive Computing, v. 3, n. 1, p. 38-45, 2004. 
Casola, V.; Gaglione, A.; Mazzeo, A. Sensim-web: A service based architecture for sensor networks integration. In: Industrial Electronics, 2009. IECON '09. 35th Annual Conference of IEEE, 2009, p. 2665-2671.

Ceriotti, M.; Mottola, L.; Picco, G.; Murphy, A.; Guna, S.; Corra, M.; Pozzi, M.; ZONTA, D.; ZANON, P. Monitoring heritage buildings with wireless sensor networks: The torre aquila deployment. In: Information Processing in Sensor Networks, 2009. IPSN 2009. International Conference on, 2009, p. 277-288.

Chen, D.; VARshney, P. K. Qos support in wireless sensor networks: A survey. In: International Conference on Wireless Networks'04, 2004, p. 227-233.

Chen, J.; DíAz, M.; Llopis, L.; Rubio, B.; Troya, J. M. A survey on quality of service support in wireless sensor and actor networks: Requirements and challenges in the context of critical infrastructure protection. J. Netw. Comput. Appl., v. 34, n. 4, p. 1225-1239, 2011.

Disponível em: http://dx.doi.org/10.1016/j.jnca.2011.01.008

Chu, X.; Buyya, R. Service oriented sensor web. In: MAhalik, N. P., ed. Sensor Networks and Configuration, Springer Berlin Heidelberg, 2007, p. 51-74.

Colan, M. Service-oriented architecture expands the vision of web service. 2004.

Contiki Contiki: The open source os for the internet of things. Disponível em: http:// www. contiki-os.org/. Último acesso: 14/01/2014, 2014.

Cucuringu, M.; Lipman, Y.; Singer, A. Sensor network localization by eigenvector synchronization over the euclidean group. ACM Trans. Sen. Netw., v. 8, n. 3, p. 19:1-19:42, 2012. Disponível em: http://doi.acm.org/10.1145/2240092.2240093

Curino, C.; Giani, M.; Giorgetta, M.; Giusti, A.; Murphy, A.; Picco, G. Tinylime: bridging mobile and sensor networks through middleware. In: Pervasive Computing and Communications, 2005. PerCom 2005. Third IEEE International Conference on, 2005, p. 61-72.

Delen, D.; Demirkan, H. Data, information and analytics as services. Decision Support Systems, v. 55, n. 1, p. $359-363,2013$.

Disponível em: http://www.sciencedirect.com/science/article/pii/ S0167923612001558

Delichto, F.; Pires, P.; Zomaya, A. Middleware platforms: State of the art, new issues, and future trends. In: Ammari, H. M., ed. The Art of Wireless Sensor Networks, Signals and Communication Technology, Springer Berlin Heidelberg, p. 645-674, 2014a.

Disponível em: http://dx.doi.org/10.1007/978-3-642-40009-4_19 
Delicato, F.; Pires, P.; ZomayA, A. Service-oriented middleware: Overview and illustrative example. In: Ammari, H. M., ed. The Art of Wireless Sensor Networks, Signals and Communication Technology, Springer Berlin Heidelberg, p. 675-693, 2014b.

Disponível em: http://dx.doi.org/10.1007/978-3-642-40009-4_20

Du, W.; Navarro, D.; Mieyeville, F.; GafFiot, F. Towards a taxonomy of simulation tools for wireless sensor networks. In: SIMUTools '10: Proceedings of the 3rd International ICST Conference on Simulation Tools and Techniques, ICST, Brussels, Belgium, Belgium: ICST (Institute for Computer Sciences, Social-Informatics and Telecommunications Engineering), 2010, p. $1-7$.

DugGan, D. Service-oriented architecture John Wiley Sons, Inc., p. 207-358, 2012.

Disponível em: http://dx.doi.org/10.1002/9781118180518.ch6

Dyo, V.; Ellwood, S. A.; Macdonald, D. W.; Markham, A.; Mascolo, C.; PÁsztor, B.; Scellato, S.; Trigoni, N.; Wohlers, R.; Yousef, K. Evolution and sustainability of a wildlife monitoring sensor network. In: Proceedings of the 8th ACM Conference on Embedded Networked Sensor Systems, SenSys '10, New York, NY, USA: ACM, 2010, p. 127-140 (SenSys '10, ).

Disponível em: http://doi.acm.org/10.1145/1869983.1869997

Elfwing, R.; PAUlsson, U.; LundberG, L. Performance of soap in web service environment compared to corba. In: Software Engineering Conference, 2002. Ninth Asia-Pacific, 2002, p. 84-93.

ERL, T. Service-oriented architecture : Concepts, technology, and design. Prentice Hall PTR, 2005.

Disponível em: http://www.amazon.ca/exec/obidos/redirect?tag= citeulike09-20\&amp; path=ASIN/0131858580

FAROOQ, M. O.; Kunz, T. Operating systems for wireless sensor networks: A survey. Sensors, v. 11, n. 6, p. 5900-5930, 2011.

Disponível em: http: / /www .mdpi . com/1424-8220/11/6/5900

FoK, C.-L.; Roman, G.-C.; LU, C. Agilla: A mobile agent middleware for self-adaptive wireless sensor networks. ACM Trans. Auton. Adapt. Syst., v. 4, n. 3, p. 16:1-16:26, 2009.

Disponível em: http: //doi.acm.org/10.1145/1552297.1552299

GARTNER Soa and application architecture key initiative overview. Disponível em: https: //www. gartner. com/doc/2513915. Último acesso: 13/01/2014, 2013.

Gay, D.; Levis, P.; Behren, R.; Welsh, M.; Brewer, E.; Culler, D. The nesc language: A holistic approach to networked embedded systems. SIGPLAN Not., v. 38, n. 5, p. 1-11, 2003. Disponível em: http://doi.acm.org/10.1145/780822.781133 
GEONOVUM Sensor observation service. Disponível em: http://geostandards. geonovum.nl/index.php/5.4.1_Sensor_observation_Service. Último acesso: 18/12/2013, 2013.

Giménez, P.; Molina, B.; Calvo-Gallego, J.; Esteve, M.; Palau, C. E. I3wsn: Industrial intelligent wireless sensor networks for indoor environments. Computers in Industry, v. 65 , n. 1 , p. $187-199,2014$.

Disponível em: http://www.sciencedirect.com/science/article/pii/ S0166361513001899

Grosky, W.; Kansal, A.; NAth, S.; LiU, J.; ZhaO, F. Senseweb: An infrastructure for shared sensing. MultiMedia, IEEE, v. 14, n. 4, p. 8-13, 2007.

GSDI Sdi cookbook. Disponível em: http://wWW.gsdidocs.org/GSDIWiki/ index.php/Main_Page. Último acesso: 26/12/2013, 2012.

Görgü, L.; Kroon, B.; CAmpbell, A.; O’HARe, G. Enabling a mobile, dynamic and heterogeneous discovery service in a sensor web by using androsixth. In: AUGUSTO, J.; WiCHERT, R.; Collier, R.; Keyson, D.; SAlah, A.; TAn, A.-H., eds. Ambient Intelligence, v. 8309 de Lecture Notes in Computer Science, Springer International Publishing, p. 287-292, 2013.

Disponível em: http://dx.doi.org/10.1007/978-3-319-03647-2_26

Hu, C.; Li, J.; Chen, N.; GUAN, Q. An object model for integrating diverse remote sensing satellite sensors: A case study of union operation. Remote Sensing, v. 6, n. 1, p. 677-699, 2014. Disponível em: http: / /www.mdpi.com/2072-4292/6/1/677

Huang, P.; XiaO, L.; Soltani, S.; MutKa, M.; Xi, N. The evolution of mac protocols in wireless sensor networks: A survey. Communications Surveys Tutorials, IEEE, v. 15, n. 1, p. 101-120, 2013.

ISO Information technology - general - purpose datatypes (gpd). Disponível em: http://www.iso.org/iso/iso_catalogue/catalogue_tc/catalogue_ detail.htm?csnumber=39479. Último acesso: 16/12/2013, 2007.

IYENGAR, S.; BROOKS, R. Distributed sensor networks, second edition: Sensor networking and applications. Chapman \& Hall/CRC Computer \& Information Science Series. Taylor \& Francis, 2012.

Disponível em: http://books.google.com.br/books?id=MRHAUtixf5kC

JAIN, R. K. The art of computer systems performance analysis: Techniques for experimental design, measurement, simulation, and modeling. Wiley, 1991.

JeOng, Y.-S.; Song, E.-H.; Chae, G.-B.; Hong, M.; PARK, D.-S. Large-scale middleware for ubiquitous sensor networks. Intelligent Systems, IEEE, v. 25, n. 2, p. 48-59, 2010. 
JiAnG, Y.; GuO, Z.; HU, K.; Shen, F.; Hong, F. Using sensor web to sharing data of ocean observing systems. In: WANG, R.; XIAO, F., eds. Advances in Wireless Sensor Networks, v. 334 de Communications in Computer and Information Science, Springer Berlin Heidelberg, p. 137-156, 2013.

Disponível em: http://dx.doi.org/10.1007/978-3-642-36252-1_14

Jung, M.; Kastner, W.; Kienesberger, G.; Leithner, M. A comparison of web service technologies for smart meter data exchange. In: Innovative Smart Grid Technologies (ISGT Europe), 2012 3rd IEEE PES International Conference and Exhibition on, 2012, p. 1-8.

Juric, M. B.; Kezmah, B.; Hericko, M.; Rozman, I.; VezocniK, I. Java rmi, rmi tunneling and web services comparison and performance analysis. SIGPLAN Not., v. 39, p. 58-65, 2004.

Disponível em: http://doi.acm.org/10.1145/997140.997146

KAhn, J. M.; KatZ, R. H.; Pister, K. S. J. Next century challenges: Mobile networking for \&ldquo;smart dust\&rdquo;. In: Proceedings of the 5th Annual ACM/IEEE International Conference on Mobile Computing and Networking, MobiCom '99, New York, NY, USA: ACM, 1999, p. 271-278 (MobiCom '99, ).

Disponível em: http://doi.acm.org/10.1145/313451.313558

Komninos, N. Sensor applications, experimentation, and logistics: First international conference, sensappeal 2009, athens, greece, september 25, 2009, revised selected papers. Lecture Notes of the Institute for Computer Sciences. Springer, 2010.

Disponível em: http: / / books.google.com.br/books?id=QVzVeLZtAeEC

Kono, K.; MASUdA, T. Efficient rmi: dynamic specialization of object serialization. In: Distributed Computing Systems, 2000. Proceedings. 20th International Conference on, 2000, p. 308-315.

Korzun, D.; Galov, I.; Kashevnik, A.; Shilov, N.; Krinkin, K.; Korolev, Y. Integration of smart-m3 applications: Blogging in smart conference. In: BALANDIN, S.; KOUCHERYAVY, Y.; Hu, H., eds. Smart Spaces and Next Generation Wired/Wireless Networking, v. 6869 de Lecture Notes in Computer Science, Springer Berlin Heidelberg, p. 51-62, 2011.

Disponível em: http://dx.doi.org/10.1007/978-3-642-22875-9_5

KRISHNAMACHARI, B.; Estrin, D.; WiCKer, S. The impact of data aggregation in wireless sensor networks. In: Distributed Computing Systems Workshops, 2002. Proceedings. 22nd International Conference on, 2002, p. 575-578.

Kyusakov, R.; Eliasson, J.; Delsing, J.; Deventer, J.; Gustafsson, J. Integration of wireless sensor and actuator nodes with it infrastructure using service-oriented architecture. Industrial Informatics, IEEE Transactions on, v. 9, n. 1, p. 43-51, 2013. 
LASAssmeh, S.; CONRAD, J. Time synchronization in wireless sensor networks: A survey. In: IEEE SoutheastCon 2010 (SoutheastCon), Proceedings of the, 2010, p. 242-245.

LAUKKarinen, T.; SuhOnen, J.; HÄNnIKÄInEN, M. A survey of wireless sensor network abstraction for application development. IJDSN, v. 2012, 2012.

Disponível em: http://dblp.uni-trier.de/db/journals/ijdsn/ ijdsn2012.html\#LaukkarinensH12

LEVIS, P.; CUller, D. Mat: A tiny virtual machine for sensor networks. SIGPLAN Not., v. 37, n. 10, p. 85-95, 2002.

Disponível em: http://doi.acm.org/10.1145/605432.605407

Levis, P.; Madden, S.; Polastre, J.; Szewczyk, R.; Woo, A.; Gay, D.; Hill, J.; Welsh, M.; Brewer, E.; Culler, D. Tinyos: An operating system for sensor networks. In: in Ambient Intelligence, Springer Verlag, 2004.

LiU, G.; TAn, R.; Zhou, R.; XING, G.; Song, W.-Z.; Lees, J. M. Volcanic earthquake timing using wireless sensor networks. In: Proceedings of the 12th International Conference on Information Processing in Sensor Networks, IPSN '13, New York, NY, USA: ACM, 2013, p. 91-102 (IPSN'13, ).

Disponível em: http://doi .acm.org/10.1145/2461381.2461396

Madden, S. R.; Franklin, M. J.; Hellerstein, J. M.; Hong, W. Tinydb: An acquisitional query processing system for sensor networks. ACM Trans. Database Syst., v. 30, n. 1, p. 122$173,2005$.

Disponível em: http://doi.acm.org/10.1145/1061318.1061322

MAEDA, K. Performance evaluation of object serialization libraries in xml, json and binary formats. In: Digital Information and Communication Technology and it's Applications (DICTAP), 2012 Second International Conference on, 2012, p. 177-182.

McFerren, G.; Hohls, D.; Fleming, G.; Sutton, T. Evaluating sensor observation service implementations. In: Geoscience and Remote Sensing Symposium,2009 IEEE International,IGARSS 2009, 2009, p. V-363-V-366.

McWilliam, H.; Li, W.; Uludag, M.; Squizzato, S.; Park, Y. M.; Buso, N.; Cowley, A. P.; LopeZ, R. Analysis tool web services from the embl-ebi. Nucleic Acids Research, v. 41, n. W1, p. W597-W600, 2013.

Disponível em: http://nar.oxfordjournals.org/content/41/W1/W597. abstract

Mikhaylov, K.; Tervonen, J.; Heikkila, J.; Kansakoski, J. Wireless sensor networks in industrial environment: Real-life evaluation results. In: Future Internet Communications (BCFIC), 2012 2nd Baltic Congress on, 2012, p. 1-7. 
Mohamed, N.; Al-JARoodi, J. Service-oriented middleware approaches for wireless sensor networks. In: System Sciences (HICSS), 2011 44th Hawaii International Conference on, 2011, p. 1-9.

Mottola, L.; Picco, G. Middleware for wireless sensor networks: an outlook. Journal of Internet Services and Applications, v. 3, n. 1, p. 31-39, 2012.

Disponível em: http://dx.doi.org/10.1007/s13174-011-0046-7

Mottola, L.; Picco, G. P. Programming wireless sensor networks: Fundamental concepts and state of the art. ACM Comput. Surv., v. 43, n. 3, p. 19:1-19:51, 2011.

Disponível em: http://doi.acm.org/10.1145/1922649.1922656

Neto, F. C.; Ribeiro, C. M. F. A. Dynamic change of services in wireless sensor network middleware based on semantic technologies. Autonomic and Autonomous Systems, International Conference on, v. 0, p. 58-63, 2010.

Nurmi, D.; BreViK, J.; Wolski, R. Modeling machine availability in enterprise and widearea distributed computing environments. In: CunHA, J.; MedeIRos, P., eds. Euro-Par 2005 Parallel Processing, v. 3648 de Lecture Notes in Computer Science, Springer Berlin Heidelberg, p. 432-441, 2005.

Disponível em: http://dx.doi.org/10.1007/11549468_50

OASIS Oasis/ebxml registry information model v2.0. Disponível em: http: / / www . ebxml . org/specs / ebrim2 . pdf. Último acesso: 06/01/2014, 2001.

OASIS Web services security (wss). Disponível em: http://www.oasis-open.org/ committees/tc_home.php?wg_abbrev=wss. Último acesso: 25/04/2009, 2004.

OGC Opengis swe service model implementation standard. Disponível em: http: //portal.opengeospatial.org/files/?artifact_id=38476. Último acesso: 25/03/2014, 2006.

OGC Opengis catalogue service implementation specification. Disponível em: http: / / portal.opengeospatial.org/files/ ?artifact_id=20555. Último acesso: 12/12/2013, 2007a.

OGC Sensor model language. Disponível em: http:/http://www. opengeospatial. org/standards/sensorml. Último acesso: 06/11/2013, $2007 \mathrm{~b}$.

OGC Sensor event service interface specification (proposed). Disponível em: http: //portal.opengeospatial.org/files/?artifact_id=29576. Último acesso: 19/12/2013, 2008a.

OGC Swe common data model encoding standard. Disponível em: http://www . opengeospatial .org/standards/swecommon. Último acesso: 12/12/2013, 2008b. 
OGC Filter encoding 2.0 encoding standard. Disponível em: http:/http://www . opengeospatial .org/standards/filter. Último acesso: 23/12/2013, 2010a.

OGC Sensor instance registry discussion paper. Disponível em: http://portal. opengeospatial.org/files/?artifact_id=40609. Último acesso: 26/12/2013, 2010b.

OGC Sensor observable registry (sor) discussion paper. Disponível em: http://portal. opengeospatial.org/files/?artifact_id=40571. Último acesso: 26/12/2013, 2010c.

OGC Observations and measurements. Disponível em: http://www. opengeospatial. org/standards / om. Último acesso: 01/12/2013, 2011a.

OGC Sensor planning service implementation standard. Disponível em: http://portal. opengeospatial.org/files/?artifact_id=38478. Último acesso: 06/01/2014, 2011b.

OGC Model and xml encoding standard. Disponível em: https://portal. opengeospatial.org/files/?artifact_id=55939. Último acesso: 25/03/2014, 2013a.

OGC Ogc standards and specifications. Disponível em: http: / / www . opengeospatial. org/standards. Último acesso: 06/05/2013, 2013 b.

OGC Sensor observation service interface standard. Disponível em: http://www . opengeospatial.org/standards/sos. Último acesso: 16/12/2013, 2013c.

OGC Sensorml 2.0 standard. Disponível em: http://http://www. opengeospatial . org/standards/requests/93. Último acesso: 06/05/2013, $2013 \mathrm{~d}$.

OGC How to model your observation data in sos 2.0? Disponível em: http://www . ogcnetwork.net/sos_2_0/tutorial/om. Último acesso: 23/02/2014, 2014a.

OGC Ogc members. Disponível em: http://www.opengeospatial.org/ogc/ members. Último acesso: 21/01/2014, 2014b.

OGC Why is the ogc involved in sensor webs? Disponível em: http://www. opengeospatial .org/domain/swe. Último acesso: 09/02/2014, 2014c.

Oppermann, F.; BoAno, C.; RÖMER, K. A decade of wireless sensing applications: Survey and taxonomy. In: Ammari, H. M., ed. The Art of Wireless Sensor Networks, Signals and Communication Technology, Springer Berlin Heidelberg, p. 11-50, 2014.

Disponível em: http://dx.doi.org/10.1007/978-3-642-40009-4_2 
Pantelopoulos, A.; Bourbakis, N. A survey on wearable sensor-based systems for health monitoring and prognosis. Systems, Man, and Cybernetics, Part C: Applications and Reviews, IEEE Transactions on, v. 40, n. 1, p. 1-12, 2010.

PAPAZOGlou, M. P. Service -oriented computing: Concepts, characteristics and directions. In: WISE '03: Proceedings of the Fourth International Conference on Web Information Systems Engineering, Washington, DC, USA: IEEE Computer Society, 2003, p. 3.

PArhi, M.; Acharya, B. M.; Puthal, B. Discovery of sensor web registry services for wsn with multi-layered soa framework. In: Computer and Communication Technology (ICCCT), 2011 2nd International Conference on, 2011, p. 524-530.

PARK, J. G.; LEE, A. Specializing the java object serialization using partial evaluation for a faster rmi [remote method invocation]. In: Parallel and Distributed Systems, 2001. ICPADS 2001. Proceedings. Eighth International Conference on, 2001, p. 451-458.

PhilipP, D.; Durr, F.; Rothermel, K. A sensor network abstraction for flexible public sensing systems. In: Mobile Adhoc and Sensor Systems (MASS), 2011 IEEE 8th International Conference on, 2011, p. 460-469.

Poorazizi, M. E.; Liang, S. H. L.; Hunter, A. J. S. Testing of sensor observation services: a performance evaluation. In: Proceedings of the First ACM SIGSPATIAL Workshop on Sensor Web Enablement, SWE' 12, New York, NY, USA: ACM, 2012, p. 32-38 (SWE '12, ).

Disponível em: http://doi.acm.org/10.1145/2451716.2451721

Priyantha, N. B.; Kansal, A.; GoraczKo, M.; Zhao, F. Tiny web services: Design and implementation of interoperable and evolvable sensor networks. In: Proceedings of the 6th ACM Conference on Embedded Network Sensor Systems, SenSys '08, New York, NY, USA: ACM, 2008, p. 253-266 (SenSys '08, ).

Disponível em: http: //doi.acm.org/10.1145/1460412.1460438

Ramamurthy, H.; Prabhu, B.; Gadh, R.; Madni, A. Wireless industrial monitoring and control using a smart sensor platform. Sensors Journal, IEEE, v. 7, n. 5, p. 611-618, 2007.

RouACHED, M.; BACCAR, S.; ABID, M. Restful sensor web enablement services for wireless sensor networks. In: Services (SERVICES), 2012 IEEE Eighth World Congress on, 2012, p. $65-72$.

Schade, S.; Díaz, L.; Ostermann, F.; Spinsanti, L.; Luraschi, G.; Cox, S.; Nuñez, M.; Longueville, B. Citizen-based sensing of crisis events: sensor web enablement for volunteered geographic information. Applied Geomatics, v. 5, n. 1, p. 3-18, 2013.

Disponível em: http://dx.doi.org/10.1007/s12518-011-0056-y 
Shnayder, V.; Chen, B.-R.; Lorincz, K.; Jones, T. R. F. F.; Welsh, M. Sensor networks for medical care. In: SenSys '05: Proceedings of the 3rd international conference on Embedded networked sensor systems, New York, NY, USA: ACM, 2005, p. 314-314.

Simon, D.; Cifuentes, C. The squawk virtual machine: Java\&\#8482; on the bare metal. In: Companion to the 20th Annual ACM SIGPLAN Conference on Object-oriented Programming, Systems, Languages, and Applications, OOPSLA '05, New York, NY, USA: ACM, 2005, p. 150-151 (OOPSLA '05, ).

Disponível em: http://doi.acm.org/10.1145/1094855.1094908

Sohraby, K.; Minoli, D.; ZnATI, T. Wireless sensor networks: Technology, protocols, and applications. 2007.

SPOT, S. Sun spot world. Disponível em: http://www. sunspotworld. com/. Último acesso: 14/01/2014, 2014.

Strazdins, G.; Elsts, A.; Nesenbergs, K.; Selavo, L. Wireless sensor network operating system design rules based on real-world deployment survey. Journal of Sensor and Actuator Networks, v. 2, n. 3, p. 509-556, 2013.

Disponível em: http://www.mdpi.com/2224-2708/2/3/509

Tamayo, A.; Granell, C.; Huerta, J. Using swe standards for ubiquitous environmental sensing: A performance analysis. Sensors, v. 12, n. 9, p. 12026-12051, 2012.

Disponível em: http://www.mdpi.com/1424-8220/12/9/12026

Tamayo, A.; Viciano, P.; Granell, C.; Huerta, J. Empirical study of sensor observation services server instances. In: GeERTMAn, S.; ReInhARDt, W.; TopPen, F., eds. Advancing Geoinformation Science for a Changing World, Lecture Notes in Geoinformation and Cartography, Springer Berlin Heidelberg, p. 185-209, 2011.

Disponível em: http://dx.doi.org/10.1007/978-3-642-19789-5_10

TAVLI, B.; BICAKCI, K.; ZilAn, R.; BARCELO-ORDINAS, J. A survey of visual sensor network platforms. Multimedia Tools and Applications, v. 60, n. 3, p. 689-726, 2012.

Disponível em: http://dx.doi.org/10.1007/s11042-011-0840-z

TINyOS Tinyos. Disponível em: http: / / www.tinyos. net/. Último acesso: 14/01/2014, 2014.

Upadhyaya, B.; Zou, Y.; XiaO, H.; NG, J.; LaU, A. Migration of soap-based services to restful services. In: Web Systems Evolution (WSE), 2011 13th IEEE International Symposium on, 2011, p. 105-114.

W3C Xml path language (xpath). Disponível em: http://www.w3.org/TR/xpath/.

Último acesso: 23/12/2013, 1999. 
W3C Latest soap versions. Disponível em: http://www.w3.org/TR/soap/. Último acesso: 10/04/2009, 2007.

WACHOWICZ, M. Movement-aware applications for sustainable mobility: Technologies and approaches. Hershey, PA: Information Science Reference - Imprint of: IGI Publishing, 2010.

WANG, M.; CAO, J.; LI, J.; DAS, S. K. Middleware for wireless sensor networks: A survey. J. Comput. Sci. Technol., v. 23, n. 3, p. 305-326, 2008.

WANG, W.; ZOU, Y.-X.; SHI, G.; ZHU, Y. A web service based gateway architecture for wireless sensor networks. In: Advanced Communication Technology, 2009. ICACT 2009. 11th International Conference on, 2009, p. 1160-1163.

Werner-Allen, G.; Lorincz, K.; Ruiz, M.; Marcillo, O.; Johnson, J.; Lees, J.; Welsh, M. Deploying a wireless sensor network on an active volcano. Internet Computing, IEEE, v. 10, n. 2, p. 18 - 25, 2006.

XIA, F. Qos challenges and opportunities in wireless sensor/actuator networks. Sensors, v. 8, n. 2, p. 1099-1110, 2008.

Disponível em: http: / /www.mdpi.com/1424-8220/8/2/1099

YAO, Y.; GEHRKE, J. The cougar approach to in-network query processing in sensor networks. SIGMOD Rec., v. 31, n. 3, p. 9-18, 2002.

Disponível em: http://doi.acm.org/10.1145/601858.601861

Yick, J.; Mukherjee, B.; Ghosal, D. Wireless sensor network survey. Comput. Netw., v. 52, n. 12, p. 2292-2330, 2008.

Yu, Y.; Lu, J.; FERnANDEZ-RAmiL, J.; YUAN, P. Comparing web services with other software components. In: ICWS'07: Proceedings of the IEEE International Conference on Web Services, Los Alamitos, CA, USA: IEEE Computer Society, 2007, p. 388-397.

Ćulibrk, D.; Vukobratovic, D.; Minic, V.; Fernandez, M.; Osuna, J.; Crnojevic, V. Gis applications for irrigation management. In: Sensing Technologies For Precision Irrigation, SpringerBriefs in Electrical and Computer Engineering, Springer New York, p. 69-93, 2014.

Disponível em: http://dx.doi.org/10.1007/978-1-4614-8329-8_3 